\title{
WestVirginiaUniversity
}

THE RESEARCH REPOSITORY @ WVU

Graduate Theses, Dissertations, and Problem Reports

2001

\section{Investigation of diesel soot-mediated oils and additive package on wear}

Santhosh Kumar Balla

West Virginia University

Follow this and additional works at: https://researchrepository.wvu.edu/etd

\section{Recommended Citation}

Balla, Santhosh Kumar, "Investigation of diesel soot-mediated oils and additive package on wear" (2001). Graduate Theses, Dissertations, and Problem Reports. 1187.

https://researchrepository.wvu.edu/etd/1187

This Thesis is protected by copyright and/or related rights. It has been brought to you by the The Research Repository @ WVU with permission from the rights-holder(s). You are free to use this Thesis in any way that is permitted by the copyright and related rights legislation that applies to your use. For other uses you must obtain permission from the rights-holder(s) directly, unless additional rights are indicated by a Creative Commons license in the record and/ or on the work itself. This Thesis has been accepted for inclusion in WVU Graduate Theses, Dissertations, and Problem Reports collection by an authorized administrator of The Research Repository @ WVU. For more information, please contact researchrepository@mail.wvu.edu. 


\title{
Investigation of Diesel Soot Mediated Oils and Additive Package on Wear
}

\section{Santhosh Kumar Balla}

Thesis submitted to the College of Engineering at West Virginia University in partial fulfillment of the requirements for the degree of

\author{
Master of Science \\ in \\ Mechanical Engineering \\ Mridul Gautam, Ph.D., Chair \\ Kenneth Means, Ph.D. \\ Bruce Kang, Ph.D.
}

Department of Mechanical and Aerospace Engineering

Morgantown, West Virginia

2001

Keywords: Soot, Base Stock, Dispersant, ZDP, Wear, Viscosity, Lubricants Copyright 2001 Santhosh Kumar Balla 


\section{ABSTRACT \\ Investigation of Diesel Soot Mediated Oils and Additive Package on Wear}

\section{Santhosh Kumar Balla}

Contamination of lubricating oil by diesel soot is one of the major causes of increased engine wear. The diesel soot interacts with the engine oil and this leads to wear of engine parts. Therefore, the study of lubricant properties and the role of additives becomes very important. The factors, which can change or modify the characteristics of the soot surface, are expected to play an important role in controlling the interactions with soot. Hence, it is important to study the interactions between engine soot and oil additives in order to develop high performance diesel engine oils for Exhaust Gas Recirculation (EGR).

In the current study, a statistically designed experiment was developed to study the effects of soot contaminated engine oil on wear. The variables that were considered were the Base stock (Group1, Group2), Dispersant level and ZDP level. The above three variables were formulated at two levels: Low (-1), and High (1), which resulted in $2^{3}$ matrix (8 oil blends). Soot was also one of the variables and was tested at three levels: Low (-1), Medium (0) and High (1).

A three-body-wear machine was employed to simulate and estimate the extent of wear, as it is very difficult to test each oil sample on an engine. The extent of wear was measured as the actual loss of material, in milligrams. A second set of experiments was performed on a milling machine (Ball-on-flat-disc setup) using a specially designed chuck and aluminum cup. The wear scars formed on the steel ball were measured using a Scanning Electron Microscope (SEM). These wear scars were analyzed qualitatively to determine the effect of soot-contaminated oils on wear.

The other primary concern of heavy-duty diesel engines has been soot related lubricant thickening. Contamination of the lubricant results in lubricant breakdown and causes an increase in viscosity of the engine oils. Hence, it is necessary to study engine oil viscosity, as it plays a major role in engine wear. A third set of experiments involved measuring the viscosity of the various oil formulations at $40^{\circ} \mathrm{C}$ and $90^{\circ} \mathrm{C}$ to examine the influence of soot present in the oil.

The results obtained were analyzed using a Statistical Analysis System (SAS) to determine the significance of variables on wear and also on viscosity. The analysis indicated that wear and viscosity increased nonlinearly as the amount of soot increased. Cumulative wear was more for samples with soot contamination than without soot contamination. The SAS analysis indicated that the base stock and soot content (soot) were the most significant at a $95 \%$ confidence level. Dispersant and ZDP were also significant at a 95\% confidence level. The highest wear was obtained from a sample that had $4 \%$ soot. Viscosity of the oil samples increased with increase in soot at $40^{\circ} \mathrm{C}$ and $90^{\circ} \mathrm{C}$. After analyzing the results, a correlation was determined to obtain the best oil formulation in the presence of soot. 


\section{ACKNOWLEDGEMENTS}

I would like to express my gratitude and sincere thanks to my advisor, Dr. Mridul Gautam, for his support, advice, and guidance. Working under his able guidance has taught me to do research and write technical papers.

I would like to thank Dr. Kenneth Means and Dr Bruce Kang for participating on my committee and for their valuable suggestions. I would also like to thank Dr Keh-Minn Chang for allowing me to use the Scanning Electron Microscope.

I am thankful to all the people in the workshop who taught me about shop skills. A special thanks to Cliff Judy and Chuck Coleman for their support and helping me out with the setup.

I wish to thank Chitoor karthik for his help and suggestions. I also would like to thank my office mates Amit Sharma, Praveen Neogi, Rohit Tanugula and Sandeep Mehta for their help and support.

I would also like to thank my parents, brothers, sister and friends for the love and motivation they have provided throughout my studies. 


\section{TABLE OF CONTENTS}

\section{Page}

ABSTRACT

ACKNOWLEDGEMENTS

ii

TABLE OF CONTENTS

iii

LIST OF FIGURES

iv

LIST OF TABLES

viii

NOMENCLATURE

xii

xiii

\section{CHAPTER}

1.0 INTRODUCTION 1

$\begin{array}{lll}\text { 2.0 } & \text { BACKGROUND } & 7\end{array}$

$\begin{array}{lll}2.1 & \text { Introduction } & 7\end{array}$

2.2 Types of Lubrication $\quad 7$

2.2.1 Hydrostatic Lubrication $\quad 8$

2.2.2 Hydrodynamic Lubrication 8

2.2.3 Elastohydrodynamic Lubrication $\quad 8$

2.2.4 Boundary Lubrication 9

2.2.5 Mixed Lubrication $\quad 9$

2.3 Necessary Properties of a Lubricant and the Role of additives 9

2.4 Oil Additives 10

2.4.1 Oxidation Inhibitors 11

2.4.2 Anti-wear and EP agents 12

2.4.3 Detergents 12

2.4.4 Corrosion and Rust Inhibitors 12

2.4.5 Dispersants 13

2.4.6 Friction Modifiers 13

2.4.7 Pour Point Depressants 13

2.4.8 Sea Swell Modifiers $\quad 14$

2.4.9 Viscosity Modifiers 14

2.4.10 Anti-Foamants 14

2.4.11 Metal Deactivator 14

2.5 Mechanisms of Engine Wear 15

$\begin{array}{ll}\text { 2.5.1 Abrasive Wear } & 15\end{array}$ 
2.5.2 Adhesive Wear 15

2.5.3 Fatigue Wear 16

2.5.4 Corrosive Wear 16

2.5.5 Lubricant Breakdown 16

2.6 Variables Affecting Wear 17

2.7 Wear Testing Devices 18

2.7.1 Four-Ball Wear Testing Machine 18

2.7.2 Flat-on-Flat Configuration 19

2.7.3 Two-Ball Wear Machine 20

2.7.4 Crossed Cylinders 20

$\begin{array}{lll}2.8 & \text { Literature Survey } & 21\end{array}$

3.0 EXPERIMENTAL SETUP AND PROCEDURES 26

3.1 Introduction 26

3.2 Three-Body Wear Testing Machine 26

3.2.1 Stand 27

3.2.2 Spindle and Bearing Housing 28

3.2.3 Motor 28

3.2.4 Driving Mechanism 29

3.2 .5 Aluminum Cup 29

3.2.6 Specimen Holder 30

3.2.7 Plate Fixture 30

3.2 .8 Post Guide 31

3.2.9 Deflector 31

3.2.10 Protective Cover 32

3.2.11 Testing Material 32

3.2.12 Infrared Chopper Disk 33

3.2.13 Infrared Sensing Circuit 33

3.3 Design of the Experiment 35

3.3.1 Lubricant Composition Matrix 35

3.3.2 Randomization 37

3.3.3 Oil Blend Content 38

$3.4 \quad$ Ball-on-Flat Disk Setup 38

3.4.1 Chuck 39

3.4.2 Cast Iron Base 39

3.4.3 Aluminum Container 39

3.4.4 Gasket 40

3.5
Microscopic Studies 
3.5.1 Scanning Electron Microscope (SEM) 40

3.5.2 SEM Description 41

3.6 Brookfield Viscometer 42

3.6.1 Description 42

3.6.2 Viscosity Measuring Setup 44

3.7 Experimental Procedures 45

3.7.1 Experimental Procedure for Three-Body Wear Tests 45

3.7.1.1 Oil Sample Preparation 46

3.7.1.2 Experimental Procedure for Wear Tests 47

3.7.1.3 Post-Processing of the Test Specimen 48

3.7.2 Experimental Procedure for Ball-on-Flat Disk Tests $\quad 48$

3.7.2.1 Load Calibration $\quad 49$

3.7.2.2 Test Procedure $\quad 50$

3.7.2.3 Post Processing 50

3.7.3 Microscopic Studies $\quad 51$

3.7.3.1 Wear Scars 51

3.7.4 Viscosity Tests 51

$\begin{array}{lll}\text { 4.0 } & \text { RESULTS AND DISCUSSIONS } & 72\end{array}$

$\begin{array}{lll}4.1 & \text { Introduction }\end{array}$

4.2 Three-Body Wear Data Analysis 73

4.2.1 Wear Data Analysis and Results 73

4.2.2 Statistical Analysis of the Three-body Wear Data 75

4.2.3 Statistical Analysis System 76

4.2.4 Results From the Statistical Analysis System 77

4.3 Viscosity Results 79

4.3.1 Viscosity Test Analysis and Results at $40^{\circ} \mathrm{C} \quad 81$

4.3.2 Viscosity Test Analysis and Results at $90^{\circ} \mathrm{C} \quad 81$

4.3.3 Statistical Results for the Viscosity Tests 82

4.3.3.1 Statistical Analysis and Results at $40^{\circ} \mathrm{C} \quad 83$

4.3.3.2 Statistical Analysis and Results at $90^{\circ} \mathrm{C} \quad 84$

4.4 Ball-on-Flat Disk Setup 85

4.4.1 Hertz Equation $\quad 85$

5.0 CONCLUSIONS AND RECOMMENDATIONS 117

$\begin{array}{ll}\text { REFERENCES } & 120\end{array}$

$\begin{array}{ll}\text { APPENDICES } & 123\end{array}$ 
APPENDIX A

APPENDIX B

APPENDIX C

138

APPENDIX D

143

APPENDIX E

148

APPENDIX $\mathbf{F}$

157

vii 
$\underline{\text { Figure }}$

\section{LIST OF FIGURES}

$\begin{array}{ll}\text { Chapter } 3 & \text { Page }\end{array}$

3.1 Schematic of the Setup for the Three-Body Wear Machine 54

3.2 Top View and Front View of the Three-Body Wear Machine Stand 55

3.3 Spindle for the Three-Body Wear Machine 56

3.4 Bearing Housing for the Spindle of the Three-Body Wear Machine 57

3.5 Infrared Chopper Disk Setup on the Three-Body Wear Machine 58

3.6 Circuit Diagram for the Infrared Sensing Circuit 59

3.7 Output Voltage Pulses from the Infrared Circuit Fed to the Counter Channel 60

3.8 Top and Front Views of the Aluminum Cup Holding the Lubricant Sample 61

3.9 Specimen Holder for the Three-Body Wear Machine 62

3.10 Front View of the Plate Fixture 63

3.11 Top and Front View of the Specimen Holder Guide 64

3.12 Protective Cover on Top of the Aluminum Cup 65

3.13 Chuck for the Ball-On-Flat-Disk Experiment 66

3.14 Schematic for the Ball-On-flat-Disk Experiment 67

3.15 Cone/Plate geometry for the Brookfield Viscometer 68

3.16 Schematic of the setup for the Viscosity Tests 69

3.17 Model SSM-250 Load Cell 70

3.18 Calibration Curve for the Load Cell 71 


\section{Chapter 4}

4.1 Variation of Actual Wear for Sample \# WVU397 88

4.2 Variation of Cumulative Wear for Sample \# WVU397 88

4.3 Variation of Actual Wear for Sample \# WVU398 89

4.4 Variation of Cumulative Wear for Sample \# WVU398 89

4.5 Variation of Actual Wear for Sample \# WVU399 90

4.6 Variation of Cumulative Wear for Sample \# WVU399 90

4.7 Variation of Actual Wear for Sample \# WVU400 91

4.8 Variation of Cumulative Wear for Sample \# WVU400 91

4.9 Variation of Actual Wear for Sample \# WVU401 92

4.10 Variation of Cumulative Wear for Sample \# WVU401 92

4.11 Variation of Actual Wear for Sample \# WVU402 93

4.12 Variation of Cumulative Wear for Sample \# WVU402 93

4.13 Variation of Actual Wear for Sample \# WVU403 94

4.14 Variation of Cumulative Wear for Sample \# WVU403 94

4.15 Variation of Actual Wear for Sample \# WVU404 95

4.16 Variation of Cumulative Wear for Sample \# WVU404 95

4.17 Variation of Wear (g) with Percentage Soot for sample \# WVU397 96

4.18 Variation of Wear (g) with Percentage Soot for sample \# WVU398 96

4.19 Variation of Wear (g) with Percentage Soot for sample \# WVU399 97

4.20 Variation of Wear (g) with Percentage Soot for sample \# WVU400 97 
4.21 Variation of Wear (g) with Percentage Soot for sample \# WVU401

4.22 Variation of Wear (g) with Percentage Soot for sample \# WVU402 98

4.23 Variation of Wear (g) with Percentage Soot for sample \# WVU403 99

4.24 Variation of Wear (g) with Percentage Soot for sample \# WVU404 99

4.25 Effect of Base Stock on Wear (g) 100

4.26 Effect of Dispersant on Wear $(\mathrm{g}) \quad 100$

$\begin{array}{ll}4.27 & \text { Effect of ZDP on Wear }(\mathrm{g}) \\ & 101\end{array}$

4.28 Effect of Soot on Wear $(\mathrm{g}) \quad 101$

4.29 Variation of Wear (g) with Percentage Soot 102

4.30 Variation of Viscosity with soot at $40^{\circ} \mathrm{C}$ for sample \# WVU397 103

4.31 Variation of Viscosity with soot at $40^{\circ} \mathrm{C}$ for sample \# WVU398 103

4.32 Variation of Viscosity with soot at $40^{\circ} \mathrm{C}$ for sample \# WVU399 104

4.33 Variation of Viscosity with soot at $40^{\circ} \mathrm{C}$ for sample \# WVU400 104

4.34 Variation of Viscosity with soot at $40^{\circ} \mathrm{C}$ for sample \# WVU401 105

4.35 Variation of Viscosity with soot at $40^{\circ} \mathrm{C}$ for sample \# WVU402 105

4.36 Variation of Viscosity with soot at $40^{\circ} \mathrm{C}$ for sample \# WVU403 106

4.37 Variation of Viscosity with soot at $40^{\circ} \mathrm{C}$ for sample \# WVU404 106

4.38 Effect of Base Stock on Viscosity (cS) at $40^{\circ} \mathrm{C} \quad 107$

4.39 Effect of Dispersant on Viscosity (cS) at $40^{\circ} \mathrm{C} \quad 108$

$\begin{array}{lll}4.40 & \text { Effect of ZDP on Viscosity }(\mathrm{cS}) \text { at } 40^{\circ} \mathrm{C} & 108\end{array}$

4.41 Effect of Soot Level on Viscosity (cS) at $40^{\circ} \mathrm{C} \quad 109$

4.42 Variation of Viscosity $(\mathrm{cS})$ with soot at $40^{\circ} \mathrm{C} \quad 109$

4.43 Variation of Viscosity with soot at $90^{\circ} \mathrm{C}$ for sample \# WVU397 110 
4.44 Variation of Viscosity with soot at $90^{\circ} \mathrm{C}$ for sample \# WVU398

4.45 Variation of Viscosity with soot at $90^{\circ} \mathrm{C}$ for sample \# WVU399

4.46 Variation of Viscosity with soot at $90^{\circ} \mathrm{C}$ for sample \# WVU400

4.47 Variation of Viscosity with soot at $90^{\circ} \mathrm{C}$ for sample \# WVU401

4.48 Variation of Viscosity with soot at $90^{\circ} \mathrm{C}$ for sample \# WVU402

4.49 Variation of Viscosity with soot at $90^{\circ} \mathrm{C}$ for sample \# WVU403

4.50 Variation of Viscosity with soot at $90^{\circ} \mathrm{C}$ for sample \# WVU404

4.51 Effect of Base Stock on Viscosity (cS) at $90^{\circ} \mathrm{C}$

4.52 Effect of Dispersant on Viscosity $(\mathrm{cS})$ at $90^{\circ} \mathrm{C}$

4.53 Effect of ZDP on Viscosity $(\mathrm{cS})$ at $90^{\circ} \mathrm{C}$

4.54 Effect of Soot Level on Viscosity $(\mathrm{cS})$ at $90^{\circ} \mathrm{C}$ 


\section{LIST OF TABLES}

Table $\quad$ Page

3.1 Lubricant Composition Matrix 35

3.2 Factor Level Combinations for the Three-Body Wear Test 37

4.1 Average Wear values for the different oil samples 76

4.2 Viscosity Tables $\quad 79$

4.2 a Viscosity of the oil samples without soot at $40^{\circ} \mathrm{C}$ and $90^{\circ} \mathrm{C} \quad 79$

$4.2 \mathrm{~b}$ Viscosity of the oil samples with $2 \%$ soot at $40^{\circ} \mathrm{C}$ and $90^{\circ} \mathrm{C} \quad 80$

$4.2 \mathrm{c}$ Viscosity of the oil samples with $4 \%$ soot at $40^{\circ} \mathrm{C}$ and $90^{\circ} \mathrm{C} \quad 80$

4.3 Wear Scar Diameters and Wear Ratios 87 
NOMENCLATURE

\begin{tabular}{ll}
$\AA$ & Angstroms $\left(10^{-9} \mathrm{~mm}\right)$ \\
Base & Base Stock \\
BDC & Bottom Dead Center \\
${ }^{\circ} \mathrm{C}$ & Degree Centigrade \\
DF & Degrees of Freedom \\
Disp & Dispersant \\
E & Young's Modulus $\left(\mathrm{N} / \mathrm{m}^{2}\right)$ \\
EDAX & Energy-Dispersive X-ray Analysis \\
EGR & Exhaist Gas Re-circulation \\
$\mathrm{g}$ & grams \\
$\mathrm{GLM}$ & General Linear Model \\
$\mathrm{HC}$ & Hydrocorbons \\
$\mathrm{H}_{\mathrm{a}}$ & Alternate Hypothesis \\
$\mathrm{H}_{\mathrm{o}}$ & Null Hypothesis \\
in & inches \\
$\mathrm{lbs}$ & pounds \\
$\mathrm{LED}$ & Light Emitting Diode \\
$\mathrm{mg}$ & milligrams \\
$\mathrm{NO}$ & Oxides of Nitrogen \\
\hline $0^{-6} \mathrm{~meters}$
\end{tabular}




\begin{tabular}{ll} 
Pr & Probability \\
psi & pounds per square inch \\
p-Value & Significance Probability \\
rcf & Relative Centrifugal Force \\
rpm & revolutions per second \\
SAS & Statistical Analysis System \\
SEM & Scanning Electron Microscope \\
SS & Sum of Squares \\
TDC & Top Dead Center \\
TEM & Transmission Electron Microscopy \\
VI & Viscosity Index \\
W & Load \\
WR & Wear Ratio \\
WSD & Wear Scar Diameter \\
ZDP & Zinc Dithiophosphate \\
$\alpha$ & Significance Probability \\
$\mu$ & Dynamic Viscosity(cP) \\
$v$ & Poisson's Ratio \\
\hline &
\end{tabular}




\section{CHAPTER 1}

\section{INTRODUCTION}

Diesel engines are extensively used in automotive systems due to their better fuel economy. Despite these advantages, the diesel engines suffer from certain environmental drawbacks such as high levels of exhaust $\mathrm{NO}_{\mathrm{x}}$, particulate matter emissions and soot induced lubrication problems. Heavy-duty diesel vehicles are major contributors to the atmospheric $\mathrm{NO}_{\mathrm{x}}$ inventories.

The major contributors of atmospheric $\mathrm{NO}_{\mathrm{x}}$ inventories are the diesel engines. At high temperatures in the internal combustion engine, nitrogen and oxygen atoms and molecules dissociate and subsequently form nitric oxide by various mechanisms. Some of the key technologies for controlling $\mathrm{NO}_{\mathrm{x}}$ emissions are controlling fuel injection system parameters, controlling in-cylinder charge conditions, Exhaust Gas Recirculation (EGR) and controlling fuel formulation (17).

One of the more attractive engine-based technologies for reducing $\mathrm{NO}_{\mathrm{x}}$ emissions is Exhaust Gas Recirculation (EGR). This technology is very effective in light-duty diesel engines but when it comes to heavy-duty diesel engines, it results in a sharp increase in particulate matter and poor combustion performance.

The contamination of the lubricating oil by diesel soot is a key factor relating to the increased engine wear. The soot-induced wear mechanism is still not fully understood 
and a more fundamental knowledge is needed in this area. Five soot-induced wear mechanisms have been proposed since the early 1970s.

- Preferential adsorption of ZDP (Zinc dithiophosphate) decomposition products by soot, lessening the antiwear film formation on metal surfaces, which results in metalto-metal contact (27).

- The surface coverage rate by ZDP is reduced because of the competition for metal surface sites between ZDP and soot.

- Properties of the antiwear film are effected by soot, which weakens the film's mechanical strength and adherence to the metal surface.

- Pumpability problems occur due to soot agglomeration at the inlet of the contact.

- Abrasive nature of soot particles.

The first four wear mechanisms involve surface interactions between soot and additives, soot and metal, or among soot particles. The factors, which can change or modify the characteristics of the soot surface, are expected to play an important role in controlling the interactions with soot. Changes in the fuel composition may significantly alter the physical structure and surface/bulk chemistry of soot. Hence, it is important to study the interactions between engine soot and oil additives in order to develop high performance diesel engine oils for Exhaust Gas Recirculation (EGR).

Soot agglomeration is one of the key wear mechanisms and this can be demonstrated by many means. Some of the methods are monitoring viscosity increases, and particle size measurement either by laser light scattering or in a transmission electron 
microscope. To prove that the abrasive action of soot plays a major role, the size information of primary and aggregated soot particles and the evidence of the existence of grooves or scars on engine parts must be available. A high-resolution TEM and SEM can be used to study the size of soot particles and scars on engine parts.

Recent studies on engine wear by moderately high soot-levels have reported that abrasive action by soot is the major wear mechanism in diesel engines. Ryason et al. showed evidence of furrows on wear scar surfaces whose widths are approximately $100 \mathrm{~nm}$, which is about three times the size of the individual carbon black particles under study (30). Kim et al. showed that wear mechanism was a possible combination of the antiwear film removal and adsorption of ZDP by soot (19). Bardasz et al. reported that wear in the GM 6.5L test roller follower was mainly caused by abrasive action of agglomerated soot particles (3). Gautam et al. reported that average wear was higher with soot contamination than without soot contamination. They concluded that diesel soot reduces the oil's anti-wear properties, presumably by abrasive wear mechanism (15). Thus, soot induced abrasive wear is a key area for investigation.

In the current study, a statistically designed experiment was developed to study the effects of soot-contaminated engine oil on wear. The variables that have been considered are the dispersant level, ZDP level and base stock. These three variables were formulated at two levels: High $(\mathrm{H})$ and Low $(\mathrm{L})$, which resulted in $2^{3}$ matrix (8 oil blends). The exact composition of the blends is not reported in this document, owing to the proprietary nature of this information. However, the author and his research advisor were intimately involved in the blending of the oil samples. 
Three-body wear mechanism occurs between the piston, cylinder, and the intermediate soot particles. In this mechanism, wear occurs at the particle-surface interface. A three-body-wear machine was designed and developed to simulate and estimate the extent of wear, as it is very difficult to test each oil sample on an engine. The tests were performed having a cast iron round as the first surface and a tempered steel specimen as the second surface with the intermediate soot particles in between them. The extent of wear was measured as the actual loss of material, in milligrams. Drain oil samples from the Cummins engines were also tested. The experimental procedures for wear are clearly discussed in detail in Chapter 3.

A second set of experiments was performed on a milling machine (Ball-on-flatdisc setup) using a specially designed chuck and an aluminum cup. Wear tests were performed with the various oil blends forming an interface between a rotating steel ball (AISI 52100) and cast iron round. The wear scars formed on the steel ball were measured using a Scanning Electron Microscope (SEM). These wear scars were analyzed qualitatively to determine the effect of soot contaminated oils on wear.

The other primary concern of heavy-duty diesel engines has been soot related lubricant thickening. Engines, which produce a relatively low level of particulate matter in exhaust emissions, show a significant level of soot contamination in the lubricant. This contamination results in lubricant breakdown. The soot contaminates the lubricant and changes the chemical properties resulting in the lubricant ceasing to perform its functions. This causes an increase in viscosity of the engine oils thus, causing 
pumpability problems. Hence, it is necessary to study engine oil viscosity, which plays a major role in engine wear.

A third set of experiments involved measuring the viscosity of the various oil formulations to examine the influence of soot present in the oil. The oil formulations are tested at three levels of soot: $0 \%$ or without soot contamination, $2 \%$ soot, and $4 \%$ soot by weight. The experiments are conducted at $40^{\circ} \mathrm{C}$ and $90^{\circ} \mathrm{C}$ to study the effect of temperature on viscosity.

The results obtained were analyzed using a Statistical Analysis System (SAS) to determine the significance of variables on wear and also on viscosity. The statistical analysis system also highlighted the significance of various interactions among the variables on wear. After analyzing the results, a correlation was determined to obtain the best oil formulation in the presence of soot with the least amount of wear.

A brief background on the various mechanisms of wear, types of lubrication, properties of a lubricant, and the oil additives is given in the initial sections of Chapter 2 . The variables considered while designing and developing the three-body wear machine and the different configurations for wear testing are also discussed in this chapter. Mechanisms of wear, variables affecting wear, and the different wear testing methods along with literature are discussed in the later sections of Chapter 2. The experimental details and the equipment for the tests performed on the three-body wear machine, the ball-on-flat-disk setup, and the viscosity measurement tests are discussed in Chapter 3. 
Results from the statistical analysis system on the various oil samples, the results from microscopic studies and viscosity measurements are discussed in Chapter 4. Conclusions and recommendations are presented in Chapter 5. 


\section{CHAPTER 2}

\section{BACKGROUND}

\subsection{Introduction}

Soot contaminated lubricating oil is one of the major causes of diesel engine wear. Diesel soot interferes with the lubricating oil thereby leading to increased wear (19). Also, addition of soot to the lubricating oil increases the viscosity of the lubricant and causes pumpability problems. Walls of the combustion chamber are not evenly coated with the lubricant and this also leads to increased wear.

This chapter gives a clear understanding about the different types of lubricants, the important oil additives used, and the various mechanisms of engine wear. Also discussed are the necessary properties of lubricants and role of additives, the important variables that effect the wear process, and the various types of testing devices.

\subsection{Types of Lubrication}

A high coefficient of friction and severe wear due to the specific properties of the surfaces generally characterize sliding between clean solid surfaces. Clean surfaces readily absorb traces of foreign substances, such as organic compounds, from the environment. The newly formed surfaces generally have a lower coefficient of friction and wear than the clean surfaces. The presence of a layer of foreign material at an interface cannot be guaranteed during a sliding process; therefore, lubricants are deliberately applied to produce low friction and wear. 


\subsubsection{Hydrostatic Lubrication}

Hydrostatic bearings support load on a thick film of fluid supplied from an external pressure source. A pump is used, which feeds pressurized fluid to the film. Hydrostatic bearings are designed for use with both incompressible and compressible fluids. They are used in applications with little or no relative motion between the surfaces.

\subsubsection{Hydrodynamic Lubrication}

Hydrodynamic lubrication is sometimes called fluid-film or thick-film lubrication. HD lubrication is often referred to as the ideal lubricated contact condition because the

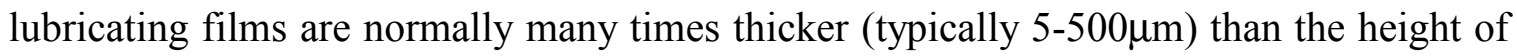
the irregularities on the bearing surface, and solid contacts do not occur. The coefficient of friction in the HD regime can be as small as .001 .

\subsubsection{Elastohydrodynamic Lubrication}

Elastohydrodynamic (EHD) lubrication is a subset of HD in which the elastic deformation of the bounding solids plays a significant role in the HD lubrication process. The film thickness in EHD lubrication is thinner (typically $0.5-2.5 \mu \mathrm{m}$ ) than that in HD lubrication, and the load is still primarily supported by the EHD film. EHD Lubrication is most readily induced in heavily loaded contacts, where loads act over relatively small contact areas. 


\subsubsection{Boundary Lubrication}

Boundary lubrication (BL) is that condition in which the solid surfaces are so close together that surface interaction between monomolecular or multimolecular films of lubricants and the solids dominate the contact. The oil film thickness in boundary lubrication is thinner (typically $.001-0.05 \mu \mathrm{m}$ ) than that in EHD. Soot particles have diameters $(0.01-0.9 \mu \mathrm{m})$ much larger than the oil film thickness in BL and could, therefore, cause abrasive wear. In the absence of boundary lubricants, friction may become very high $(>1)$.

\subsubsection{Mixed Lubrication}

The transition between the Hydrodynamic/elastohydrodynamic and boundary lubrication regimes constitutes a gray area known as mixed lubrication, in which two lubrication mechanisms may be functioning. The mixed regime is sometimes referred to as quasihydrodynamic, partial film, or thin film (typically $0.5-2.5 \mu \mathrm{m}$ ) lubrication.

\subsection{Necessary Properties of a Lubricant and the Role of Additives}

Some of the most important properties necessary for satisfactory lubricant performance are:

- Low volatility under operating conditions, which is essentially inherent in the choice of base oil and cannot be improved by the use of additive materials.

- Flow characteristics should be satisfactory in the temperature range of use. Flow characteristics largely depend on the choice of base oil. They can be improved by using pour point depressants and viscosity modifiers. 
- Ability of a lubricant to maintain desirable characteristics for a reasonable period of use is one of the important properties necessary for satisfactory lubricant performance. Lubricant stability is affected by factors such as temperature, oxidation potential and contamination with water. Unburned fuel fragments and corrosive acids limit the useful life of a lubricant. Adding additives and extending the useful life of lubricants can enhance the performance of the lubricant.

- The lubricant should be compatible with other materials in the system such as seals, bearings, clutch plates, etc. Addition of additives can have a major influence on such characteristics.

\section{$2.4 \quad$ Oil Additives}

Lubricant additives perform a number of diverse functions. They can be classified into chemically inert and chemically active types. Chemically inert additives improve a lubricants physical properties and include emulsifiers, demulsifiers, pour point depressants, foam inhibitors, and viscosity modifiers. Chemically active additives interact with metals to form protective films, reducing wear. Chemically active additives include dispersants, detergents, antiwear and extreme pressure agents, oxidation inhibitors, and rust and corrosion inhibitors. Almost all commercial lubricants contain additives to enhance their performances in amounts ranging from less than $1 \%$ to $25 \%$ or more. The function of these additives is to protect metal surfaces (rings, bearings, gears, etc.), resist oxidation, minimize deposit formation, prevent corrosion and wear, extend the range of lubricant applicability, flow characteristics, improve lubricant stability and to extend the lubricant life. The most commonly used additives in a lubricant are: 
1. Detergents

2. Corrosion and rust inhibitors

3. Anti-wear and EP agents

4. Dispersants

5. Friction modifiers

6. Pour point depressants

7. Viscosity modifiers

8. Seal swell agent

9. Anti-oxidants

10. Anti-foamants

11. Metal deactivators

\subsubsection{Oxidation Inhibitors}

All mineral lubricants undergo some oxidation during typical engine operation. The products formed are usually oil-soluble and their high molecular weight (500-3000) and viscous nature often lead to a marked increase in oil viscosity. The main purpose of the anti-oxidants is to retard the oxidative decomposition by decomposing the organic peroxides to harmless products as they are formed and reduce the activity of metallic catalysts. Typical examples include alkyl and aryl phosphites, zinc dialkyl and zinc diaryl dithiophosphates, aromatic amines, alkyl phenol sulfides, amines and phenolic derivatives. 


\subsubsection{Anti-wear and EP agents}

Anti-wear agents minimize friction and reduce wear by producing a surface film by either a chemical or physical absorption mechanism under boundary lubrication conditions. The anti-wear agents are based on oxygen, sulfur, chlorinated wax, phosphorous and organic lead compounds. Typical anti-wear agents used are Tricresyl phosphate and zinc dialkyldithio phosphate to minimize wear. Active sulfur, chlorine and lead compounds are used where severe metal-to-metal contact is encountered. These additives react chemically to form low shear strength surface films such as sulfide, iron chloride or iron sulfide. Other anti-wear agents used are organic phosphites, sulfurized olefins, zinc dithiophosphates and alkaline compounds as acid neutralizers.

\subsubsection{Detergents}

Oil detergents prevent or remove deposits of oil-soluble sludge, varnish, carbon and lead. They perform their function by undergoing a chemical reaction with sludge and varnish precursors to neutralize them and keep them soluble. In recent years, ashless detergents have been developed which minimize low temperature sludging. Typical examples include Barium and calcium sulphonates, alkenyl succinimides, high molecular weight esters, polyesters and organic acids.

\subsubsection{Corrosion and rust inhibitors}

The main purpose of this is to prevent corrosion and rusting of metal parts in contact with the lubricant. This provides a protective layer by preferential adsorption of polar constituents on the metal surface and by neutralizing the corrosive acids. Typical 
examples include zinc dithiophosphates, metal phenolates, basic metal sulfonates, fatty acids and amines.

\subsubsection{Dispersants}

The main purpose of the dispersant is to keep the insoluble contaminants dispersed in the lubricant. The contaminants are bonded to the dispersant molecule by polar attractive forces and are kept in suspension and prevented from agglomerating due to the solubility of the dispersant. Typical examples of the dispersant include alkylsuccinimides, alkylsuccinic esters, and mannich reaction products.

\subsubsection{Friction modifiers}

The main purpose of the friction modifier is to alter the coefficient of friction. They perform their function by preferential adsorption of surface-active materials. Typical examples include organic fatty acids and amides, lard oil, high molecular weight organic phosphorus and phosphoric acid esters.

\subsubsection{Pour point depressants}

Oil at low temperatures becomes so viscous that it does not flow readily. The main purpose of the pour point depressants is to enable the lubricant to flow at low temperatures. They perform their function by depositing a film on the surface of each wax crystal so that the crystals can no longer adhere to form a matrix. Typical examples include: Alkylated naphthalene and phenolic polymers, polymethacrylates, maleate / fumerate copolymer esters. 


\subsubsection{Sea swell agents}

The main purpose of the sea swell agents is to swell elastomeric seals. They perform their function by involving in a chemical reaction with elastomer to cause a slight swell. Typical examples include organic phosphates and aromatic hydrocarbons.

\subsubsection{Viscosity modifiers}

The main purpose of the viscosity modifier is to reduce the rate of viscosity change with temperature. In this case the polymers expand with increasing temperature to counteract oil thinning. Typical examples include polymers and copolymers of olefins, methacrylates, dienes or alkylated styrenes.

\subsubsection{Anti-foamants}

The main purpose of the anti-foamants is to prevent the lubricant from forming persistent foam. They perform their function by reducing the surface tension to speed collapse of foam. Typical examples include silicone polymers, organic copolymers.

\subsubsection{Metal deactivator}

The main purpose of the metal deactivator is to reduce the catalytic effect of metals on oxidation rate. They perform the function by forming inactive film on metal surfaces by complexing with metallic ions. Typical examples include organic complexes containing nitrogen or sulfur, amines, sulfides and phosphites. 


\subsection{Mechanisms of Engine Wear}

The five major wear mechanisms in a diesel engine are abrasion, adhesion, fatigue, corrosion and lubricant breakdown. Corrosion and lubricant breakdown involves a series of chemical reactions that lead to wear while abrasion, fatigue and adhesion involve mechanical damage of surfaces. For all the above five forms of wear, lubricant contamination is a predominant driver of wear.

\subsubsection{Abrasive wear}

Abrasive wear occurs when the contaminant particles cut away the material from the component surface. The rate of abrasive wear of a component is proportional to the number of contaminant particles making simultaneous contact with the component's opposing surface. Abrasive wear results in generation of wear debris and roughening of the surface with loss of clearance and misalignment. The wear debris that is generated due to abrasive wear adds to the oil and contributes to the chain reaction of wear. The engine wear that occurs in diesel engines are presumably caused due to abrasive wear. The soot particles contaminate the engine oil which results in three body wear.

\subsubsection{Adhesive Wear}

Adhesive wear occurs when two opposing surfaces come into contact at high pressures, resulting in welding between the surfaces. As the asperities of the opposing surfaces separate, the microscopic spot welds break, thus removing the material from the surface having a lower yield strength. Degradation of the surfaces contributes to the chain reaction of adhesive wear. 


\subsubsection{Fatigue Wear}

Fatigue wear occurs due to an accumulation of cracks on the working surface. These cracks increase in length with time forming voids, which enhances the wearing process. The wearing process leaves a roughened surface and work hardened particles continue the chain reaction. For component surfaces in rolling or squeeze contact, surface fatigue caused by particles may be the primary wear mechanism.

\subsubsection{Corrosive wear}

Corrosive wear occurs when the chemical reactions take place between the surface and the adjoining chemicals. This leads to corrosion of the surface resulting in wear. Oxides of sulfur, oxides of nitrogen and water are some of the chemical agents that cause corrosion in a diesel engine. The sulfur in the fuel reacts with the water forming sulfuric acid $\left(\mathrm{H}_{2} \mathrm{SO}_{4}\right)$, which corrodes the surface of the engine parts. However, as new regulations have limited sulfur content in diesel fuel to $0.05 \%(\mathrm{wt})$, corrosion is probably not the major cause of engine wear.

\subsubsection{Lubricant Breakdown}

Lubricant breakdown occurs when the lubricant looses its oil properties. Viscosity is a very important property and when soot particles combine with the oil, the viscosity properties of the oil change, resulting in pumpability problems. The lubricant ceases to perform its functions resulting in lubricant breakdown. This results in metal to metal contact, thus, increasing wear. 
Lubricant breakdown could also occur if the decomposed products of the antiwear agents, such as zinc dithiophosphate (ZDP), in the oil are preferentially adsorbed by soot particles. This results in no anti-wear protection of the engine parts and causes metal-to-metal contact.

\subsection{Variables Affecting Wear}

There are various types of wear testing devices that have been reported in published literature. These devices covered a wide variety of conditions and configurations. For wear and viscosity measurements, it is very important to decide on the variables that need to be controlled, the variables that may be ignored and those that need to be measured. The significant variables in the friction and wear process are (6):

- Load

- Velocity

- Temperature

- Contact area

- Geometry

- Surface finish

Load plays a very significant role in wear testing as it directly influences the surface temperature and can affect the real contact area. However, most wear experiments are run at relatively low loads and this limitation is imposed by a need for more rugged equipment and higher power requirement. In the current study, a load of $35 \mathrm{lbs} .(15.9 \mathrm{~kg})$ was applied. 
At higher speeds, temperature varies significantly as such velocity also influences both the surface temperature and the fluid film thickness in lubricant applications. In the current study, tests were performed at a lower speed of $200 \mathrm{rpm}(6)$.

Sliding distance is linearly proportional to the wear. Hence, tests could be performed for a shorter period of time and could be extrapolated to longer times.

Surface film of the wearing surface determines the regime of lubrication and, thus, plays a significant role. Moderately rough surface operates in the boundary lubrication regime and allows more contact. In this study, the cast iron rounds are turned on the lathe at a low speed of $250 \mathrm{rpm}$ to obtain boundary lubrication condition.

\subsection{Wear Testing Devices}

Previous wear tests were conducted on different types of wear configurations, depending on the purpose of study The primary reasons for conducting the wear tests were to simulate the wear process in the diesel engine, evaluate the lubricant properties, and to characterize the materials. There are four important wear testing machines that simulate the wear process. The following section gives a brief description of the four wear testing devices.

\subsubsection{Four-Ball Wear Testing Machine}

Four-ball friction and wear testing originated with Boerlage. He used the machine for testing highly-doped lubricants. Modifications have been made to his machine to allow more precise measurements under a great variety of conditions. The modern fourball wear-testing machine consists of: 
- An oil cup fitted with clamps to hold three balls in a planar configuration

- A precision chuck to hold the fourth spinning ball.

- A motor to drive the chuck

- A loading arm calibrated for the desired range

- A heating block below the cup

- A frictionless contact provided for the thermocouples and heater connections, consisting of a mercury pool into which contacts are dipped.

The Four-Ball-Wear Testing machine consists of four 0.5" diameter AISI 52100 steel balls. Three balls forming an equilateral base with the fourth on top of them forming an equilateral tetrahedron. The lubricant is contained in a cup surrounding the four-ball assembly. The upper ball rotates and due to friction, rubs against the lower three balls, which are stationary. The rotating motion causes scars to form on the lower three balls and tracks on the rotating ball. The wear scars obtained are in three shapes: circular, elliptical and teardrop. These wear scars are measured to determine the lubricant properties (9).

\subsubsection{Flat-on-Flat Configuration}

In this type of configuration the results are more reliable as the actual contact area remains constant throughout the test. Flat-on-Flat configuration is used for point contact friction, wear and lubrication studies. It is used when a wide range of load, speed, temperature, and atmospheric conditions are required. The rig consists of a stationary flat specimen rubbing against a flat rotating disc. The required normal load is applied through hydraulic / pneumatic systems or by pre-calibrated dead weights. 


\subsubsection{Two-Ball Wear Machine}

The two-ball wear machine consists of two steel balls each $1.5^{\prime \prime}(38.1 \mathrm{~mm})$ in diameter. The two steel balls are mounted onto the ends of two vertical spindle, the axis of which are $0.25 "(6.35 \mathrm{~mm})$ apart. The two vertical spindles are capable of rotating in the same or opposite directions at different speeds. The load is applied by means of a loading lever. The test lubricant is held in a cup mounted co-axially on the lower chuck. Using this Two-Ball-Wear machine configuration we can obtain complete boundary lubrication.

\subsubsection{Crossed Cylinders}

The crossed cylinders test device consists of two solid rod cylinders bearing on each other with the axes inclined at an angle. A common setup consists of a rod held in the chuck of a lathe and the other loaded against it at a $90^{\circ}$ angle. One rod is moved axially and the other rotates generating a fresh track on the rotating rod. This device is mainly employed to study low friction forces. 


\subsection{Literature Survey}

Rounds performed tests on a 4-ball wear testing machine with soot contaminated oil samples. The oil samples were obtained from a number of sources by normal oil drain process. Tests were performed on a 4-ball wear-testing machine using the collected samples to evaluate the oil properties in presence of soot. According to the Rounds Diesel engine, soot did not act as an abrasive, but soot preferential absorbed the anti-wear additive. This was the plausible reason he provided for the wear taking place in a diesel engine. He concluded that ZDP was the most effective anti-wear additive in the presence of diesel soot. He also performed hardness tests on soot and alumina, which is a known abrasive. Rounds concluded that since the hardness of soot is lower than the hardness of alumina ,he disagreed with the concept that soot removed the surface coating by abrasive phenomenon. He also suggested that engine load and EGR have a large effect on the soot pro-wear characteristics (28).

Many authors have disputed the adsorption theory proposed by Rounds. Ryason et al. performed wear tests on a ball-on-flat-disk tribometer using carbon black and steel balls made of AISI 52100 steel. Wear tests were performed on carbon black, alumina and silica. Investigations were carried out on the wear scars from the tests using Scanning Electron Microscopy (SEM) and Electron Probe Micro-Analysis. The SEM pictures show that the scars on the surfaces of the balls worn in the presence of oils containing carbon black, alumina and silica were similar and differ from that of the ball worn in the presence of oil alone. Ryason concluded that the wear that occurred was abrasive in nature. He also suggested that although the wear was abrasive in nature, the cutting of the material did not take place. The soot particles ploughed through the surface, forming a 
groove whose cross-section was a smooth curve, depressed at the center and raised at the edges (30).

Nagai et al. performed tests on valve train and studied the wear in the presence of soot. He concluded that the wear of cam noses and rocker arm tips was found to increase significantly with the increase in EGR rate. The drain oil analysis at the end of each EGR test run indicated evidence of elements such as zinc and phosphorous. This contradicted the adsorption theory proposed by Rounds initially. Nagai et al. also performed tests on four-ball wear testing machine and concluded that the soot strips off the anti-wear film formed on the lubricated metal surface and the subsequent metallic contact itself accelerated the wear process. They also concluded that soot might change to a very hard particle under the high-pressure conditions and might be abrasive to the metal (24).

Berbeizer et al. investigated that role of carbon black on mild lubricated wear. The test setup they used involved a plane-on-plane tribometer to simulate lubricated mild wear between ring, cylinder and particles in suspension. They conducted a systematic study of carbon black parameters on mild wear by evaluating special test blends in which different types of commercial carbon black were used as model compounds. They also concluded that bore polishing is influenced more by the size, nature, and concentration of carbon black rather that by the products of oil degradation. They suggested that decreasing the amount of carbon black reaching the piston or suspension in the lubricant could reduce bore polishing. Bore polishing can also be reduced by reducing the elementary carbon black particles, or by completely changing the microstructure of graphitized carbon. These modifications were only feasible if the combustion parameters such as temperature, gas oil additives or the lubricant additives were changed (7). 
On the mechanism of wear, Berbeizer et al. suggested that abrasive wear is not the sole factor contributing to increased wear. They suggested that two other important phenomena also play a role in increasing wear. A decrease of the surface coverage rate by ZDP molecules due to physical adsorption of carbon black on the surface and a subsequent modification of the physical and mechanical properties of the reaction film by the introduction of carbon in their composition are cited as possible reasons for increased wear (7).

Corso et al. suggested that soot contaminants interact with the adsorption / chemisorption mechanism of ZDP on metal surfaces inducing a transition from anti-wear $\mathrm{Fe}_{3} \mathrm{O}_{4}$ to pro-wear FeO. This transition apparently occurs due to the presence of soot in the lubricant limiting the access of oxygen to the metal surfaces (11).

Needelman and Madhavan studied the effect of lubricating oil components, nature of contamination on engine wear. They proposed the chain-reaction of wear and conducted a survey of engine oil contamination and the necessary improvements that have to be accomplished to reduce this contamination. They concluded that contamination of the lube oil causes wear of engine components. They also suggested that, a special relationship is present between the size of the contaminant particles and the thickness of dynamic oil films. The contaminant particles larger than the oil film cause wear of engine components by making simultaneous contact with both the surfaces (26).

Akiyama et al. studied the phenomena of abnormal cylinder wear in EGR equipped diesel engines. They concluded that the cylinder wear of a diesel engine, which is equipped with EGR, increases at low temperatures and suggested that the abnormal wear may be due to corrosion of cast iron. Corrosion of cast iron is due to formation of 
sulfuric acid formed when condensed water reacts with the combustion $\mathrm{SO}_{\mathrm{x}}$. However, this may not be the primary reason for engine wear as the sulfur content in diesel engines has been reduced to $0.05 \%$ wt (1).

Cadman and Johnson studied the effect of EGR on engine wear used analytical ferrography technique. The collected oil samples from the engine were analyzed for metal wear debris using analytical ferrography technique. A 15\% EGR showed a significant increase in the concentration of the wear particles and equilibrium concentrations with 15\% EGR were ten times higher than normal baseline levels. They also believed that soot acts as an abrasive to remove the anti-wear surface coating provided by the additives in the lubricant (10).

Kim et al. conducted experiments using a statistically designed oil test matrix to investigate both oil viscosity and diesel engine oil additive components. He investigated the effect of oil formulations on diesel engine valve train wear. They concluded that laboratory wear tests could properly differentiate the anti-wear performance provided by different engine oils. They concluded that an anti-wear additive film must form on the metal surface to reduce wear. The anti-wear properties of the diesel engine oil could be improved by increasing the ZDP concentration. Kim et al suggested that improved specifications were needed, as the existing diesel engine oil specifications were not adequate to protect every engine (19).

Murali investigated the effects of soot contaminated engine oil on three-body wear. Phosphorous level, dispersant level and sulfonate substrate level are the three oil additives he tested and concluded that there is an interaction between oil additives and soot in reducing the oil's anti-wear properties. He concluded that wear increases with 
higher soot concentration and decreases with higher phosphorous concentration. He also performed tests on the Ball-on-flat-disc setup with soot and alumina and compared their wear ratios. He concluded that abrasion could be the major mechanism involved in the diesel engine wear (23). 


\section{CHAPTER 3}

\section{EXPERIMENTAL SETUP AND PROCEDURES}

\subsection{Introduction}

The primary objective of this study was to study the effect of soot, dispersant and zdp on engine wear. Viscosity and wear tests were performed to obtain quantitative information on wear due to diesel soot. The diesel soot used in the tests was obtained from the mini-dilution tunnel facility at the WVU engine research center.

A three-body wear-testing machine was designed and developed to study the effect of soot on engine wear. This machine has a stationary surface as the first body, a rotating surface as the second body, and the entrapped intermediate particles (soot) as the third body. The description and operational parameters of this machine are discussed in detail in this chapter.

To study the effect of soot on viscosity, tests were performed using a rotary type Brookfield viscometer at $40^{\circ} \mathrm{C}$ and $90^{\circ} \mathrm{C}$. The viscosity tests were performed on three levels of soot, two levels for base, dispersant and zdp. The experimental setup and test procedures for viscosity tests are discussed in this chapter.

\subsection{Three-body Wear Testing Machine}

Engine wear takes place between the piston rings and engine cylinder with soot particles entrapped between the two surfaces. To simulate this condition, a three-body wear-testing machine was employed (18). The three-body wear testing machine has a stationary surface (specimen) as the first body, a rotating surface (cast iron round) as the second body and the entrapped intermediate particles (soot) as the third body. 
The wear tests are conducted at a constant speed of rotation, time and radius. Thus, a constant linear sliding distance was maintained. The effect of temperature was not taken into consideration as the continuous flow of oil provided the necessary cooling.

A 4140 tempered steel specimen of $0.25 "(6.35 \mathrm{~mm})$ diameter is used as the stationary body. This specimen was made to wear against a cast iron round in the presence of various oil formulations. Due to crossed cylinders or other configurations that could vary the contact area during the test, thus, giving inconsistent results, a flat-on-flat configuration was taken into consideration. The schematic of the three-body wear machine setup is shown in figure 3.1. The different parts of the wear testing machine are discussed in detail in the following sections.

\subsubsection{Stand}

The design of the wear-testing machine was a box type construction. The stand of the wear machine was designed to be robust. It provides a solid platform for mounting the various components of the wear testing machine. The stand was constructed of $1.5^{\prime \prime}(38.1$ $\mathrm{mm}$ ) mild steel angle cut to length and welded together. The legs of the machine had bolts of 1" $(25.4 \mathrm{~mm})$ length and $0.75 "(19 \mathrm{~mm})$ diameter welded onto them. Either loosening or tightening the nuts on the bolts levels the machine (18).

The bearing housing of the spindle assembly was held in a small box. The bearing housing was held in place by means of screws and these screws allowed leveling of the spindle assembly. Opposite to the housing box, the motor was placed, which is mounted rigidly to the lower two frame rails. The top view and the front view of the Three-Body Wear Machine stand are as shown in figure 3.2. 


\subsubsection{Spindle and Bearing Housing}

The spindle of the three-body wear machine rotated about its own axis. This provided the relative motion needed between the cast iron round, steel specimen, and the intermediate soot particles. All of the other degrees of freedom of the spindle were restrained and the alignment was achieved using bearings.

The spindle was made of 1020 mild steel (figure 3.3). It consisted of a 10" (25.4 $\mathrm{cm})$ long drive shaft with a $6 "(15.24 \mathrm{~cm})$ wide by $1.5 "(38.1 \mathrm{~mm})$ thick disk attached to it which acted as the turn-table. On this table the aluminum cup was placed containing the various oil samples. The drive shaft had two raised platforms for bearings. Fafnir Models $7306 \mathrm{WN}-\mathrm{DU}$ and $7307 \mathrm{WN}-\mathrm{DU}$ counter-bore bearings were used with angular contact seats mounted in a dual opposing configuration. The bottom set maintained proper alignment while the top set withstood the thrust load. The bearing housing was made of 1020 mild steel (Figure 3.4) and was provided with a housing to keep the spindle in position. For a secure mounting and leveling of the housing, it had pilot holes drilled on its outside surface that mated with the setscrews on the stand.

\subsubsection{Motor}

Three basic criteria were taken into account while selecting the motor for the three-body wear machine. The motor should fit in the stand with no major modifications and have a variable speed range. The motor should also provide enough drive power for the system.

The basic criteria was satisfied by a 2Z846B variable speed, permanent magnetic DC motor from Dayton Electric Company. This motor supplied a constant power up to 0.75 
HP $(558 \mathrm{~W})$ and had a variable speed range of $0-2500 \mathrm{rpm}$. The motor, being a variable speed reversible motor, had a soft start acceleration option. This helped to greatly reduce jerks during starting and stopping of the motor.

\subsubsection{Driving Mechanism}

To rotate the turntable containing the aluminum cup, a belt mechanism was used. Two identical pulleys were used to drive the machine. One pulley of 4" $(10.16 \mathrm{~cm})$ was keyed onto the motor shaft while the other pulley with exactly the same dimensions was mounted to the shaft of the spindle. Power was transmitted to the table by means of a type-A belt of $0.5 "(12.7 \mathrm{~mm})$ thickness, which ran over the pulley. To adjust the speed, a hand held controller was used. The tension in the belt was maintained by tightening or loosening of the motor mount bolts.

\subsubsection{Aluminum Cup}

An aluminum cup was used in order to reduce the weight and also to offer ease of machining. The various oil samples were placed in this cup, which was made out of an aluminum block of 1' $(30.48 \mathrm{~cm})$ length, 1' $(30.48 \mathrm{~cm})$ width, and 4" $(10.16 \mathrm{~cm})$ thickness. The block was cut to shape on a band saw and was machined on a lathe to obtain the desired dimensions. Four holes of $0.25 "(6.35 \mathrm{~mm})$ diameter were drilled and tapped on the sides as shown in figure 3.8. The cup was then firmly bolted to the top of the turntable of the spindle. On the bottom of the cup toward the periphery, four holes of $0.125^{\prime \prime}(3.175 \mathrm{~mm})$ diameter were drilled in order to attach the gray cast iron round onto the cup. The top and front view of the aluminum cup is as shown in figure 3.8. 
A dial indicator was used to align the aluminum cup horizontally. This prevented wobbling of the cup, especially when the spindle was rotating. The indicator was placed on the aluminum cup and the spindle was gradually rotated. The deflection on the dial indicator was observed and was brought close to zero by tightening or loosening the bolts on the side of the cup. A similar approach was followed to level the gray cast iron round on the surface of the cup. Very thin shims, of the order of thousandth of an inch, were placed between the cast iron round and the aluminum cup to align it horizontally.

\subsubsection{Specimen Holder}

The specimen holder consists of a chuck to hold the specimen, and a vertical post of square cross-section. The vertical post was made of high strength and stiffness that was used for applying the load on the specimen. The holder was made of a solid steel rod of 1" x 1" (25.4 mm x $25.4 \mathrm{~mm})$ cross section and 16" $(40.64 \mathrm{~mm})$ height. A $0.25 "$ $(6.35 \mathrm{~mm})$ diameter was welded to the vertical post. The desired load was applied by means of the dead weights that were mounted on the rod. The specimen holder for the Three-Body-Wear Machine is as shown in figure 3.9.

\subsubsection{Plate Fixture}

The vertical post of the specimen was held in place by means of a plate fixture. A steel plate $0.25 "(6.35 \mathrm{~mm})$ thick, $20 "(50.8 \mathrm{~cm})$ wide and $14 "(35.56 \mathrm{~cm})$ high was welded to one angle of the stand. The plate was aligned vertically such that the post that held the specimen was also perfectly vertical. A spirit level was used to level the plate and the bottom of the plate was welded on all sides to hold it firmly. Three angle steels 
were welded between the top of the plate and the machine stand to prevent bending of the plate. Two hollow pipes of $0.5^{\prime \prime}(12.7 \mathrm{~mm})$ internal hole were also welded to the plate. The front view of the plate fixture is as shown in figure 3.10.

\subsubsection{Post Guide}

To guide the specimen holder along the vertical direction, a vertical post guide was fabricated. The guide was a hollow square pipe of 1" $(25.4 \mathrm{~mm})$ square cross section A square cross section was used instead of a circular cross section in order to restrain the vertical post placed inside it. Another reason for the square cross section was to ensure that the post did not rotate along its own axis while the table was rotating. This helped in holding the specimen in place during the experiment. Two solid steel rods 0.5 " (12.7 mm) in diameter and 3.5" $(88.9 \mathrm{~mm})$ long were welded to the guide. These rods could slide inside the 0.5 " $(12.7 \mathrm{~mm})$ hollow pipes welded to the steel plate fixture. Through this type of design, the position of the specimen on the cast iron round could be varied and also for the easy removal of the cast iron round placed inside the aluminum cup. The tests were conducted on the outermost track of the cast iron round whose radial distance from the center was $2.5 "(62.5 \mathrm{~mm})$. The top and front view of the specimen holder guide is as shown in figure 3.11 .

\subsubsection{Deflector}

To ensure a constant and a continuous flow of oil, a deflector was used to deflect the oil/soot-oil mixture under the specimen. The deflector was made of Neoprene rubber of $0.25 "(6.35 \mathrm{~mm})$ thick. Neoprene was used because it offered resistance to buckling 
that could occur due to the oil pressure acting on it and also has great strength and flexibility. The deflector was attached to the vertical post guide by means of screws. This provided ease of attachment and detachment of the deflector.

\subsubsection{Protective Cover}

A round track made out of a thin aluminum sheet having the same size as the periphery of the aluminum cup was fabricated. This protective cover was screwed to the top of the cup, which prevented the oil from spilling during the wear tests. A rubber gasket between the cup and the cover provided a good seal. The protective cover on top of the aluminum cup is as shown in figure 3.12 .

\subsubsection{Testing Material}

The specimen material used in the experiments was cylindrical tempered 4140 steel. Tempered 4140 steel is soft when compared to other materials and was chosen because the extent of wear from the sample could be estimated by weighing the samples before and after the test. Harder materials showed negligible wear, thus making it extremely difficult to measure the weight loss due to wear. The specimen was first cut on the band saw to slightly over $0.5 "(12.7 \mathrm{~mm})$ and the surface is made plain using an emery paper. The gray cast iron round was also cut on the band saw to about $0.5 "(12.7 \mathrm{~mm})$ thickness. Both sides of the cast iron surface were faced-off on the lathe using a carbidetip tool at $250 \mathrm{rpm}$. The parameters on the lathe (speed, feed and depth of cut) were kept constant for all the cast iron rounds to maintain similar surface finish. Four holes were drilled on the cast iron surface and beveled. The cast iron round was then aligned with the 
holes on the aluminum cup and was perfectly seated inside the cup using flat-headed screws.

\subsubsection{Infrared Chopper Disk}

An infrared sensing circuit was used to determine the sliding distance traversed by the test specimen. An infrared chopper disk was used to determine the instantaneous rotational velocity of the machine. The infrared chopper disk provided steady pulses to a circuit that calculated the velocity.

The infrared chopper disk was made of aluminum and it had 36 slots cut radially inward from the edge of the disk. The disk was 6" $(15.24 \mathrm{~cm})$ in diameter and $0.0625 "$ $(1.59 \mathrm{~mm})$ thick. The long slot was $0.125 "(3.18 \mathrm{~mm})$ wide and 1" $(25.4 \mathrm{~mm})$ long. All of the other slots were $0.125^{\prime \prime}(3.18 \mathrm{~mm})$ wide and $0.5^{\prime \prime}(12.7 \mathrm{~mm})$ long and were referred to as short slots. The setup for the chopper disk is as shown in figure 3.5.

\subsubsection{Infrared Sensing Circuit}

The infrared sensing circuit consisted of two infrared light emitting diodes (LEDs) and two phototransistors, which sensed the infrared light beam. The diodes and the phototransistors were all mounted on a fork shaped aluminum block. One pair of LED-transistors detected the long slots while the other pair detected all the other slots. On the fork shaped aluminum block, the LEDs were placed on one arm of the fork and the corresponding phototransistors were located on the other arm, exactly opposite to the LEDs. The aluminum block was fixed to the bottom rail of the machine stand frame with the chopper disk placed inside the block between the LED emitters and the 
Phototransistors. A 5V-power supply was supplied to the circuit to power the LEDs, which emit infrared light. The LED's emitted a continuous beam of infrared energy which was detected by the phototransistor. This completed the circuit giving an output of $+5 \mathrm{~V}$. The chopper disk had a long slot and during this time the beam was not interrupted and the output was $+5 \mathrm{~V}$. During the time the disk interrupted the beam, the circuit was broken and the output was zero volts. Thus, for every rotation of the disk, the long slot was detected once giving one pulse of $5 \mathrm{~V}$ output (Figure 3.7 ). The output of the circuit was fed to a transistor, which completes a circuit on the counter/timer channel of the RTI board. The second set of emitter phototransistor pair detected 36 slots per rotation, which gave 36 pulses per rotation (Figure 3.7). These pulses were also fed into a transistor, which completed a circuit on a frequency measurement channel of the RTI board. The transistor ( $\mathrm{p}-\mathrm{n}-\mathrm{p}$ type) acted as a switch which turns on when there was a $+5 \mathrm{~V}$ pulse and turned off when the circuit was broken by the chopper disk. Hence, there were 36 pulses per rotation for the short slot circuit and one pulse per rotation for the long slot circuit. A QBasic program was written to convert the pulses into actual rotational velocity in rpm. The linear sliding distance traveled by the specimen was also calculated making use of the pulses. A graphical user interface was used to provide a clear digital display on the monitor. Graphic interface was used to provide proper digital display on the monitor screen. The infrared sensing circuit is as shown in figure 3.6. Details of the Qbasic subroutines are given in appendix B. 


\subsection{Design of the Experiment}

Experiments are conducted to study the effects of one or more factors on a particular response. If the designed experiment consists of more than one factor, the factors can influence the response individually or combined. In order to take care of such responses, an appropriate statistical model needs to be designed and developed to determine the effects of the various factors and the interactions between them.

\subsubsection{Lubricant Composition Matrix}

The factors that were taken into consideration for the present study are base stock, dispersant level, and zinc dithiophosphate level. The three factors were tested at two levels high (1) and low (-1). This resulted in a $2^{3}$ matrix. The lubricant composition matrix is as shown in the table 3.1 .

Table 3.1 Lubricant composition matrix

\begin{tabular}{|c|c|c|c|}
\hline $\begin{array}{c}\text { Oil } \\
\text { sample \# }\end{array}$ & Base Stock & $\begin{array}{c}\text { Dispersant } \\
\text { Level }\end{array}$ & ZDP Level \\
\hline & & & \\
\hline WVU397 & -1 & -1 & -1 \\
\hline WVU398 & -1 & 1 & 1 \\
\hline WVU399 & -1 & -1 & 1 \\
\hline WVU400 & -1 & 1 & -1 \\
\hline WVU401 & 1 & -1 & -1 \\
\hline WVU402 & 1 & 1 & 1 \\
\hline WVU403 & 1 & -1 & 1 \\
\hline WVU404 & 1 & 1 & -1 \\
\hline
\end{tabular}

The eight samples in the table 3.1 were tested at three levels of soot. The levels of soot used are low (-1), medium (0) and high (1). Apart from the three variables mentioned, soot is one of the important variables in this study. The amount of soot for 
level low was $0 \%$ wt or no soot contamination, for medium $2 \%$ wt and for high, $4 \%$ wt. This resulted in 24 samples for the wear tests. The Exxon base stock was assigned a value of (-1) and the RLOP base stock a value of (1). The factor-level combinations for the designed experiments are shown in Table 3.2.

The 24 samples produced from the factor-level combination for the designed experiments were tested on the wear-testing machine and the results obtained are analyzed statistically using the Statistical Analysis System (SAS) package. The Statistical Analysis System gave the effects and interactions of the three variables, base stock, dispersant and ZDP with soot. 
Table 3.2 Factor-Level combinations for the three-body wear testing experiments.

\begin{tabular}{|c|c|c|c|c|c|c|c|c|c|c|}
\hline Sample \# & Base Stock & Disp & ZDP & Soot & Disp & ZDP & Soot & ZDP & Soot & Soot \\
\hline & & & & & & & & & & \\
\hline 1 & -1 & -1 & -1 & -1 & 1 & 1 & 1 & 1 & 1 & 1 \\
\hline 2 & -1 & 1 & 1 & -1 & -1 & -1 & 1 & 1 & -1 & -1 \\
\hline 3 & -1 & -1 & 1 & -1 & 1 & -1 & 1 & -1 & 1 & -1 \\
\hline 4 & -1 & 1 & -1 & -1 & -1 & 1 & 1 & -1 & -1 & 1 \\
\hline 5 & 1 & -1 & -1 & -1 & -1 & -1 & -1 & 1 & 1 & 1 \\
\hline 6 & 1 & 1 & 1 & -1 & 1 & 1 & -1 & 1 & -1 & -1 \\
\hline 7 & 1 & -1 & 1 & -1 & -1 & 1 & -1 & -1 & 1 & -1 \\
\hline 8 & 1 & 1 & -1 & -1 & 1 & -1 & -1 & -1 & -1 & 1 \\
\hline 9 & -1 & -1 & -1 & 0 & 1 & 1 & 0 & 1 & 0 & 0 \\
\hline 10 & -1 & 1 & 1 & 0 & -1 & -1 & 0 & 1 & 0 & 0 \\
\hline 11 & -1 & -1 & 1 & 0 & 1 & -1 & 0 & -1 & 0 & 0 \\
\hline 12 & -1 & 1 & -1 & 0 & -1 & 1 & 0 & -1 & 0 & 0 \\
\hline 13 & 1 & -1 & -1 & 0 & -1 & -1 & 0 & 1 & 0 & 0 \\
\hline 14 & 1 & 1 & 1 & 0 & 1 & 1 & 0 & 1 & 0 & 0 \\
\hline 15 & 1 & -1 & 1 & 0 & -1 & 1 & 0 & -1 & 0 & 0 \\
\hline 16 & 1 & 1 & -1 & 0 & 1 & -1 & 0 & -1 & 0 & 0 \\
\hline 17 & -1 & -1 & -1 & 1 & 1 & 1 & -1 & 1 & -1 & -1 \\
\hline 18 & -1 & 1 & 1 & 1 & -1 & -1 & -1 & 1 & 1 & 1 \\
\hline 19 & -1 & -1 & 1 & 1 & 1 & -1 & -1 & -1 & -1 & 1 \\
\hline 20 & -1 & 1 & -1 & 1 & -1 & 1 & -1 & -1 & 1 & -1 \\
\hline 21 & 1 & -1 & -1 & 1 & -1 & -1 & 1 & 1 & -1 & -1 \\
\hline 22 & 1 & 1 & 1 & 1 & 1 & 1 & 1 & 1 & 1 & 1 \\
\hline 23 & 1 & -1 & 1 & 1 & -1 & 1 & 1 & -1 & -1 & 1 \\
\hline 24 & 1 & 1 & -1 & 1 & 1 & -1 & 1 & -1 & 1 & -1 \\
\hline
\end{tabular}

\subsubsection{Randomization}

In any experimental design, all the factors that affect the response must be taken into consideration. But this is not the case always and there is always a possibility that some factor might be neglected. In order to average out all these uncertain factors in the experiment, the test runs are completely randomized. In a randomized design, all the factor-level combinations in the experiment including the repeat tests were randomized. 
In the present study, all the 24 oil samples were randomized first and then the wear tests were conducted according to the random sequence.

\subsubsection{Oil Blend Content}

The oil blends were prepared by using varying combinations of dispersant levels, zinc dithiophosphate level, and different base stocks. Two types of base stocks were used, Exxon oils represented the group 1 base stocks while Richland Lubricant Oil Plant (RLOP) oils represented the group 2 base stocks. Two dispersant levels, the low (-1) and the high (1) were obtained by varying the basic succinimide dispersant level. The ZDP used in each oil sample was prepared from a mixture of secondary alcohol. The ZDP levels were also varied, thus obtaining two levels the low (-1) and the high (1). To study just the above three important variables, other components such as anti-oxidants, viscosity index improver, calcium, magnesium detergent, rust inhibitor, anti-foamant, and a pour point depressant were kept constant. The above mentioned compounds are generally present in all commercial lubricants. The samples were tested at three levels of soot to clearly determine how each of the three additives behaved.

\subsection{Ball-on-flat-disk Setup}

To qualitatively analyze the wear process, a set of experiments was performed on a ball-on-flat-disk setup on a milling machine. AISI 52100 stainless steel ball, 0.5 " (12.7 $\mathrm{mm}$ ) in diameter, was worn against a gray cast iron surface in the presence of soot-oil formulation at $30 \mathrm{lbs}$. (13.63 kg) load for 30 minutes. The oil samples, having the highest and the lowest wear on the wear-testing machine, were considered for the experiments. 
Drain oil samples from the Cummins engines were also tested using the ball-on-flat-disk setup. The schematic of the setup is shown in figure 3.14 and the design and description of the various parts of the setup are discussed below.

\subsubsection{Chuck}

To hold the stainless steel ball, a chuck was designed and developed in the workshop. The chuck was solid and is made out of cast iron. The chuck had a long handle that fits into the milling machine to rotate the ball along its axis. To hold the ball in place, a set of nuts and bolts were used along with two iron plates for reinforcement. The ball is placed in between the jaws of the chuck and held in place by tightening the nut, bolt combination. The chuck for the Ball-On-Flat-Disk experiment is as shown in figure 3.13.

\subsubsection{Cast Iron Base}

The stainless steel ball was made to wear against a cast iron round. The cast iron round used had exactly the same specifications as the one used the wear test experiments. The T-bolts that ran through the T-groves in the milling machine were used to hold the cast iron round in place.

\subsubsection{Aluminum Container}

A cylindrical aluminum tube of inside diameter 3.75" $(95.25 \mathrm{~mm})$ and an outside diameter of 4.5 " $(114.23 \mathrm{~mm})$ with a height $2.5 "(62.5 \mathrm{~mm})$ was made at the workshop. The edges of the aluminum tube are chamfered and the surface was made 
plain by using the help of a lathe. The aluminum container was held in place by using the T-bolts that ran through the T-groves in the milling machine.

\subsubsection{Gasket}

The rubber gasket was placed in between the aluminum tube and the cast iron round so that the oil samples continue to stay inside the tube during the course of the experiment.

\subsection{Microscopic Studies}

A Scanning Electron Microscope (SEM) was used for the microscopic studies, in order to determine the wear scar diameters. The wear scars were caused due to the abrasive nature of soot particles on the stainless steel ball. The following sections explain about the instruments in detail.

\subsubsection{Scanning Electron Microscope (SEM)}

The Scanning Electron Microscope is a powerful tool for analyzing the surface of materials. It is analogous to reflected light microscope, except that it uses electrons for image formation. The wavelength of the electrons (less than $0.5 \mathrm{X}$ ) is much shorter than the wavelength of the visible light $(2000 \mathrm{X})$. These short wavelengths are capable of generating high-resolution images. The magnification power of the SEM is also very high. Looking at the advantages, the SEM was selected for the study. 


\subsubsection{SEM Description}

The SEM consists basically of four systems.

- The illuminating / imaging system, that produces the electron beam and directs it onto the sample.

- The information system that includes the data released by the sample during electron bombardment and detectors, which discriminate among and analyze these information signals.

- The display system, which consists of one or two cathode ray tubes for observing and photographing the surface of interest.

- The vacuum system, which removes gas from the microscope column which would otherwise interfere with high-resolution imaging (13).

The illuminating/imaging system comprises of an electron gun and several magnetic lenses that serve to produce a collimated, coherent beam of electrons that can be focused on the specimen. The electron gun has a filament (cathode) or electron source which generates electrons, that pass through the aperture of the shield, which is at a slightly positive potential relative to the filament, and are attracted towards the anode. The difference in the potential between the filament and the anode is called the accelerating voltage, as this potential difference is responsible for accelerating the electrons. The magnetic lenses focus the electron beam onto the specimen and are responsible for varying the magnification of the image.

The information system consists of the sample which releases a variety of data signals resulting from interaction with the imaging beam, and a series of detectors that 
recognize and analyze the data signals. The sample is mounted on a conductive substrate, like aluminum or carbon, and then secured within the sample stage of the microscope. The stage serves as an electrical pathway to ground and is equipped with several controls for specimen movement.

The display system of the SEM consists of a cathode-ray tube (CRT) on which the images are displayed.

The SEM optical column and the specimen chamber are operated under high vacuum. This is to prevent scattering of the electron beam due to residual gas molecules, which may reduce the image resolution. For this purpose, the SEM is equipped with pumps that operate continuously to maintain high vacuum.

In this study, the wear scars obtained due to the ball-on-flat setup were observed using a Hitachi 570 SEM.

\subsection{Brookfield Viscometer}

\subsubsection{Description}

A Wells Brookfield Micro Viscometer was used for the current study as the geometry of the cone and plate offered precise measurements and it required only a small volume of oil to perform the tests. It was originally developed to investigate the rheological characteristics of biologic fluids. The Wells Brookfield Micro Viscometer can be driven at six different speeds of rotation and is a precise rotating torque meter. The small volume of oil sample in the cup offers a resistance to the cone rotating upon a flat surface. The Wells Brookfield Viscometer is shown in figure 3.15 (36). 
A beryllium spring connects the driving mechanism of the viscometer to a vertical shaft. A cone is suspended from the shaft. During the tests, the cone acts as a torque measuring device. The oil sample present between the cone and plate offers a resistance to the rotation of the cone. This develops a torque in the beryllium spring to a degree, which is a function of the shear stress in the fluid. The deflections are different for different oil samples depending upon their viscosities and this is clearly indicated on the dial provided on the instrument. The dial gauge readings are converted to absolute centipoise units from pre-calculated range charts.

The sample cup clamped onto a micrometer adjusting ring which, in turn, screwed to the aluminum cylinder. This arrangement facilitates the easy removal of the cup and maintains the precise position and clearance in relation to the cone for future experiments. The threads on the micrometer adjusting ring were extremely fine and one full rotation caused a rise or fall of the cup relative to the cone of $0.0024 "(0.06 \mathrm{~mm})$. To measure viscosity accurately, the clearance should be set to within $0.0001 "(0.0254 \mathrm{~mm})$ by following a simple calibration procedure. The oil sample cup was removed after every experiment and was cleaned with acetone for the next experiment. The sample cup could be removed and remounted without disturbing the setting and the rest of the setup. The entire setup was supported on a vertical bar with a tripod stand. A rack and pinion gear on the vertical bar permitted easy adjustment of the viscometer to a convenient working height. 


\subsubsection{Viscosity Measuring Setup}

The entire setup for conducting viscosity tests is shown in Figure 3.16. The experiments were conducted at $40^{\circ} \mathrm{C}$ and $90^{\circ} \mathrm{C}$. For measuring the viscosity at $90^{\circ} \mathrm{C}$, the viscometer was connected to a temperature bath through a positive displacement pump. The oil bath was a micro-rotary evaporator, Labconco Model No 421-4001. For attaining temperatures above $100^{\circ} \mathrm{C}$ quickly and easily, silicon oil was used for the bath. The pump was a rotary valve type, Masterflex Model 7518-00. During one half rotation of the rotor, oil was sucked from the bath and during the other half of rotation, the heated oil was delivered to the viscometer. The viscometer cup had a jacket around it for the flow of the heating oil that transferred heat across the jacket wall to the oil sample inside the cup. A small tube ran between the outlet of the jacket and the heating bath, thus completing the loop. The pump maintained a constant flow rate of heated silicon oil around the jacket, thus maintaining a constant sample oil temperature during viscosity measurements. There was tremendous heat loss at elevated temperatures and this affected the viscosity values. In order to reduce this heat loss the entire inlet and the outlet tubes along with the jacket were completely insulated. A heater was also used to keep the surrounding temperature of the air warm to prevent heat loss, due to convection. Two thermocouples, one for the inlet and one for the outlet, were used to monitor the temperature during the course of the experiments. A schematic of the setup for conducting viscosity tests is shown in figure 3.16 . 


\subsection{Experimental Procedures}

The three experimental procedures were the Three-Body-Wear testing experiment, Viscosity Measuring experiments, and the Ball-on-Flat-Disk experiments. For the current study, a $2^{3}$ matrix of eight oil blends was considered. Base stock, the dispersant level and the ZDP level were the three variables that were considered for the present study. Sections 3.7.1 to 3.7.4 discuss the procedures adopted for performing tests on the Three-Body-Wear machine, viscosity measuring system, and the Ball-on-Flat-Disk setup. The procedures for three body wear testing include actual wear test procedures, preparing a stable soot suspension in the oil, and the post-processing of the steel specimen. The procedure for performing tests on the ball-on-flat disc setup is shown in section 3.7.2. This section includes a detailed description of the load calibration of the load cell and the milling machine and the post-processing of the test specimen. The procedure for performing the viscosity measurements is shown in section 3.7.3. This section includes a detailed description of the viscosity measurements at $40^{\circ} \mathrm{C}$ and $90^{\circ} \mathrm{C}$. It also includes a description for preparing the oil samples. The information on the microscopic studies on the wear scars on the steel balls is shown in section 3.7.4. This includes a detailed description on the scanning electron microscope.

\subsubsection{Experimental procedure for Three-Body Wear Testing Machine}

The oil samples that were considered for the test are the eight samples mentioned previously in the composition lubricant matrix. The tests were conducted under constant load and sliding distance at three levels of soot. Therefore the total number of tests performed were as shown in the Table 3.2, Factor-Level combinations for the three-body 
wear testing experiments. All of the 24 samples have been randomized and tests are conducted in a particular sequence. The experiments have been performed 4 times for consistency and also to minimize errors. A detailed description of the specimen preparation, the testing procedures involved, and the post-processing of the test specimen are described in the following section.

\subsubsection{Oil Sample Preparation}

The preparation of a stable soot suspension is a challenging task because the density of the soot particles (approx. $1.8 \mathrm{~g} / \mathrm{ml}$ ) is higher than the density of oil (approx. $0.88 \mathrm{~g} / \mathrm{ml})$. Soot particles generally tend to agglomerate if the dispersant does not perform its function and this makes it very difficult to prepare a stable soot suspension artificially. The sedimentation of the soot particles is possible if the sample is stored for a long period of time before performing the tests. In order to avoid this and to prepare stable soot suspension, Ryason et al. proposed a detailed procedure that is given in Appendix A. An ounce of the oil sample was measured using an electronic weighing machine and was poured into a glass vial. Soot was also weighed using the electronic weighing machine and is poured into the glass vial to obtain the required soot-oil sample. Then the procedure in Appendix A suggested by Ryason et al. to prepare a stable soot suspension was performed on the soot oil sample. The soot oil sample was then poured into the aluminum cup on the three wear testing machine and the wear tests were performed. The oil formulations are tested at three levels of soot: $0 \%$ or without soot contamination, $2 \%$ soot, and $4 \%$ soot by weight (31). 


\subsubsection{Experimental Procedure for the Wear tests}

The wear tests were performed at a radius of $2.5 \mathrm{~cm}$ on the cast iron round. The specimen holder was placed at a radius of $2.5 \mathrm{~cm}$ by moving the sliding column in and out. The specimen holder was then raised and the specimen was placed in the chuck of the holder. The deflectors were then properly placed inside the aluminum cup and connected to the holder with the help of screws. After connecting the deflector, the oil sample to be tested was poured into the aluminum cup. The bolts on the holder were now loosened and the steel specimen was now allowed to rest on the cast iron surface. A load was then applied by placing dead weights of $35 \mathrm{lbs} .(15.9 \mathrm{~kg})$ on the circular rod welded on top of the square cross-sectioned holder. The wear-testing machine was then turned on and was operated at a constant speed of $200 \mathrm{rpm}$. The machine is operated at a safe speed of $200 \mathrm{rpm}$ so that the oil sample in the aluminum cup does not spill out. The above wear test procedure was followed after the steel specimen was given a run-in. At the end of the run-in period, the specimen was removed and thoroughly cleaned in an acetone bath. After allowing the specimen to dry, it was weighed on an electronic balance that had a sensitivity of $0.1 \mathrm{mg}$. This weight was recorded as the initial weight of the specimen. The specimen was then reinserted into the chuck of the holder to perform the actual test. The wear test is carried out for a period of $6 \mathrm{~min}$. The speed of the machine is monitored every minute using a digital tachometer and an infrared sensing circuit. The required linear sliding distance of $18,850 "$ was achieved after running the machine at a speed of $200 \mathrm{rpm}$ for 6 minutes. During the course of the test, centrifugal force pushed the oil towards the periphery of the cup. The deflector attached to the holder re-directed the oil toward the specimen, thus ensuring continuous oil flow under the specimen. The 
machine was stopped when the pre-determined distance was attained after 6 minutes. The test specimen was then removed from the chuck and post-processed before measuring its final weight. The final weight of the specimen was measured using the electronic balance and wear was calculated by subtracting the final weight from the initial weight. The amount of wear was measured in terms of weight loss of the specimen and is in milligrams.

\subsubsection{Post-Processing of the Test Specimen}

Post processing of the test specimen was completed after the machine was run for a period of 6 minutes. The specimen was then removed from the chuck of the holder and was thoroughly cleaned, first in a hexane bath, and then in an acetone bath to remove the soot particles and oil adhering to the specimen. The specimen was then dried using a drier to remove any hexane or acetone adhering to the surface. The specimen was then carefully weighed using the electronic balance and the weight of the specimen at the end of the wear test was determined. The above wear test procedure was repeated three more times and the average wear was determined.

\subsubsection{Experimental procedure for Ball-on-flat-disk Tests.}

The ball-on-flat-disk tests were used to study wear qualitatively. A load cell was used to calibrate the milling machine, as dead weights could not be applied. The Model SSM-250 load cell was also calibrated initially to convert strain to weight applied. The calibration procedure is discussed in detail in load calibration. 
The ball-on-flat-disk experiments were carried out on a milling machine with the motor providing the required rotation to the steel ball (AISI 52100). A specially designed chuck was designed to hold the steel ball in place. In order to prevent the ball from rotating on its own axis, a bolt and nut arrangement was used to hold the ball in place. The milling machine table held the cast iron surface and the aluminum container holding the oil sample. Compressive Load was applied on the steel ball by cranking up the milling machine table

\subsubsection{Load Calibration}

To calibrate the Milling Machine, a Model SSM-250 load cell was used. For the calibration of the load cell, a 10V DC supply, a Voltmeter, and dead weights were used. Dead weights were placed on the load cell and the load was plotted against voltage to obtain a relationship between the load and voltage. The linear fit of the plot between load and voltage yielded a voltage of $0.275 \mathrm{mV} / \mathrm{Kg}$ of the applied load. The load cell was then placed between the ball holder and the milling machine table and compressive load was applied by cranking up the milling machine. The machine table was slowly moved up by one division and voltage corresponding to each division was noted. The table was again moved up in increments of one division until a voltage $(19.22 \mathrm{mV})$ corresponding to 30 lbs. (13.6-kg) was reached. During the calibration process, it was found that a voltage of $19.22 \mathrm{mV}$ was obtained if the table moved up by three divisions. Thus, the table was always moved three divisions in the upward direction before performing the tests on the oil samples. The Model SSM-250 load cell used for calibration is as shown in figure 3.17. 


\subsubsection{Test Procedure}

The cast iron round was first placed on the milling machine table with the aluminum container on top of it. A gasket was placed in between the cast iron round and the aluminum cup to prevent the oil sample from flowing out. T-bolts were used to hold the cast iron holder and the aluminum cup in place. The stainless steel ball specimen was placed in the chuck which was held in the jaws of the collet. The soot oil sample was then poured into the aluminum cup. The collet that held the chuck containing the specimen was locked in place and the milling machine table was raised to three divisions to apply a compressive load of $30 \mathrm{lbs}$. (13.6 kg). The machine was turned on and operated at a speed of $600 \mathrm{rpm}$ for 30 minutes. Wear scars were created on the steel specimen and an indentation was produced on the cast iron surface. At the end of the test, the collet was loosened and the steel ball specimen was removed from the chuck and a new steel ball was placed in its place. The tests were repeated on oil samples having the least and highest wear on the wear-testing machine. Tests were also performed on the drain oil samples obtained from Cummins and the wear scars obtained were compared with that of the oil samples.

\subsubsection{Post-Processing}

After performing the tests, the stainless steel specimen was removed from the chuck and then thoroughly cleaned with acetone. The soot-oil sample was then collected in a vial and was stored. The cast iron holder, the aluminum cup, and the chuck were then thoroughly cleaned with acetone to perform the next set of experiments. 


\subsubsection{Microscopic Studies}

\subsubsection{Wear Scars}

Microscopic studies were performed on the steel ball to understand the mechanism of engine wear. The steel ball specimen was first thoroughly cleaned with acetone to get a clear picture of the scar. The steel ball specimen was then placed in a specimen holder with the scar facing the electron gun. For the easy identification of the scar, the scar was precisely marked by a black pen and placed under a magnifying glass for proper identification. These scars were viewed using a Hitachi 570 SEM by applying an acceleration voltage of 20 kilovolts. Using the controls on the keyboard the scar was magnified until a clear picture emerged. The operational details of the SEM are given in Appendix C (35). To take the pictures of the scar, a Polaroid camera that was interfaced to the SEM was used. Polaroid film was placed in the film holder to take the picture of the scar. The diameter of the scar was measured and the wear ratio was calculated using the Hertz equation. Wear ratio is defined as the mean diameter of the wear scar normalized by the Hertz diameter. Hertz diameter is the scar size due to plastic deformation caused by a static load. Details of the Hertz equation and the concept of wear ratio are given in section 4.4.1.

\subsubsection{Viscosity Tests}

There is an increase in viscosity when soot particles contaminate the lubricating oil. This increase in viscosity of the lubricant results in the breakdown of the lubricant. This effect causes pumpability problems in the engine resulting in inadequate amount of engine oil reaching the cylinder liner walls. This leads to increased engine wear and 
hence, it is of importance to determine the oil additives that are influenced by the contamination of soot in order to develop novel high performance engine oils for EGR equipped diesel engines. Keeping these factors in mind viscosity tests were performed on the various oil formulations to study the effect of soot-oil additive interaction on the oil viscosity.

The Viscosity measuring system consisted of a heater, a pump and a high range Wells-Brookfield viscometer with a $1.565^{\circ}$ cone. The details of the instrument are discussed in section 3.6. The Wells-Brookfield viscometer was first calibrated for accuracy by testing a known silicon oil sample and the results were compared with the actual viscosity. The viscosity tests were performed at $40^{\circ} \mathrm{C}$ and $90^{\circ} \mathrm{C}$ at three levels of soot. The silicon oil bath was set at about $5^{\circ} \mathrm{C}$ higher than the test temperatures $\left(40^{\circ} \mathrm{C}\right.$ or $90^{\circ} \mathrm{C}$ ). The oil sample was also heated to about $5^{\circ} \mathrm{C}$ higher than the test temperature and exactly $1 \mathrm{ml}$ of the oil sample was poured into the cup by using a pipette. The pump was then turned on to circulate the heated silicon oil for a few minutes to stabilize the sample temperature. The temperature of the oil sample was maintained constant at the desired temperature by using thermocouples at the inlet and outlet of the viscometer. Performing the tests at $40^{\circ} \mathrm{C}$ was easy, but at higher temperatures special care was taken in maintaining the temperature constant. In order to maintain the temperature constant even at $90^{\circ} \mathrm{C}$, the entire oil circulating circuit was properly insulated. To prevent the heat loss due to convection, a heater was used to blow hot air at the setup. At the end of the test, the oil sample was first removed and then cup and cone were thoroughly cleaned with acetone. The instrument was then re-calibrated (8). The same procedure was followed for all the oil samples. The tests were randomized to ensure a proper statistical design and 
each sample was tested four times to ensure repeatability. The data obtained from the tests was statistically analyzed using SAS. The results obtained after running the SAS program determined the significant oil additive variables and their interactions in the presence of soot and its influence on the viscosity. 


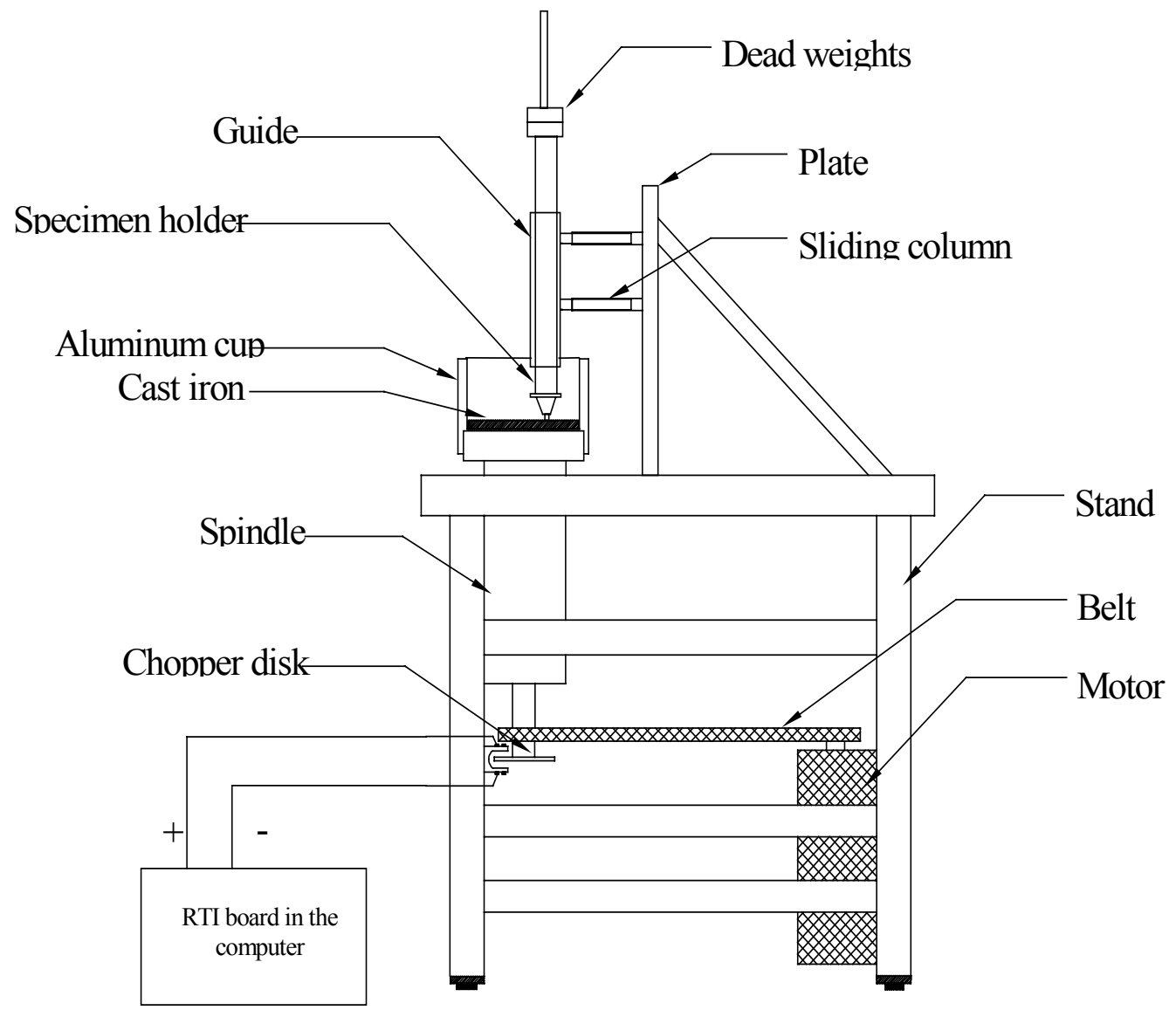

Figure 3.1 Schematic of the Setup for the Three-Body Wear Machine 

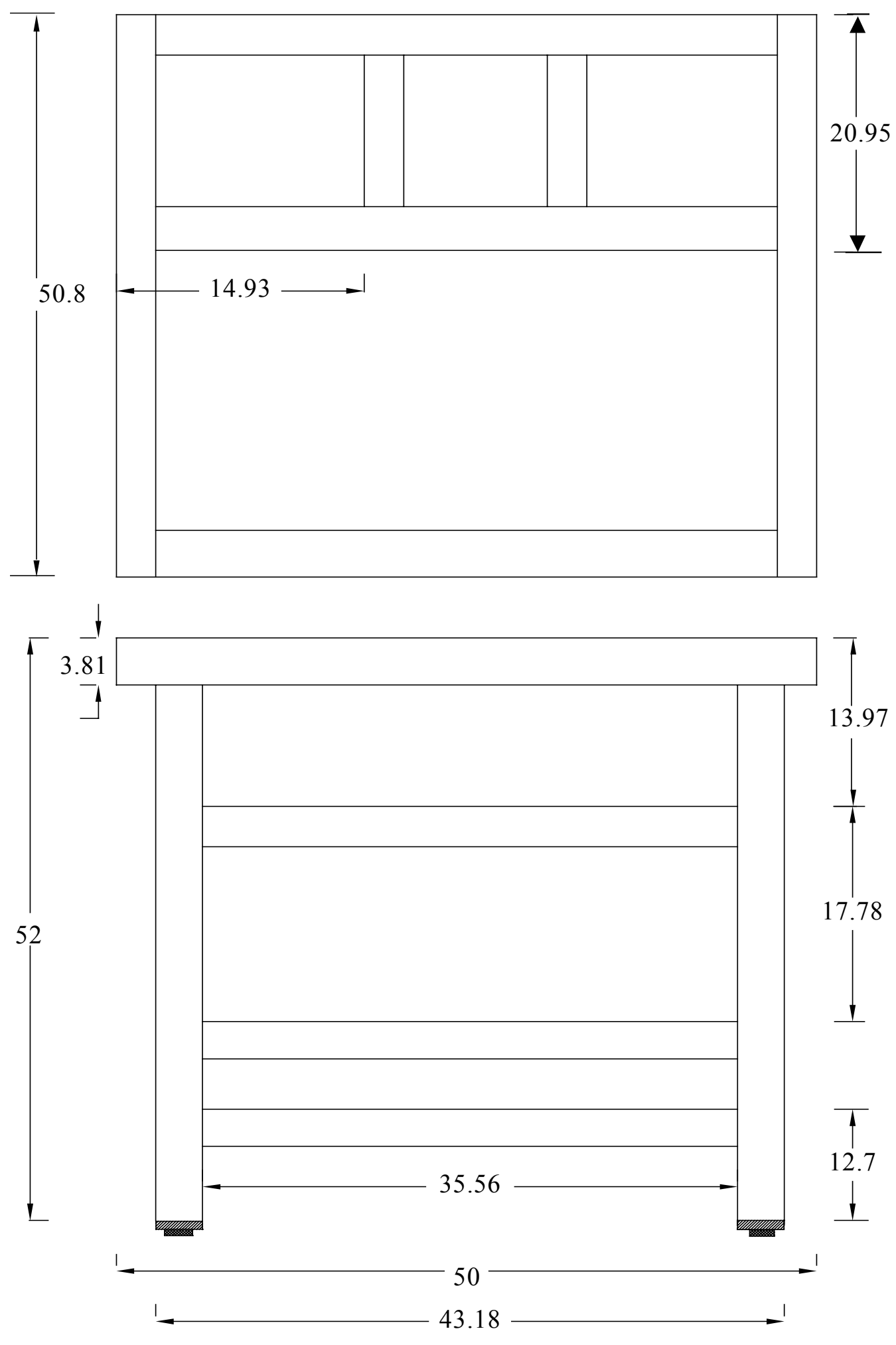

All dimensions are in $\mathrm{cm}$.

Figure 3.2 Top View and Front View of the Three-Body Wear Machine Stand 


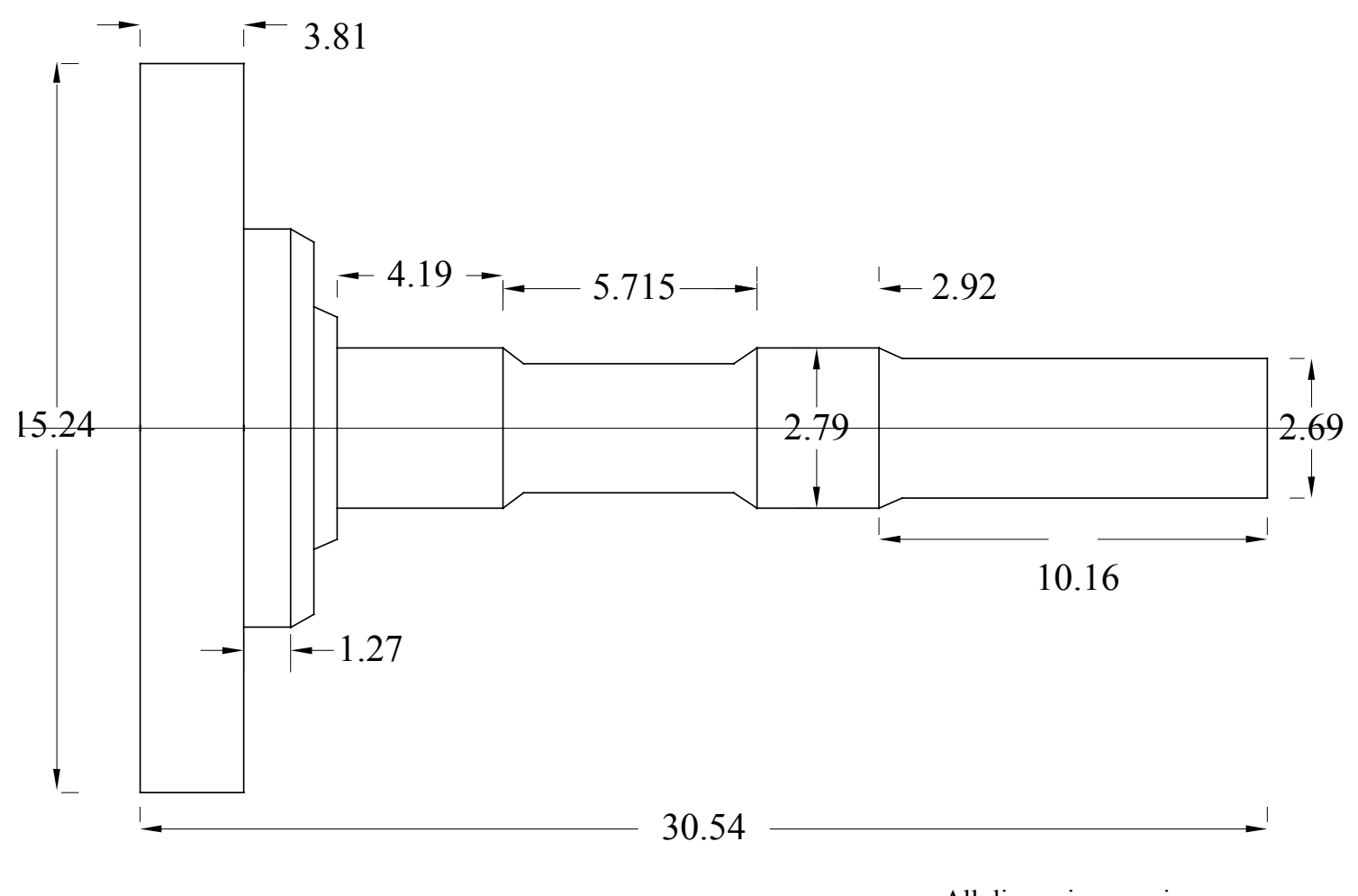

All dimensions are in $\mathrm{cm}$.

Figure 3.3 Spindle for the Three-Body Wear Machine 


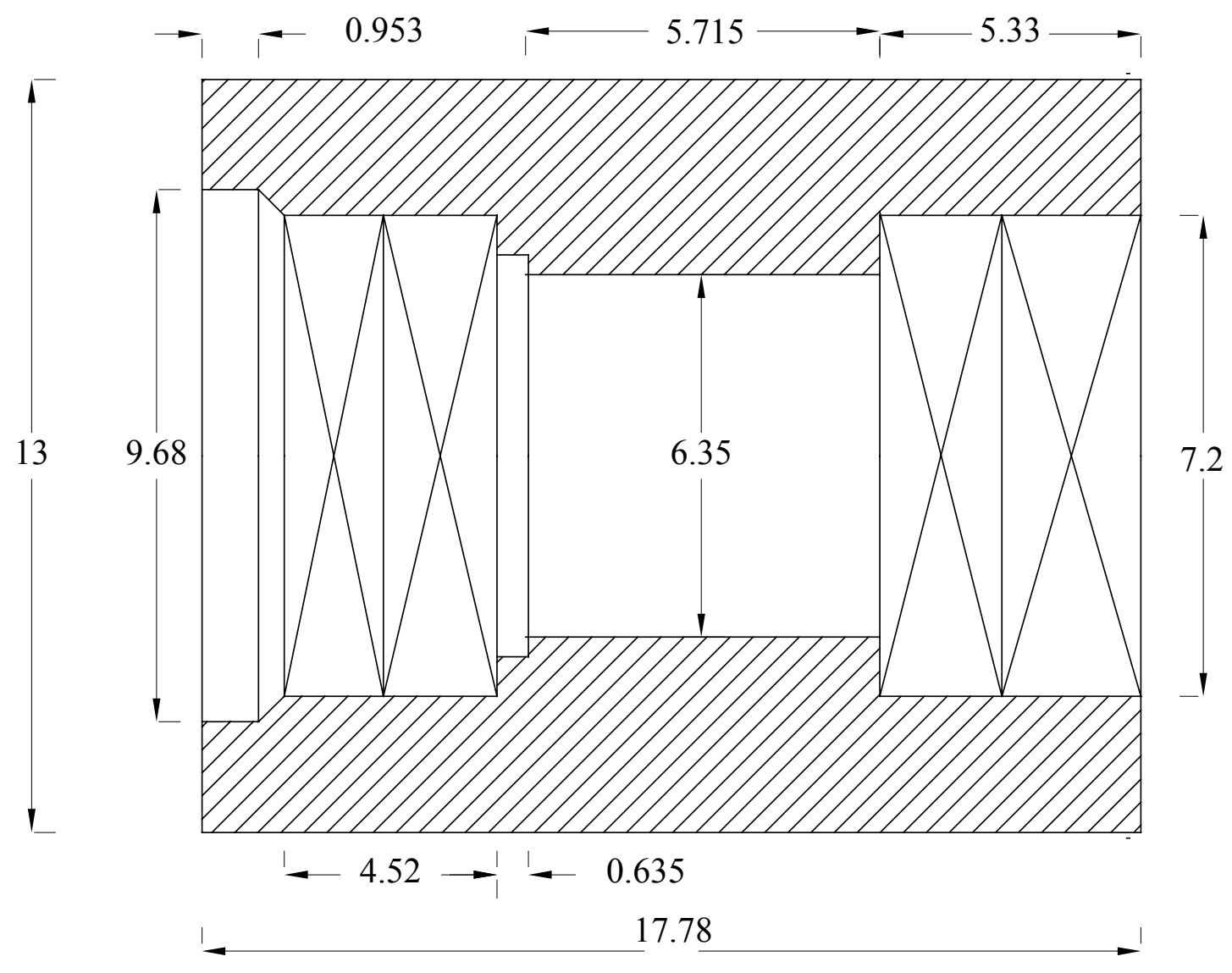

All dimensions are in $\mathrm{cm}$.

Figure 3.4 Bearing Housing for the Spindle of the Three-Body Wear Machine 


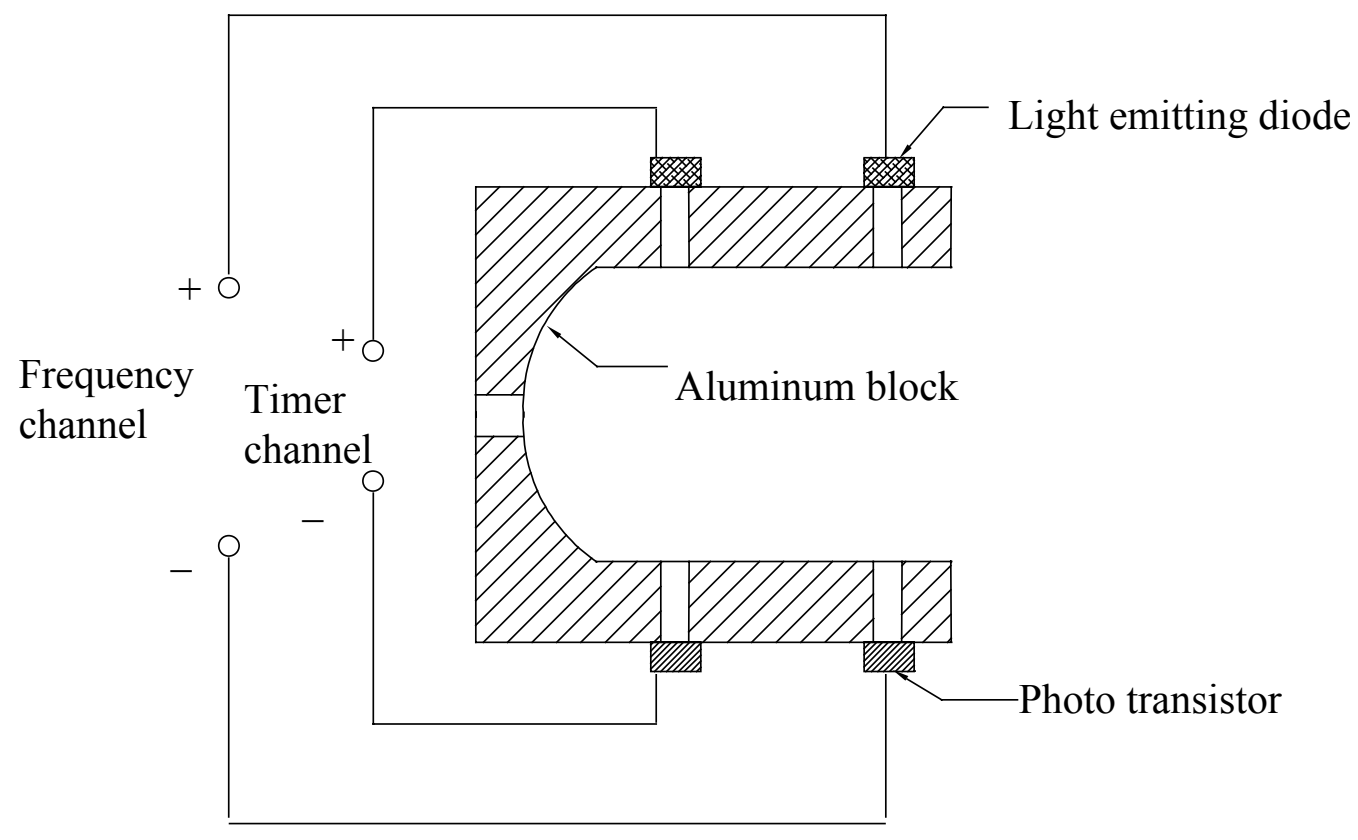

Figure 3.5 Infrared Chopper Disk Setup on the Three-Body Wear Machine 


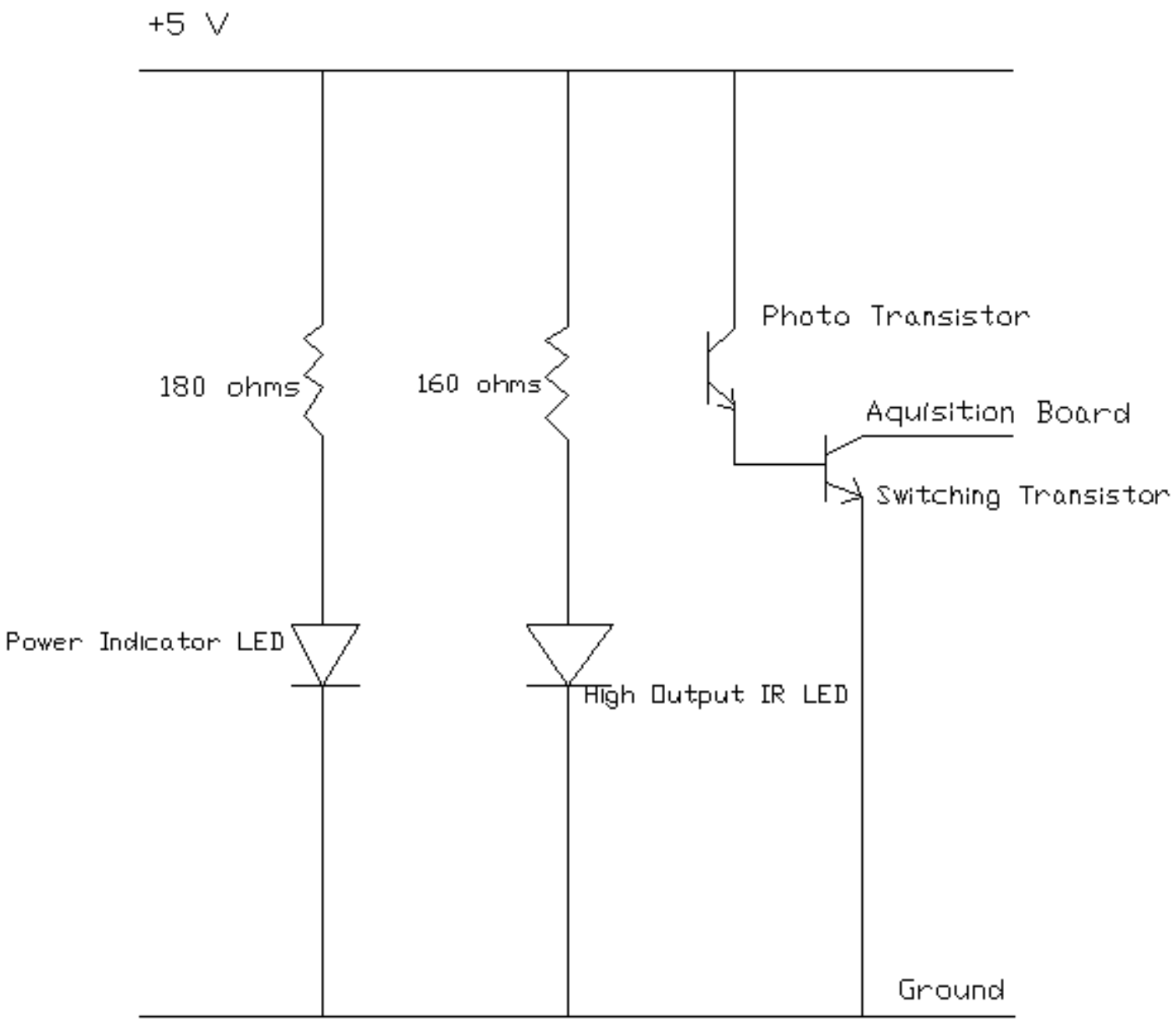

Figure 3.6 Circuit Diagram for the Infrared Sensing Circuit 


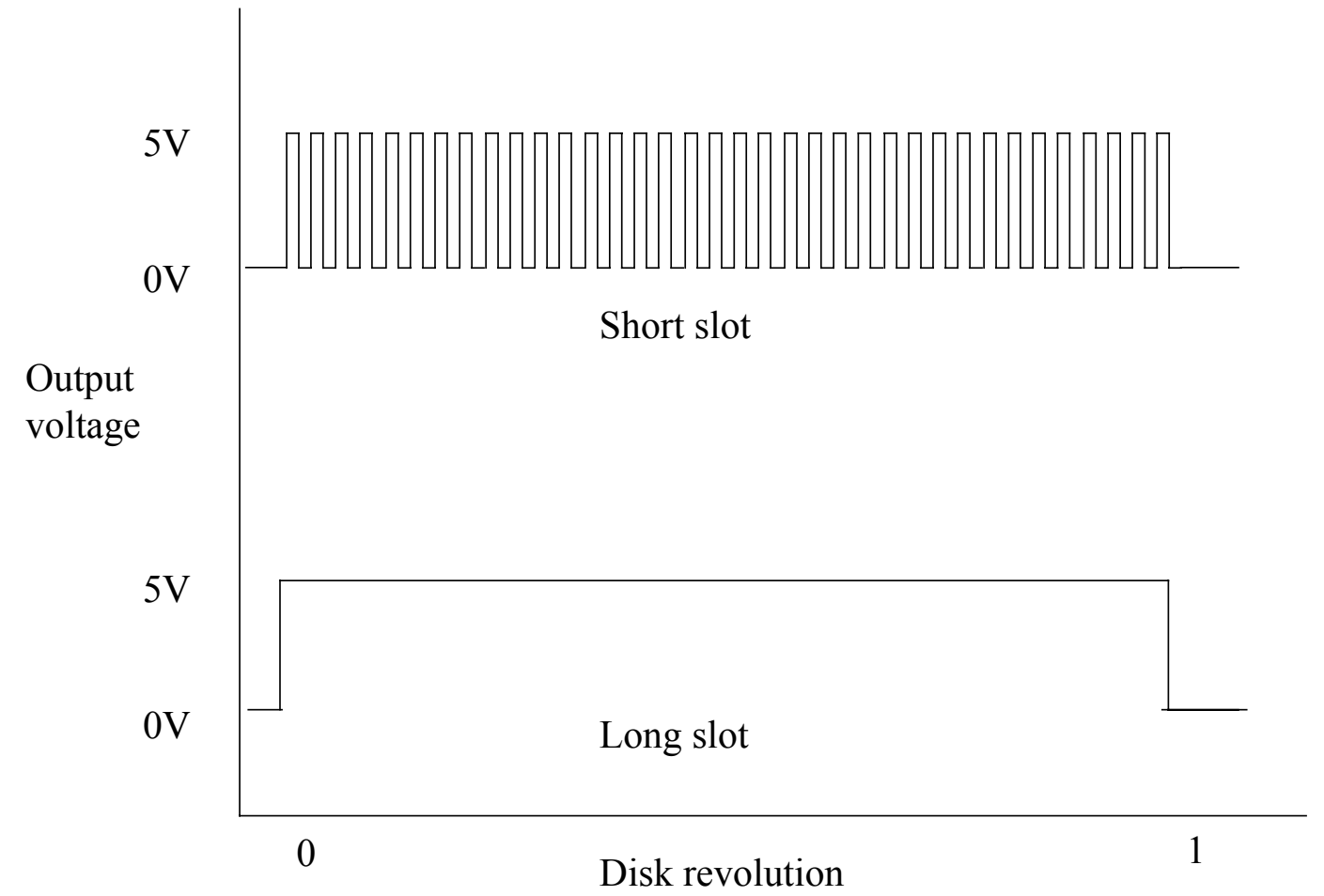

Figure 3.7 Output Voltage Pulses from the Infrared Circuit Fed to the Counter Channel and Frequency Channel of the RTI Board 

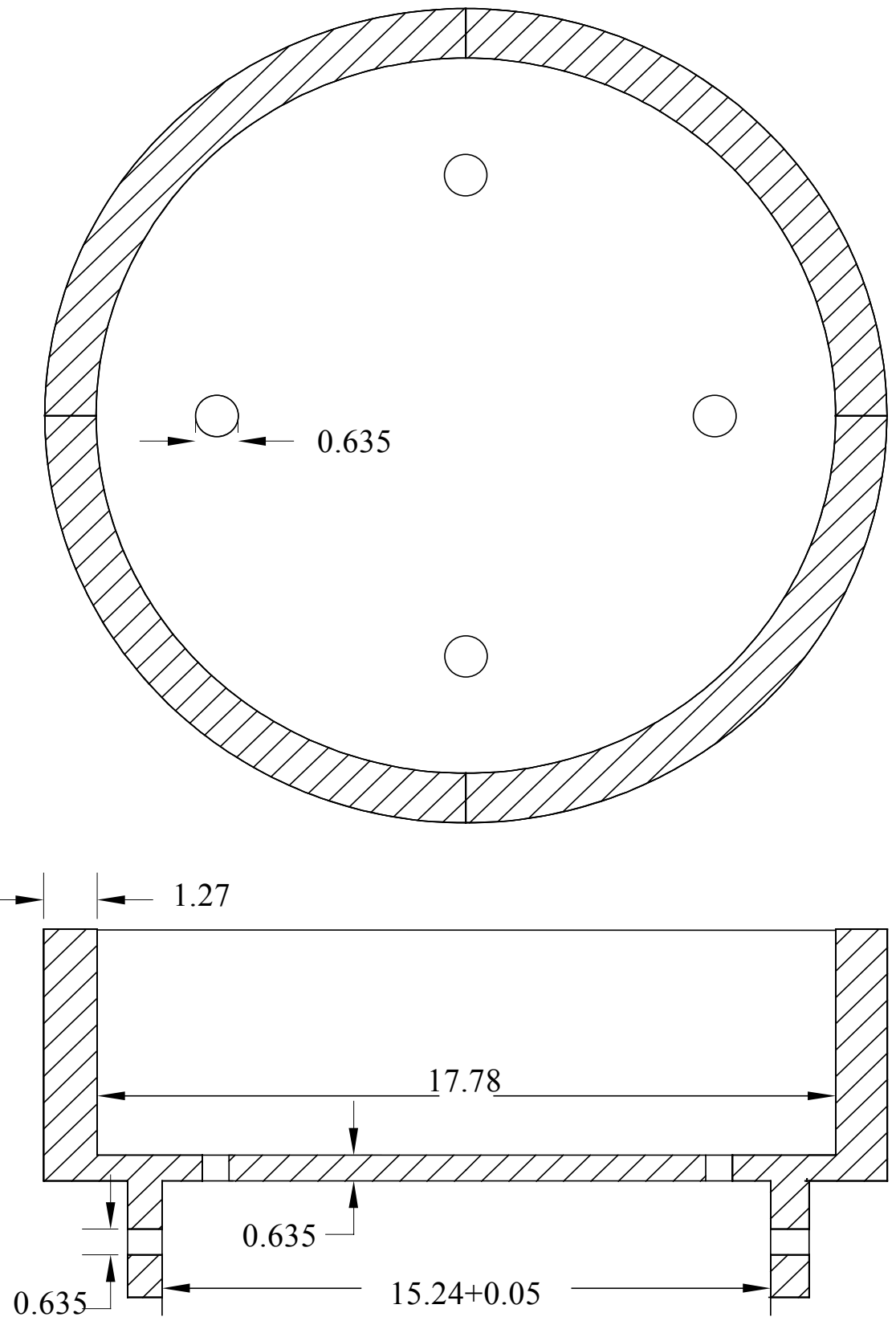

All dimensions are in $\mathrm{cm}$.

Figure 3.8 Top and Front Views of the Aluminum Cup Holding the Lubricant Sample 


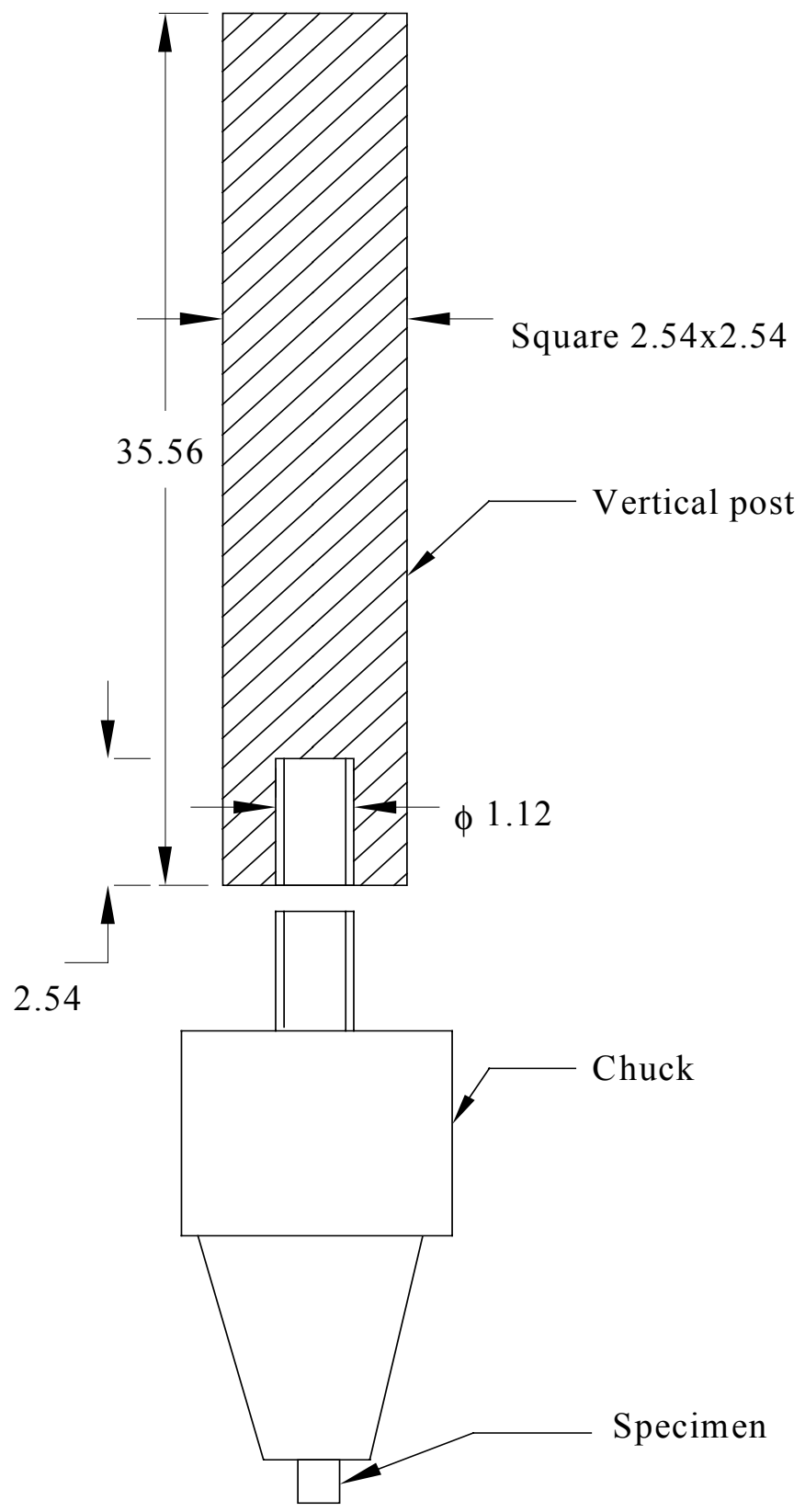

All dimensions are in $\mathrm{cm}$.

Figure 3.9 Specimen Holder for the Three-Body Wear Machine 


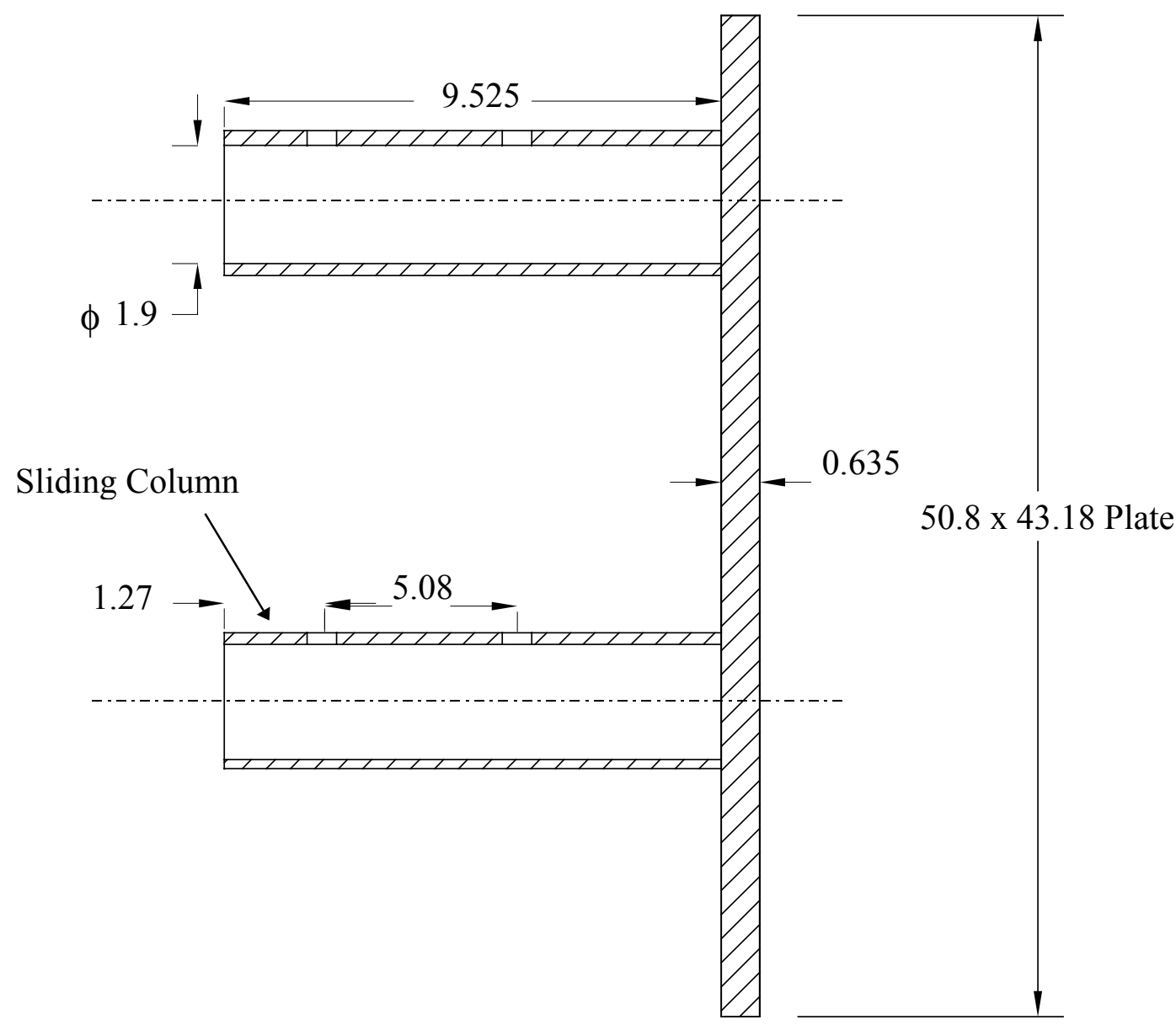

All dimensions are in $\mathrm{cm}$.

Figure 3.10 Front View of the Plate Fixture. 

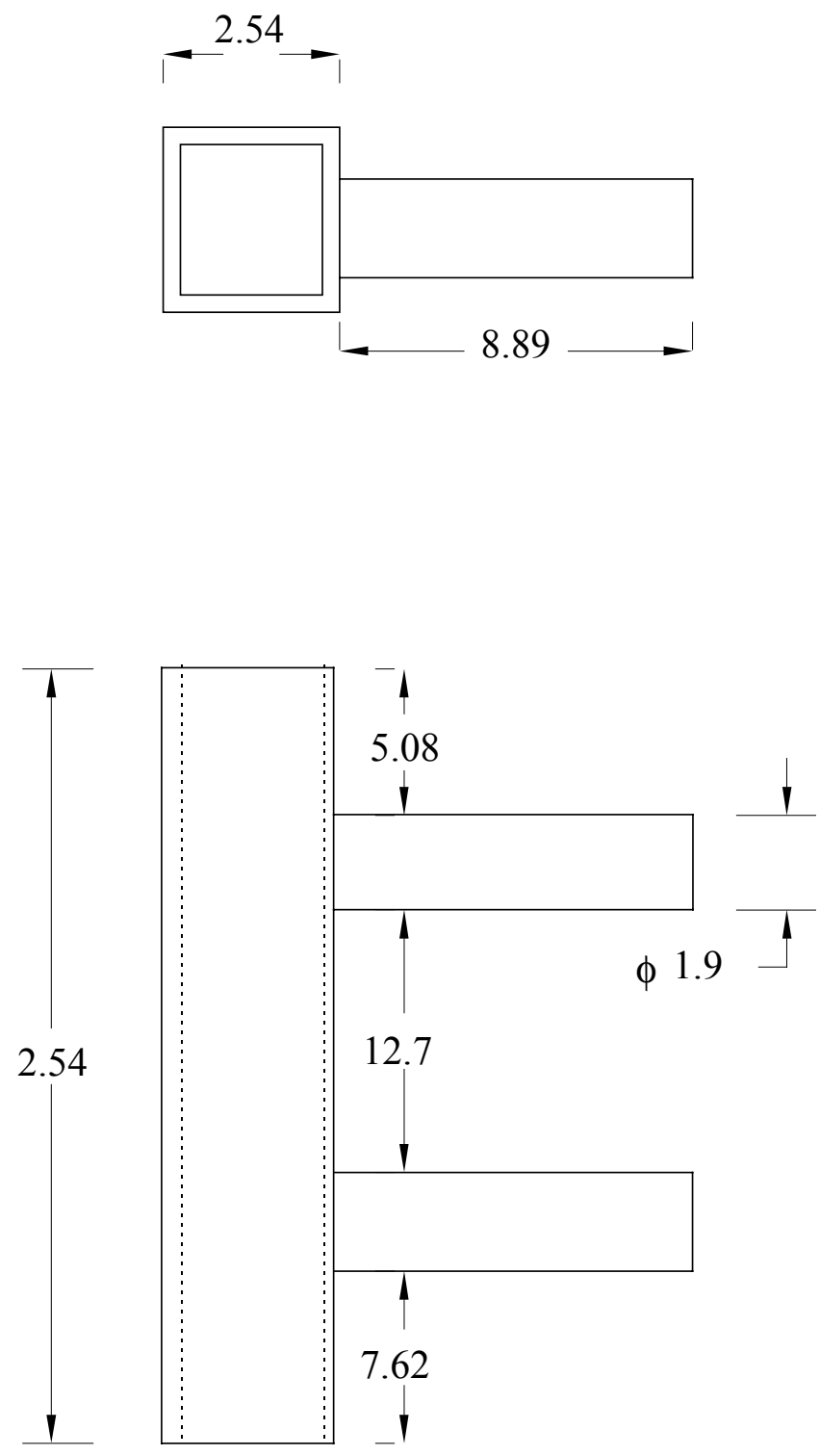

All dimensions are in $\mathrm{cm}$.

Figure 3.11 Top and Front View of the Specimen Holder Guide 


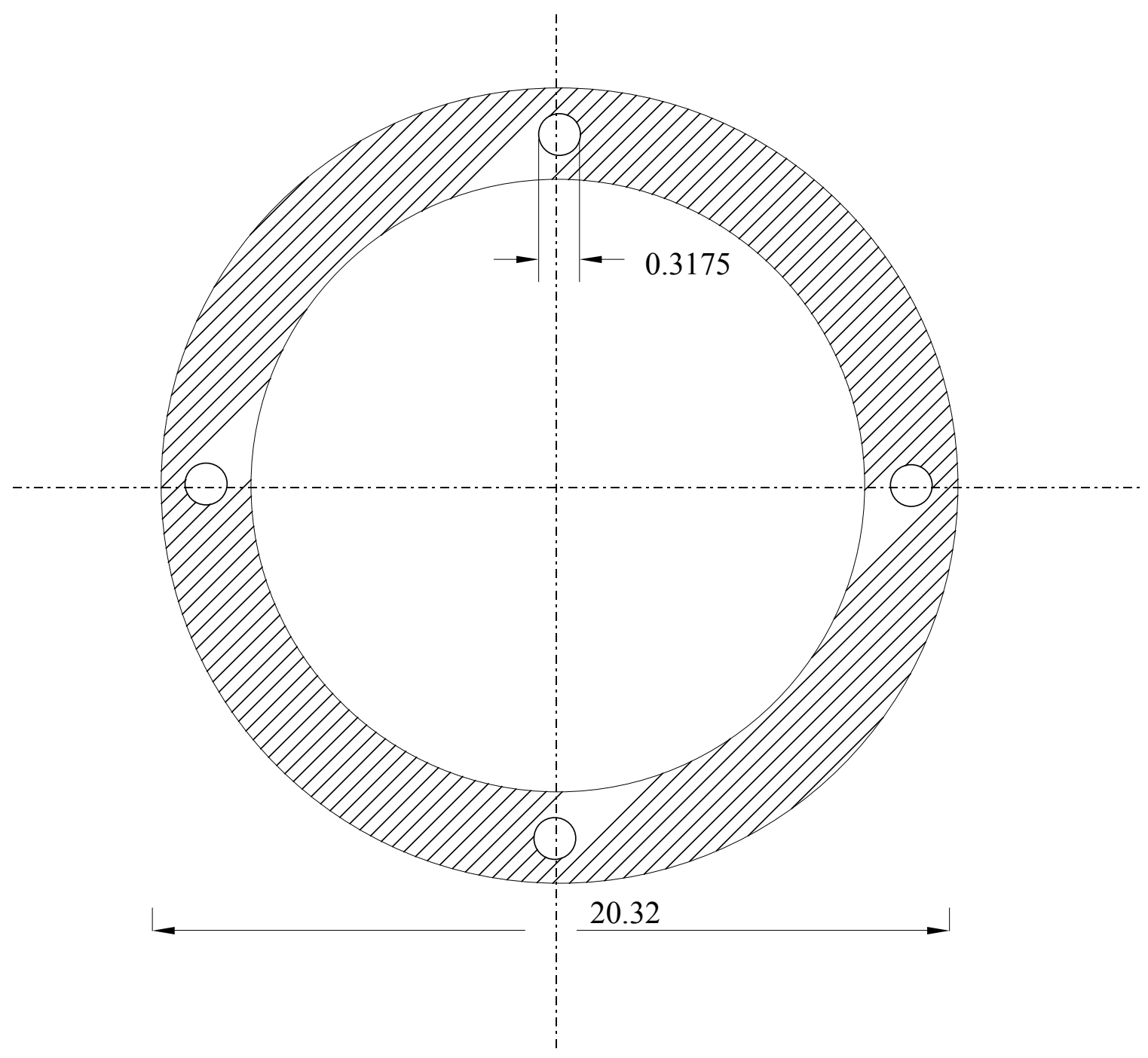

All dimensions are in $\mathrm{cm}$.

Figure 3.12 Protective Cover on Top of the Aluminum Cup 


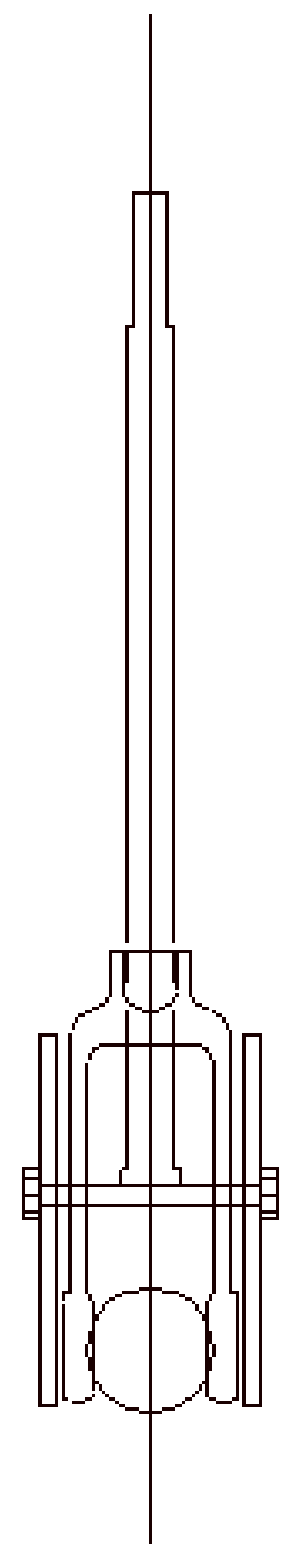

Figure 3.13 Chuck for the Ball-On-Flat-Disk Experiment 


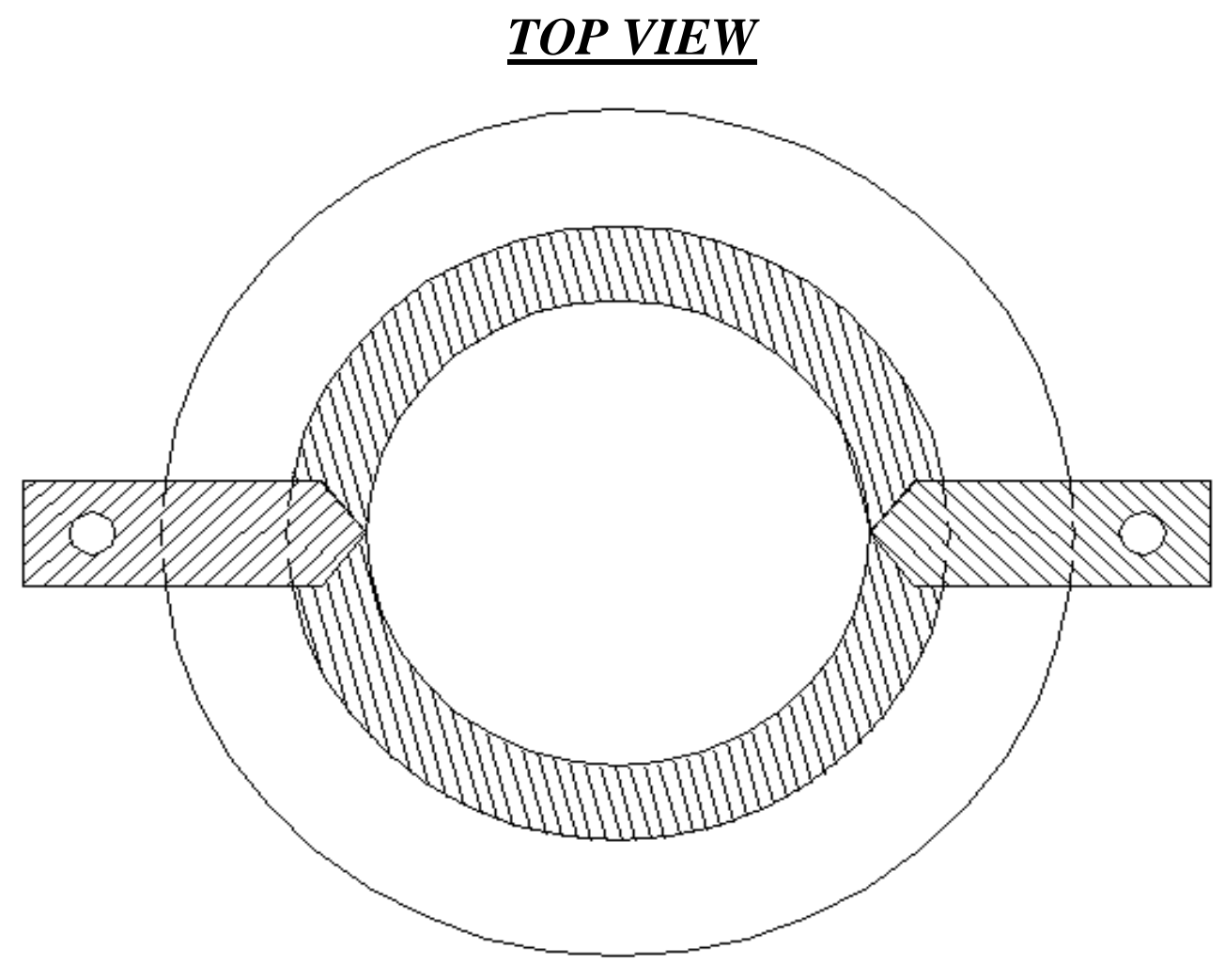

All dimensions are in $\mathrm{cm}$.

\section{FRONT VIEW}

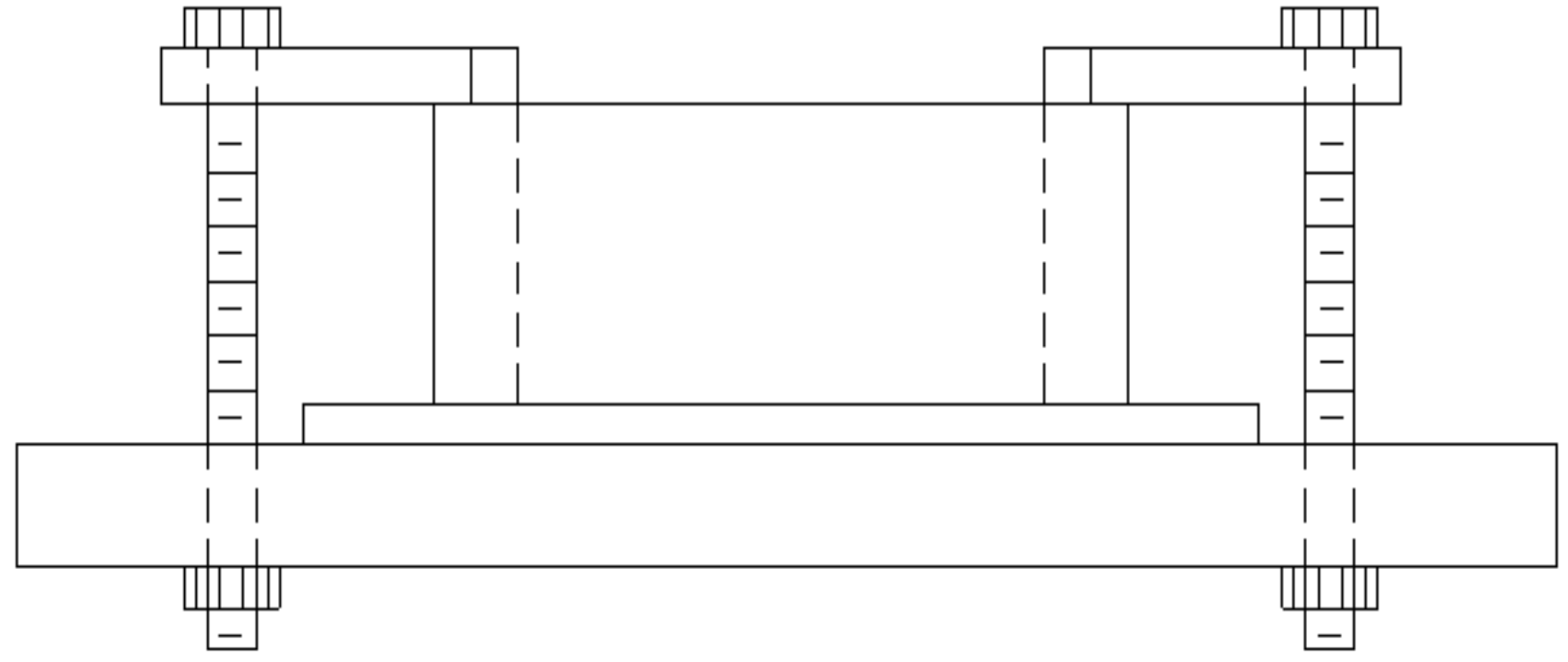

Figure 3.14 Schematic for the Ball-On-flat-Disk Experiment 


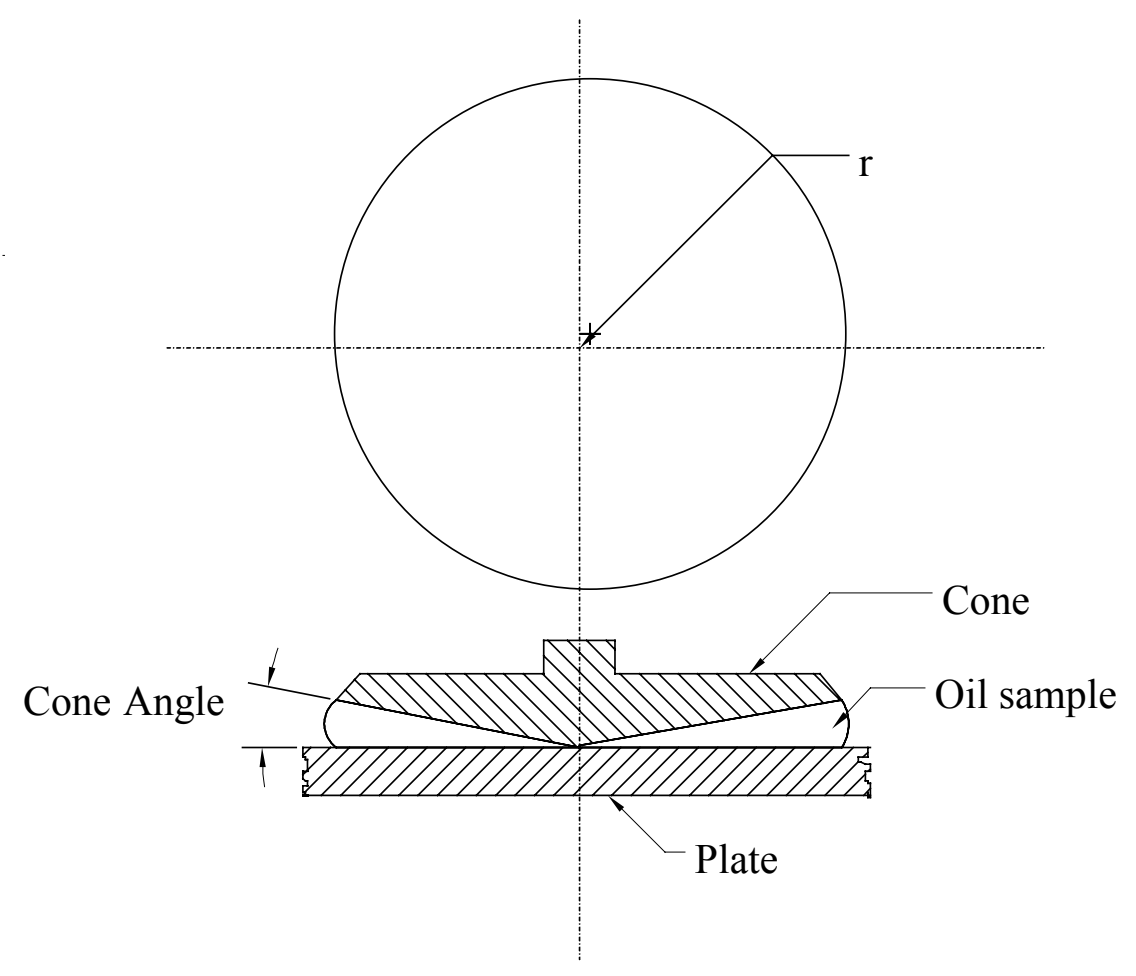

Figure 3.15 Cone/Plate geometry for the Brookfield Viscometer. 


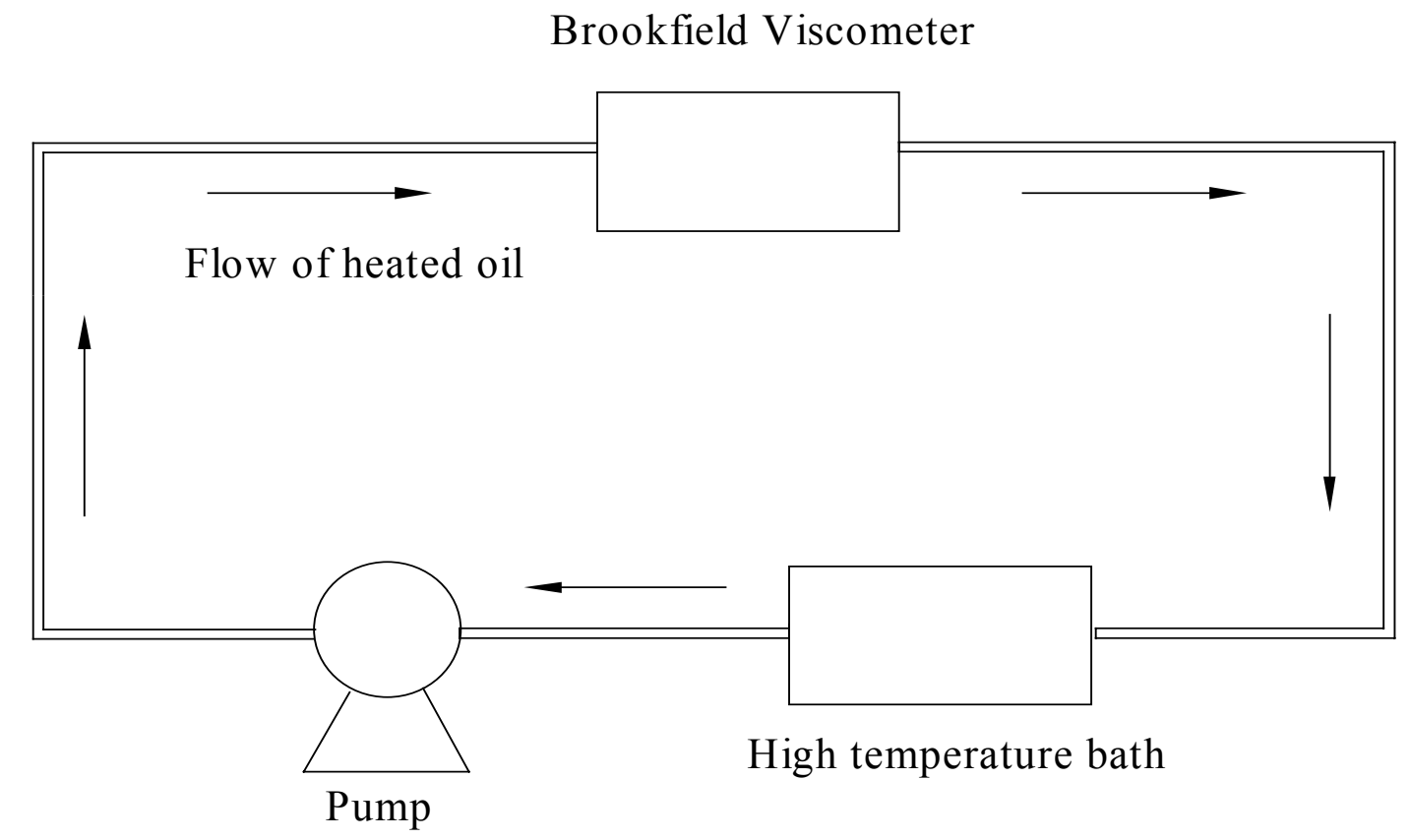

Figure 3.16 Schematic of the setup of the viscosity tests. 


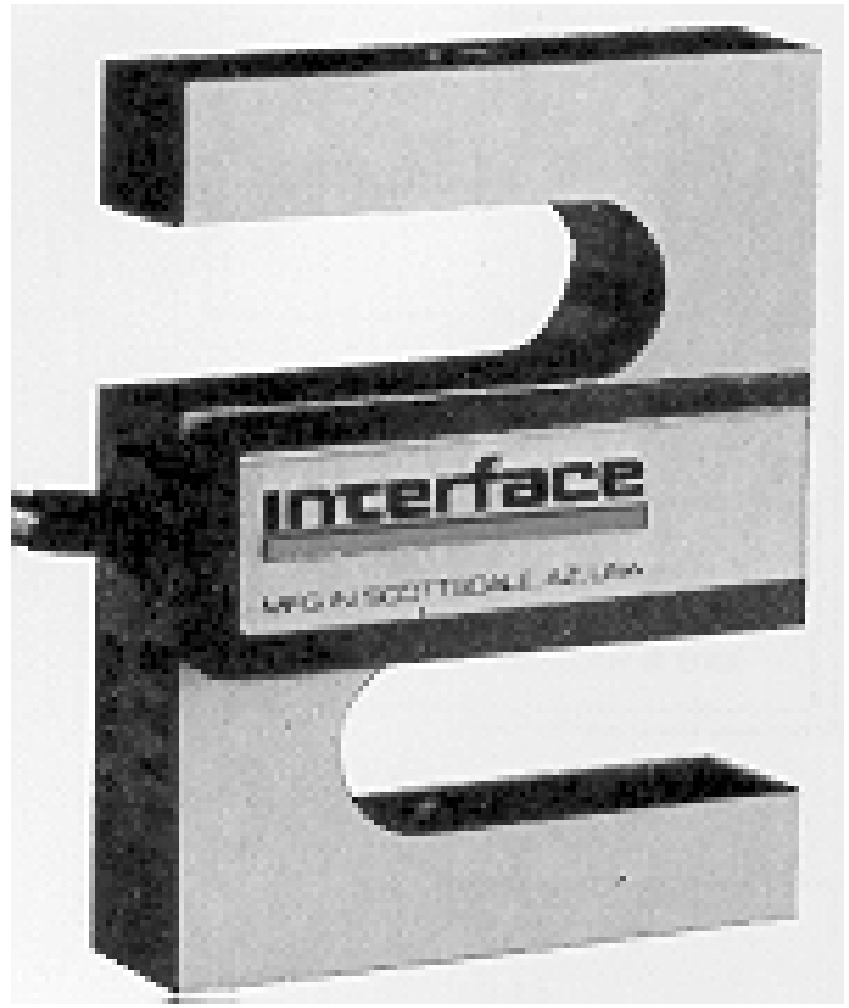

Figure 3.17 Model SSM-250 load cell 


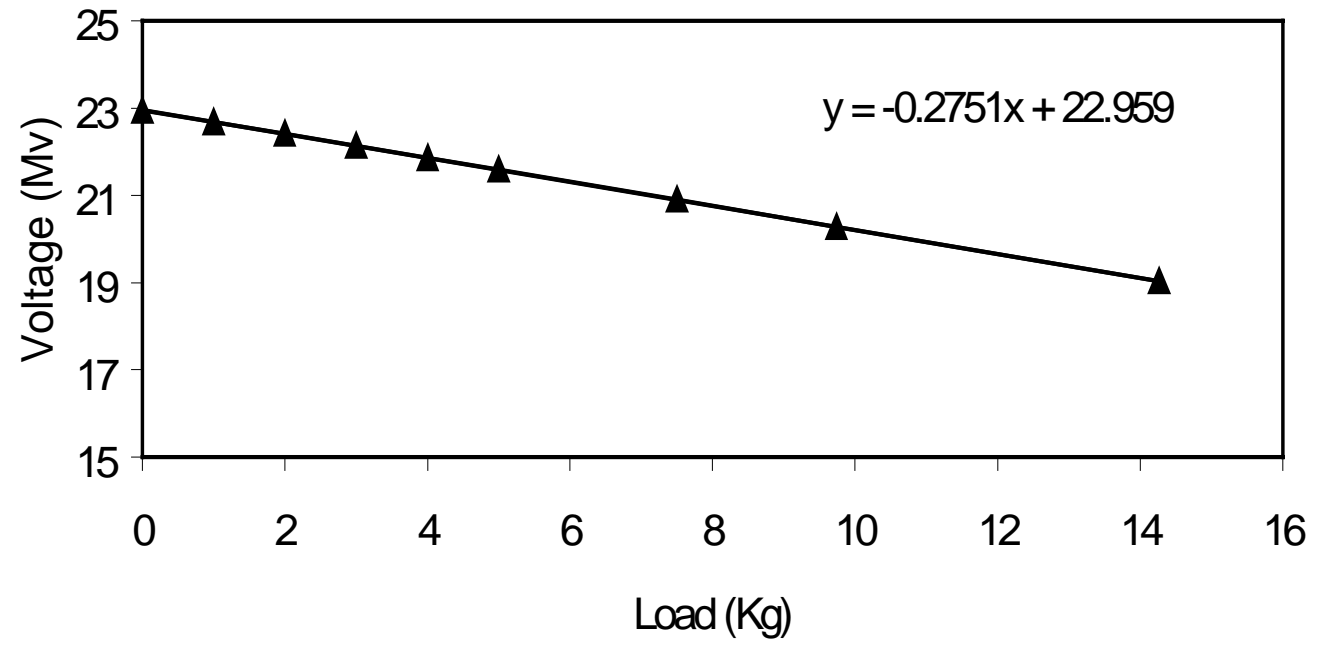

Figure 3.18 Calibration Curve for the load Cell 


\section{CHAPTER 4}

\section{RESULTS AND CONCLUSIONS}

\subsection{Introduction}

The primary objective of this study was to determine the effect of lubricant contaminated oils with soot on engine wear and also to study the viscosity characteristics of engine oils. Tests were performed to study the effect of soot, base, dispersant and ZDP on diesel engine wear. This study was aimed at formulating novel oil blends for future EGR equipped diesel engines. The tests were performed on the Wear Testing Machine to study the effect of soot on the three oil variables. Diesel engine conditions were simulated on the wear testing machine and the amount of wear (gms) for each oil sample is noted. The data obtained was analyzed statically using the SAS (Statistical Analysis System) software to determine the effect of soot on the three oil variables. This chapter discusses the results obtained from the analysis performed on the statistical model.

A second set of experiments was performed on a Brookfield Rotary Viscometer to study the effect of viscosity on engine wear. Viscosity effects are of primary concern as it effects wear. An increase in viscosity of the lubricating oil results in breakdown of the lubricant, which in turn causes pumpability problems. Pumpability problems cause improper circulation of the lubricating oil, which leads to increased wear. To study the effect of viscosity on engine wear, a set up was built consisting of an oil bath, a pump, a couple of thermocouples and a Brookfield Rotary Viscometer. The experiments were conducted on oil samples at $40^{\circ} \mathrm{C}$ and $90^{\circ} \mathrm{C}$. Results were statistically analyzed to determine the significant oil additives that influence viscosity. This chapter discusses the results obtained from the analysis performed on the statistical model. 
A third set of experiments was performed on a Ball-on-flat-disk setup to qualitatively analyze the effect of soot contaminated lubricating oil on wear. The set up consisted of an Aluminum cup, a specially designed chuck to hold the steel ball, a cast iron round and a load cell. The tests were performed on a milling machine to rotate the steel ball over the cast iron round, causing wear scars on the steel ball. These wear scars were examined under the SEM to determine the wear scar diameter and the mechanism of wear. Results from the experiments are also discussed in the following sections.

\subsection{Three-Body Wear Data Analysis}

The three-body wear data basically consists of the wear values obtained for each of the four trials on the three-body wear testing machine. Graphs were plotted to study the variation of wear against amount of soot over the four trials. Graphs were also plotted to determine the variation of cumulative wear over the four trials and to study the consistency of the wear. The cumulative wear curves showed a higher wear for the oil samples with soot contamination than without soot contamination. The graphs also showed an increase in wear when the amount of soot increased. This showed a detrimental effect of soot on the oil blends wear performance. Graphs were also plotted to study the effect of variables on soot contaminated engine oils.

\subsubsection{Wear Data Analysis and Results}

The results clearly showed that an increase in soot, increased wear. The average of the four trials is used for comparing the wear values for the different oil formulations. The wear data for the samples with $0 \%, 2 \%$ and $4 \%$ is as shown in table 4.1 . From the 
table we can conclude that the wear is more for group2 (1) base stocks than for group1 (1) base stocks. As the amount of soot increased, there was an increase in wear. The percentage increases in wear from $2 \%$ to $4 \%$ is comparatively more than the percentage increase in wear from $0 \%$ to $2 \%$. The oil samples with low dispersant and high ZDP performed better than samples having high dispersant and low ZDP. The reason behind this could be the fact that dispersants generally increase the viscosity of the oil sample, which could result in increased wear. The lowest wear obtained from the tests was from sample \# WVU399 and highest wear from sample \# WVU404 at 4\% soot. The above effects can be clearly determined from the graphs and the tables.

Figures 4.1 to 4.16 are the figures for the variation of actual wear and variation of cumulative wear for the eight samples at the three soot levels. From the figures we can see that cumulative wear is more for samples with soot contamination than without soot contamination. This showed a detrimental effect of soot on the oil blends wear performance. Figures 4.17 to 4.24 indicate the variation of wear with percentage soot for the eight samples. The figures showed that the $\%$ increase in wear from $0 \%$ soot to $2 \%$ soot was less than the $\%$ increase in wear from $2 \%$ to $4 \%$ soot. This clearly indicated the nonlinear behavior of wear for the three levels of soot used in this study. Graphs were also drawn to understand the effect of the variables on wear. Figure 4.25 shows the effect of base stock on wear. From the graph we can clearly say that wear values were more when group 1 base stock was used as compared to group 2 base stock. Figure 4.26 shows the effect of Dispersant on wear. Wear values were close at low levels of soot, but increased for samples having a high dispersant level. The reason behind this could be the fact that dispersants generally increase the viscosity of the oil samples, which leads to 
increased wear. Figure 4.27 shows the effect of ZDP on wear. Wear values were low for samples having a high level of ZDP as compared to a low level. The reason behind this is

the fact the ZDP has an antiwear property that reduces friction and wear. Figure 4.28 shows the effect of soot on wear and figure 4.29 gives the Variation of wear with percentage soot for the eight samples at the three levels of soot. The bar graph clearly shows that sample \# WVU399 has the lowest wear and sample \# WVU404 has the highest wear.

\subsubsection{Statistical Analysis of the Three-Body Wear Data}

The data obtained from the wear-testing machine is statistically analyzed. The factors that are involved in the study were the base stock, dispersant level, ZDP (zinc dithiophosphate) and soot. Base stock, dispersant and ZDP were tested at two levels, high (1) and low (-1). Soot was tested at three levels, high (1), medium (0) and low (-1). Apart from soot another factor, sootq, was added to study the nonlinear behaviour of wear. Sootq was tested at two levels, high(1) and low(-2). The average of the four trials is used at the end of the tests for analyzing the data statistically.

The average wear values obtained from the three-body wear tests for the different oil samples are given in table 4.1 
Table 4.1 Average Wear values for Different Oil Formulations

\begin{tabular}{|l|c|c|c|c|c|}
\hline SAMPLE \# & BASE STOCK & DISPERSANT & ZDP & SOOT & $\begin{array}{c}\text { MEAN WEAR } \\
\text { (gms) }\end{array}$ \\
\hline & & & & & \\
\hline WVU397 & -1 & -1 & -1 & -1 & 0.0024 \\
\hline WVU398 & -1 & 1 & 1 & -1 & 0.0023 \\
\hline WVU399 & -1 & -1 & 1 & -1 & 0.0022 \\
\hline WVU400 & -1 & 1 & -1 & -1 & 0.0026 \\
\hline WVU401 & 1 & -1 & -1 & -1 & 0.0035 \\
\hline WVU402 & 1 & 1 & 1 & -1 & 0.0032 \\
\hline WVU403 & 1 & -1 & 1 & -1 & 0.0029 \\
\hline WVU404 & 1 & 1 & -1 & -1 & 0.0031 \\
\hline & & & & & \\
\hline WVU397 & -1 & -1 & -1 & 0 & 0.0031 \\
\hline WVU398 & -1 & 1 & 1 & 0 & 0.0035 \\
\hline WVU399 & -1 & -1 & 1 & 0 & 0.0032 \\
\hline WVU400 & -1 & 1 & -1 & 0 & 0.0039 \\
\hline WVU401 & 1 & -1 & -1 & 0 & 0.0045 \\
\hline WVU402 & 1 & 1 & 1 & 0 & 0.0043 \\
\hline WVU403 & 1 & -1 & 1 & 0 & 0.0039 \\
\hline WVU404 & 1 & 1 & -1 & 0 & 0.0049 \\
\hline & & & & & \\
\hline WVU397 & -1 & -1 & -1 & 1 & 0.0048 \\
\hline WVU398 & -1 & 1 & 1 & 1 & 0.0057 \\
\hline WVU399 & -1 & -1 & 1 & 1 & 0.0048 \\
\hline WVU400 & -1 & 1 & -1 & 1 & 0.0068 \\
\hline WVU401 & 1 & -1 & -1 & 1 & 0.0071 \\
\hline WVU402 & 1 & 1 & 1 & 1 & 0.0065 \\
\hline WVU403 & 1 & -1 & 1 & 1 & 0.0062 \\
\hline WVU404 & 1 & 1 & -1 & 1 & 0.0079 \\
\hline
\end{tabular}

\subsubsection{Statistical Analysis System}

A Statistical Analysis System (SAS) was used to analyze the results from the wear data. A General Linear Model (GLM) analysis was done on the three-factor experiment performed using the various oil samples. The GLM procedure partitions or separates the variation, which is observed in a response variable in two basic components. The two basic components are variation due to assignable causes and 
random variation (21). The sources of variations in an experiment that are known come under the assignable causes. The variations that are not controlled or measured during the experiment come under the random variations.

\subsubsection{Results from the Statistical Analysis System}

To determine the influence of significant factors such as base, dispersant, ZDP, soot and sootq on wear, a SAS program was written and run. The new variable sootq was added to the list of significant factors to study the nonlinear behavior of wear at various soot levels. All the significant factors and their interaction with each other were also taken care of with this SAS program.

The input file (wear.sas) and the output file (wear.lis) are the corresponding SAS analyses for the wear tests given in Appendix D. The output file for the SAS analysis gave the effect of the interactions of the various oil additives. The output file also gave the significance probability ( $\mathrm{p}$-value) for the various factors and their interactions. The degree of discrepancy between the estimated parameter value and the corresponding hypothesized value is quantified by significance probability. The null hypothesis (Ho) and the alternate hypothesis have to be taken care of before understanding the results. The null hypothesis states that none of the factors influence wear whereas the alternate hypothesis states that the factors are significant. If the p-value is smaller than the significance level $(\alpha)$, the null hypothesis is rejected and the factor corresponding to that p-value is considered to be significant. The results obtained for the model showed a pvalue less the significance level $(\alpha)$. 
The analysis gave a clear indication of the variables that were significant and those variables, which are not. From the output file(wear.lis) it was clear that the base stock(base) with a p-value of 0.0001 , and soot content(soot) with a p-value of 0.0001 were the most significant at a $95 \%$ confidence level $(\alpha=0.05)$. Dispersant with a $p$-value of 0.0018 and ZDP with a p-value of 0.0022 were also significant at a $95 \%$ confidence level. To study the nonlinear behavior of wear with different levels of soot, sootq was included in the list of factors, which affect wear. Sootq with a p-value of 0.0010 clearly indicates that it is significant at a $95 \%$ confidence level and it confirms the nonlinear behavior of wear.

The analysis also gave the p-value for the interactions between the various factors. The only interaction worth mentioning is that between dispersant and soot whose p-value is 0.0088 which is also significant at $95 \%$ confidence level. The interaction between base and soot, and the interaction between ZDP and soot could be considered significant only at $90 \%$ confidence. The above analyses confirm with the analysis and results obtained from the graphs.

From the GLM analysis, the following regression model was developed to obtain the best oil formulation for minimum wear. The statistical model obtained from the GLM procedure is given below:

$\mathrm{E}(\mathrm{Y})=0.00430+0.00053 \mathrm{X}_{1}+0.00025 \mathrm{X}_{2}-0.00025 \mathrm{X}_{3}+0.00173 \mathrm{X}_{4}+0.00020 \mathrm{X}_{5}^{2}+0.00024 \mathrm{X}_{2} \mathrm{X}_{4}$ Where

$\mathrm{E}(\mathrm{Y})$ is the expected value of wear, $\mathrm{X}_{1}$ is the base stock, $\mathrm{X}_{2}$ is the dispersant level 
$\mathrm{X}_{3}$ is the ZDP level

$\mathrm{X}_{4}$ is the soot level,

$\mathrm{X}_{5}^{2}$ quadratic term for soot (sootq),

$\mathrm{X}_{2} \mathrm{X}_{4}$ is the dispersant-soot interaction.

\subsection{Viscosity Results}

Viscosity of the various oil formulations was found using a rotary type Brookfield viscometer. For each of the oil formulations, the tests were performed with $0 \%, 2 \%$ and $4 \%$ soot. The tests were performed at $40^{\circ} \mathrm{C}$ and $90^{\circ} \mathrm{C}$. and each sample was tested four times and the results obtained were averaged and this average was used for the statistical model. Randomization of the oil samples was completed initially, and the tests were then performed at $40^{\circ} \mathrm{C}$ and $90^{\circ} \mathrm{C}$. The results from the viscosity tests are shown in Table $4.2 \mathrm{a}$, $4.2 \mathrm{~b}$ and $4.2 \mathrm{c}$

Table 4.2a Viscosity of the oil samples without soot at $40^{\circ} \mathrm{C}$ and $90^{\circ} \mathrm{C}$.

\begin{tabular}{|c|c|c|}
\hline Sample\# & Sample Temperature $\left({ }^{\circ} \mathrm{C}\right)$ & Viscosity without soot(cS) \\
\hline WVU397 & 40 & 69.67 \\
\hline WVU398 & 40 & 81.79 \\
\hline WVU399 & 40 & 73.84 \\
\hline WVU400 & 40 & 89.18 \\
\hline WVU401 & 40 & 77.25 \\
\hline WVU402 & 40 & 89.74 \\
\hline WVU403 & 40 & 58.31 \\
\hline WVU404 & 40 & 90.12 \\
\hline & & \\
\hline WVU397 & 90 & 14.77 \\
\hline WVU398 & 90 & 16.67 \\
\hline WVU399 & 90 & 14.58 \\
\hline WVU400 & 90 & 17.05 \\
\hline WVU401 & 90 & 14.01 \\
\hline WVU402 & 90 & 16.48 \\
\hline WVU403 & 90 & 13.83 \\
\hline WVU404 & 90 & 16.86 \\
\hline
\end{tabular}


Table 4.2b Viscosity of the oil samples with $2 \%$ soot at $40^{\circ} \mathrm{C}$ and $90^{\circ} \mathrm{C}$.

\begin{tabular}{|c|c|c|}
\hline Sample\# & Sample Temperature $\left({ }^{\circ} \mathrm{C}\right)$ & Viscosity with $2 \%$ soot(cS) \\
\hline WVU397 & 40 & 81.07 \\
\hline WVU398 & 40 & 95.45 \\
\hline WVU399 & 40 & 85.61 \\
\hline WVU400 & 40 & 96.20 \\
\hline WVU401 & 40 & 90.91 \\
\hline WVU402 & 40 & 108.34 \\
\hline WVU403 & 40 & 83.34 \\
\hline WVU404 & 40 & 101.52 \\
\hline & & \\
\hline WVU397 & 90 & 17.42 \\
\hline WVU398 & 90 & 20.08 \\
\hline WVU399 & 90 & 17.61 \\
\hline WVU400 & 90 & 17.05 \\
\hline WVU401 & 90 & 15.15 \\
\hline WVU402 & 90 & 20.08 \\
\hline WVU403 & 90 & 16.86 \\
\hline WVU404 & 90 & 18.37 \\
\hline
\end{tabular}

Table 4.2c Viscosity of the oil samples with $4 \%$ soot at $40^{\circ} \mathrm{C}$ and $90^{\circ} \mathrm{C}$.

\begin{tabular}{|c|c|c|}
\hline Sample\# & Sample Temperature $\left({ }^{\circ} \mathrm{C}\right)$ & Viscosity with $4 \%$ soot(cS) \\
\hline WVU397 & 40 & 151.52 \\
\hline WVU398 & 40 & 182.95 \\
\hline WVU399 & 40 & 177.84 \\
\hline WVU400 & 40 & 202.27 \\
\hline WVU401 & 40 & 185.61 \\
\hline WVU402 & 40 & 202.27 \\
\hline WVU403 & 40 & 126.13 \\
\hline WVU404 & 40 & 200.74 \\
\hline & & \\
\hline WVU397 & 90 & 24.05 \\
\hline WVU398 & 90 & 26.89 \\
\hline WVU399 & 90 & 23.86 \\
\hline WVU400 & 90 & 18.37 \\
\hline WVU401 & 90 & 19.70 \\
\hline WVU402 & 90 & 21.78 \\
\hline WVU403 & 90 & 19.32 \\
\hline WVU404 & 90 & 20.26 \\
\hline
\end{tabular}




\subsubsection{Viscosity Test Analysis and Results at $40^{\circ} \mathrm{C}$}

Figures 4.30 to 4.37 are the figures for the variation of viscosity with soot at $40^{\circ} \mathrm{C}$ for the eight samples. The figures show the same trend as in the wear curves. Viscosity increases with the increase in soot and the increase is more at higher levels of soot. The increase in viscosity from $0 \%$ soot to $2 \%$ soot is less than the increase in soot from $2 \%$ soot to $4 \%$ soot. The trend seen here is similar to the trend obtained from the wear values and we come to the conclusion that viscosity also has a nonlinear behavior at different soot levels. Figures were also drawn to study the effect of the variables on viscosity. Figure 4.38 shows the relationship between base stock and viscosity. As seen from the graph there is no effect of base stock on viscosity at $40^{\circ} \mathrm{C}$. The performance of the group 1 base stock oil samples were similar to those of the group 2 base stock oil samples. The viscosity for oil samples having a higher level of dispersant was more than those with lower levels as clearly seen in figure 4.39. The figure proves the fact that dispersants generally tend to increase the viscosity of the oil samples. The effect of ZDP on viscosity was negligible as seen from figure 4.40. Figure 4.41 shows the nonlinear behavior of viscosity at different levels of soot. Finally figure 4.42 shows the variation of viscosity at $40^{\circ} \mathrm{C}$ for the eight oil samples at different levels of soot. The sample with the lowest viscosity was sample \# WVU403 and the samples with the highest viscosity were sample \# WVU402 and sample \# WVU400.

\subsubsection{Viscosity Results at $90^{\circ} \mathrm{C}$}

Temperature has a very important role in the viscosity of the various oil samples. As temperature increases viscosity decreases and vice-versa. To obtain consistent results 
at high temperatures, the entire set-up was insulated thoroughly to reduce heat loss due to convection and conduction.

Figures 4.43 to 4.50 are the figures for the variation of viscosity with soot at $90^{\circ} \mathrm{C}$ for the eight samples. The viscosity values obtained showed a linear trend at different levels of soot. Viscosity increased with increase in percentage soot, but the increase was linear with increase in percentage soot. The effect of base stock on viscosity was negligible at low levels of soot, but the group 1 base stock oil samples indicated an increase in viscosity at higher soot levels as compared to the group 2 base stock oil samples. Viscosity of the oil samples with a higher level of dispersant was more than samples having a lower level of dispersant. This trend was observed at low levels of soot, but indicated a negligible difference at a high level of soot. The effect of ZDP on viscosity was quite opposite to that of dispersant. Viscosity again showed a nonlinear behavior at different levels of soot. The above effects are as shown in figures 4.51 to 4.55 .

\subsubsection{Statistical Results for the Viscosity Tests}

To determine the influence of significant factor like base stock, dispersant, ZDP, soot and sootq on viscosity, a SAS program was written and run. The new variable sootq was added to the list of significant factors to study the nonlinear behavior of viscosity at various soot levels. All the significant factors and their interaction with each other were also taken care of with this SAS program.

The data obtained from the viscosity tests at $40^{\circ} \mathrm{C}$ and $90^{\circ} \mathrm{C}$ for the various oil formulations were analyzed statistically using a GLM model. The output of the SAS 
analysis gave the effect of the interactions of the various oil additives like base stock, dispersant level, ZDP level and soot content on the viscosity. The input files for the viscosity tests at $40^{\circ} \mathrm{C}$ and $90^{\circ} \mathrm{C}$ are visc40.sas and visc 90 .sas respectively. The output files for the viscosity tests at $40^{\circ} \mathrm{C}$ and $90^{\circ} \mathrm{C}$ are visc 40. lis and visc 90.1 lis respectively. The input and output files for viscosity tests at $40^{\circ} \mathrm{C}$ and $90^{\circ} \mathrm{C}$ are given in Appendix E.1 and Appendix E.2

\subsubsection{Statistical Analysis and Results at $40^{\circ} \mathrm{C}$}

The null hypothesis is rejected for the analysis at $40^{\circ} \mathrm{C}$, which states that none of the factors influence viscosity. This is because the p-value is smaller than the significance level $(\alpha)$. The alternate hypothesis was considered which states that the factors are significant.

The analysis gave a clear indication of the variables that were significant and those variables, which are not. From the output file(visc40.lis), it was clear that the dispersant with a p-value of 0.0034 , soot with a p-value of 0.0001 , and sootq with a pvalue of 0.0003 were significant at $95 \%$ confidence level $(\alpha=0.05)$. Base stock and ZDP were not significant, even at $90 \%$ confidence level $(\alpha=0.1)$. The interactions between the various factors were also not significant.

From the GLM analysis, the following regression model was developed to obtain the viscosity at $40^{\circ} \mathrm{C}$. The significant variables are considered for the regression model and the regression equation is as shown below:

$$
\mathrm{E}(\mathrm{Y})=116.736+11.645 \mathrm{X}_{1}+49.964 \mathrm{X}_{2}+11.966 \mathrm{X}_{3}^{2}
$$

Where 
$\mathrm{E}(\mathrm{Y})$ is the expected value of viscosity at $40^{\circ} \mathrm{C}$,

$\mathrm{X}_{1}$ is the dispersant level,

$\mathrm{X}_{2}$ is the soot level

$\mathrm{X}_{3}^{2}$ is the quadratic term for soot (sootq)

\subsubsection{Statistical Analysis and Results at $90^{\circ} \mathrm{C}$}

The null hypothesis is rejected and the alternate hypothesis is considered for the analysis at $90^{\circ} \mathrm{C}$.The analysis gave a clear indication of the variables that were significant and those variables which are not. From the output file(visc90.lis) it was clear that the dispersant with a p-value of 0.0320 and soot with a p-value of 0.0001 were significant at $95 \%$ confidence level $(\alpha=0.05)$. Base stock with a p-value of 0.0632 and ZDP with a pvalue of 0.0740 can be considered to be significant at $90 \%$ confidence level $(\alpha=0.1)$. The interactions between the various factors were not significant.

From the GLM analysis, the following regression model was developed to obtain the viscosity at $90^{\circ} \mathrm{C}$. The significant variables are considered for the regression model and the regression equation is as shown below:

$$
\mathrm{E}(\mathrm{Y})=18.379+0.7825 \mathrm{X}_{1}+3.1236 \mathrm{X}_{2}
$$

Where

$\mathrm{E}(\mathrm{Y})$ is the expected value of viscosity $90^{\circ} \mathrm{C}$

$\mathrm{X}_{1}$ is the dispersant level,

$\mathrm{X}_{2}$ is the soot level. 


\subsection{Ball-on-flat-disk set-up}

The ball-on-flat-disk wear tests were performed on the milling machine using a specially designed chuck to qualitatively analyze the wear scar on the steel ball specimen. The experiments were performed on samples having the lowest and highest wear obtained after performing the tests on the wear testing machine. The sample with the lowest wear was sample \# WVU399 and the sample with the highest wear was WVU404. Samples from the Cummins engine were also tested and then compared with the above samples mentioned.

SEM photographs were taken for the wear scars and the wear scar diameter was determined from these photographs. The wear scar diameters were then normalized by the Hertz diameter, which is calculated by the Hertz equation to calculate the wear ration for each test. Wear ratio is determined as the ratio of wear scar diameter to Hertz diameter.

\subsubsection{Hertz Equation}

The wear scars obtained from the ball-on-flat-disk tests were normalized with respect to the Hertz diameter. The normalized wear scar is the scar size due to plastic deformation caused by static load.

The Hertz diameter is determined using the Hertz equation given by (25).

$$
a=0.75\left(\frac{W R}{E}\right)^{1 / 3}
$$

Where

$$
\begin{aligned}
& \mathrm{a}=\text { contact radius or Hertz radius } \\
& \mathrm{W}=\text { Load acting on the stainless steel ball specimen }
\end{aligned}
$$


E is given by

$$
\frac{1}{E}=\frac{1-v_{1}^{2}}{E_{1}}+\frac{1-v_{2}^{2}}{E_{2}}
$$

Where,

$E_{1}$ and $E_{2}$ are the Young's modulii of the two materials and $v_{1}$ and $v_{2}$ are the Poisson's ratio of the two materials in contact.

$\mathrm{R}$ is obtained from the equation:

$$
\frac{1}{R}=\frac{1}{R_{1}}+\frac{1}{R_{2}}
$$

Where, $R_{1}$ and $R_{2}$ are the radii of curvature of the two bodies in contact. Since $R_{2}=\infty$, we have $\mathrm{R}=\mathrm{R}_{1}$, where $\mathrm{R}_{1}$ is the radius of the steel ball.

Following are the values of the cast iron surface and the steel ball specimen:

$$
\begin{array}{ll}
\text { Radius of the steel ball }(\mathrm{R}) & =0.25^{\prime \prime} \\
\mathrm{E}_{\text {Steel ball }} & =30^{*} 10^{6} \mathrm{psi}(210,000 \mathrm{Mpa}) \\
v_{\text {Steel ball }} & =0.3 \\
\mathrm{E}_{\text {Cast iron }} & =14.5^{*} 10^{6} \mathrm{psi}(101,500 \mathrm{Mpa}) \\
v_{\text {Cast iron }} & =0.211
\end{array}
$$

The above values have been substituted in the equations and the Hertz Diameter (2a) is found out to be $0.34 \mathrm{~mm}$.

Wear ratio is the ratio of the mean scar diameter to the Hertz diameter.

$$
\text { WearRatio }=\frac{\text { WearScarDiameter }}{\text { HertzDiameter }}
$$


Table 4.3 Wear Scar Diameters and Wear Ratios

\begin{tabular}{|c|c|c|}
\hline Sample \# & Wear Scar Diameter & Wear Ratio \\
\hline WVU399 without soot & 0.0170 & 0.0500 \\
\hline WVU399 with 2\% soot & 0.0350 & 0.1029 \\
\hline WVU404 without soot & 0.0200 & 0.0588 \\
\hline WVU404 with 2\% soot & 0.0400 & 0.1176 \\
\hline
\end{tabular}

The results showed that the wear ratios were higher for oil samples with soot than oil samples without soot. The wear ratios, with and without soot contamination for oil sample \# WVU404, is higher than sample \# WVU399 which is in agreement with the three-body wear result. Wear scar tests were also performed on oil samples WVU399 and WVU404 at 4\% soot. The SEM pictures showed that the stainless steel specimen had traces of cast iron material. Adhesive wear occurred between the two surfaces in contact. The reason behind this could be the fact that the contamination of the lubricating oil affected the antiwear characteristics, leading to the breakdown of the lubricant. The SEM pictures taken are as shown in appendix F. 


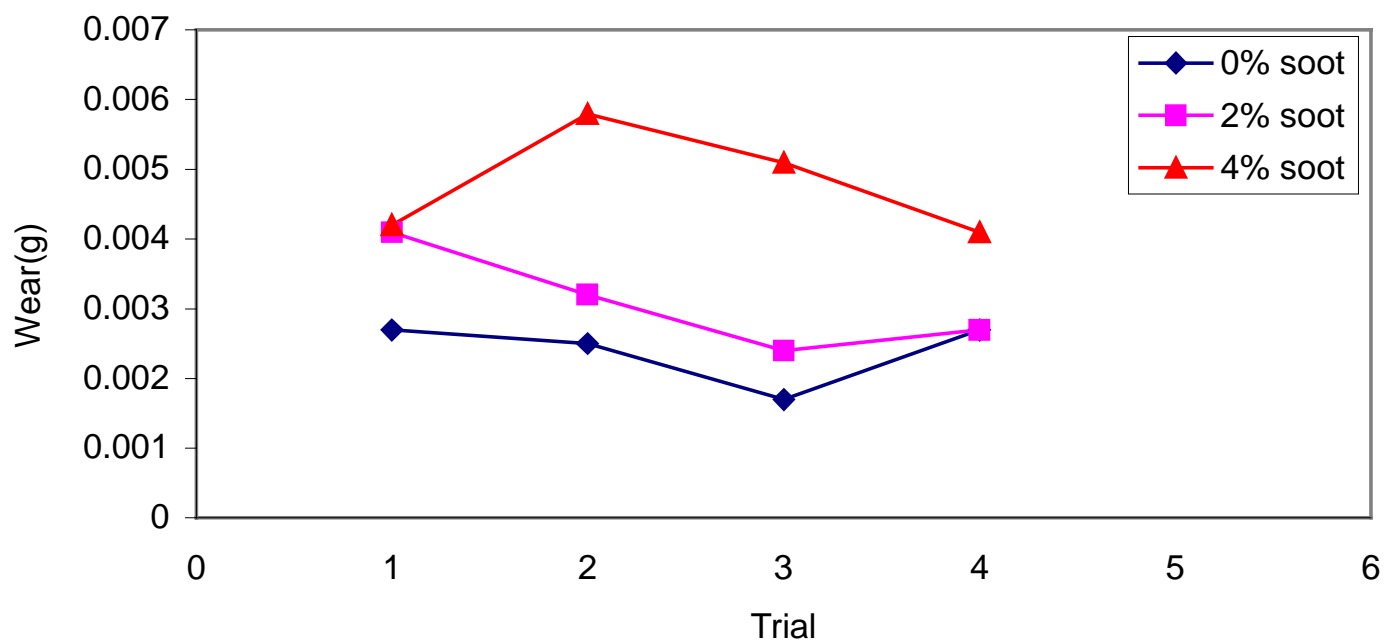

Figure 4.1 Variation of Actual Wear for Sample \# WVU397

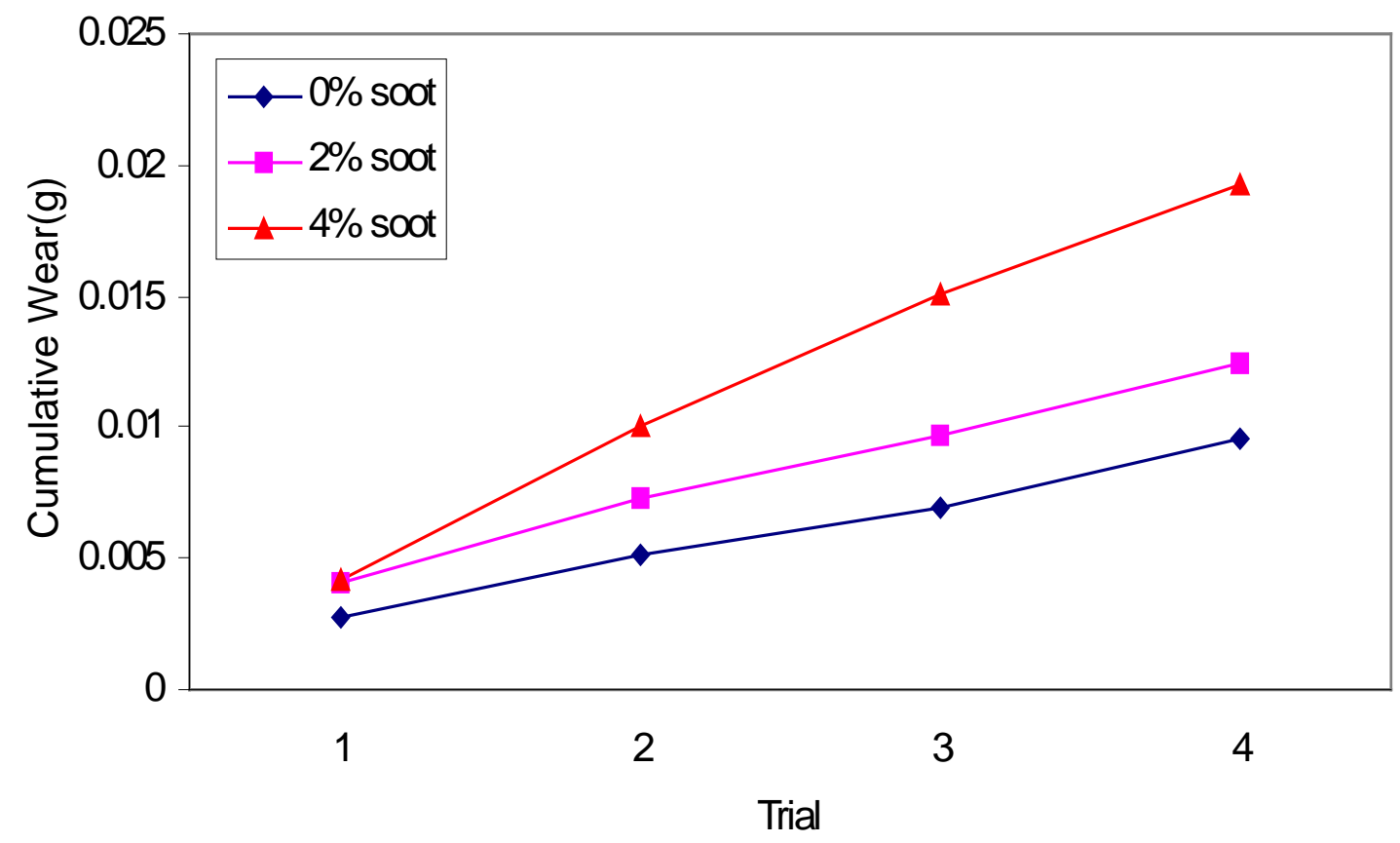

Figure 4.2 Variation of Cumulative Wear for Sample \# WVU397 


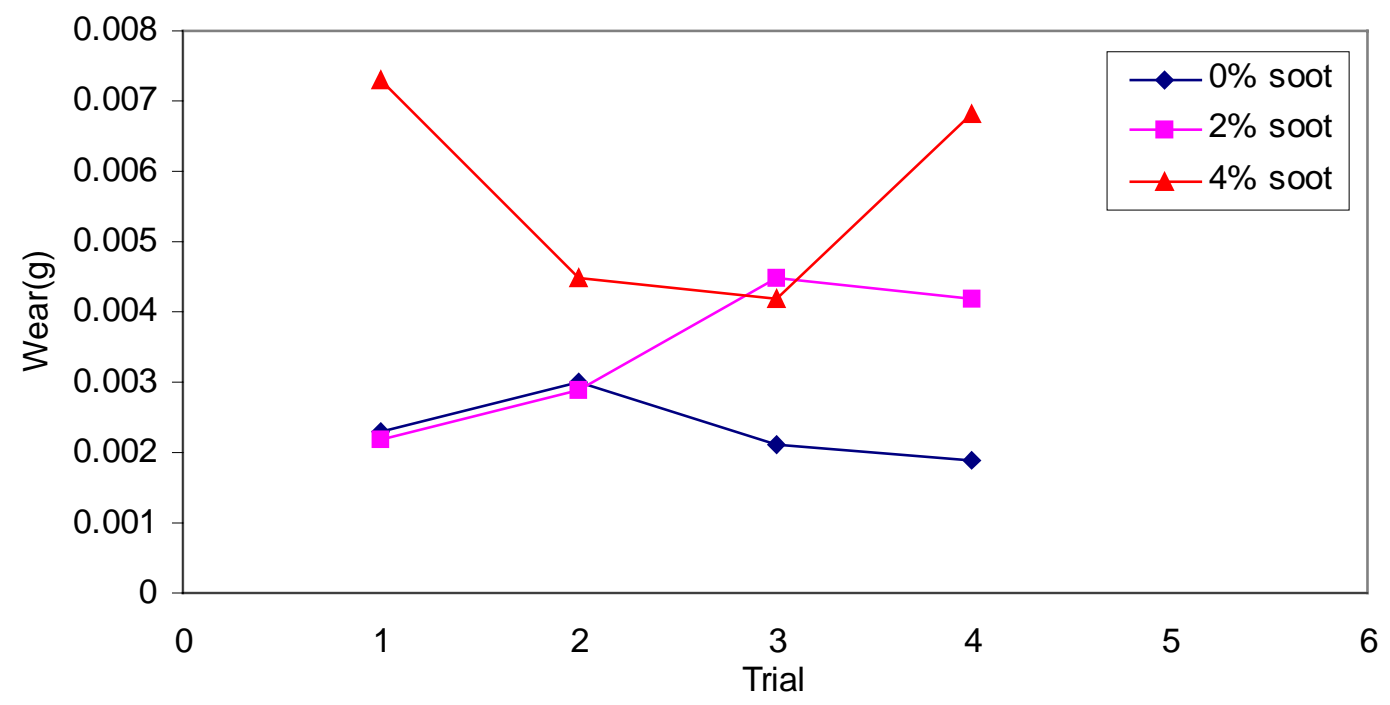

Figure 4.3 Variation of Actual Wear for Sample \# WVU398

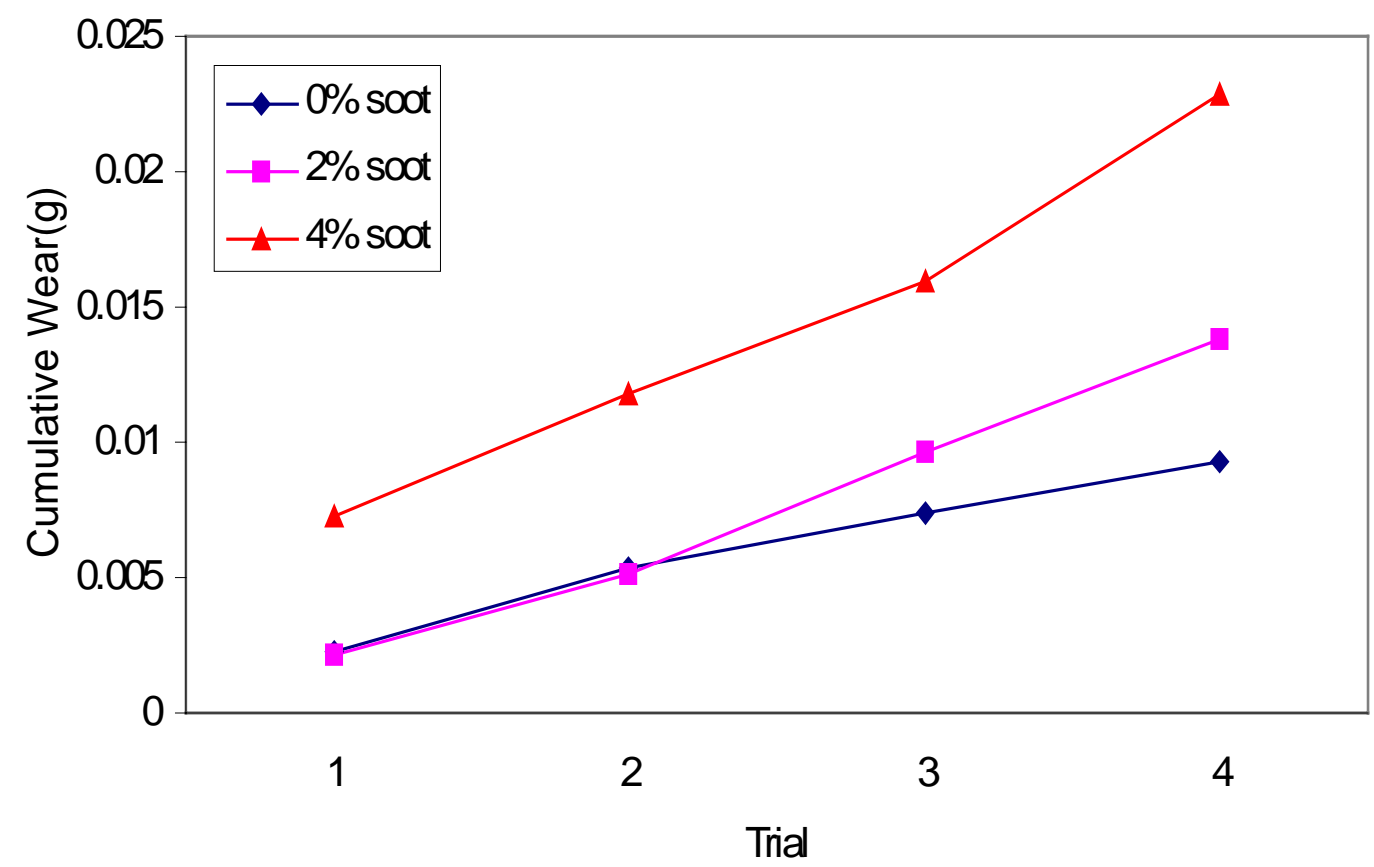

Figure 4.4 Variation of Cumulative Wear for Sample \# WVU398 


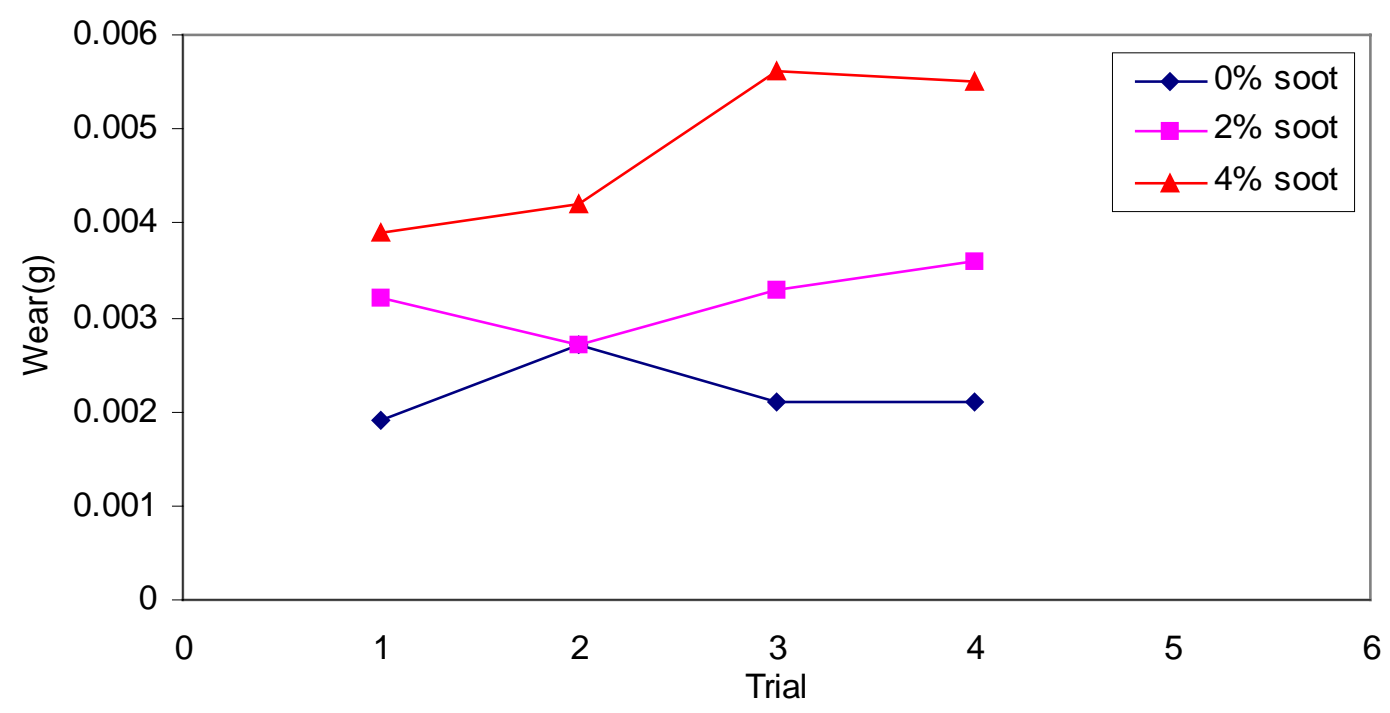

Figure 4.5 Variation of Actual Wear for Sample \# WVU399

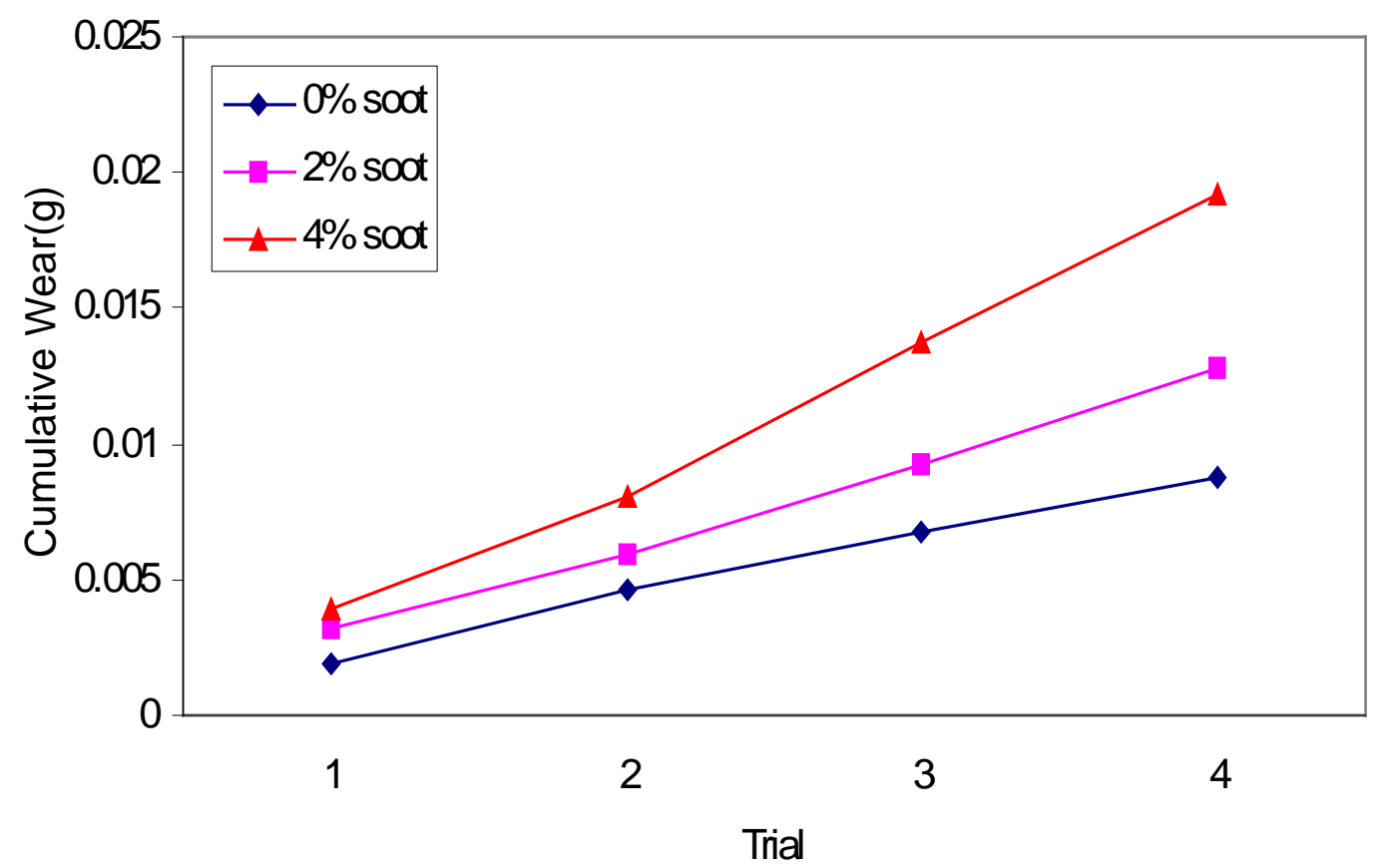

Figure 4.6 Variation of Cumulative Wear for Sample \# WVU399 


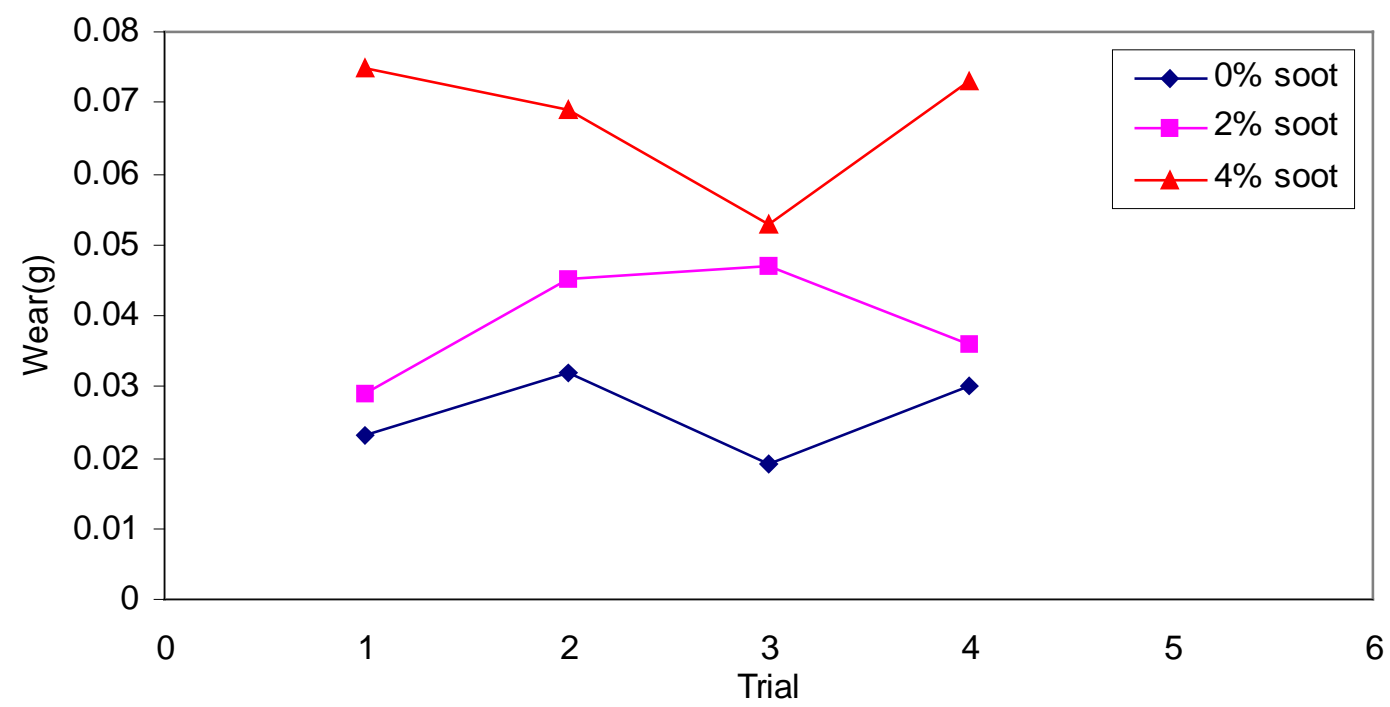

Figure 4.7 Variation of Actual Wear for Sample \# WVU400

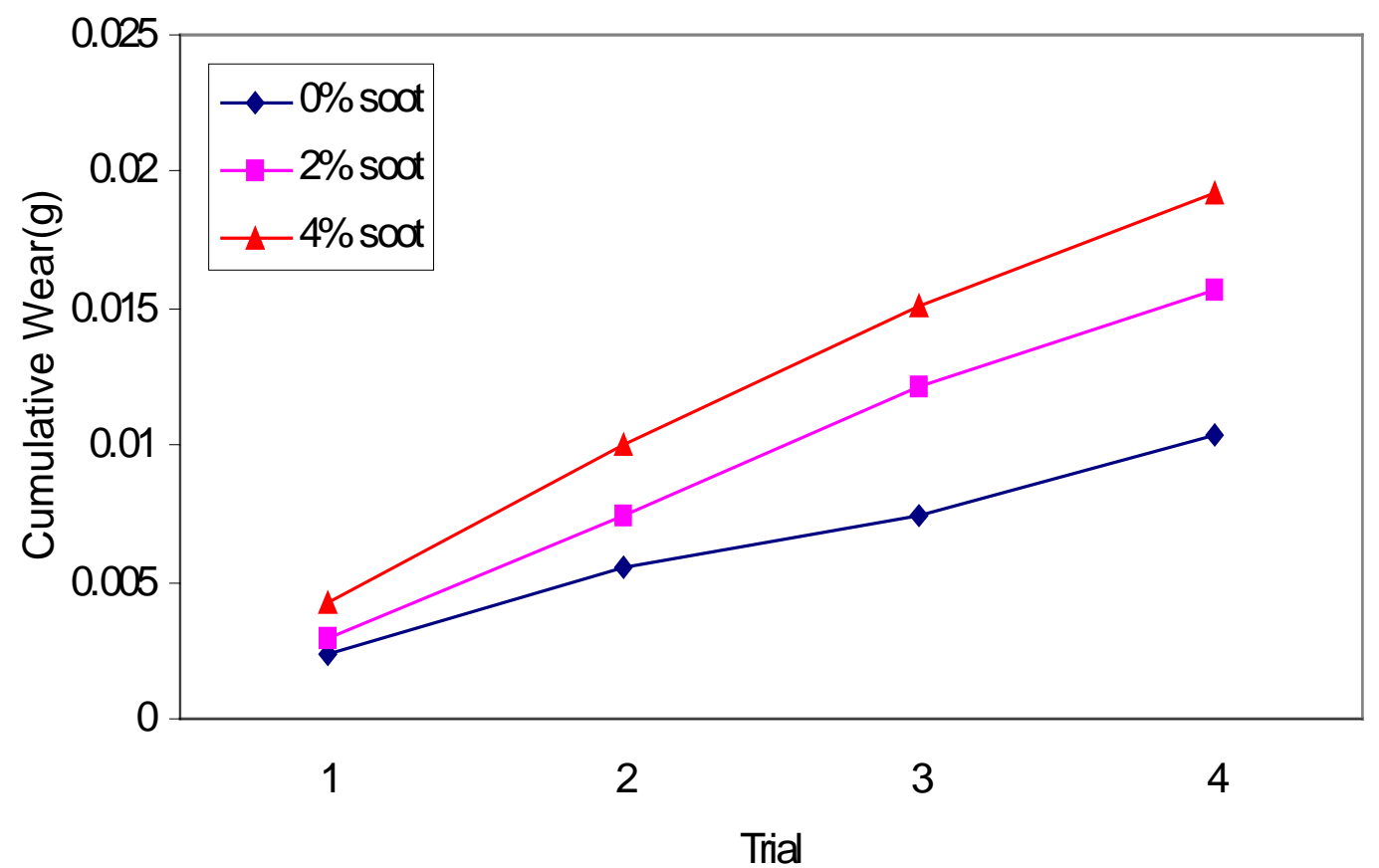

Figure 4.8 Variation of Cumulative Wear for Sample \# WVU400 


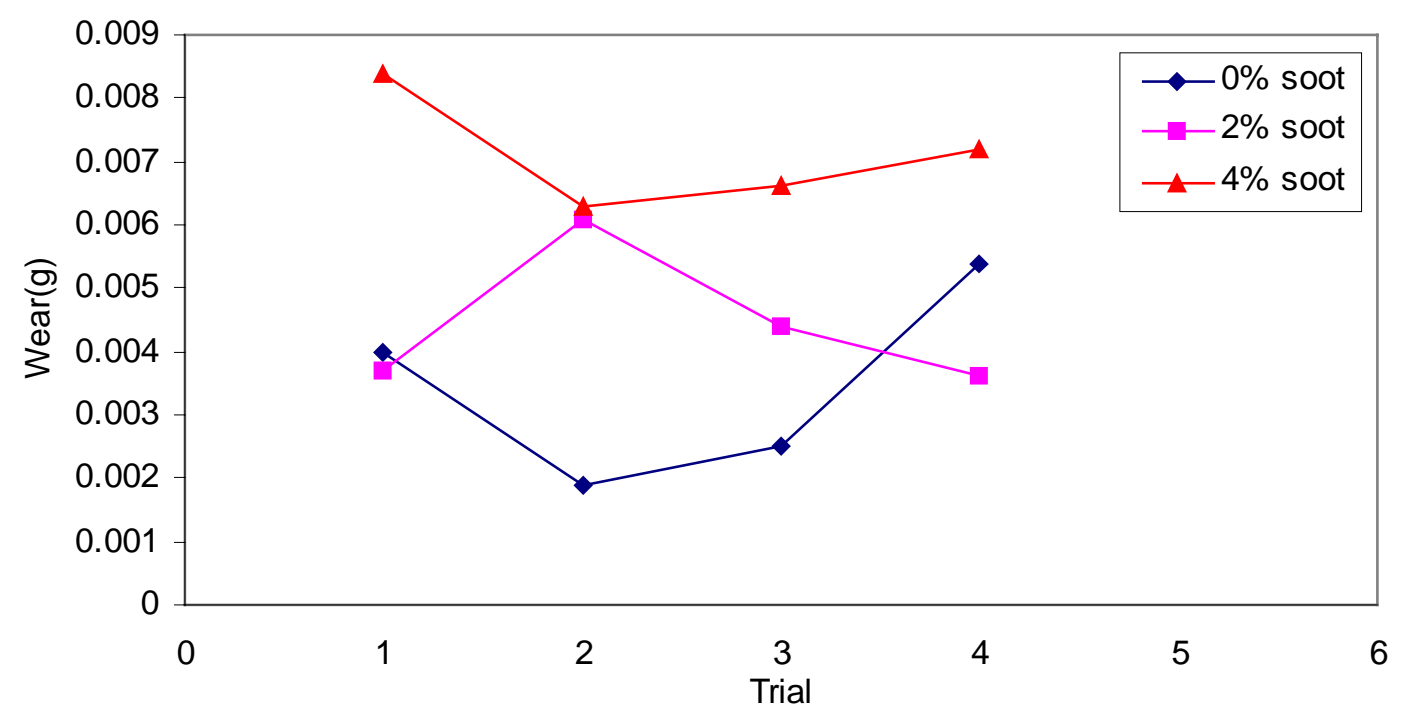

Figure 4.9 Variation of Actual Wear for Sample \# WVU401

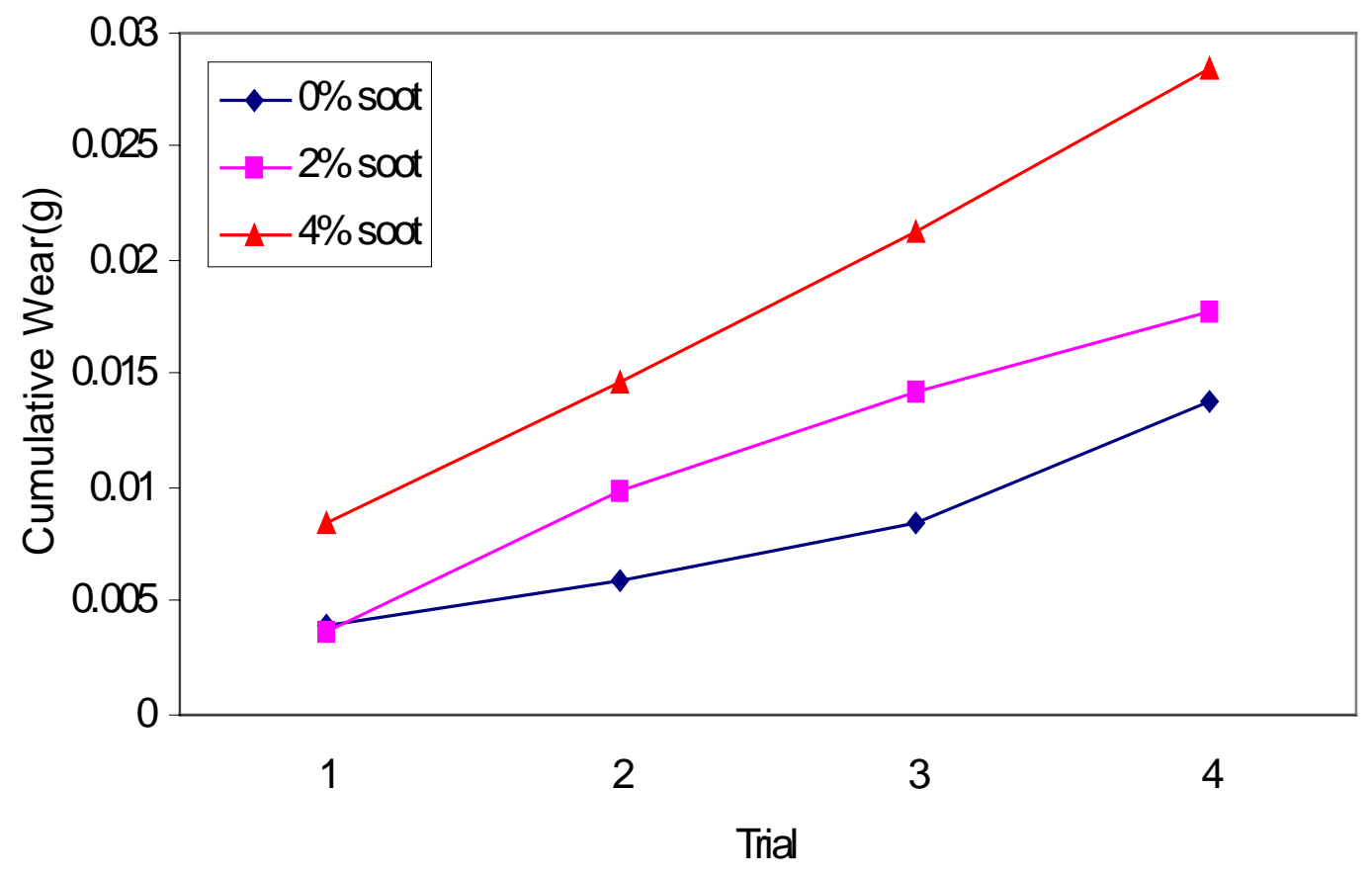

Figure 4.10 Variation of Cumulative Wear for Sample \# WVU401 


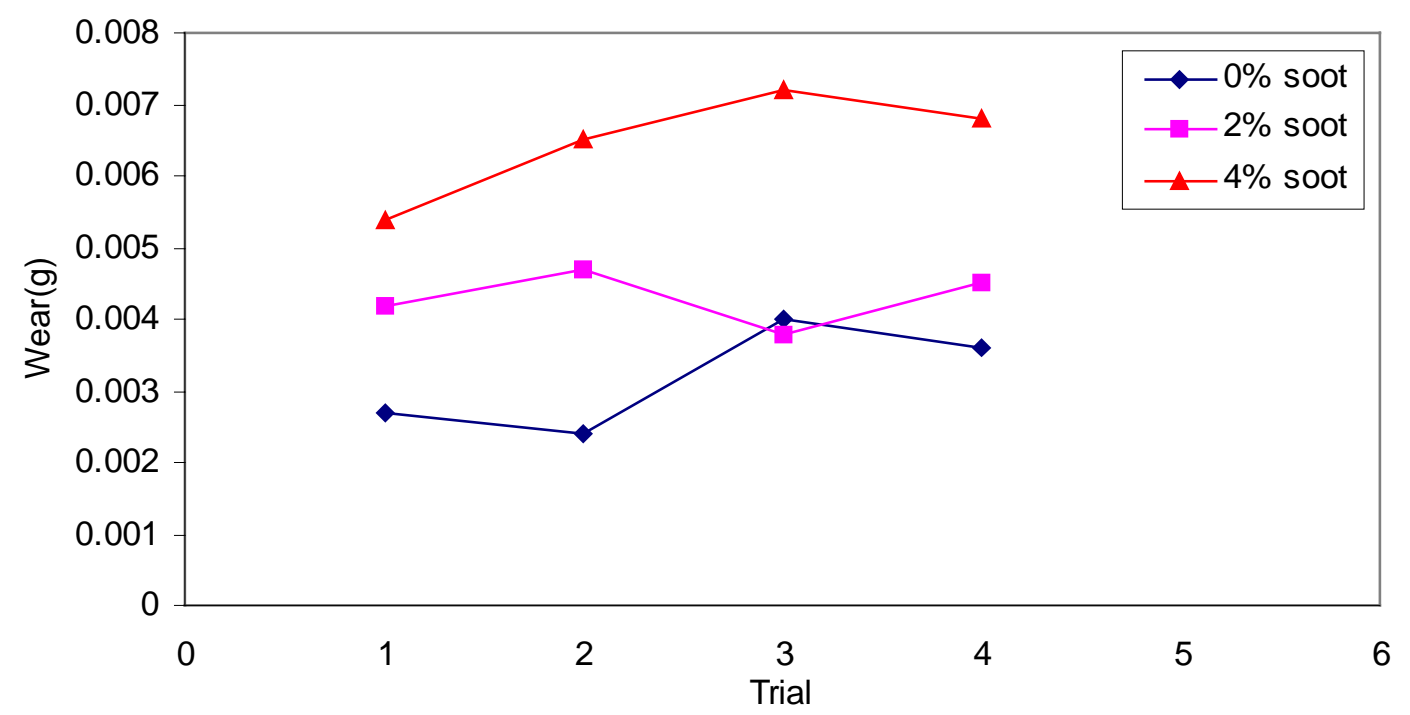

Figure 4.11 Variation of Actual Wear for Sample \# WVU402

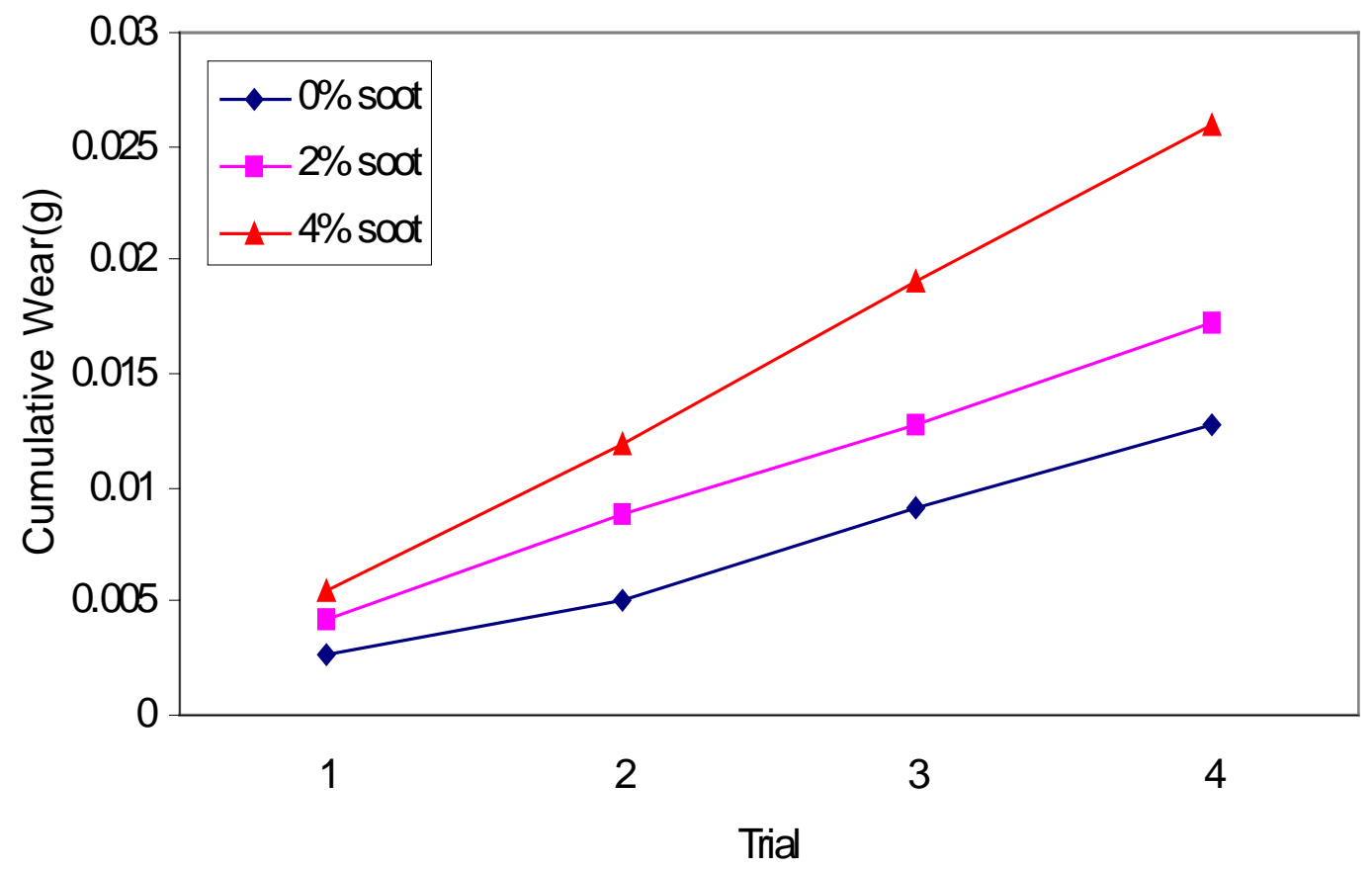

Figure 4.12 Variation of Cumulative Wear for Sample \# WVU402 


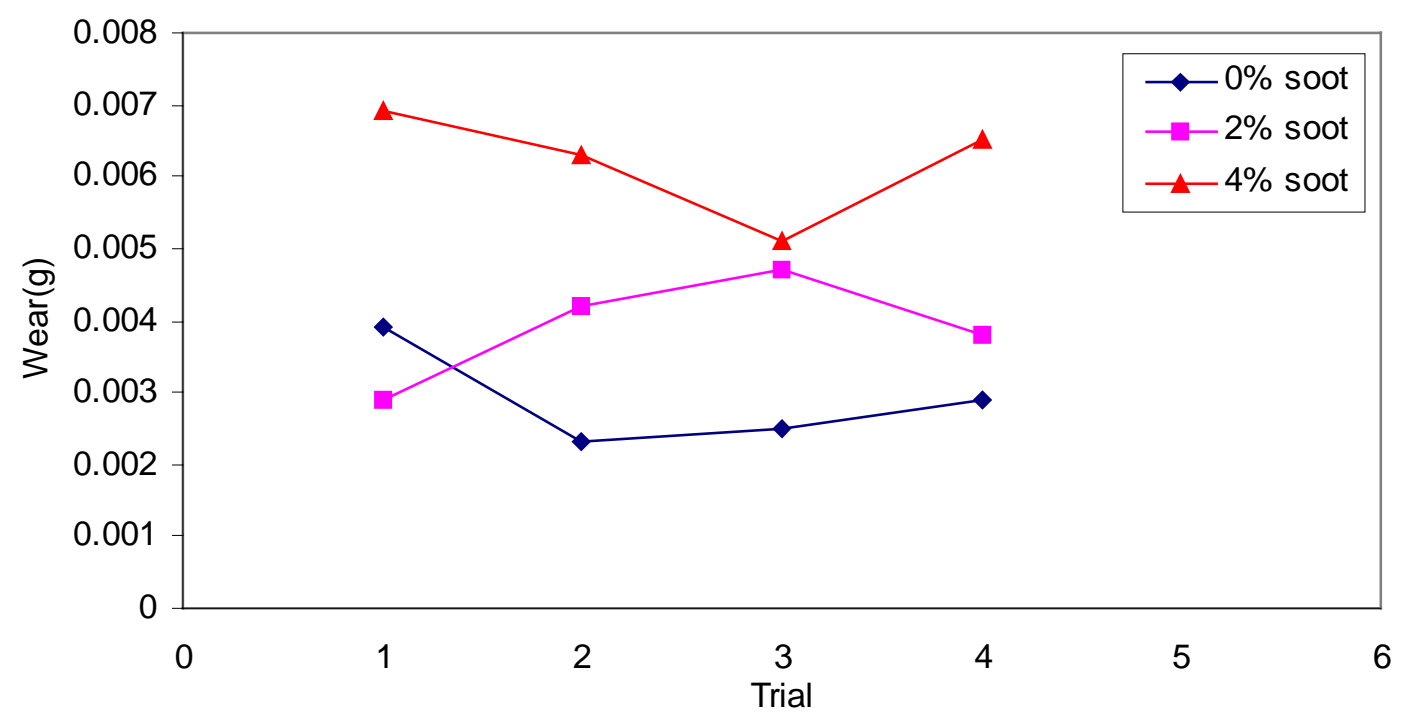

Figure 4.13 Variation of Actual Wear for Sample \# WVU403

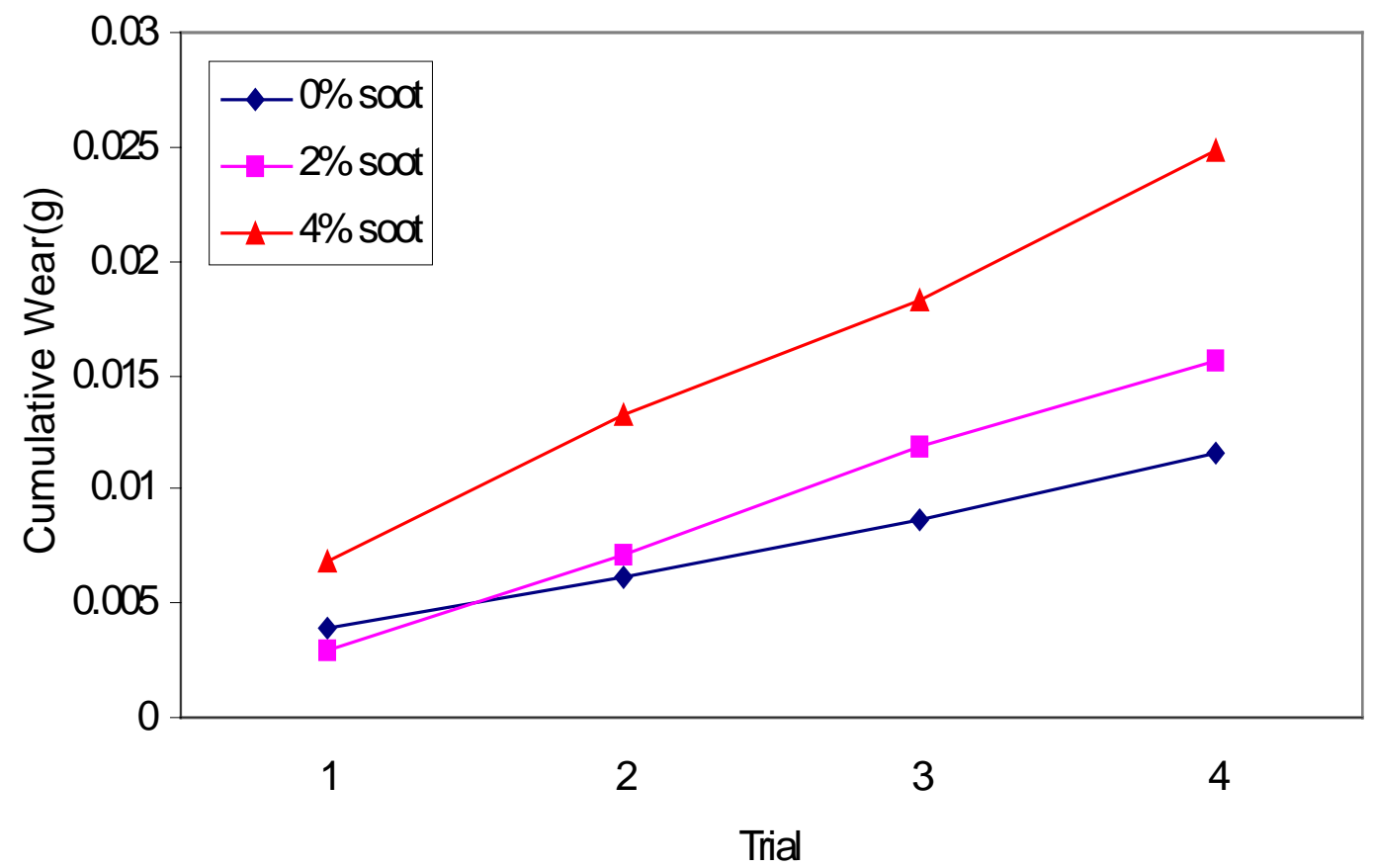

Figure 4.14 Variation of Cumulative Wear for Sample \# WVU403 


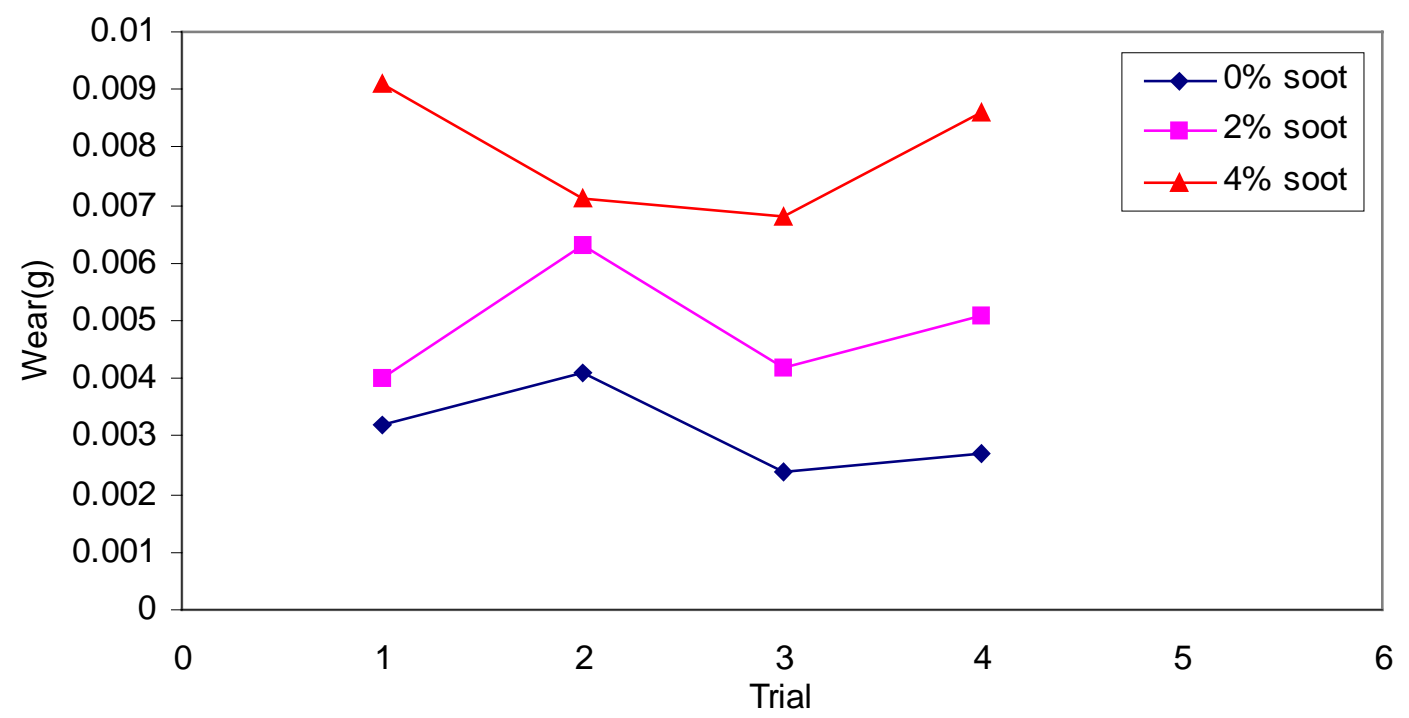

Figure 4.15 Variation of Actual Wear for Sample \# WVU404

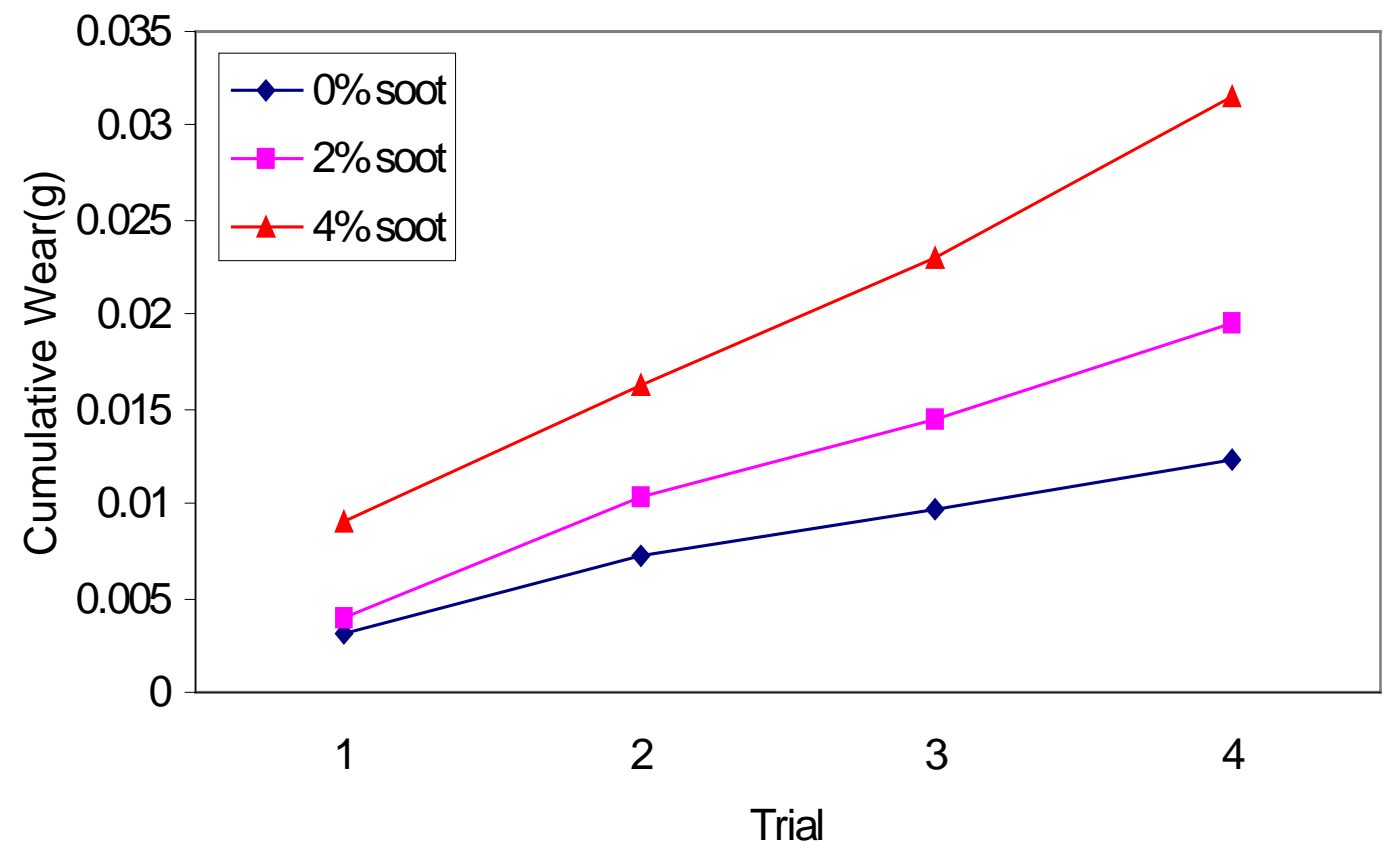

Figure 4.16 Variation of Cumulative Wear for Sample \# WVU404 


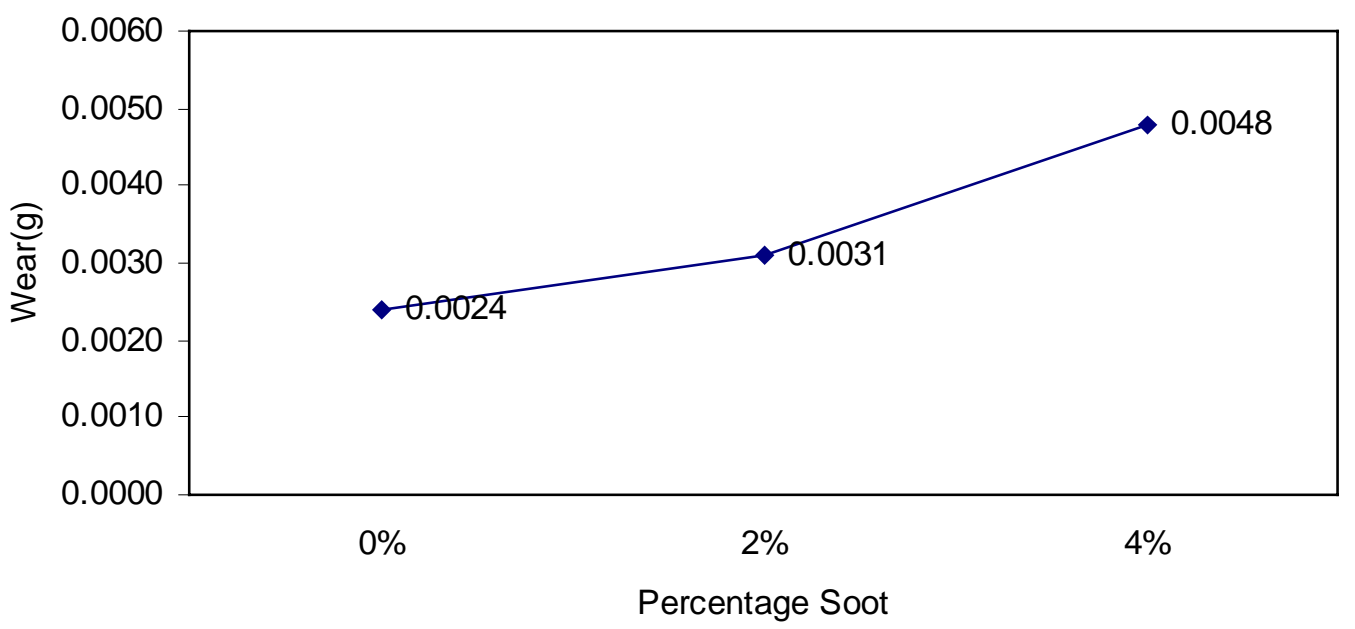

Figure 4.17 Variation of Wear(g) with Percentage Soot for sample \# WVU397

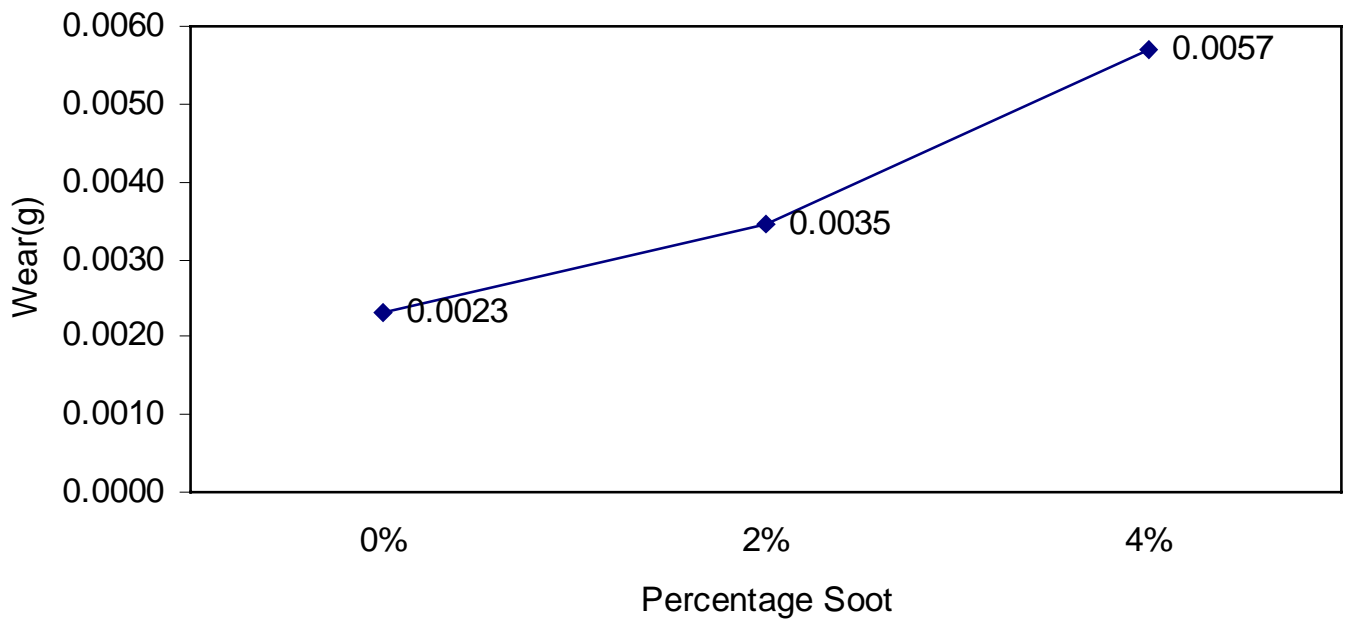

Figure 4.18 Variation of Wear(g) with Percentage Soot for sample \# WVU398 


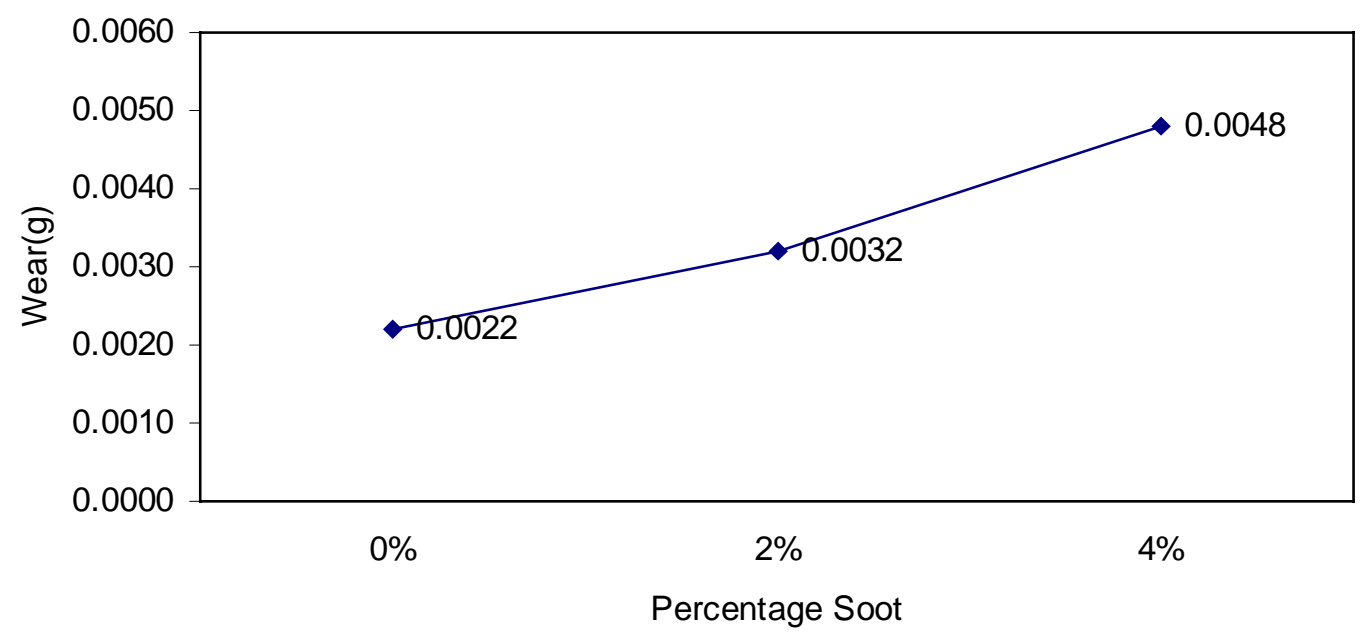

Figure 4.19 Variation of Wear(g) with Percentage Soot for sample \# WVU399

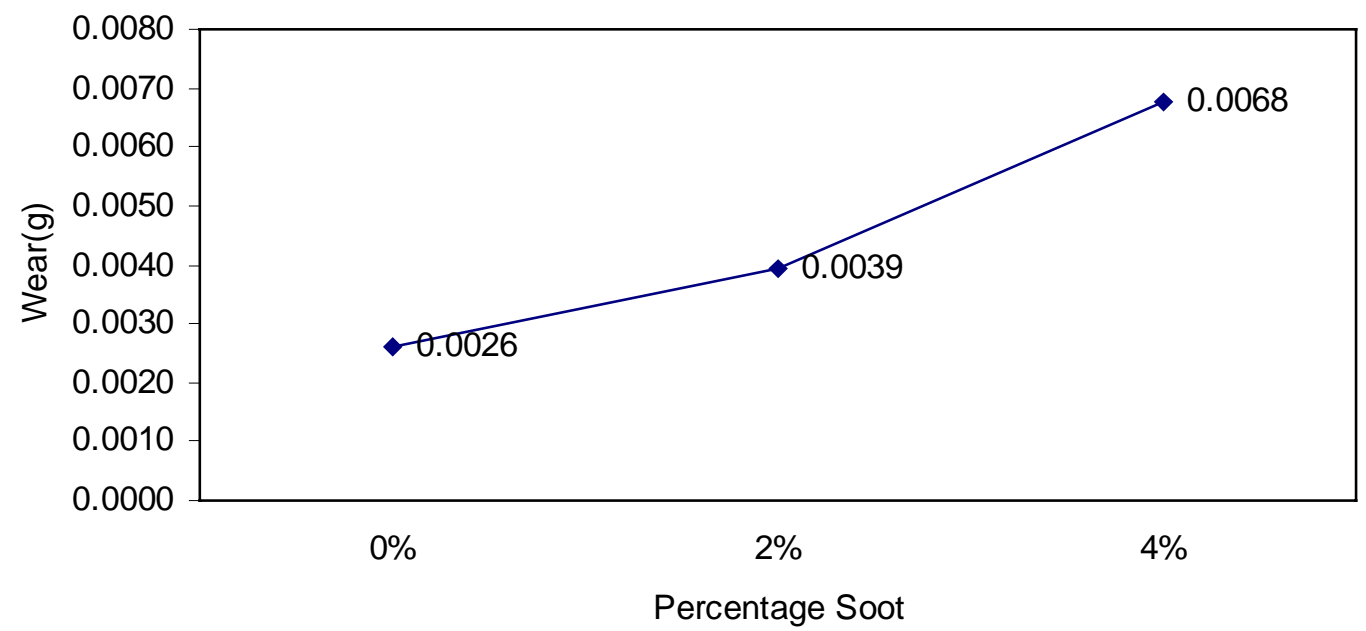

Figure 4.20 Variation of Wear(g) with Percentage Soot for sample \# WVU400 


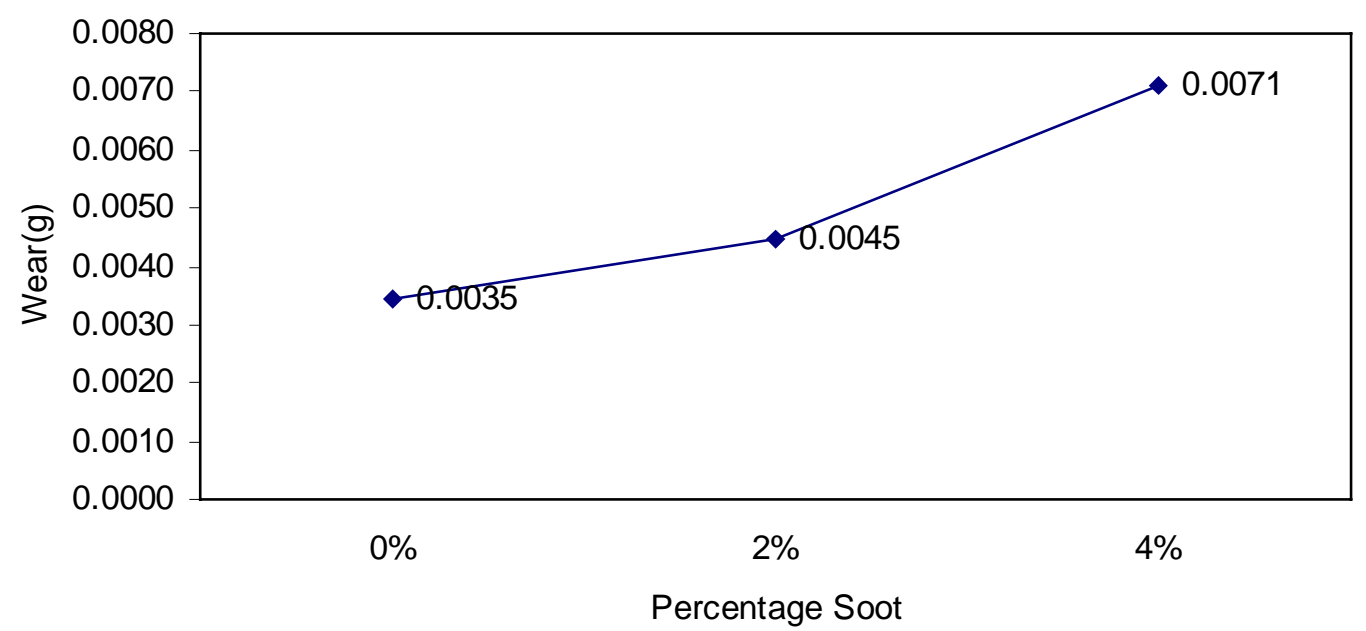

Figure 4.21 Variation of Wear(g) with Percentage Soot for sample \# WVU401

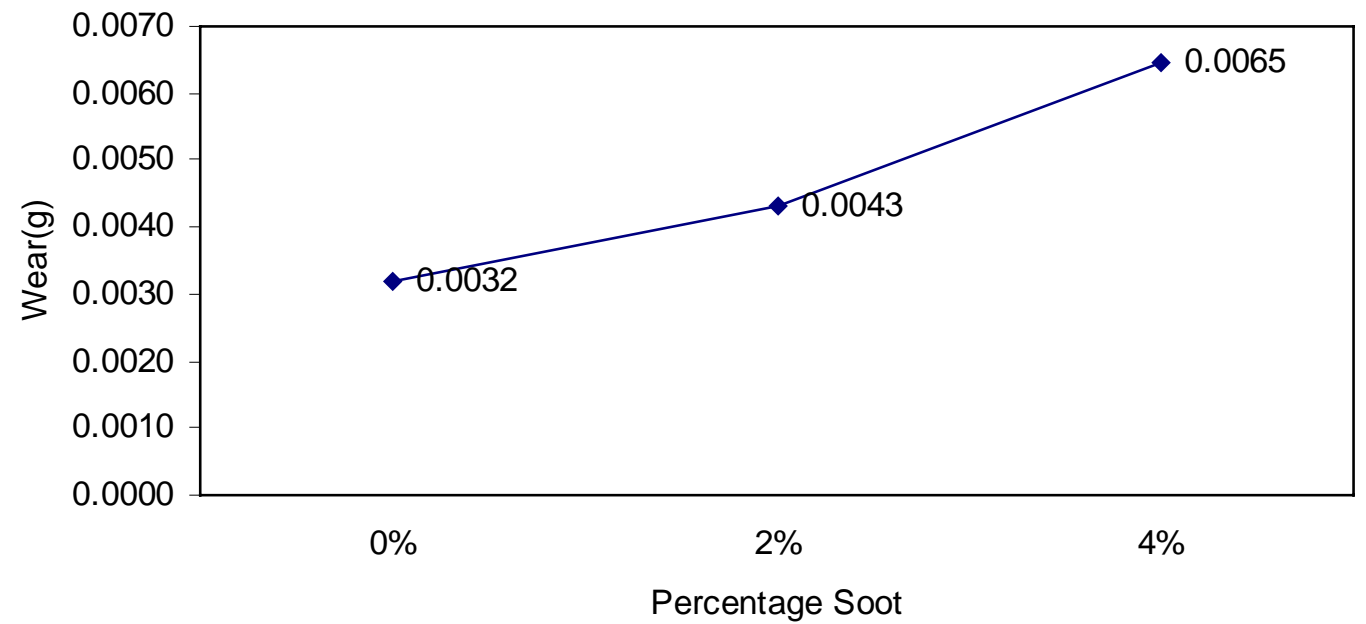

Figure 4.22 Variation of Wear(g) with Percentage Soot for sample \# WVU402 


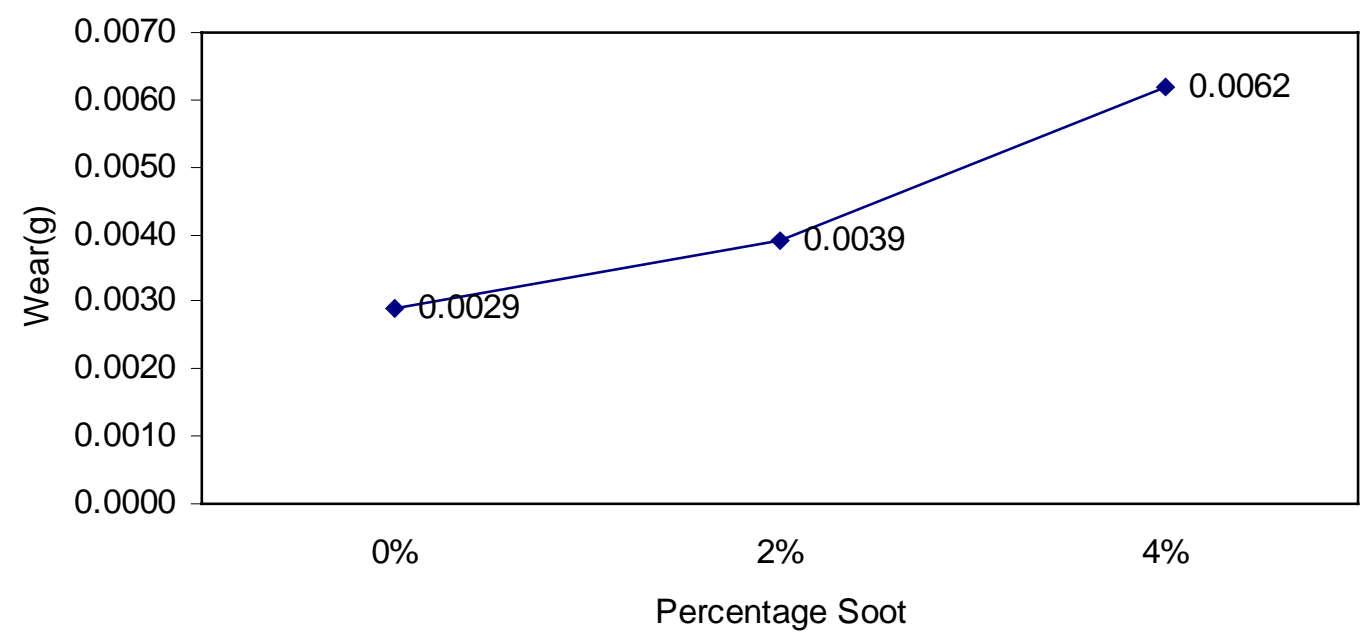

Figure 4.23 Variation of Wear(g) with Percentage Soot for sample \# WVU403

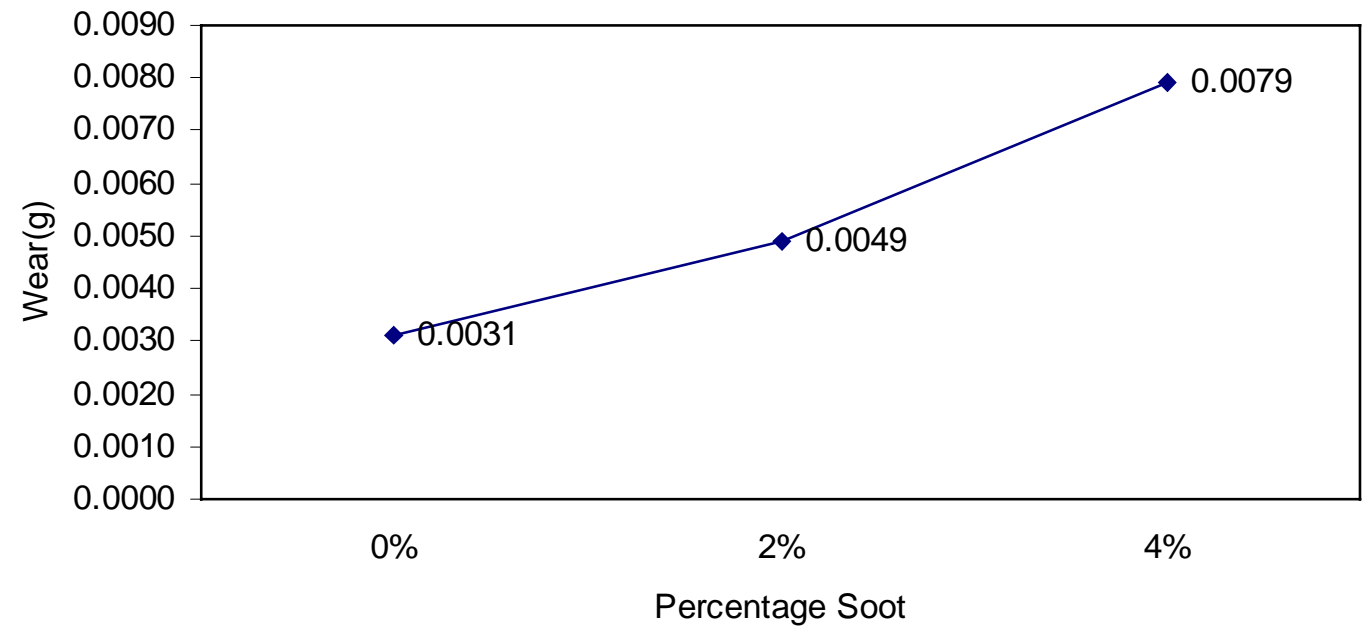

Figure 4.24 Variation of Wear(g) with Percentage Soot for sample \# WVU404 


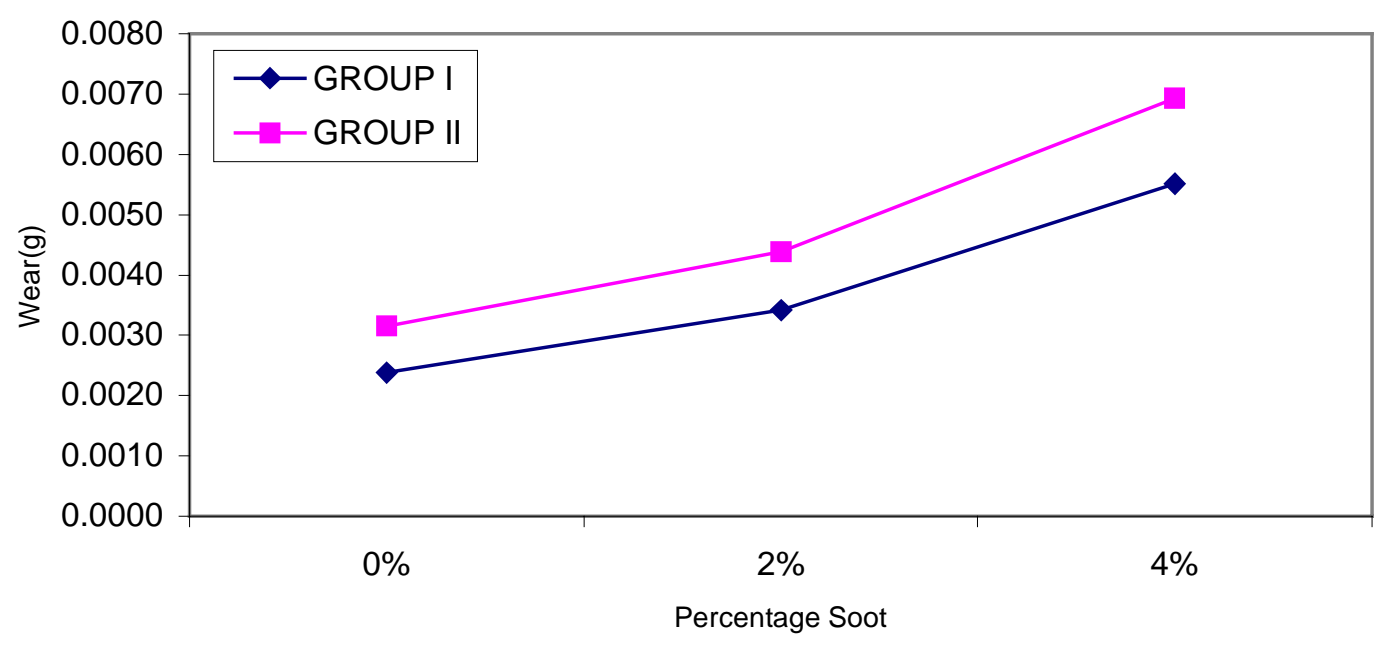

Figure 4.25 Effect of Base Stock on Wear(g)

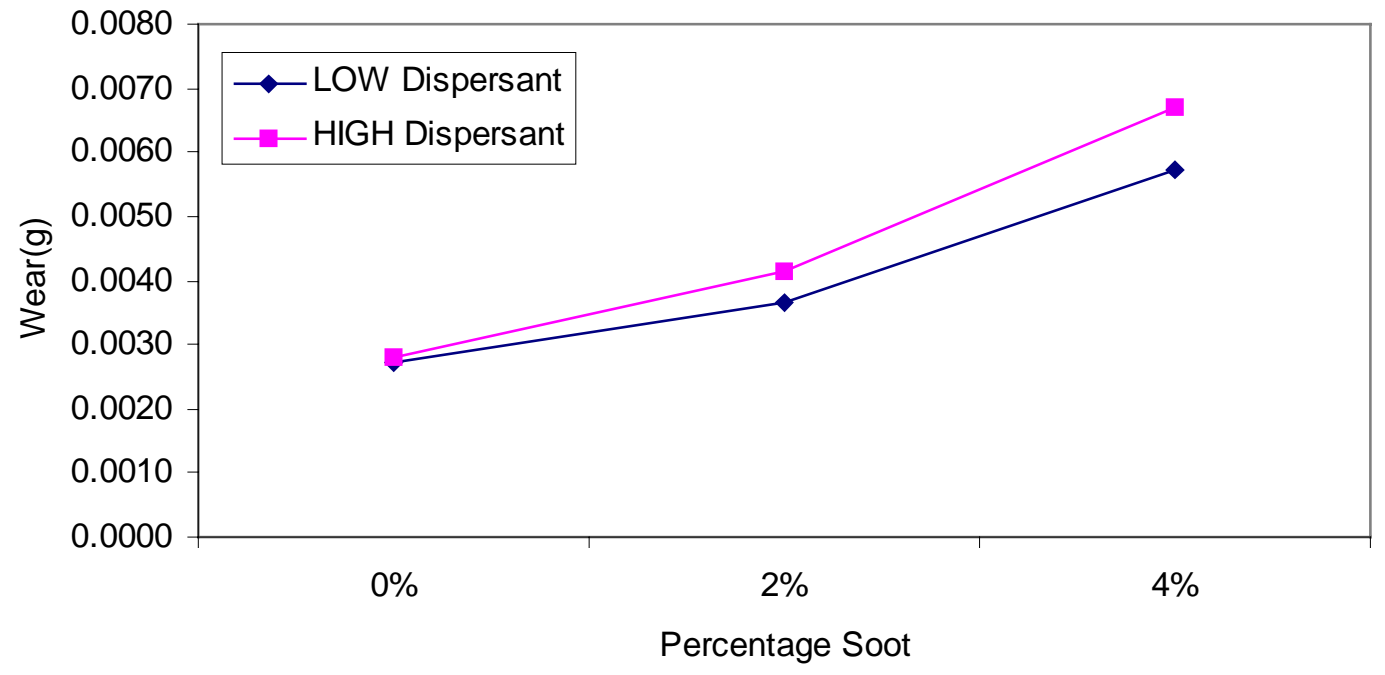

Figure 4.26 Effect of Dispersant on Wear(g) 


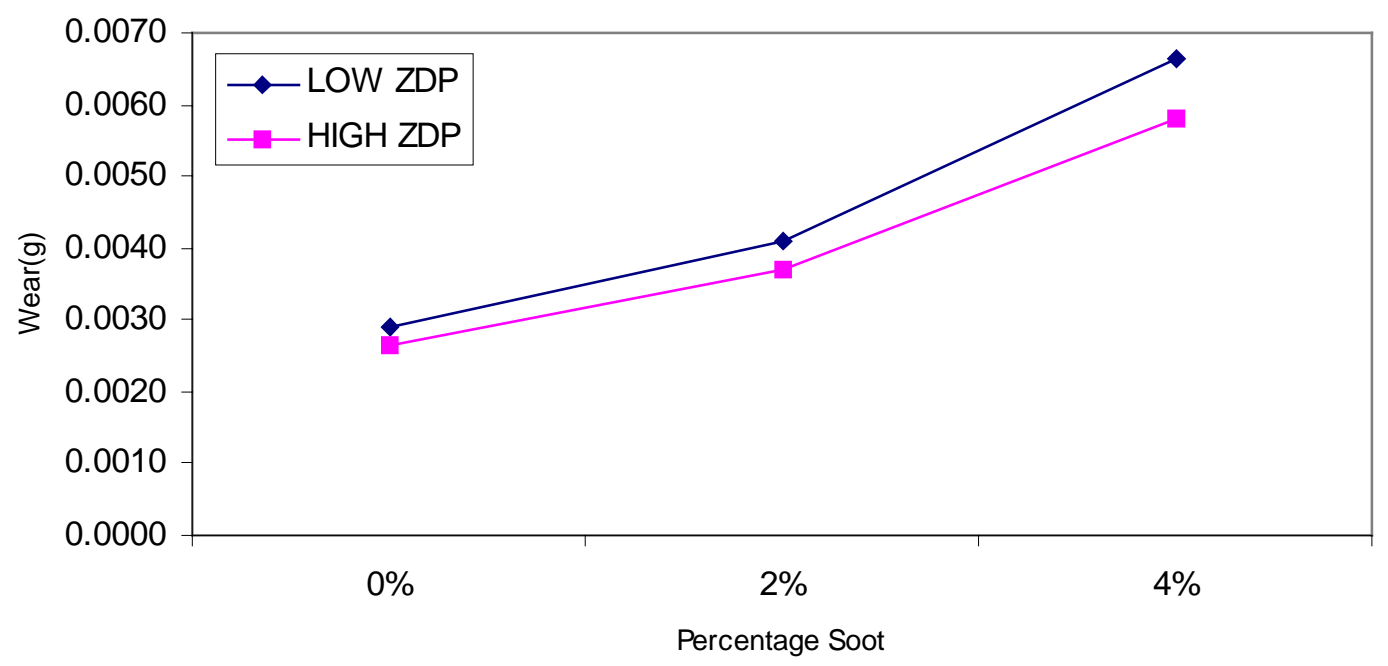

Figure 4.27 Effect of ZDP on Wear(g)

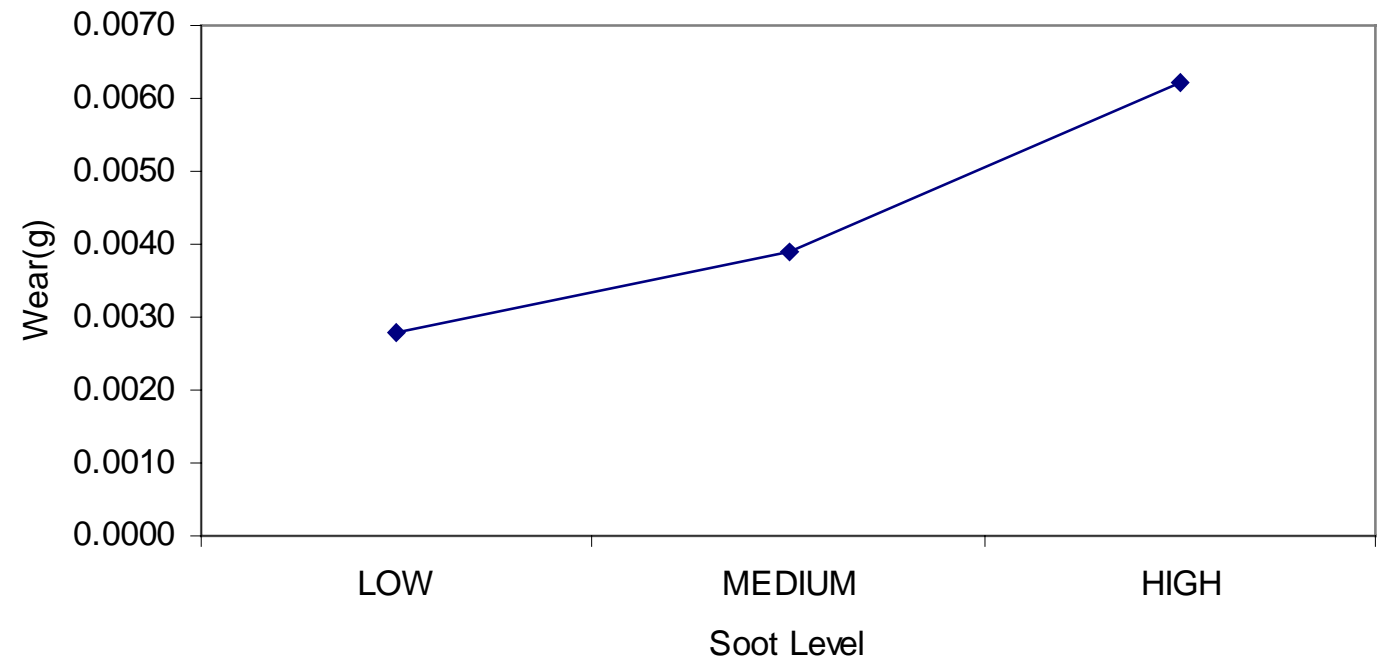

Figure 4.28 Effect of Soot on Wear(g) 


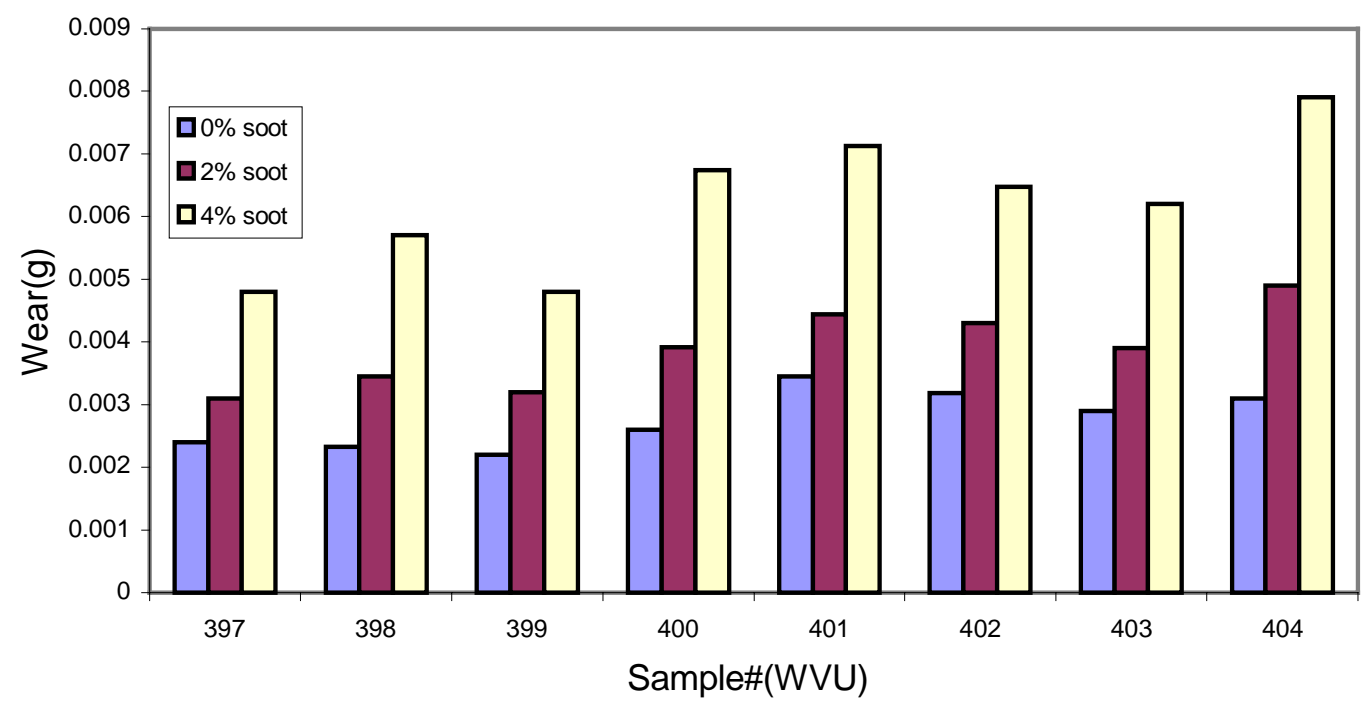

Figure 4.29 Variation of Wear(g) with Percentage Soot 


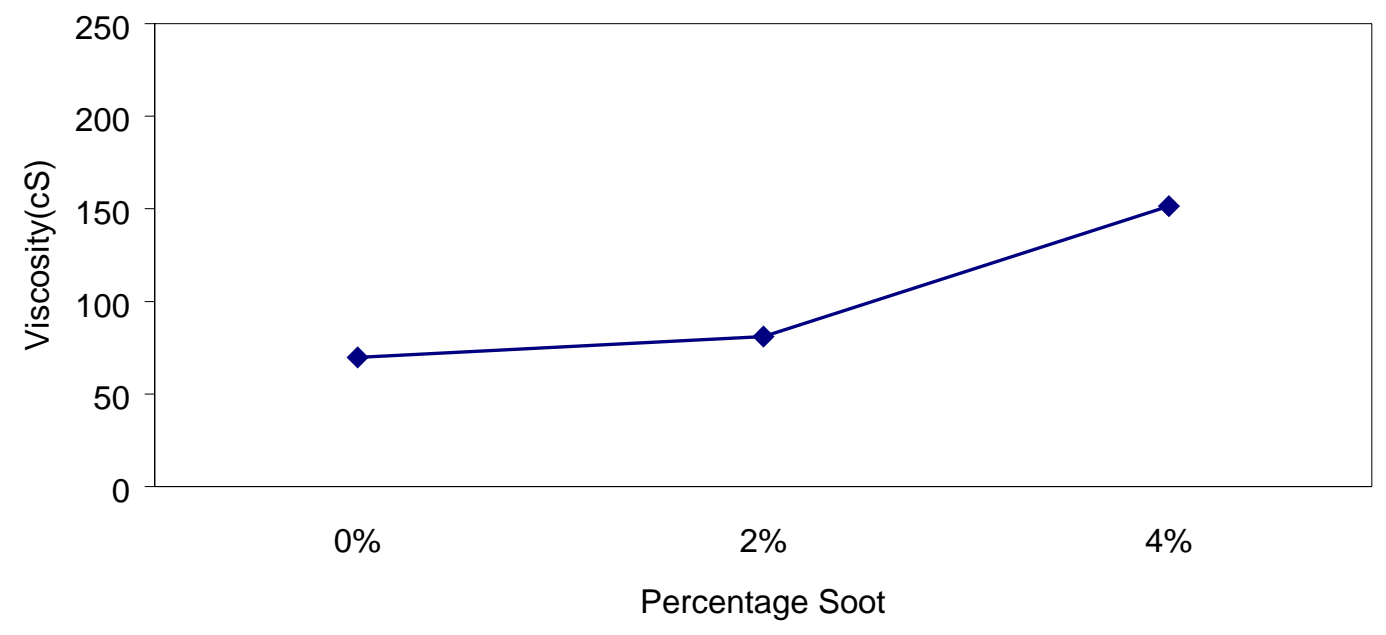

Figure 4.30 Variation of Viscosity with soot at $40^{\circ} \mathrm{C}$ for sample \# WVU397

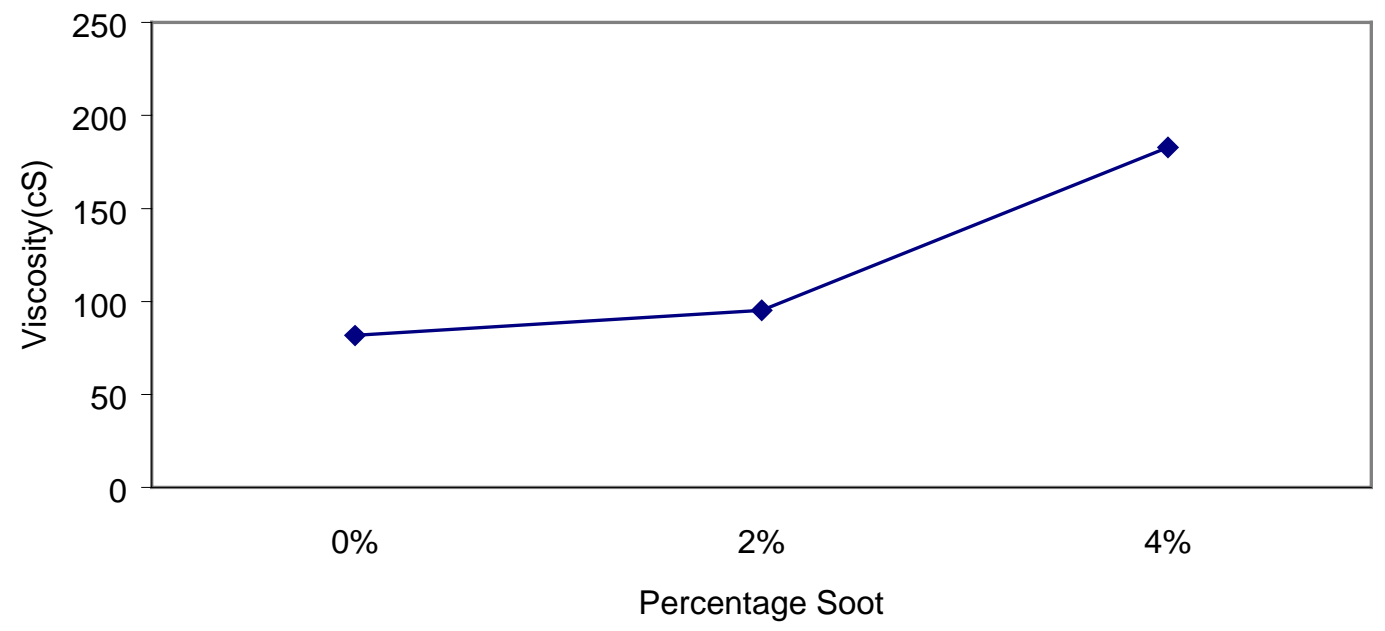

Figure 4.31 Variation of Viscosity with soot at $40^{\circ} \mathrm{C}$ for sample \# WVU398 


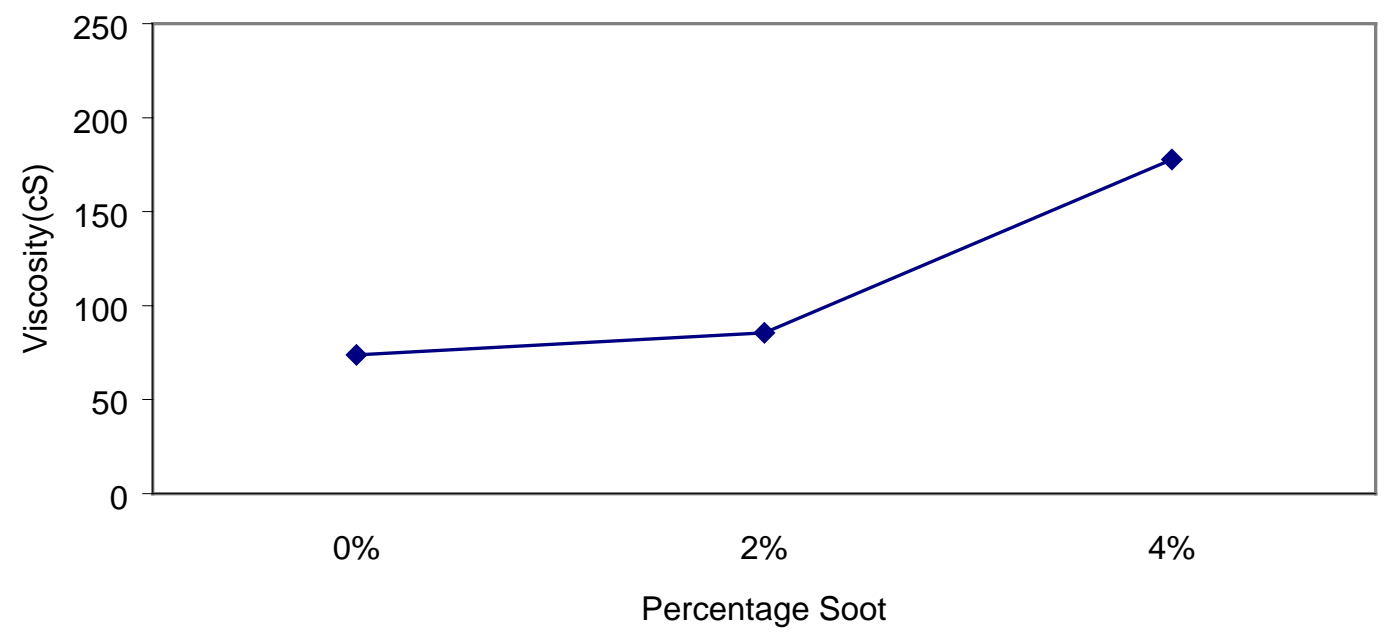

Figure 4.32 Variation of Viscosity with soot at $40^{\circ} \mathrm{C}$ for sample \# WVU399

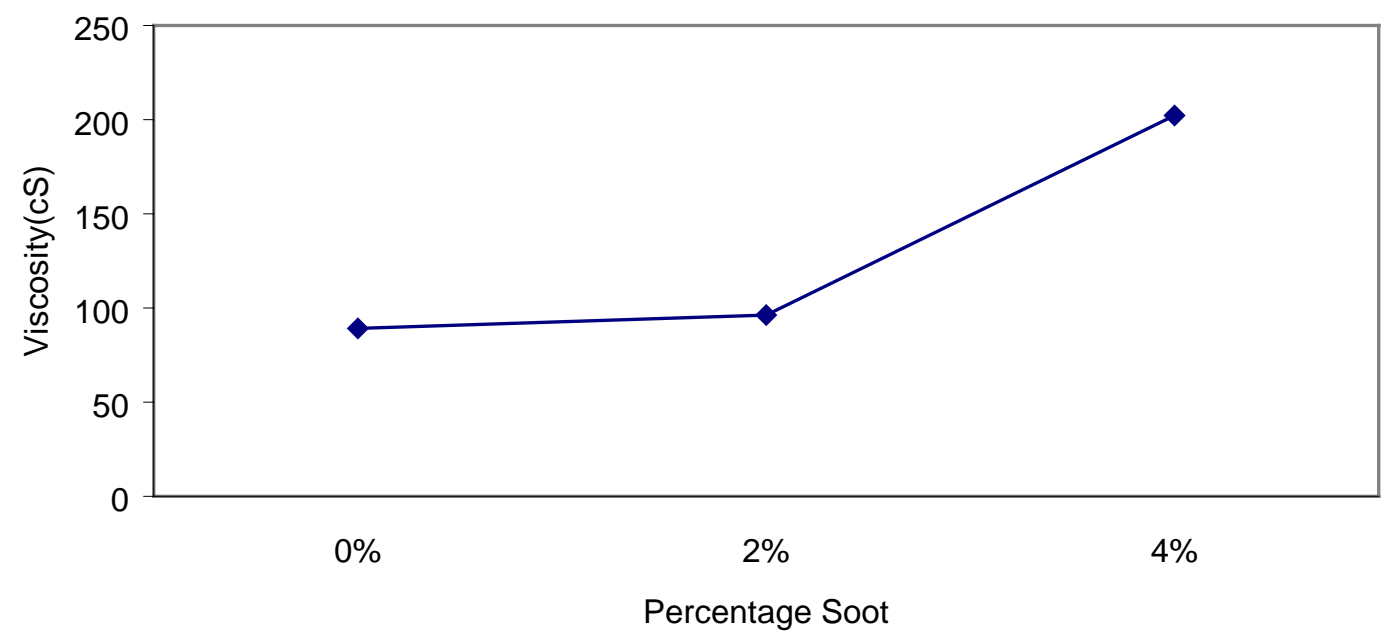

Figure 4.33 Variation of Viscosity with soot at $40^{\circ} \mathrm{C}$ for sample \# WVU400 


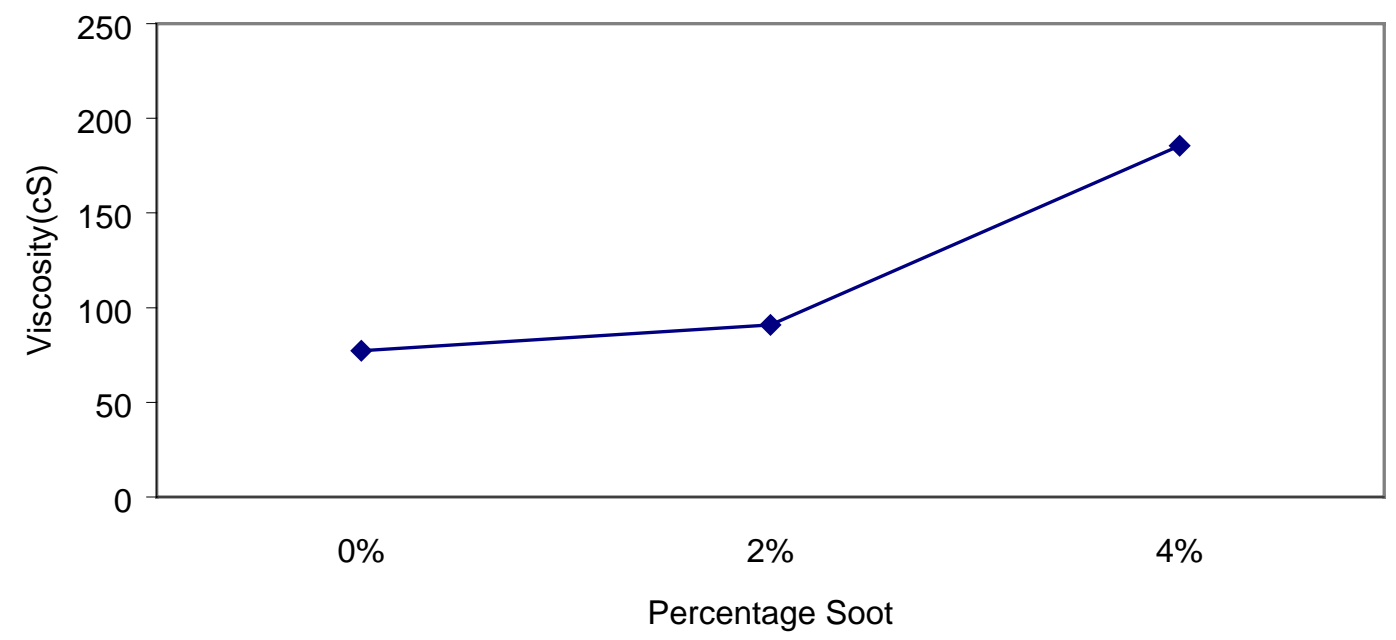

Figure 4.34 Variation of Viscosity with soot at $40^{\circ} \mathrm{C}$ for sample \# WVU401

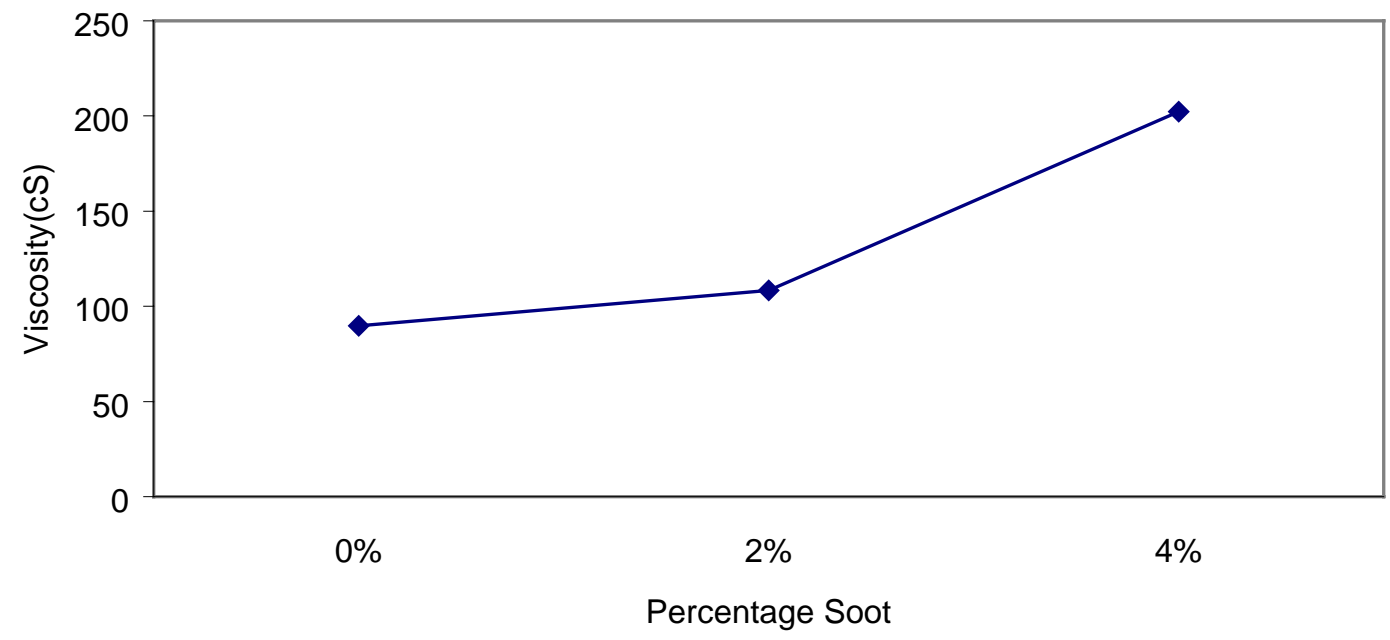

Figure 4.35 Variation of Viscosity with soot at $40^{\circ} \mathrm{C}$ for sample \# WVU402 


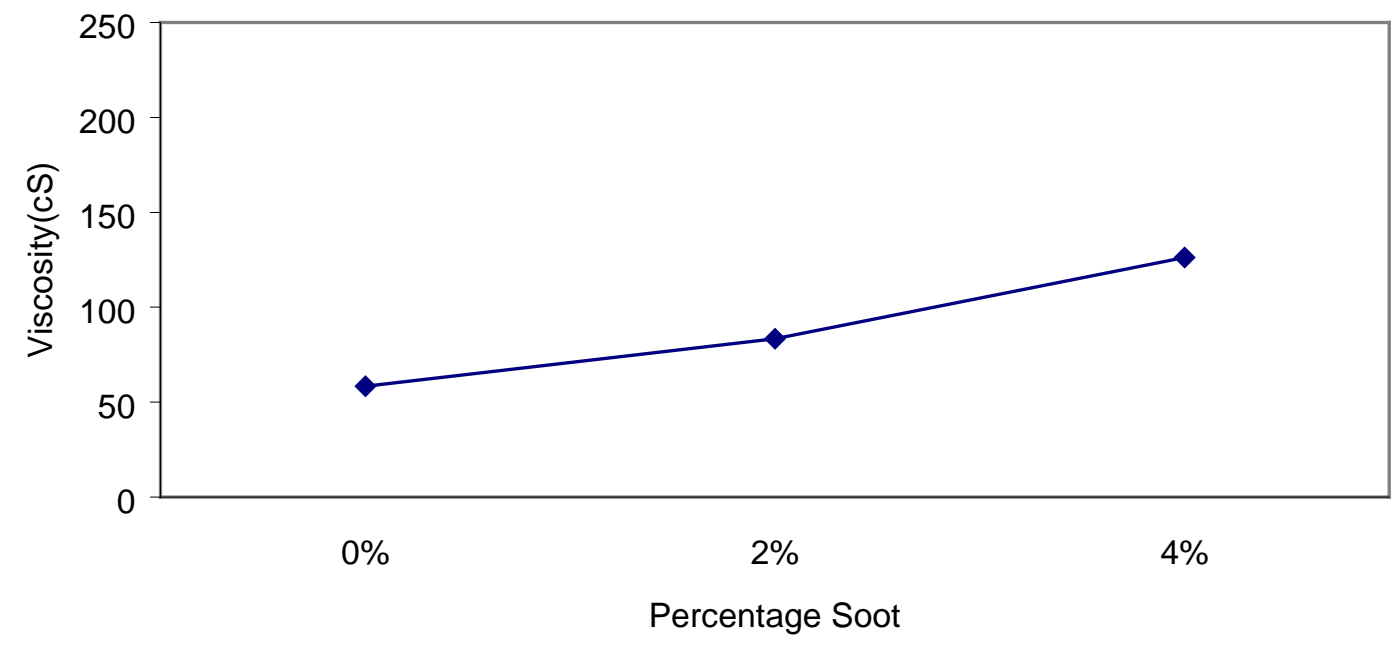

Figure 4.36 Variation of Viscosity with soot at $40^{\circ} \mathrm{C}$ for sample \# WVU403

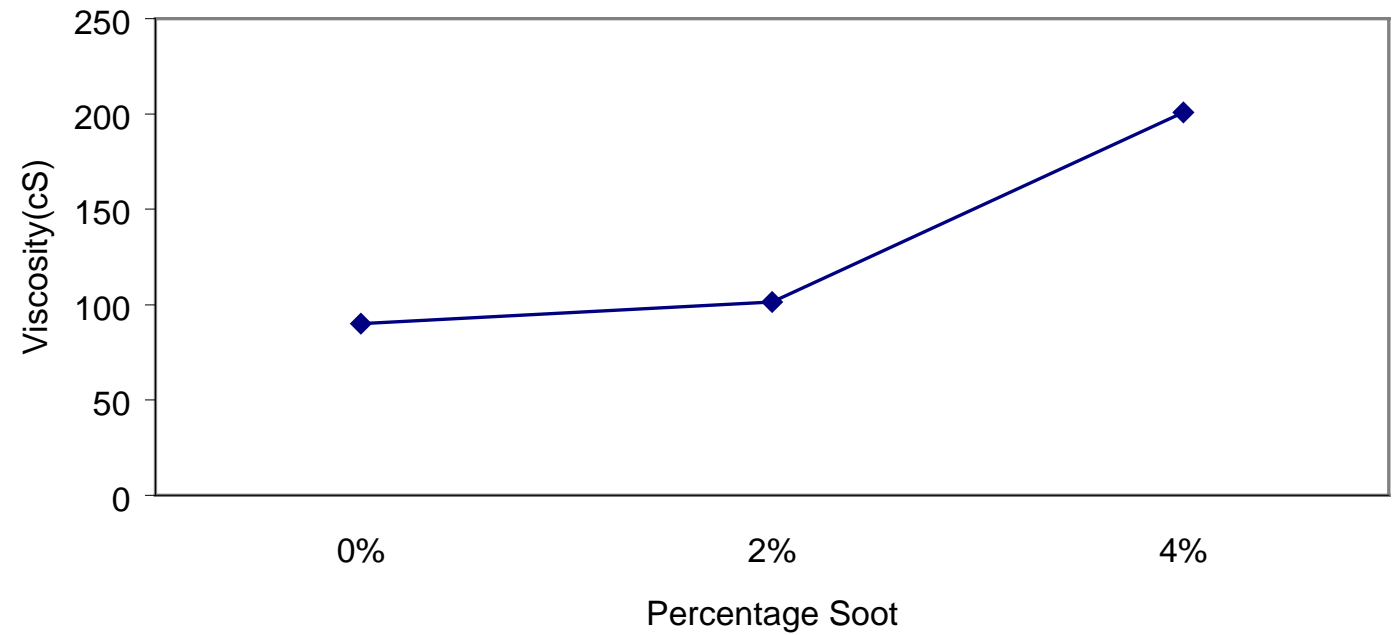

Figure 4.37 Variation of Viscosity with soot at $40^{\circ} \mathrm{C}$ for sample \# WVU404 


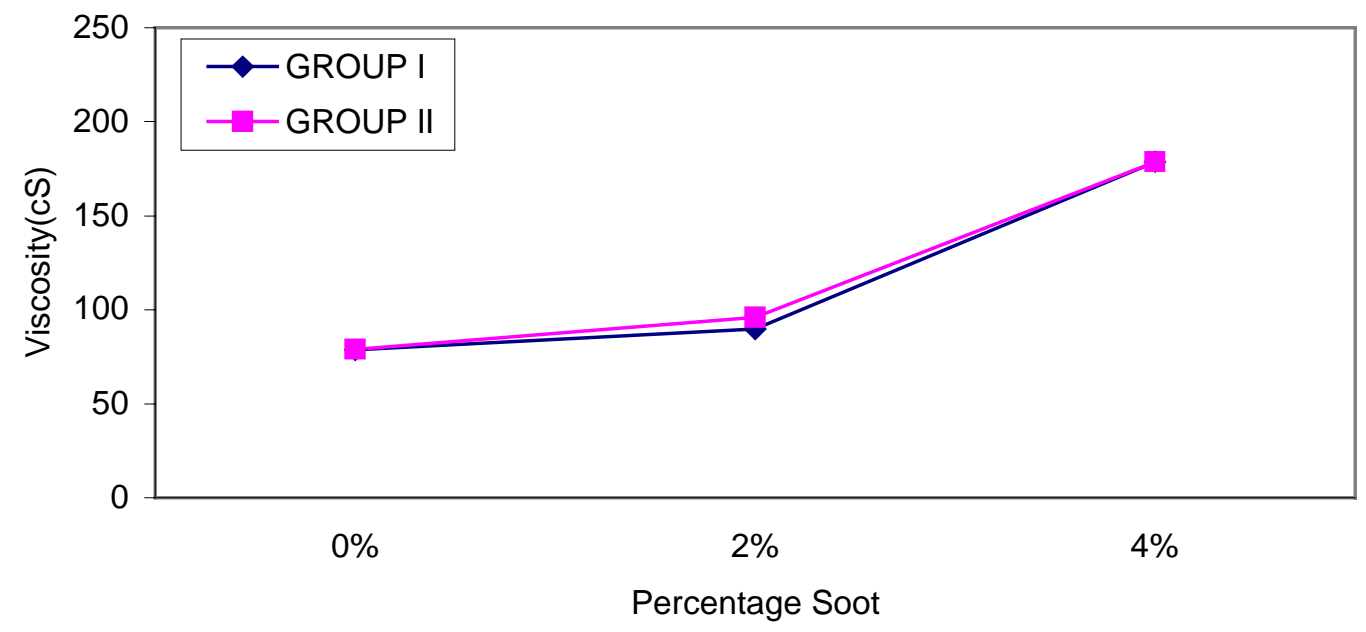

Figure 4.38 Effect of Base Stock on Viscosity(cS) at $40^{\circ} \mathrm{C}$

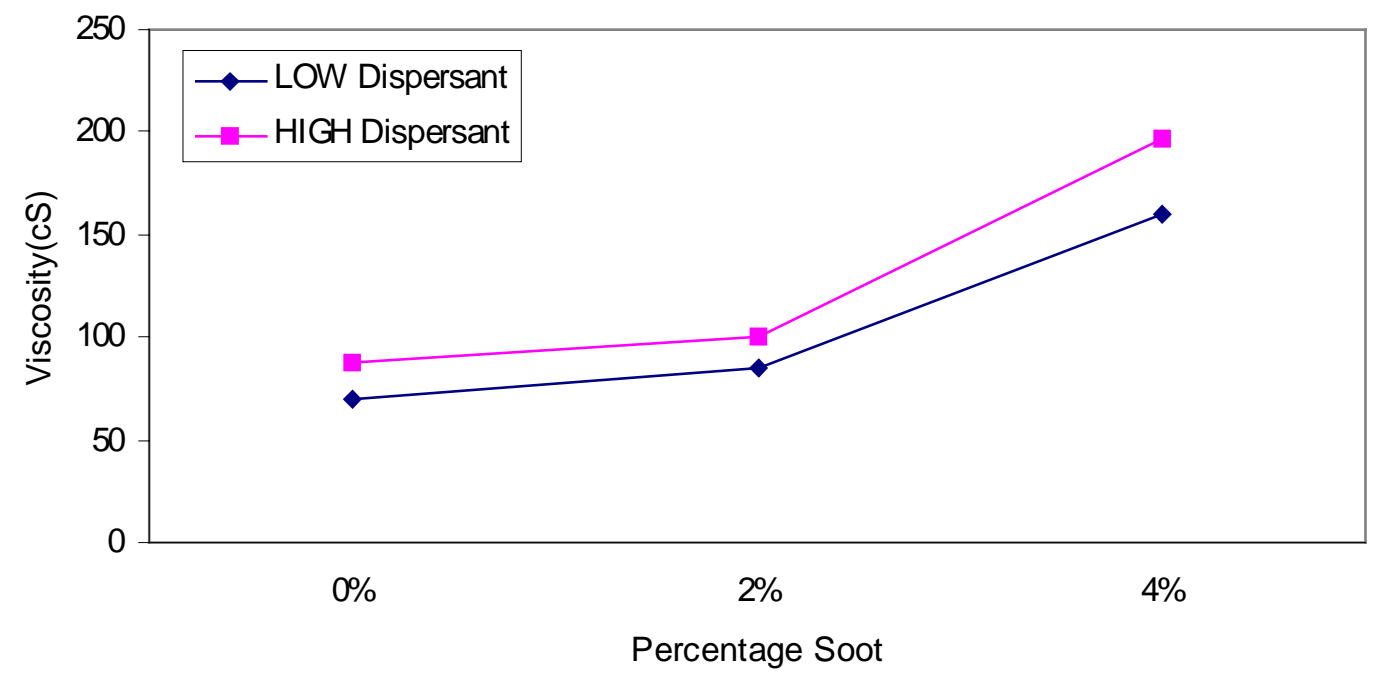

Figure 4.39 Effect of Dispersant on Viscosity $(\mathrm{cS})$ at $40^{\circ} \mathrm{C}$ 


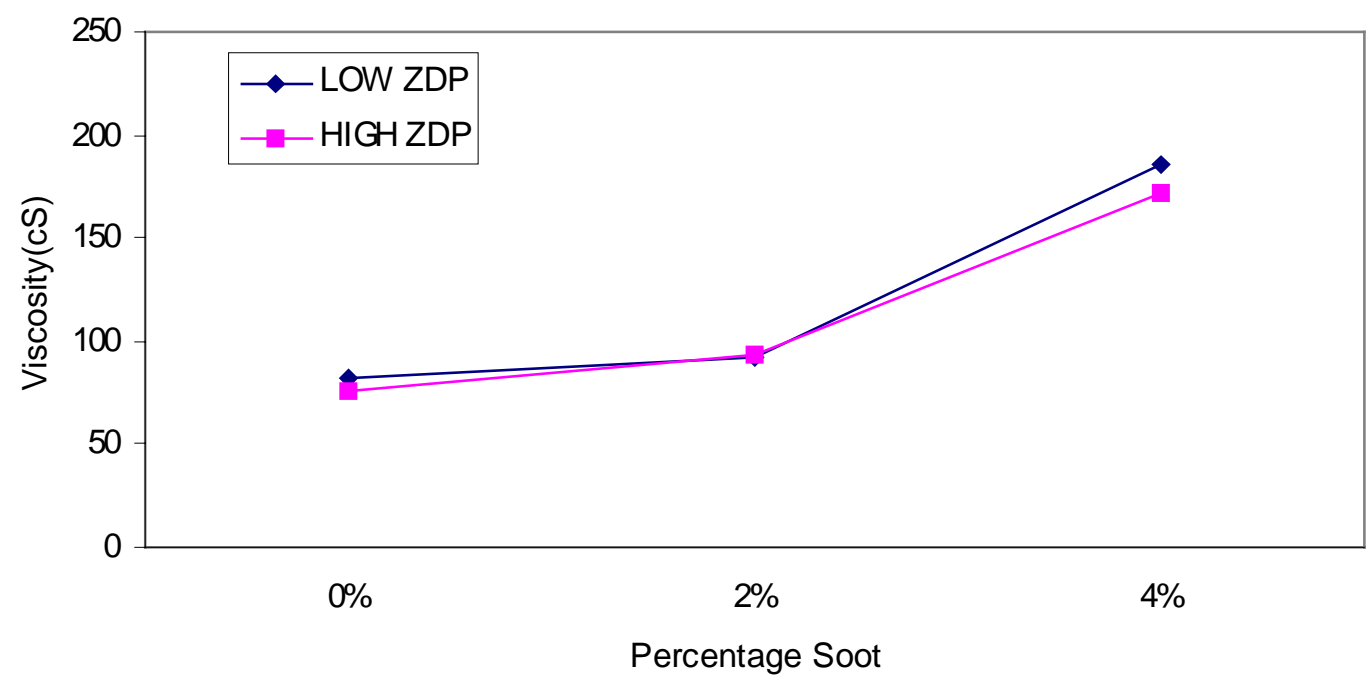

Figure 4.40 Effect of ZDP on Viscosity $(\mathrm{cS})$ at $40^{\circ} \mathrm{C}$

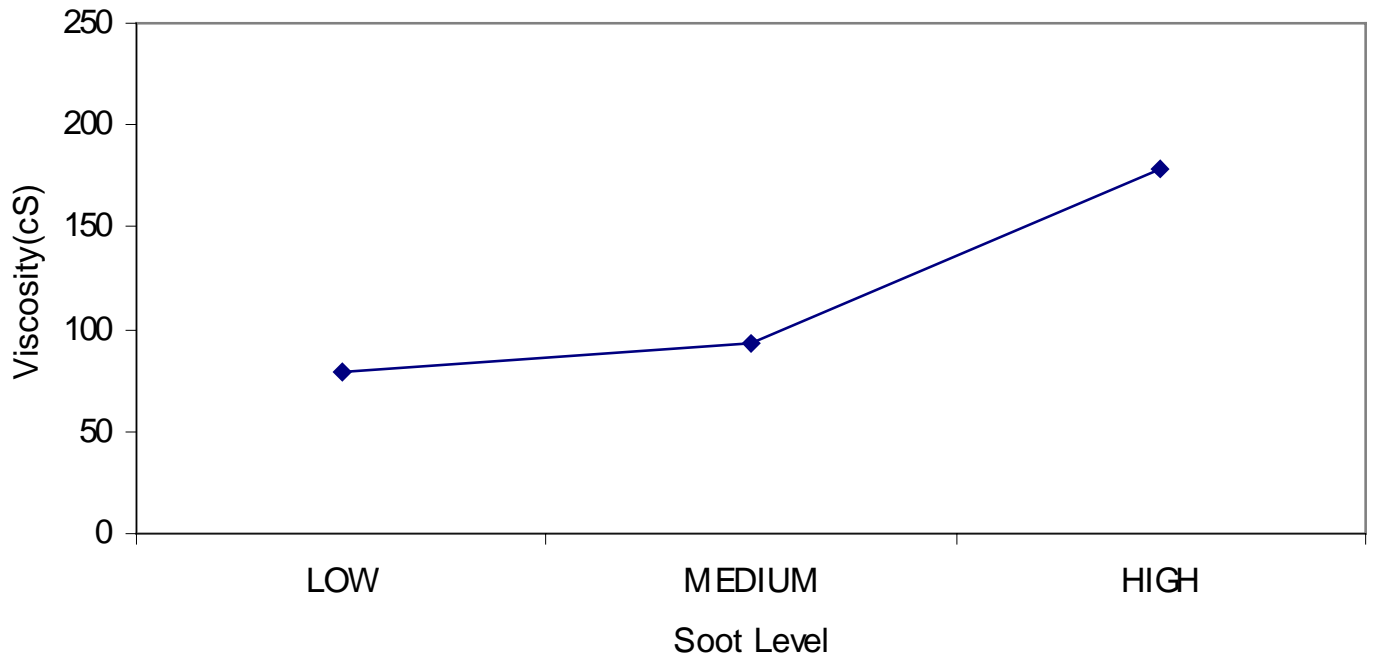

Figure 4.41 Effect of Soot Level on Viscosity $(\mathrm{cS})$ at $40^{\circ} \mathrm{C}$ 


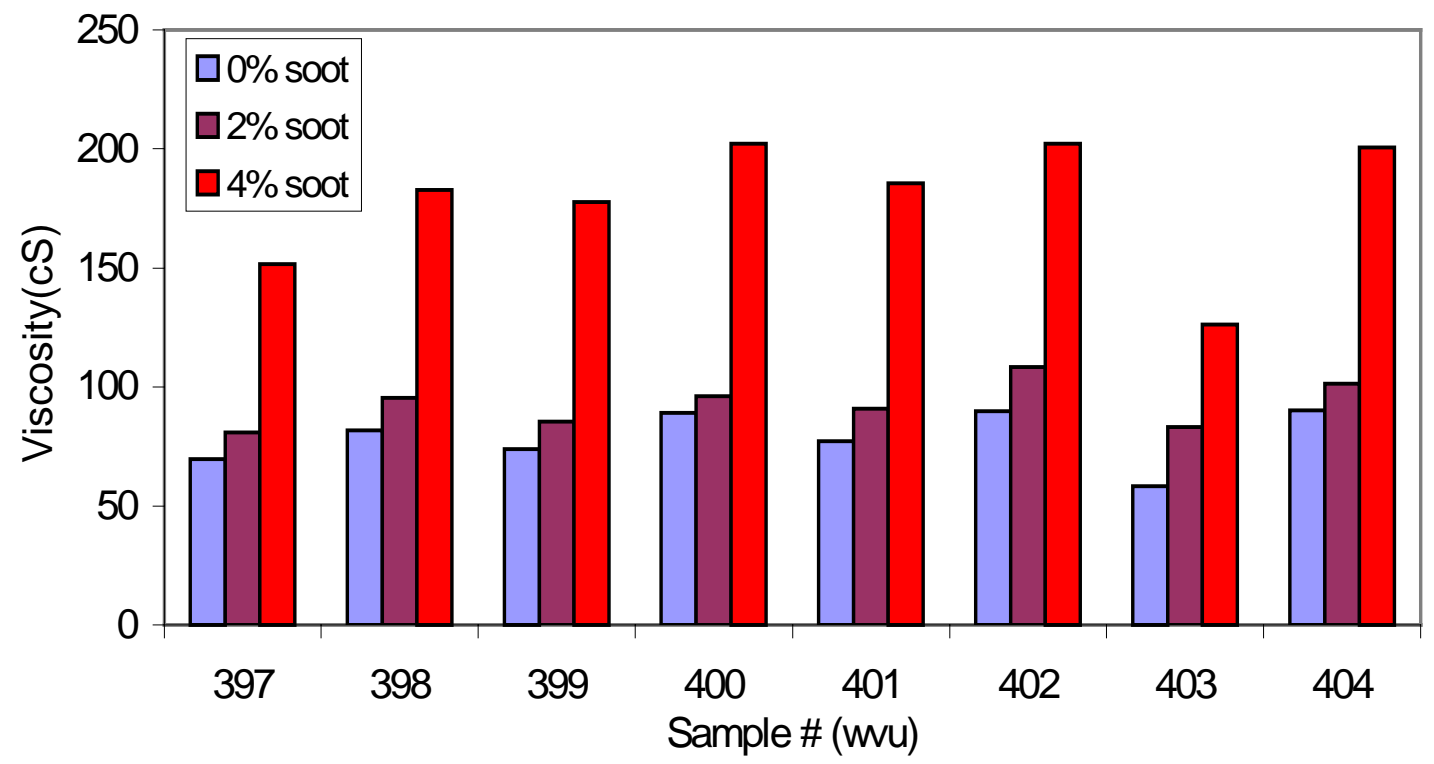

Figure 4.42 Variation of Viscosity (cS) with soot at $40^{\circ} \mathrm{C}$ 


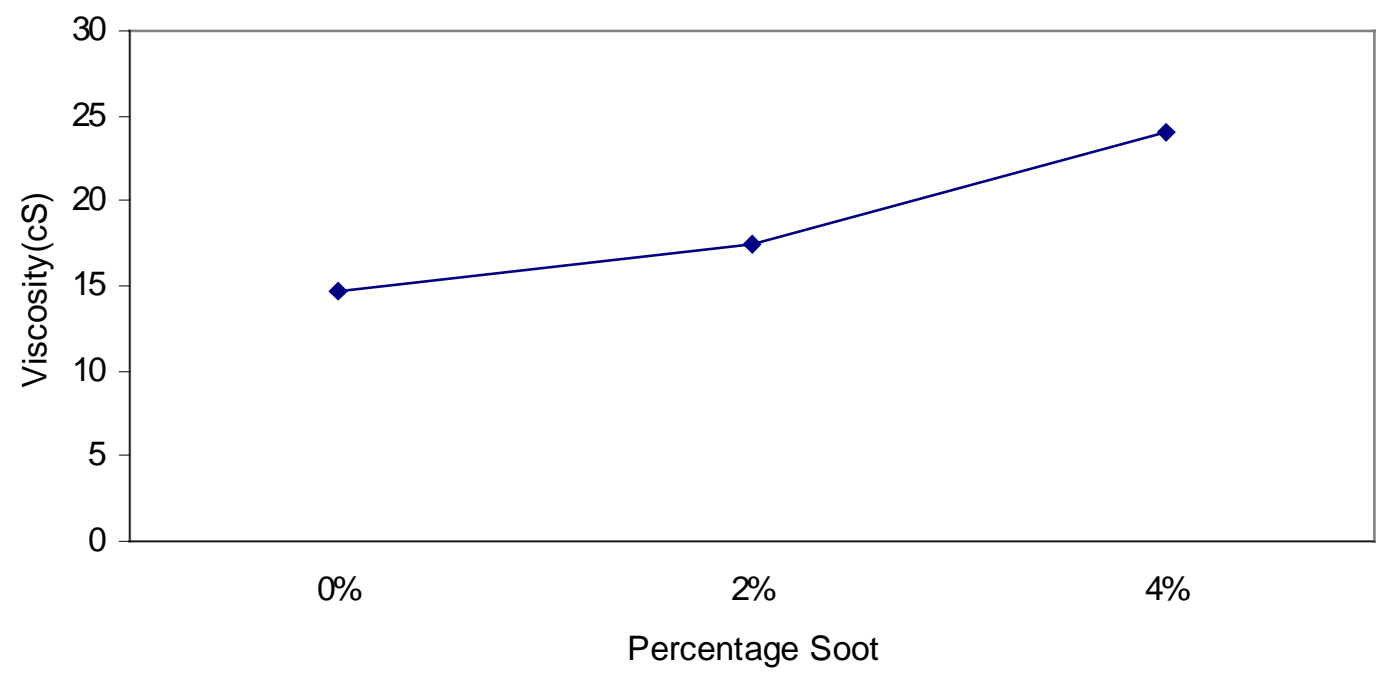

Figure 4.43 Variation of Viscosity with soot at $90^{\circ} \mathrm{C}$ for sample \# WVU397

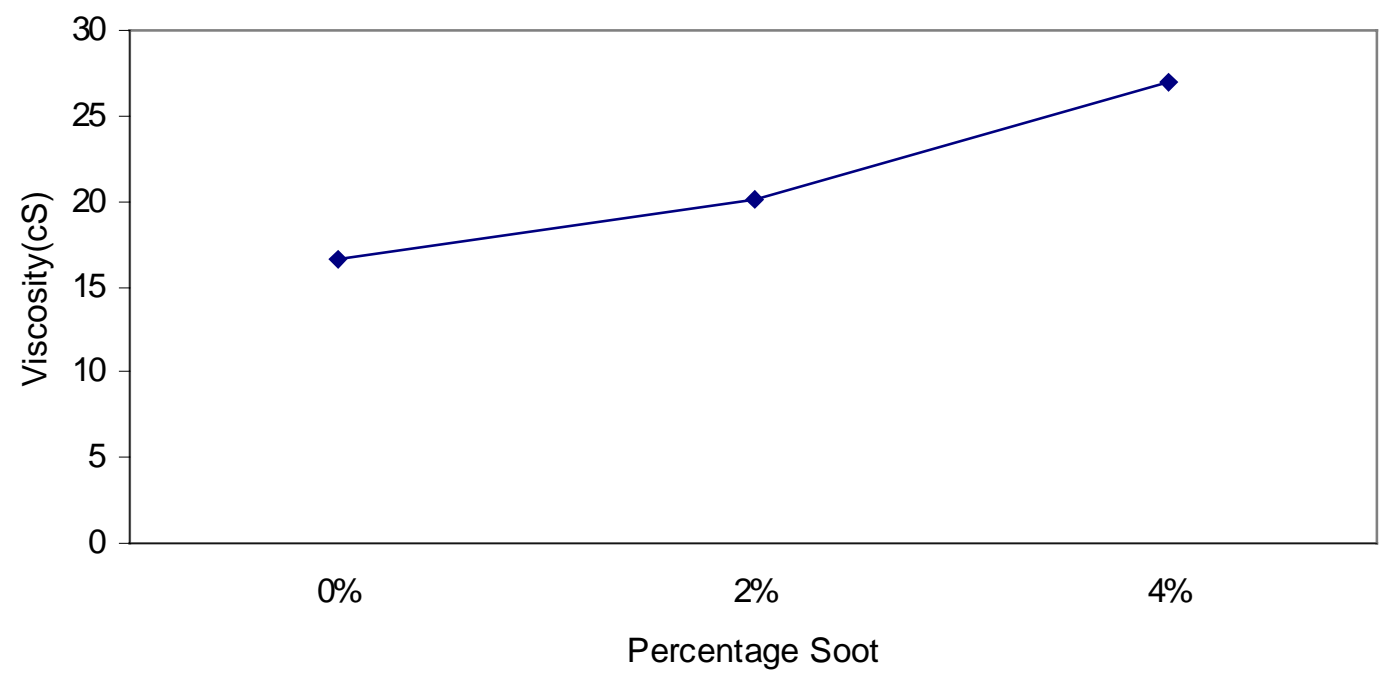

Figure 4.44 Variation of Viscosity with soot at $90^{\circ} \mathrm{C}$ for sample \# WVU398 


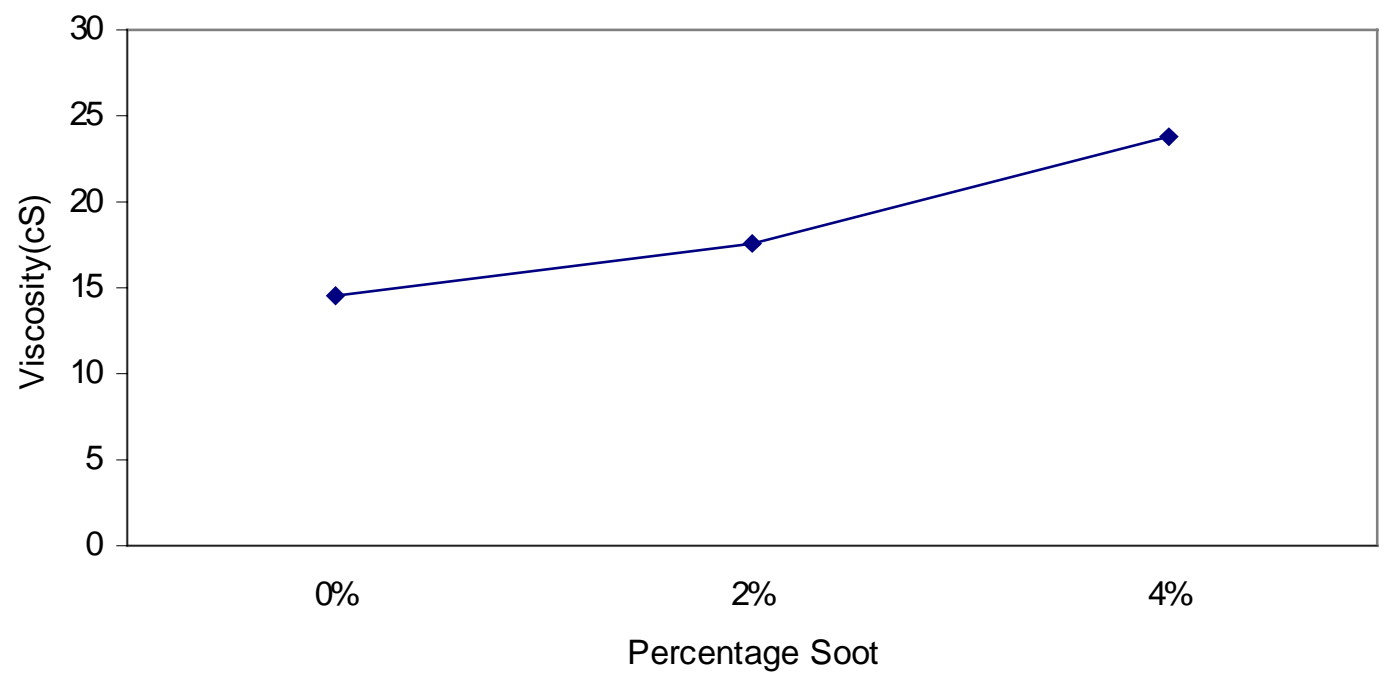

Figure 4.45 Variation of Viscosity with soot at $90^{\circ} \mathrm{C}$ for sample \# WVU399

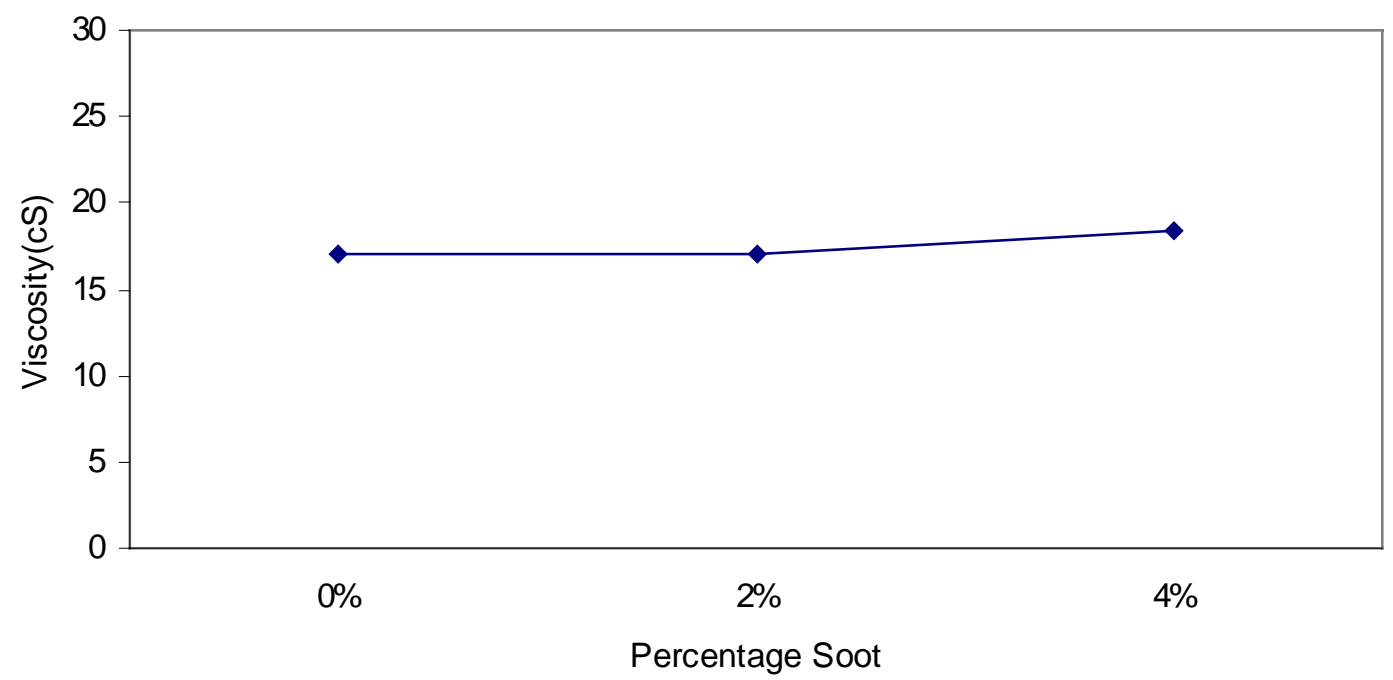

Figure 4.46 Variation of Viscosity with soot at $90^{\circ} \mathrm{C}$ for sample \# WVU400 


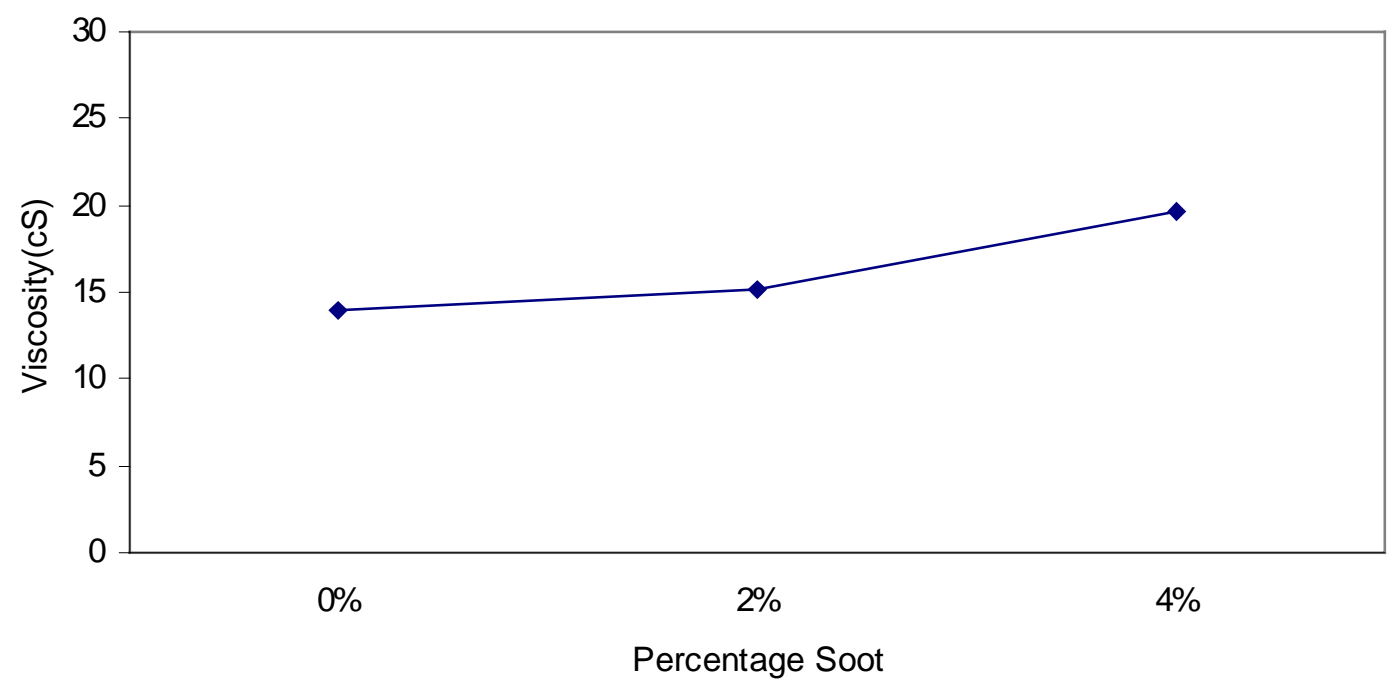

Figure 4.47 Variation of Viscosity with soot at $90^{\circ} \mathrm{C}$ for sample \# WVU401

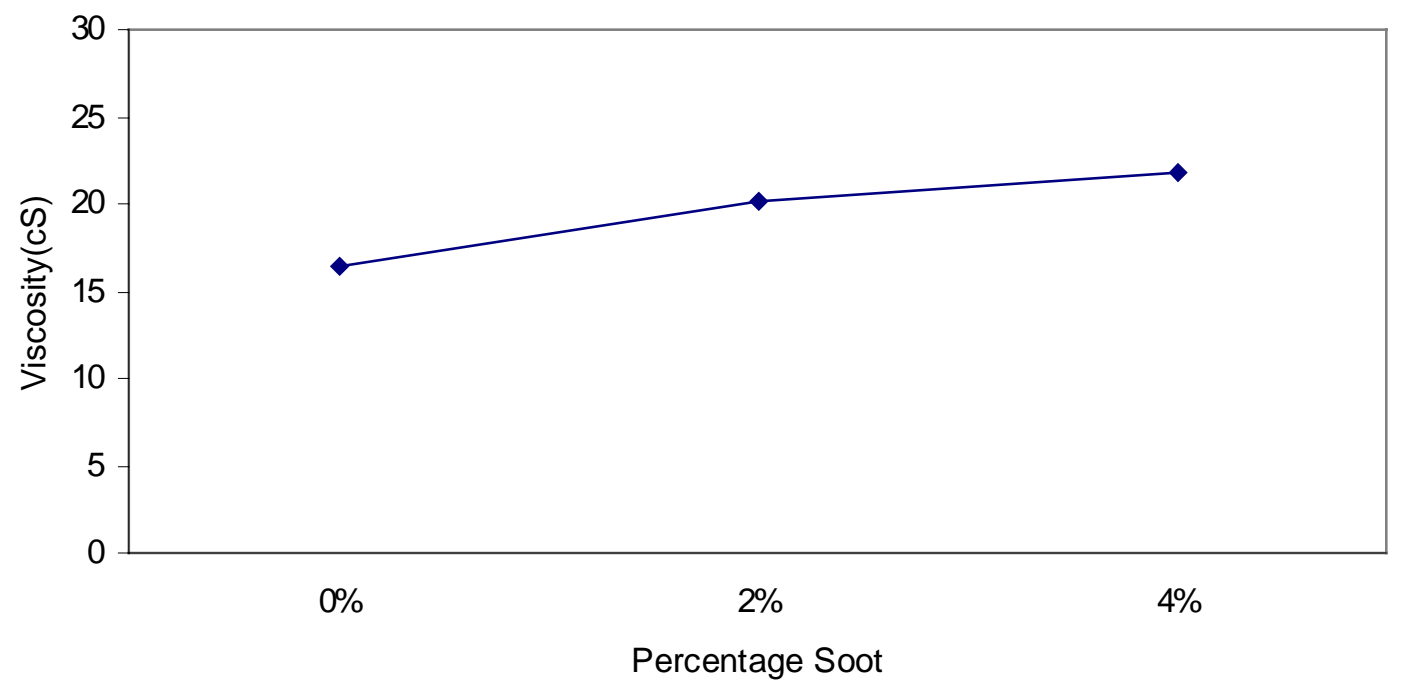

Figure 4.48 Variation of Viscosity with soot at $90^{\circ} \mathrm{C}$ for sample \# WVU402 


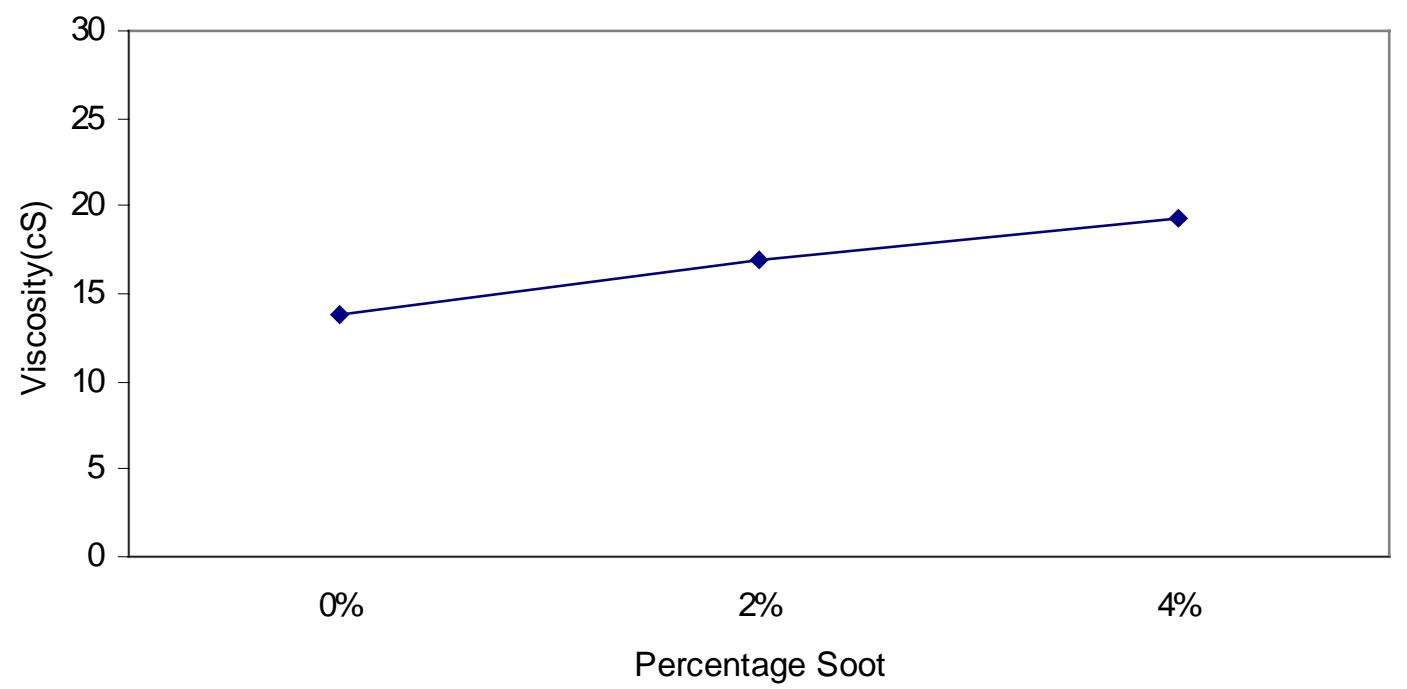

Figure 4.49 Variation of Viscosity with soot at $90^{\circ} \mathrm{C}$ for sample \# WVU403

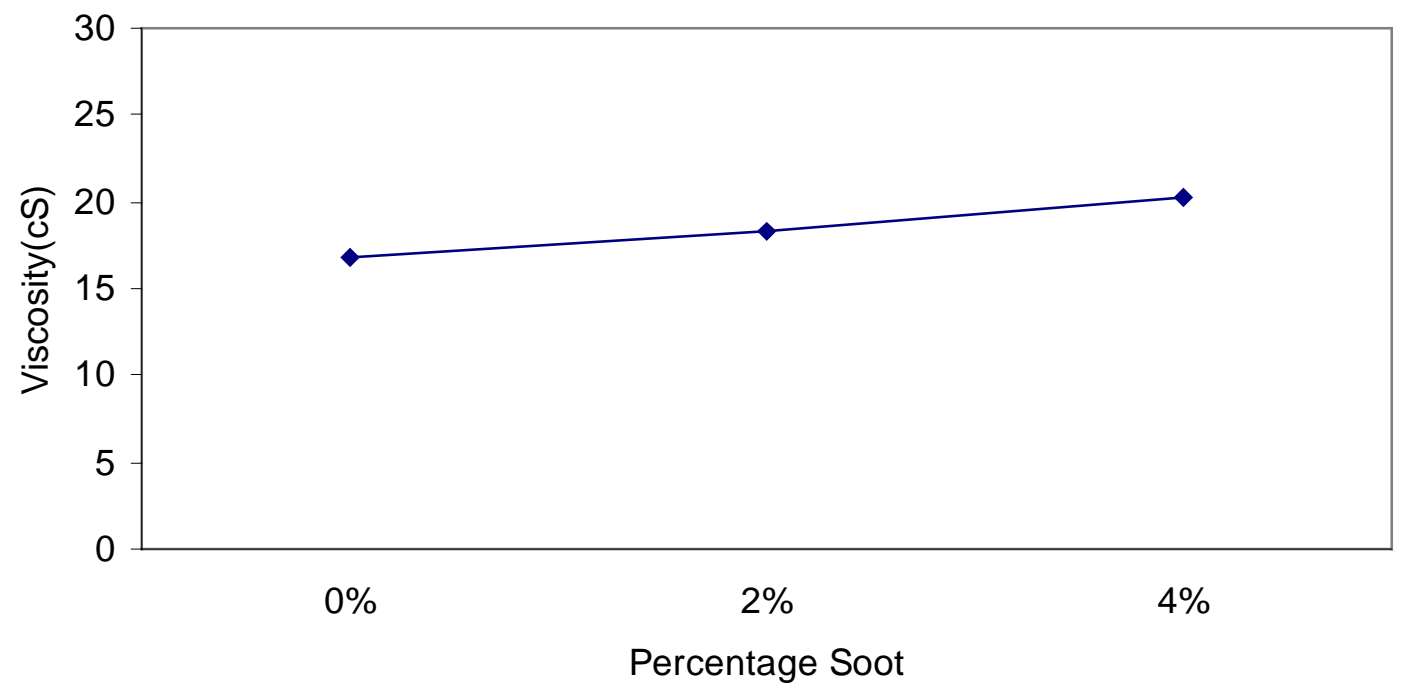

Figure 4.50 Variation of Viscosity with soot at $90^{\circ} \mathrm{C}$ for sample \# WVU404 


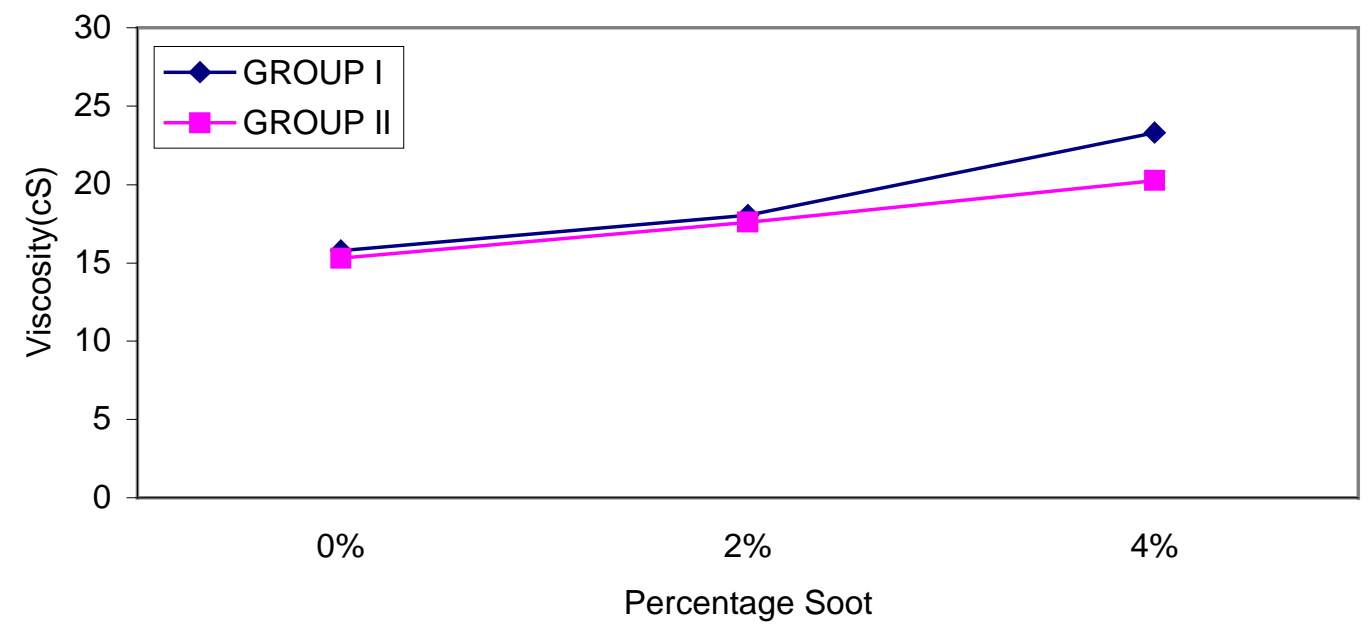

Figure 4.51 Effect of Base Stock on Viscosity(cS) at $90^{\circ} \mathrm{C}$

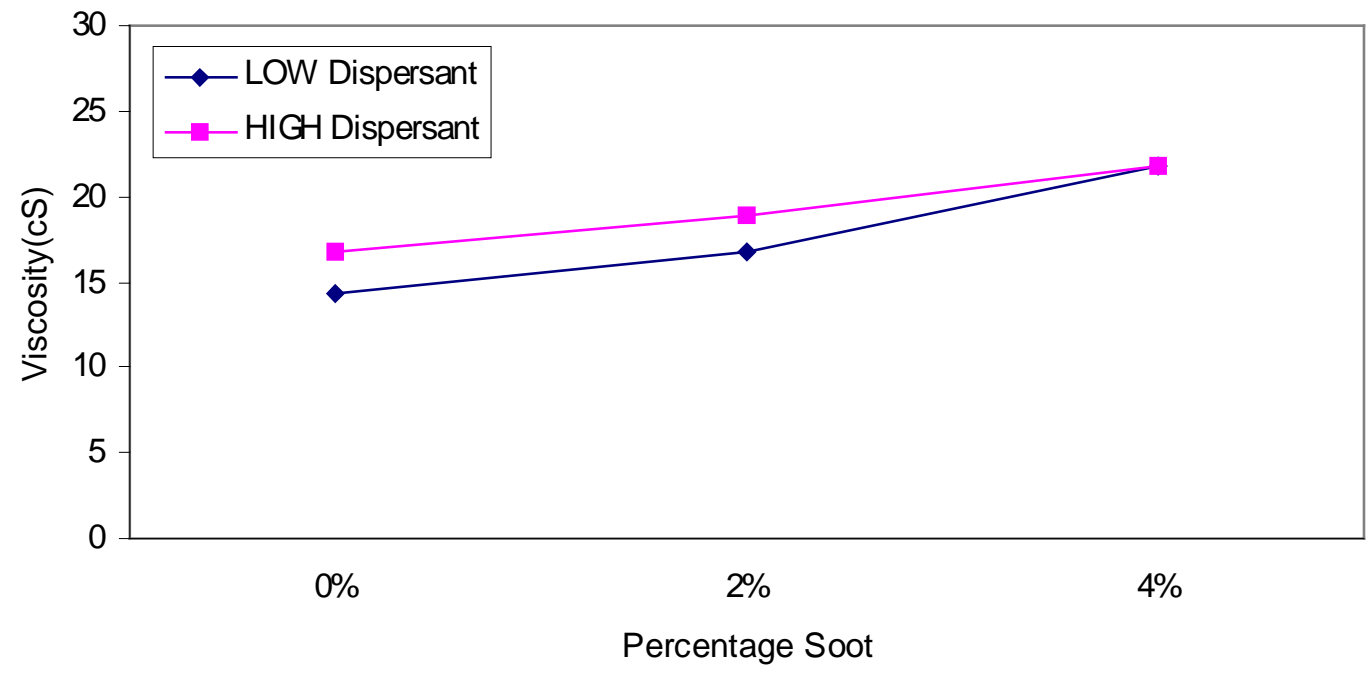

Figure 4.52 Effect of Dispersant on Viscosity $(\mathrm{cS})$ at $90^{\circ} \mathrm{C}$ 


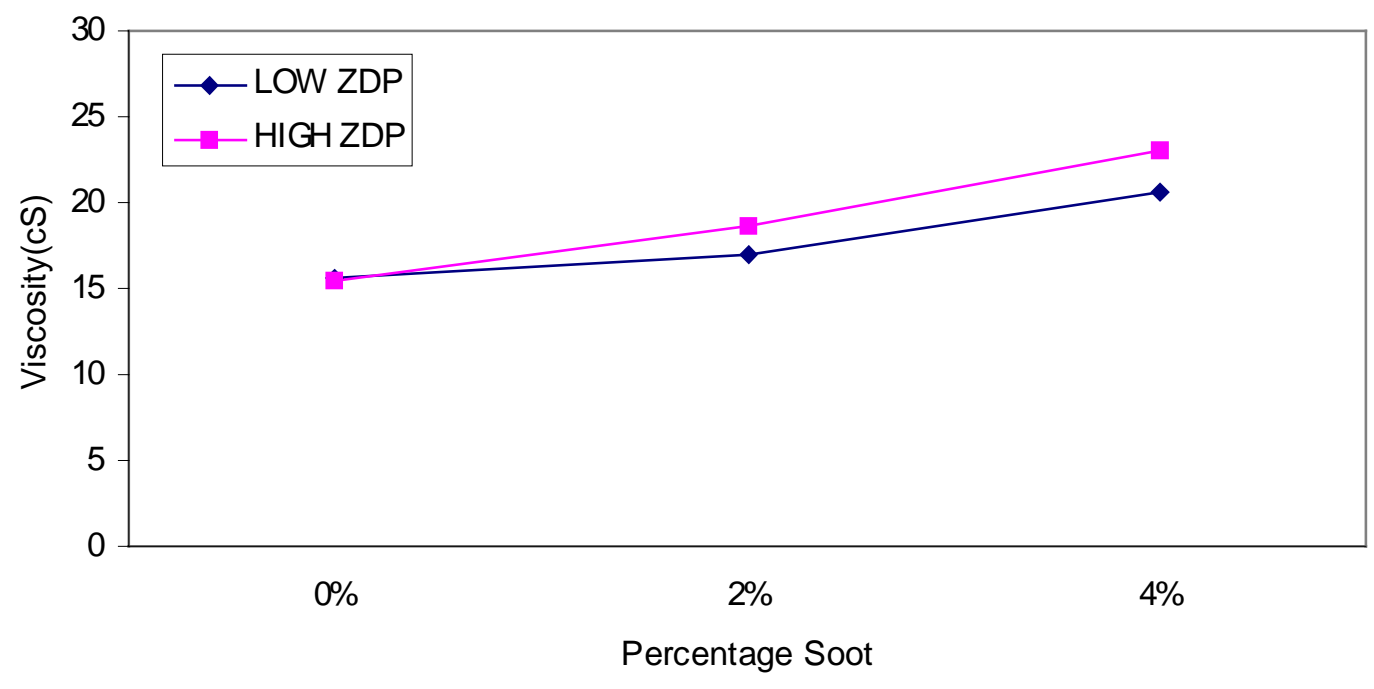

Figure 4.53 Effect of ZDP on Viscosity $(\mathrm{cS})$ at $90^{\circ} \mathrm{C}$

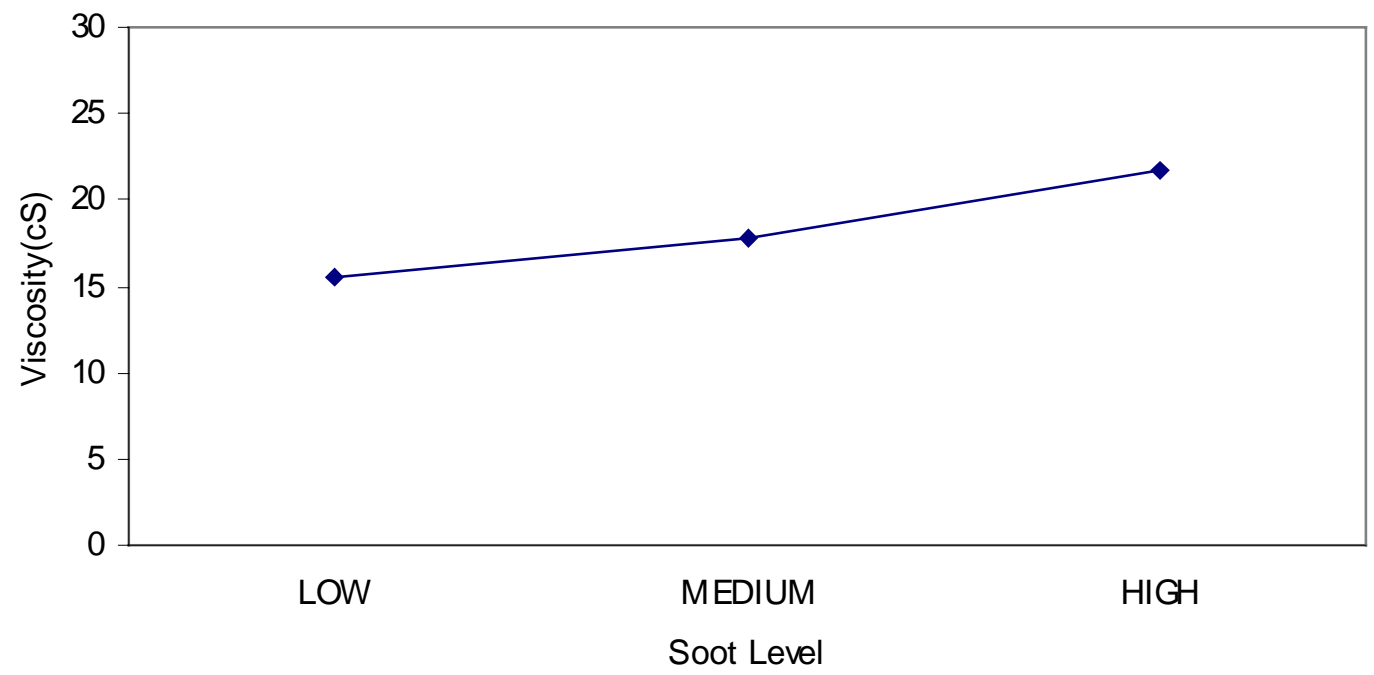

Figure 4.54 Effect of Soot Level on Viscosity $(\mathrm{cS})$ at $90^{\circ} \mathrm{C}$ 


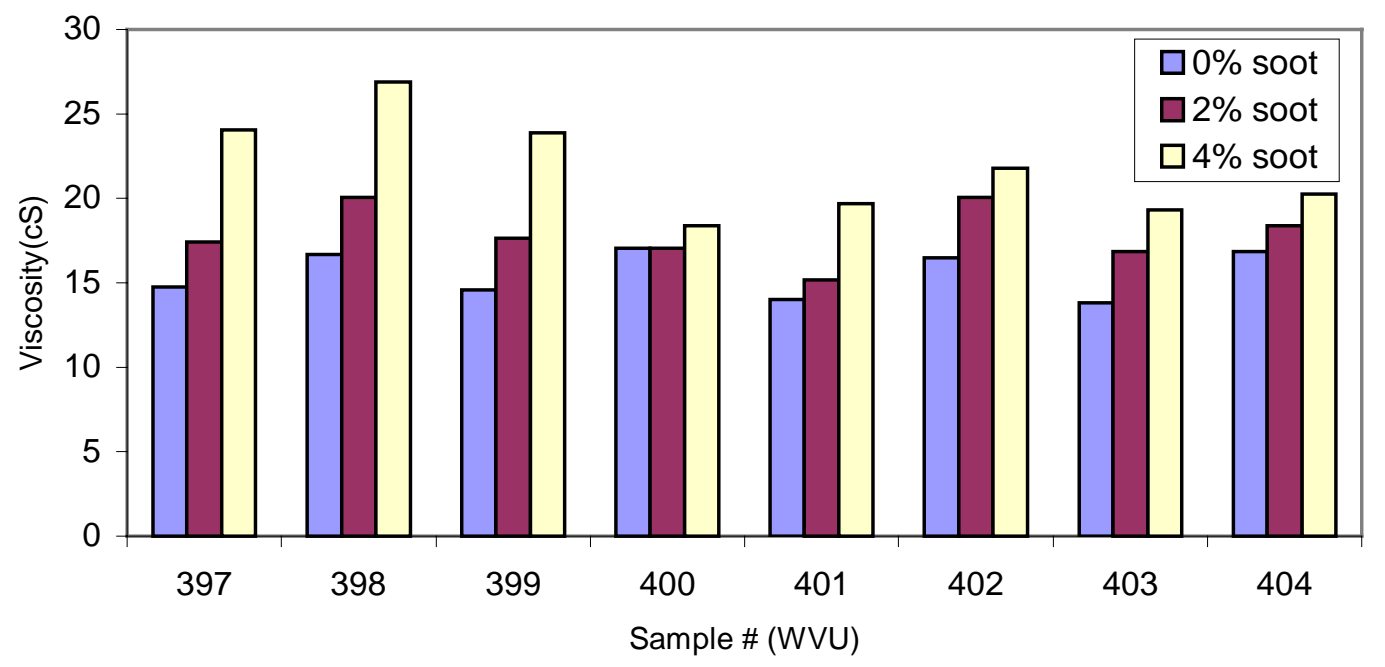

Figure 4.55 Variation of Viscosity $(\mathrm{cS})$ with Soot at $90^{\circ} \mathrm{C}$ 


\section{CHAPTER 5}

\section{CONCLUSIONS AND RECOMMENDATIONS}

A Three-Body Wear testing machine was designed and developed to simulate and estimate the extent of wear. A second set of experiments were performed on the Brookfield viscometer to study the viscosity characteristics of the oil samples at $40^{\circ} \mathrm{C}$ and $90^{\circ} \mathrm{C}$. A third set of experiments were carried out on the milling machine to qualitatively analyze the effect of soot contaminated oils on wear. The test data obtained from the experiments were analyzed using a Statistical Analysis System to determine the significance of variables on wear and also on viscosity. The conclusions and recommendations from the analysis are as follows.

The analysis indicated that wear increased nonlinearly as the amount of soot increased. Cumulative wear was more for samples with soot contamination than without soot contamination. This showed the detrimental effect of soot on the oil samples wear performance. The analysis also indicated that wear decreased when group1 base stock was used instead of group 2 base stock. Oil samples with low dispersant and high ZDP performed better than samples having high dispersant and low ZDP. The reason behind this could be the fact that dispersants generally increase the viscosity of the oil sample, which results in increased wear. The other reason could be that ZDP has an antiwear property that reduces friction and wear. The Statistical Analysis System indicated that base stock, dispersant, ZDP and soot were significant and they affected the wear performance of the oil samples.

Viscosity of the oil samples increased with increase in soot at $40^{\circ} \mathrm{C}$ and $90^{\circ} \mathrm{C}$. The analysis indicated a nonlinear behavior for viscosity as the amount of soot increased. The 
effect of base stock and ZDP on the viscosity of the oil samples at $40^{\circ} \mathrm{C}$ was negligible but the oil samples showed increased viscosity at high levels of dispersant and soot. Viscosity values were low for samples having a low level of dispersant. Viscosity values were low when group2 base stock was used with low dispersant and high ZDP at $40^{\circ} \mathrm{C}$.

The effect of base stock and ZDP on the viscosity of the oil samples at $90^{\circ} \mathrm{C}$ was negligible. Dispersant and soot were significant and affected the viscosity of the samples. Viscosity of the oil samples with a higher level of dispersant was more than samples having a lower level of dispersant. At $90^{\circ} \mathrm{C}$, group 1 base stock oil samples indicated an increase in viscosity at higher soot levels as compared to the group 2 base stock oil samples.

Comparing the viscosity test results at $40^{\circ} \mathrm{C}$ and $90^{\circ} \mathrm{C}$, a conclusion maybe drawn that the effect of base stock and ZDP were negligible. The presence of high dispersant and soot increased the viscosity values of the oil samples at both temperatures. Temperature plays an important role on the viscosity of the oil samples. Viscosity values were low at $90^{\circ} \mathrm{C}$ as compared to viscosity of the oil samples at $40^{\circ} \mathrm{C}$.

The wear scar diameters and the wear ratios from the ball-on-flat-disk tests confirmed with results obtained the three-body wear-testing machine. At higher levels of soot, the performance of the oil samples deteriorated. 


\section{RECOMMENDATIONS}

There is a great deal of work, which can be done in this area. To improve the oil formulations for modern EGR diesel engines, oil blends should be tested on other wear testing devices and on actual diesel engines. The oil additives added should be tested at various levels of concentrations. Oil additives such as friction modifiers, viscosity modifiers and other important additives should also be studied for better oil blends for EGR equipped diesel engines. 


\section{REFERENCES}

1. Akiyama, K., Masunaga, K., Kado, K. and Yoshioka, T., 1987, "Cylinder Wear Mechanism in an EGR-Equipped Diesel Engine and Wear Protection by the Engine Oil", SAE 872158.

2. Bardasz, E.A., Cowling, S.V., Ebeling, V.L., George, H.F., Graf, M.M., Kornbrekke,R.E. and Ripple, D.E., 1995, "Understanding Soot Mediated Oil Thickening Through Designed Experimentation-Part 1: Mack EM6-287, GM 6.2L", SAE 952527.

3. Bardasz, E.A., Carrick, V.A., Ebeling, V.L., George, H.F., Graf, M.M., Kornbrekke,R.E. and Pocinki, S.B., 1996, "Understanding Soot Mediated Oil Thickening Through Designed Experimentation-Part 2:, GM 6.5L”, SAE 952527.

4. Bardasz, E.A., Ebeling, V.L., Carrick, V.A., George, H.F., Graf, M.M., Kornbrekke, R.E. and Ripple, D.E., 1995, "Understanding Soot Mediated Oil ThickeningThrough Designed Experimentation-Part 4: Mack T-8 Test, SAE 971693.

5. Bardasz, E.A., Ebeling, V.L., Carrick, V.A., George, H.F., Graf, M.M., Kornbrekke, R.E. and Ripple, D.E., 1995, "Understanding Soot Mediated Oil Thickening Through Designed Experimentation-Part 5: Knowledge enhancement in the GM 6.5L, SAE 972952.

6. Benzing, R., Goldblatt, I., Hopkins, V., Jamison, W., Mecklenburg, K. and Peterson, M. 1976, "FRICTION AND WEAR DEVICES", American Society of Lubrication Engineers.

7. Berbeizer, I., Martin, J. and Kapsa, Ph., 1986, " The Role of Carbon in Lubricated Mild Wear", CNRS, France, June 1986.

8. Brookfield Viscometer Manual, 1996, Brookfield Engineering Laboratories, Inc.

9. Brown, E., “ FRICTION AND WEAR TESTING WITH THE MODERN FOURBALL APPARATUS”, Wear, Volume 17, pages 381-388, 1971.

10. Cadman, W. and Johnson, J., 1986 "The Study of the Effect of Exhaust Gas Recirculation on Engine Wear in a Heavy-Duty Diesel Engine Using Analytical Ferrography", SAE 860378.

11. Corso S. and Adamo R., 1984, "The Effect of Diesel Soot on Reactivity of Oil Additives and Valve Train Materials", SAE 841369.

12. Dam, W.V., Willis, W.W., and Cooper, M.W, 1999, "The Impact Of Additive Chemistry and Lubricant Rheology on Wear in Heavy Duty Diesel Engines", SAE 1999-01-3575. 
13. Gabriel, B., 1985, "SEM: A USER'S MANUAL FOR MATERIALS SCIENCE", American Society for Metals, Metals Park, Ohio.

14. Gautam, M., Durbha, M., Chitoor, K., Jaraiedi, M., Mariwalla, N and Ripple, D, 1998, " Contribution of Soot Contaminated Oils to Wear", SAE 981406.

15. Gautam, M., Chitoor, K., Balla, S and Keane, M, 1999, "Contribution of Soot Contaminated Oils to Wear-Part II", SAE 1999-01-1519.

16. Gergel, W., "Lubricant Additive Chemistry", 1992, Lubrizol Petroleum Additive Company.

17. Herzog, P., Bugler, L., Winklhofer, E., Zelenka, P. and Cartellieri W., 1992, " $\mathrm{NO}_{\mathrm{x}}$ Reduction Strategies for DI Diesel Engines", SAE 920470.

18. James, R., 1991, "Design and Development of a New Three-Body Wear Testing Machine", M.S. Thesis, West Virginia University, Morgantown, WV.

19. Kim, C., Passut, C. and Zang, D., 1992, "Relationships Among Oil Composition Combustion-Generated Soot, and Diesel Engine Valve Train Wear", SAE 922199.

20. Kuo, C.C., Passut, C.A., Tze-Chi Jao., Csontos, A.A and Howe, J.M, 1998, "Wear Mechanism In Cummins M-11 High Soot Diesel test Engines", SAE 981372.

21. Mason, R.L., Gunst, R. and Hess, J., 1989, "STATISTICAL DESIGN AND ANALYSIS OF EXPERIMENTS", John Wiley \& Sons, New York.

22. Moore, D.F., 1975, "PRINCIPLES AND APPLICATIONS OF TRIBOLOGY", Pergamon Press, New York.

23. Murali, D., 1997, "Effect of Diesel Soot Contaminated Oil on Engine WearInvestigation of Novel Oil Formulations", MS Thesis, West Virginia University, Morgantown, WV.

24. Nagai I., Endo, H., Nakamura H. and Yano, H., 1983, "Soot and Valve Train Wear in Passenger Car Diesel Engines", SAE 831757.

25. Neale M., 1973, “TRIBOLOGY HANDBOOK”, Butterworths, London.

26. Needelman, W. and Madhavan, P., 1988, "Review of Lubricant Contamination and Diesel Engine Wear", SAE 881827.

27. Rounds, F.G., 1977, “Carbon: Cause of Diesel Engine Wear?”, SAE 770829. 
28. Rounds, F.G., 1981, "Soots from Used Diesel Engine Oils-Their Effects on Wear as Measured in 4-Ball Wear Tests", SAE 810499.

29. Ryan III, T.W., Owens, Ed., NaeGeli, D., Doglio, J., Blyth, G., Dam, W.V., Damin, B., Olikara, C and Villforth, F, 1999, "Effects of Exhaust Gas Recirculation on the Degradation Rates of Lubricating Oil in a Heavy-Duty Diesel Engine", SAE 1999-013574 .

30. Ryason, P.R., Chan, I. and Gilmore, J., 1990, “ Polishing Wear by Soot”, Wear, Volume 137, pages 15-24, 1990.

31. Ryason P.R., Hillyer, M.J. and Hansen, T.P., 1994, "Infrared Absorptivities of Several Diesel Engine Soots; Application to the Analysis of Soot in Used Engine Oils", SAE 942030.

32. Sato, H., Tokuoka, N., Yamamoto, H and Sasaki, M, 1999, "Study on Wear Mechanism By Soot Contaminated In Engine Oil", SAE 1999-01-3573.

33. Selby, K, 1998, "Rheology of Soot Thickened Diesel Engine Oils", SAE 981369.

34. Wedlock, D.J., Shuff, P., Edwards, M.D., Jia, X., and Williams, R.A, 1999, "Experimental and Simulation Approaches to Understantding Soot Aggregation", SAE 1999-01-1516.

35. Wilson, L., 1996, "Guide for Operating the Hitachi SEM", Department of Mechanical and Aerospace Engineering, West Virginia University, Morgantown, WV.

36. Well-Brookfield Viscometer Operating Instructions-I, 1972, Brookfield Engineering Laboratories, Inc., Massachusetts, USA. 


\section{APPENDICES}




\section{APPENDIX A}

\section{PROCEDURE FOR PREPARING A STABLE SOOT SUSPENSION IN OIL BY CHEMICAL TREATMENT}




\section{Procedure for preparing a stable soot suspension in oil by chemical treatment.}

The primary purpose of this procedure is to artificially prepare a stable soot suspension in oil. Soot settles at the bottom of the oil if left for a period of time and therefore it becomes necessary to prepare a stable soot suspension in oil.

\section{Procedure:}

1. Loosen the cap of the soot + oil sample container.

2. Immerse the sample in a $200^{\circ} \mathrm{F}\left(93^{\circ} \mathrm{C}\right)$ water bath up to just beneath the threaded part at the top of the container for 15 to 20 seconds.

3. Remove the container and tighten the cap.

4. Shake vigorously for at least 30 seconds (time the period of shaking). It may be necessary to hold the container in a cloth, or wear gloves if it is uncomfortably hot at this stage.

5. Invert the container.

6. Again, shake the container vigorously for at least 30 seconds (time the shake period).

7. Invert the container to return it to an upright position.

8. Carefully remove the cap.

9. With a small, clean, dry stainless steel spatula, stir the sample, inserting the spatula all the way to the bottom of the container. Check for the presence of a thickened, viscous layer at the bottom of the container using the spatula. If such a layer appears to be present, as judged by the appearance of the material on the tip of the spatula, re-insert the spatula and stir vigorously until the bottom sediment is completely mixed with the 
remainder of the sample. When the spatula is withdrawn, the used oil clinging to it should have a uniform appearance and drain uniformly.

10. Recap the container loosely.

11. Again, immerse the container in the $200^{\circ} \mathrm{F}\left(93^{\circ} \mathrm{C}\right)$ water bath up to the threaded part for 15 to 20 seconds.

12. Remove the container.

13. Tighten the cap.

14. Shake vigorously for 15 seconds.

15 . Rotate the container $180^{\circ}$ and again shake vigorously for 15 seconds.

16. Invert the container.

17. Repeat steps 14 and 15.

No rigorous tests have been made, but the above procedure should provide a stable soot suspension for about one or two hours. If the sample is not utilized within that time, the above procedure should be carried out again. 


\section{APPENDIX B}

\section{QBASIC SUBROUTINES USED FOR THE INFRARED SENSOR}

CIRCUIT IN THE THREE-BODY WEAR MACHINE. 


\section{QBASIC SUBROUTINES}

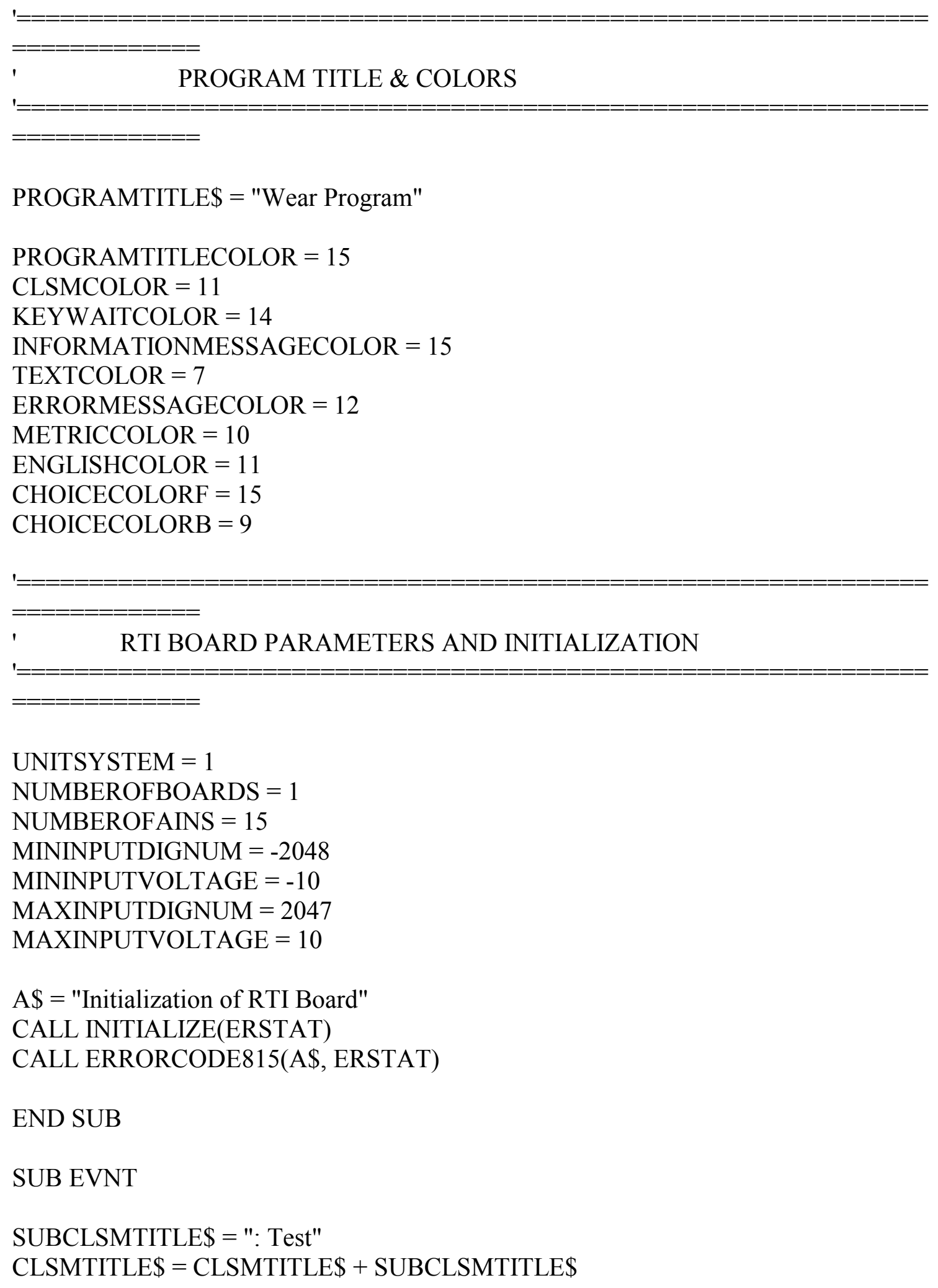


CLSM 80

$\mathrm{LCHAN}=1$

$\mathrm{BOARD}=1$

$\mathrm{PCHAN}=0$

$\mathrm{EDGE}=1$ 'COUNT FALLING EDGES

CALL CLCHAN(LCHAN, ERSTAT)

CALL ERRORCODE815("CLCHAN", ERSTAT)

CALL EVENT815(LCHAN, BOARD, PCHAN, EDGE, ERSTAT)

CALL ERRORCODE815("EVENT815", ERSTAT)

CALL EVINIT(LCHAN, ERSTAT)

CALL ERRORCODE815("EVINIT", ERSTAT)

CALL EVSTART(LCHAN, ERSTAT)

CALL ERRORCODE815("EVSTART", ERSTAT)

$\mathrm{DO}$

NCOUNTS\& = EVREAD $($ LCHAN, ERSTAT $)$

CALL ERRORCODE815("EVREAD", ERSTAT)

LOCATE 12

PRINT "NCOUNTS = "; NCOUNTS\&

LOOP WHILE INKEY\$ = "'"

CALL EVSTOP(LCHAN, ERSTAT)

CALL ERRORCODE815("EVSTOP", ERSTAT)

CLSM 80: LOCATE 12: PRINT "EVENT COUNTING STOPPED": DO: LOOP WHILE INKEY\$ = "'"

CLSM 80

CALL EVSTART(LCHAN, ERSTAT)

CALL ERRORCODE815("EVSTART", ERSTAT)

DO

NCOUNTS\& $=$ EVREAD $($ LCHAN, ERSTAT $)$

CALL ERRORCODE815("EVREAD", ERSTAT)

LOCATE 12 
PRINT "NCOUNTS = "; NCOUNTS\&

LOOP WHILE INKEY\$ = "'

CLSMTITLE\$ = LEFT\$(CLSMTITLE\$, LEN(CLSMTITLE\$) -

LEN(SUBCLSMTITLE\$))

END SUB

SUB TEST

SUBCLSMTITLE $\$=$ ": Test"

CLSMTITLE $\$=$ CLSMTITLE $\$$ SUBCLSMTITLE $\$$

CLSM 80

LCHAN $=1$

BOARD $=1$

PCHAN $=1$

RANGE $=10000$

GATE $=100$

CALL CLCHAN(LCHAN, ERSTAT)

CALL ERRORCODE815("CLCHAN", ERSTAT)

CALL FIN815(LCHAN, BOARD, PCHAN, RANGE, GATE, ERSTAT)

CALL ERRORCODE815("FIN815", ERSTAT)

CALL FINSTART(LCHAN, ERSTAT)

CALL ERRORCODE815("FINSTART", ERSTAT)

DO

NCOUNTS $\&=$ FINREAD(LCHAN, ERSTAT $)$

CALL ERRORCODE815("FINREAD", ERSTAT)

IF NOT $($ ERSTAT $=128)$ THEN

FREQ $\#=$ CDBL(NCOUNTS\& $) /($ CDBL $($ RANGE $) *(C D B L(G A T E) /$ $1000000 \#))$

CALL FINSTART(LCHAN, ERSTAT)

CALL ERRORCODE815("FINSTART", ERSTAT)

END IF

LOCATE 12

PRINT "FREQUENCY = "; FREQ\#;" 
LOOP WHILE INKEY\$ = "'

CALL FINSTOP(LCHAN, ERSTAT)

CALL ERRORCODE815("FINSTOP", ERSTAT)

CLSMTITLE\$ = LEFT\$(CLSMTITLE\$, LEN(CLSMTITLE\$) -

LEN(SUBCLSMTITLE\$))

END SUB

SUB WEARTEST

SUBCLSMTITLE $\$=$ ": Perform Wear Test"

CLSMTITLE $\$=$ CLSMTITLE $\$$ SUBCLSMTITLE $\$$

CLSM 80

$\mathrm{L}=7$

DO

LOCATE L

INPUT "Enter radius (inches, $<$ ENTER $>$ to abort) $==>$ ", A\$

IF A $\$=$ "' OR UCASE $\$(A \$)=$ "E" THEN

CLSMTITLE $\$=$ LEFT (CLSMTITLE\$, LEN(CLSMTITLE\$) LEN(SUBCLSMTITLE\$))

EXIT SUB

ELSEIF VAL(A $\$)<=0$ THEN

INVALIDINPUT L, "Enter a number greater than zero dumbass!"

ELSE

RADIUS\# $=$ CDBL $(\operatorname{VAL}(A \$))$

EXIT DO

END IF

LOOP

$\mathrm{L}=\mathrm{L}+2$ 
DO

LOCATE L

INPUT "Enter the test distance (inches, $<$ ENTER $>$ to abort) $==>$ ", A $\$$

IF A $\$=$ "' OR UCASE $\$(A \$)=$ "E" THEN

CLSMTITLE\$ = LEFT\$(CLSMTITLE\$, LEN(CLSMTITLE\$) -

LEN(SUBCLSMTITLE\$))

EXIT SUB

ELSEIF VAL(A $\$)<=0$ THEN

INVALIDINPUT L, "Enter a number greater than zero dumbass!"

ELSE

DISTANCE\# = CDBL(VAL(A $\$))$

EXIT DO

END IF

LOOP

$\mathrm{L}=\mathrm{L}+2$

DO

LOCATE L

INPUT "Enter desired test speed $($ RPM,$<$ ENTER $>$ to abort $)==>$ ", A $\$$

IF A $\$=$ "' OR UCASE\$(A $\$)=$ "E" THEN

CLSMTITLE\$ = LEFT\$(CLSMTITLE\$, LEN(CLSMTITLE\$) LEN(SUBCLSMTITLE\$))

EXIT SUB

ELSEIF VAL(A\$) $<=0$ THEN

INVALIDINPUT L, "Enter a number greater than zero dumbass!"

ELSE

TESTRPM! = CDBL $(\operatorname{VAL}(\mathrm{A} \$))$

EXIT DO 
END IF

LOOP

$\mathrm{BOARD}=1$

'SET UP COUNTER PARAMETERS

$==========$
$=========$

COUNTERLCHAN $=1$

COUNTERPCHAN $=0$

COUNTEREDGE $=1$ 'COUNT FALLING EDGES

CALL CLCHAN(COUNTERLCHAN, ERSTAT)

CALL ERRORCODE815("CLCHAN", ERSTAT)

CALL EVENT815(COUNTERLCHAN, BOARD, COUNTERPCHAN, COUNTEREDGE, ERSTAT)

CALL ERRORCODE815("EVENT815", ERSTAT)

CALL EVINIT(COUNTERLCHAN, ERSTAT)

CALL ERRORCODE815("EVINIT", ERSTAT)

'SET UP FREQUENCY (RPM) PARAMETERS

FREQLCHAN $=2$

FREQPCHAN $=1$

FREQRANGE $=10000$

FREQGATE $=25$

CALL CLCHAN(FREQLCHAN, ERSTAT)

CALL ERRORCODE815("CLCHAN", ERSTAT)

CALL FIN815(FREQLCHAN, BOARD, FREQPCHAN, FREQRANGE, FREQGATE, ERSTAT)

CALL ERRORCODE815("FIN815", ERSTAT) 


\section{$==========$
$=========$}

$\mathrm{L}=\mathrm{L}+2$

LOCATE L

COLOR INFORMATIONMESSAGECOLOR

PRINT "Press any key to begin test."

KEYWAIT L +2

'DRAW RPM DIAL

\footnotetext{
$===========$
$==========$

SCREEN 12

WINDOW $(0,0)-(639,479)$

CLS

$\mathrm{XCENTER} 1=157$

YCENTER $1=322$

RADIUS1 $=157$

MODE $1=1$

MAXIMUMREADING1! = TESTRPM! + 50!

MINIMUMREADING1 $!=0$ !

MAJORTICK1! = MAXIMUMREADING1! / 10!

MINORTICK1! = MAXIMUMREADING1! / 20!

LRZS $1 !=0$ !

LRZE1! = TESTRPM! - 20!

LYZS1! = TESTRPM! - 20!

LYZE1! = TESTRPM! - 10!

GZS1! = TESTRPM! - 10!

GZE1! = TESTRPM! + 10!

UYZS1! = TESTRPM! + 10!

UYZE1! = TESTRPM! + 20!

URZS1! = TESTRPM! + 20!

URZE1! = MAXIMUMREADING1!
} 
GAGETITLE1\$ = "DISK SPEED"

GAGEUNITS1\$ = "RPM"

ACCURACY $1=0$

CALL DRAWROUNDGAGE(XCENTER1, YCENTER1, RADIUS1, MODE1, MAXIMUMREADING1!, MINIMUMREADING1!, MAJORTICK1!, MINORTICK1!, LRZS1!, LRZE1!, LYZS1!, LYZE1!, GZS1!, GZE1!, UYZS1!, UYZE1!, URZS1!, URZE1!, GAGETITLE1\$, GAGEUNITS1\$, ACCURACY1)

'DRAW DISTANCE DIAL

'===========

$\mathrm{XCENTER} 2=482$

YCENTER $2=322$

RADIUS2 $=157$

MODE2 $=1$

MINIMUMREADING2 $!=0$ !

MAXIMUMREADING $2 !=100 !$

MAJORTICK $2 !=10$ !

MINORTICK2! $=5$

LRZS2! $=0$ !

LRZE2 $!=0$ !

LYZS2 $!=0 !$

LYZE $2 !=0$ !

$\mathrm{GZS} 2 !=0$ !

GZE $2 !=85$ !

UYZS2 $!=85$ !

UYZE2! $=95$ !

URZS2 $!=95 !$

URZE2! $=100$ !

GAGETITLE2 $\$=$ "TRAVELED DISTANCE"

GAGEUNITS2 $\$=$ "PERCENT OF TOTAL"

ACCURACY2 $=0$ 
CALL DRAWROUNDGAGE(XCENTER2, YCENTER2, RADIUS2, MODE2, MAXIMUMREADING2!, MINIMUMREADING2!, MAJORTICK2!, MINORTICK2!, LRZS2!, LRZE2!, LYZS2!, LYZE2!, GZS2!, GZE2!, UYZS2!, UYZE2!, URZS2!, URZE2!, GAGETITLE2\$, GAGEUNITS2\$, ACCURACY2)

'READ AND DISPLAY TEST PARAMETERS

CALL EVSTART(COUNTERLCHAN, ERSTAT)

CALL ERRORCODE815("EVSTART", ERSTAT)

CALL FINSTART(FREQLCHAN, ERSTAT)

CALL ERRORCODE815("FINSTART", ERSTAT)

RPMNEWREADING! $=0$ !

$\mathrm{PI}=\operatorname{ATN}(1 \#) * 4 \#$

CENTER 80, "Press any key to end test", 22

DO

NCOUNTS $\&=$ EVREAD $($ COUNTERLCHAN, EERSTAT $)$

CALL ERRORCODE815("EVREAD", EERSTAT)

TRAVELDISTANCE! $=$ CSNG(CDBL(NCOUNTS\&) $* 2 \# *$ PI\# * RADIUS\#)

DISTANCERATIO! $=$ CSNG(CDBL(TRAVELDISTANCE!) $/$ DISTANCE\# * 100\#)

IF NOT (TRAVELDISTANCE! $=0$ !) THEN

DSCALE! = DISTANCERATIO! / TRAVELDISTANCE!

ELSE

DSCALE! $=1 !$

END IF

RPMCOUNTS\& $=$ FINREAD(FREQLCHAN, FERSTAT)

CALL ERRORCODE815("FINREAD", FERSTAT)

IF NOT $($ FERSTAT $=128)$ THEN

RPMNEWREADING! $=$ CSNG(CDBL $($ RPMCOUNTS\& $) /$

(CDBL(FREQRANGE) * CDBL(FREQGATE) / 1000000\#) $/ 36 ! * 60$ !

CALL FINSTART(FREQLCHAN, ERSTAT)

CALL ERRORCODE815("FINSTART", ERSTAT)

END IF 
CALL DRAWROUNDHAND(XCENTER1, YCENTER1, OLDREADING1!, RPMNEWREADING!, 0, 1!, MODE1, MAXIMUMREADING1!, MINIMUMREADING1!, LRZS1!, LRZE1!, LYZS1!, LYZE1!, GZS1!, GZE1!, UYZS1!, UYZE1!, URZS1!, URZE1!, RADIUS1, 1)

CALL DRAWROUNDHAND(XCENTER2, YCENTER2, OLDREADING2!, TRAVELDISTANCE!, 0, DSCALE!, MODE2, MAXIMUMREADING2!, MINIMUMREADING2!, LRZS2!, LRZE2!, LYZS2!, LYZE2!, GZS2!, GZE2!, UYZS2!, UYZE2!, URZS2!, URZE2!, RADIUS2, 1)

IF NOT (INKEY\$ = "') AND RPMNEWREADING! = 0! THEN EXIT DO

LOOP

CALL FINSTOP(FREQLCHAN, ERSTAT)

CALL EVSTOP(COUNTERLCHAN, ERSTAT)

CLSMTITLE\$ = LEFT\$(CLSMTITLE\$, LEN(CLSMTITLE\$) LEN(SUBCLSMTITLE\$))

SCREEN 0

END SUB 
APPENDIX C

GUIDELINES FOR OPERATING THE SCANNING ELECTRON MICROSCOPE 


\section{GUIDE FOR OPERATING THE SEM}

1. Press the air/evac button on the testing chamber to release the vacuum. Note: if the vent light is not on, the chamber will not vent and you must move the stage up or down to allow this light to come on.

2. Wait until the pressure gauge shows low vacuum and the red low vac light is on.

3. Pull the stage out slowly and change the sample as needed.

4. Push the stage back in carefully. Note: if the sample is thick or the specimen holder is tall be very careful when pushing the stage back in. You can damage the electron gun if your sample touches it. You may need to lower the stage before putting the stage back in it's proper position.

5. Estimate the height between your sample and the electron gun $(\mathrm{mm})$. This will come in useful later when you are trying to focus.

6. Push the air/evac button on the stage apparatus to begin pumping the unit down. Wait for both the bottom high vac and the top high vac lights to come on. (Approximately 7 minutes).

7. Carefully rotate the e-gun valve clockwise $90^{\circ}$ and pull it out gently and then rotate the valve $90^{\circ}$ counter-clockwise. At this point the red light labeled gate valve open should come on.

8. Now move over to the SEM operating keyboard and wait for the green "ready" light to come on. (Approximately 10-15 seconds).

9. Press the acc. on button to activate the SEM accelerating voltage.

10. Turn the filament knob clockwise one mark every minute until it is all the way on.

11. Turn the brightness and contrast knobs until the marks are vertically pointing away 
from you. This is just to begin, you may need to adjust these settings to suit your desired interests.

12. You are now ready to begin focusing the machine on your sample. Recall your estimation of how far your sample is away from the e-gun.

13. Press the call button on the keypad. You will now see a list of specifications regarding the SEM. You will notice that 0 is the acceleration voltage, if you wish to change this voltage you may do so by pressing 0 and then the desired voltage and then press enter to store the number. The second item 1 is the working distance, this is the distance at which the machine thinks the sample is as compared to the e-gun. Enter your approximation by pressing 1, your guess and then enter.

14. Adjust the focus knob until you can clearly see your specimen. Note, this does not always work so keep playing around with the working distance and focus knob until you achieve your goal.

15. To move up and down in magnification simply press up or down on the keyboard area marked mag.

16. To move your sample left or right or in and out use the $\mathrm{x}$ and $\mathrm{y}$ cranks on the sample stage.

17. To move your specimen up and down use the knob on top of the stage platform marked z. You must use extreme caution when doing this in order to avoid crashing your sample into the e-gun. It is not necessary to have your sample closer than $10 \mathrm{~mm}$ unless you are doing very detailed work.

18. To fine-tune the system you need to perform two checks.

19. The first is to zoom to about 500x or ikx and focus on something distinguishable. 
Then press the aperture button on the keyboard and adjust the two aperture knobs, located halfway between the stage platform and the gate valve apparatus, to get the picture to be as still as possible. You will know what this refers to once you push the aperture button. When you are finished, push the aperture button again to return to normal viewing

20. The second thing is to press the wave form oblique button. A zig zag style line will now appear on your screen. To the left of the keyboard there is a trap door style lid that you need to lift up, under this lid is a series of knobs, you only need to adjust the four on the top left corner. The objective of adjusting these knobs is to maximize vertically the line on the screen (to make the line as high as possible). When you have finished this, you need to press the normal button that is located beside the wave form oblique button to return to normal viewing.

21. To get the characteristic information on the bottom of the screen such as number, magnification and scale you need to press the data display button until the information you desire is on the screen. The data display has four different options, blank, cursor in the top left corner, info at bottom $\sim$ cursor in corner and the most desired just info at corner. Just keep pressing the data display button until the correct setting comes up.

22. Note on film taking: the brightness and contrast that you see on the screen is not always what you get on the photo. In order to maximize your $\$ 3.00$ each time you take a picture, I recommend following these procedures before taking a photo. Push the button above the brightness/contrast knobs, you will see an oscillating line on the screen. The objective is to use the brightness and contrast knobs to center the line and 
to control the oscillations such that the amplitude is about an inch each way, then depress the knob above the brightness/contrast knobs again to return to normal viewing.

23. To take a picture, make sure the latch on the photographic box is pointed to the right. Then insert your film all the way into the box (the film has a "this side toward lens" marked on it, this side goes down). Next pull the film slowly back just as if you were removing it (but it will stop just before it comes out). Now press the photo button and wait until the machine beeps to tell you it is finished. Push the film back in all the way, flip the latch such that it is pointing toward the left and then firmly pull the film out of the box, wait 20-25 seconds and peel the film apart to expose your picture.

24. To shut down the machine follow the steps in reverse order except that the filament knob can be turned to zero quickly. 


\section{APPENDIX D}

\section{SAS PROGRAM FOR THE THREE-BODY WEAR TESTS}




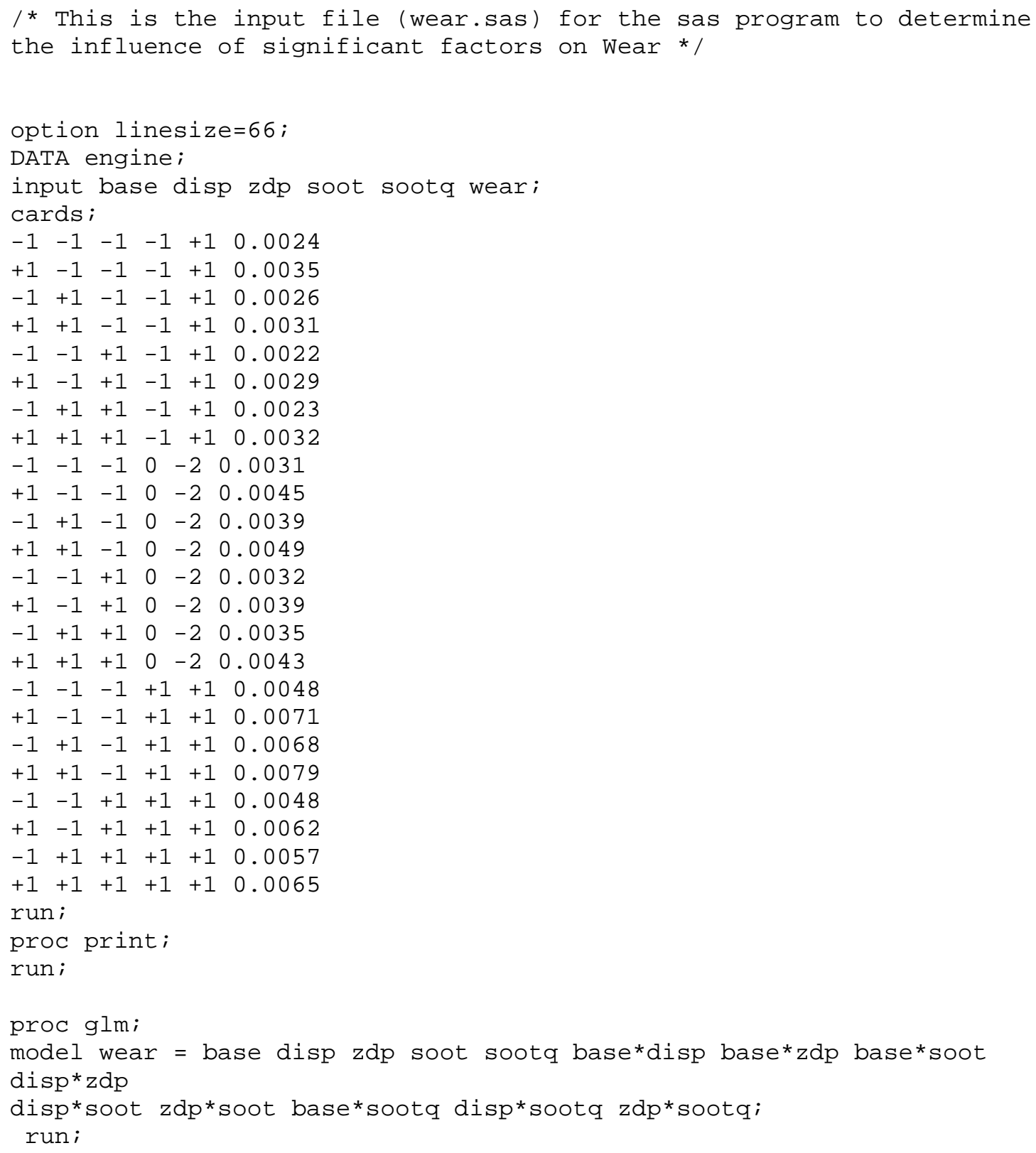


/* This is the output file (wear.lis) for the sas program to determine the influence of significant factors on Wear */

The SAS system

\begin{tabular}{|c|c|c|c|c|c|c|}
\hline OBS & BASE & DISP & $\mathrm{ZDP}$ & SOOT & SOOTQ & WEAR \\
\hline 1 & -1 & -1 & -1 & -1 & 1 & .0024 \\
\hline 2 & 1 & -1 & -1 & -1 & 1 & .0035 \\
\hline 3 & -1 & 1 & -1 & -1 & 1 & .0026 \\
\hline 4 & 1 & 1 & -1 & -1 & 1 & .0031 \\
\hline 5 & -1 & -1 & 1 & -1 & 1 & .0022 \\
\hline 6 & 1 & -1 & 1 & -1 & 1 & .0029 \\
\hline 7 & -1 & 1 & 1 & -1 & 1 & .0023 \\
\hline 8 & 1 & 1 & 1 & -1 & 1 & .0032 \\
\hline 9 & -1 & -1 & -1 & 0 & -2 & .0031 \\
\hline 10 & 1 & -1 & -1 & 0 & -2 & .0045 \\
\hline 11 & -1 & 1 & -1 & 0 & -2 & .0039 \\
\hline 12 & 1 & 1 & -1 & 0 & -2 & .0049 \\
\hline 13 & -1 & -1 & 1 & 0 & -2 & .0032 \\
\hline 14 & 1 & -1 & 1 & 0 & -2 & .0039 \\
\hline 15 & -1 & 1 & 1 & 0 & -2 & .0035 \\
\hline 16 & 1 & 1 & 1 & 0 & -2 & .0043 \\
\hline 17 & -1 & -1 & -1 & 1 & 1 & .0048 \\
\hline 18 & 1 & -1 & -1 & 1 & 1 & .0071 \\
\hline 19 & -1 & 1 & -1 & 1 & 1 & .0068 \\
\hline 20 & 1 & 1 & -1 & 1 & 1 & .0079 \\
\hline 21 & -1 & -1 & 1 & 1 & 1 & .0048 \\
\hline 22 & 1 & -1 & 1 & 1 & 1 & .0062 \\
\hline 23 & -1 & 1 & 1 & 1 & 1 & .0057 \\
\hline 24 & 1 & 1 & 1 & 1 & 1 & .0065 \\
\hline
\end{tabular}

General Linear Models Procedure

Number of observations in data set $=24$

The SAS system

General Linear Models Procedure

Dependent Variable: WEAR

$\begin{array}{lrrrr}\text { Source } & \text { DF } & \text { Sum of Squares } & \text { F Value } & \text { Pr }>\text { F } \\ \text { Model } & 14 & 0.00006140 & 53.91 & 0.0001 \\ \text { Error } & 9 & 0.00000073 & \\ \text { Corrected Total } & 23 & 0.00006213 & \text { WEAR Mean } \\ & \text { R-Square } & \text { C.V. } & \text { Mean } \\ & 0.988217 & 6.626282 & 0.00430417\end{array}$




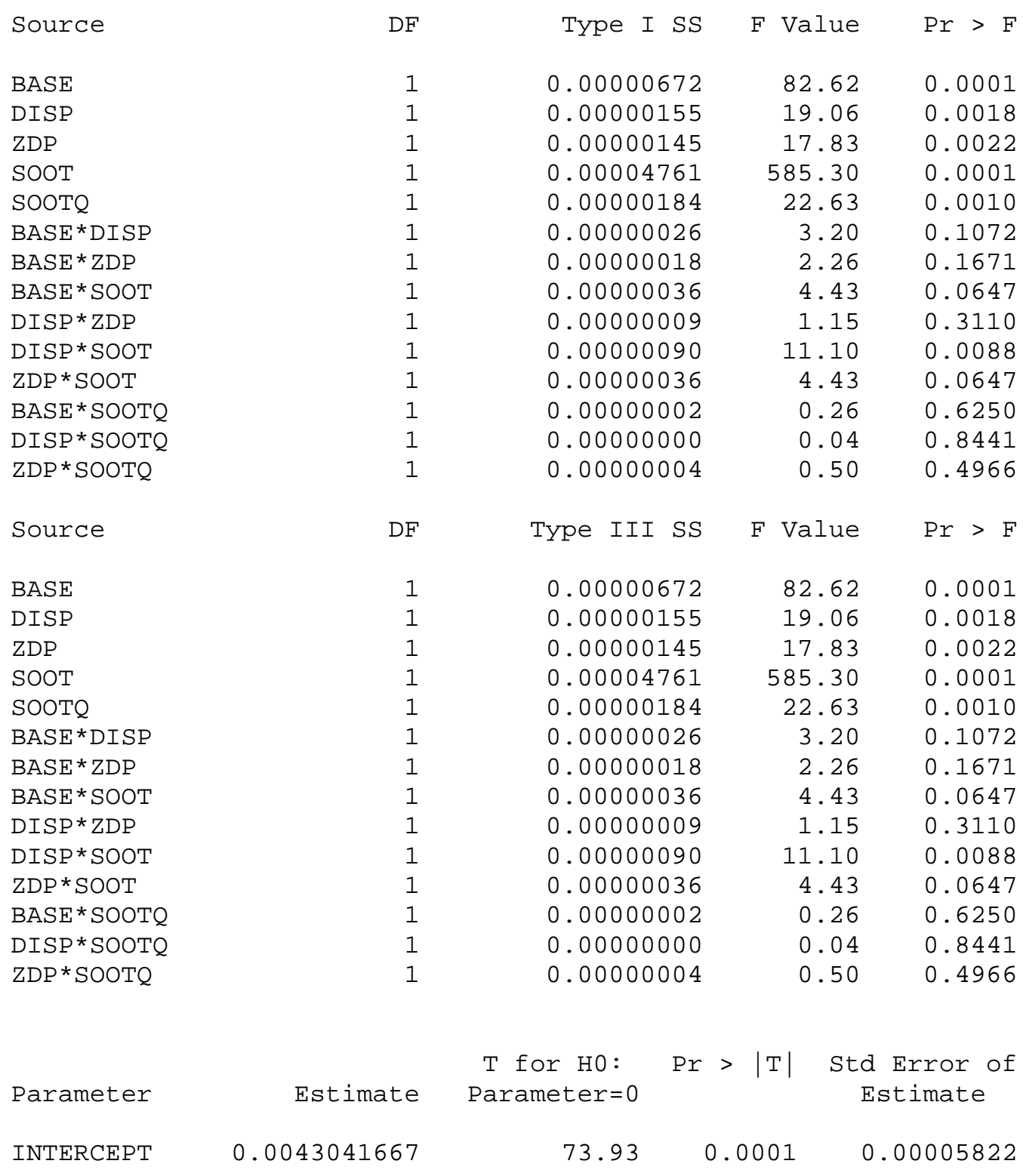

The SAS system

General Linear Models Procedure

Dependent Variable: WEAR

$\begin{array}{lrrrr}\text { Parameter } & \begin{array}{r}\text { Estimate } \\ \text { Parameter=0 }\end{array} & \text { Pr }>|\mathrm{T}| & \begin{array}{c}\text { Std Error of } \\ \text { Estimate }\end{array} \\ \text { BASE } & 0.0005291667 & 9.09 & 0.0001 & 0.00005822 \\ \text { DISP } & 0.0002541667 & 4.37 & 0.0018 & 0.00005822 \\ \text { ZDP } & -.0002458333 & -4.22 & 0.0022 & 0.00005822 \\ \text { SOOT } & 0.0017250000 & 24.19 & 0.0001 & 0.00007130 \\ \text { SOOTQ } & 0.0001958333 & 4.76 & 0.0010 & 0.00004117 \\ \text { BASE*DISP } & -.0001041667 & -1.79 & 0.1072 & 0.00005822\end{array}$




$\begin{array}{llrll}\text { BASE*ZDP } & -.0000875000 & -1.50 & 0.1671 & 0.00005822 \\ \text { BASE*SOOT } & 0.0001500000 & 2.10 & 0.0647 & 0.00007130 \\ \text { DISP*ZDP } & -.0000625000 & -1.07 & 0.3110 & 0.00005822 \\ \text { DISP*SOOT } & 0.0002375000 & 3.33 & 0.0088 & 0.00007130 \\ \text { ZDP*SOOT } & -.0001500000 & -2.10 & 0.0647 & 0.00007130 \\ \text { BASE*SOOTQ } & 0.0000208333 & 0.51 & 0.6250 & 0.00004117 \\ \text { DISP*SOOTQ } & 0.0000083333 & 0.20 & 0.8441 & 0.00004117 \\ \text { ZDP*SOOTQ } & -.0000291667 & -0.71 & 0.4966 & 0.00004117\end{array}$




\section{APPENDIX E}

SAS PROGRAM FOR THE VISCOSITY TESTS 


\section{APPENDIX E.1}

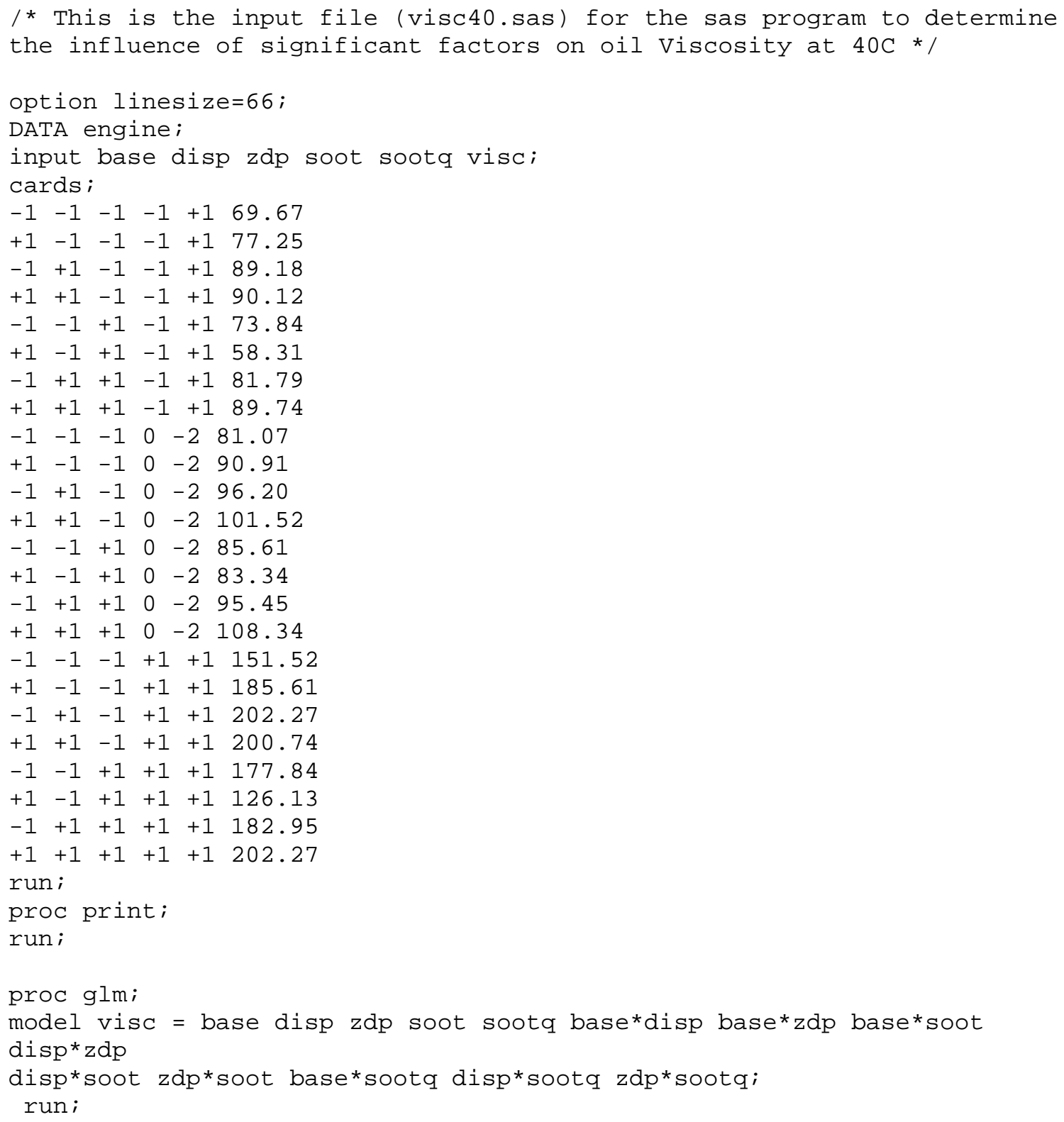


/* This is the output file (visc40.lis) for the sas program to determine the influence of significant factors on oil Viscosity at $40 \mathrm{C}$ *

The SAS System

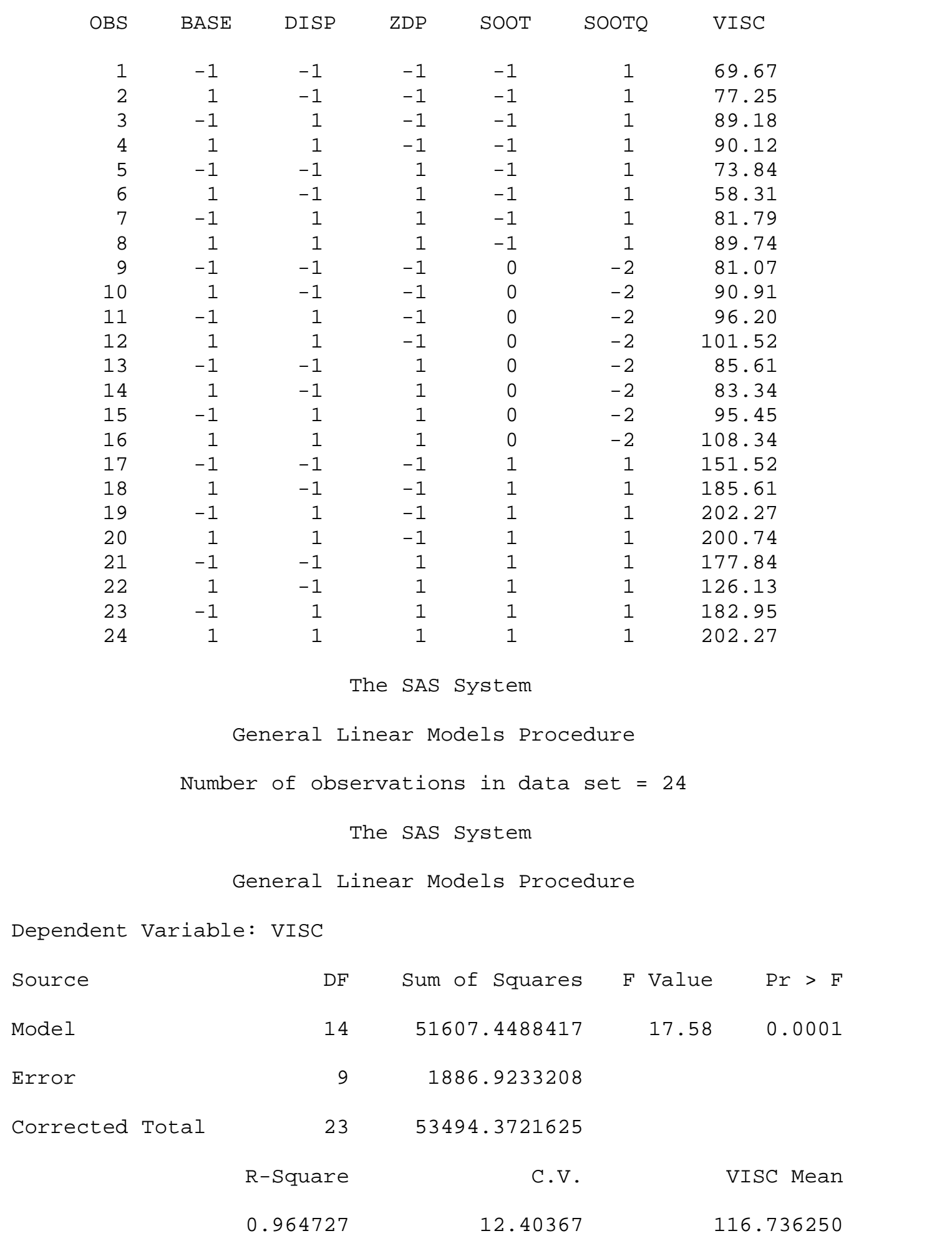




\begin{tabular}{|c|c|c|c|c|c|c|}
\hline Source & $\mathrm{DF}$ & \multicolumn{2}{|c|}{ Type I SS } & \multicolumn{2}{|c|}{ F Value } & $\operatorname{Pr}>\mathrm{F}$ \\
\hline BASE & 1 & \multicolumn{2}{|c|}{30.1280042} & \multicolumn{2}{|c|}{0.14} & 0.7134 \\
\hline DISP & 1 & \multicolumn{2}{|c|}{3254.3117042} & \multicolumn{2}{|c|}{15.52} & 0.0034 \\
\hline ZDP & 1 & \multicolumn{2}{|c|}{206.8001042} & \multicolumn{2}{|c|}{0.99} & 0.3466 \\
\hline SOOT & 1 & \multicolumn{2}{|c|}{39943.0203063} & \multicolumn{2}{|c|}{190.51} & 0.0001 \\
\hline SOOTQ & 1 & \multicolumn{2}{|c|}{6872.4567188} & \multicolumn{2}{|c|}{32.78} & 0.0003 \\
\hline $\mathrm{BASE} * \mathrm{DISP}$ & 1 & \multicolumn{2}{|c|}{164.7980042} & \multicolumn{2}{|c|}{0.79} & 0.3984 \\
\hline $\mathrm{BASE} \star \mathrm{ZDP}$ & 1 & \multicolumn{2}{|c|}{305.2353375} & \multicolumn{2}{|c|}{1.46} & 0.2583 \\
\hline $\mathrm{BASE}{ }^{*} \mathrm{SOOT}$ & 1 & \multicolumn{2}{|c|}{0.0370562} & \multicolumn{2}{|c|}{0.00} & 0.9897 \\
\hline $\mathrm{DISP} \star \mathrm{ZDP}$ & 1 & \multicolumn{2}{|c|}{41.2650375} & \multicolumn{2}{|c|}{0.20} & 0.6678 \\
\hline $\mathrm{DISP} * \mathrm{SOOT}$ & 1 & \multicolumn{2}{|c|}{355.0398062} & \multicolumn{2}{|c|}{1.69} & 0.2255 \\
\hline $\mathrm{ZDP} * \mathrm{SOOT}$ & 1 & \multicolumn{2}{|c|}{50.4455062} & \multicolumn{2}{|c|}{0.24} & 0.6355 \\
\hline $\mathrm{BASE} * \mathrm{SOOTQ}$ & 1 & \multicolumn{2}{|c|}{53.0250521} & & .25 & 0.6271 \\
\hline $\mathrm{DISP} \star \mathrm{SOOTQ}$ & 1 & 198.98235 & 521 & & .95 & 0.3554 \\
\hline $\mathrm{ZDP} * \mathrm{SOOTQ}$ & 1 & 131.90385 & 521 & & .63 & 0.4481 \\
\hline Source & $\mathrm{DF}$ & Type III & SS & $\mathrm{F} \quad \mathrm{Va}$ & lue & $\operatorname{Pr}>F$ \\
\hline BASE & 1 & 30.12800 & 42 & & .14 & 0.7134 \\
\hline DISP & 1 & 3254.31170 & 42 & & .52 & 0.0034 \\
\hline ZDP & 1 & 206.80010 & 42 & & .99 & 0.3466 \\
\hline SOOT & 1 & 39943.02030 & 63 & 190 & .51 & 0.0001 \\
\hline SOOTQ & 1 & 6872.45671 & 88 & & .78 & 0.0003 \\
\hline $\mathrm{BASE}{ }^{\star} \mathrm{DISP}$ & 1 & 164.79800 & 42 & & .79 & 0.3984 \\
\hline $\mathrm{BASE} \approx \mathrm{ZDP}$ & 1 & $305.23533^{\circ}$ & 375 & & .46 & 0.2583 \\
\hline $\mathrm{BASE} * \mathrm{SOOT}$ & 1 & 0.03705 & 563 & & .00 & 0.9897 \\
\hline $\mathrm{DISP} \star \mathrm{ZDP}$ & 1 & $41.26503^{\circ}$ & 375 & & .20 & 0.6678 \\
\hline $\mathrm{DISP} * \mathrm{SOOT}$ & 1 & 355.03980 & 62 & & .69 & 0.2255 \\
\hline $\mathrm{ZDP} * \mathrm{SOOT}$ & 1 & 50.44550 & & & .24 & 0.6355 \\
\hline $\mathrm{BASE} * \mathrm{SOOTQ}$ & 1 & 53.02505 & 521 & & .25 & 0.6271 \\
\hline $\mathrm{DISP} * \mathrm{SOOTQ}$ & 1 & 198.98235 & 521 & & .95 & 0.3554 \\
\hline $\mathrm{ZDP} * \mathrm{SOOTQ}$ & 1 & 131.90385 & 521 & & .63 & 0.4481 \\
\hline Parameter & Estimate & $\begin{array}{c}\mathrm{T} \text { for } \mathrm{H} 0: \\
\text { Parameter }=0\end{array}$ & $\operatorname{Pr}>$ & $>|\mathrm{T}|$ & $\begin{array}{l}\text { Std } \\
E s\end{array}$ & $\begin{array}{l}\text { Error of } \\
\text { stimate }\end{array}$ \\
\hline INTERCEPT & 116.7362500 & 39.50 & & .0001 & & .95563125 \\
\hline & & The SAS Syste & & & & \\
\hline & General & Linear Models & Pro & cedur & & \\
\hline Dependent & Variable: VISC & & & & & \\
\hline Parameter & Estimate & $\begin{array}{c}\mathrm{T} \text { for } \mathrm{H} 0: \\
\text { Parameter }=0\end{array}$ & $\operatorname{Pr}>$ & $>|\mathrm{T}|$ & $\begin{array}{l}\text { Std } \\
E s\end{array}$ & $\begin{array}{l}\text { Error of } \\
\text { stimate }\end{array}$ \\
\hline BASE & 1.1204167 & 0.38 & & .7134 & & .95563125 \\
\hline DISP & 11.6445833 & 3.94 & & .0034 & & .95563125 \\
\hline ZDP & -2.9354167 & -0.99 & & .3466 & & .95563125 \\
\hline $\mathrm{SOOT}$ & 49.9643750 & 13.80 & & .0001 & & .61989422 \\
\hline SOOTQ & 11.9656250 & 5.73 & & .0003 & & .08994690 \\
\hline $\mathrm{BASE} \star \mathrm{DISP}$ & 2.6204167 & 0.89 & & .3984 & & .95563125 \\
\hline
\end{tabular}




$\begin{array}{lrrrr}\text { BASE*ZDP } & -3.5662500 & -1.21 & 0.2583 & 2.95563125 \\ \text { BASE*SOOT } & -0.0481250 & -0.01 & 0.9897 & 3.61989422 \\ \text { DISP*ZDP } & 1.3112500 & 0.44 & 0.6678 & 2.95563125 \\ \text { DISP*SOOT } & 4.7106250 & 1.30 & 0.2255 & 3.61989422 \\ \text { ZDP*SOOT } & -1.7756250 & -0.49 & 0.6355 & 3.61989422 \\ \text { BASE*SOOTQ } & -1.0510417 & -0.50 & 0.6271 & 2.08994690 \\ \text { DISP*SOOTQ } & 2.0360417 & 0.97 & 0.3554 & 2.08994690 \\ \text { ZDP*SOOTQ } & -1.6577083 & -0.79 & 0.4481 & 2.08994690\end{array}$




\section{APPENDIX E.2}

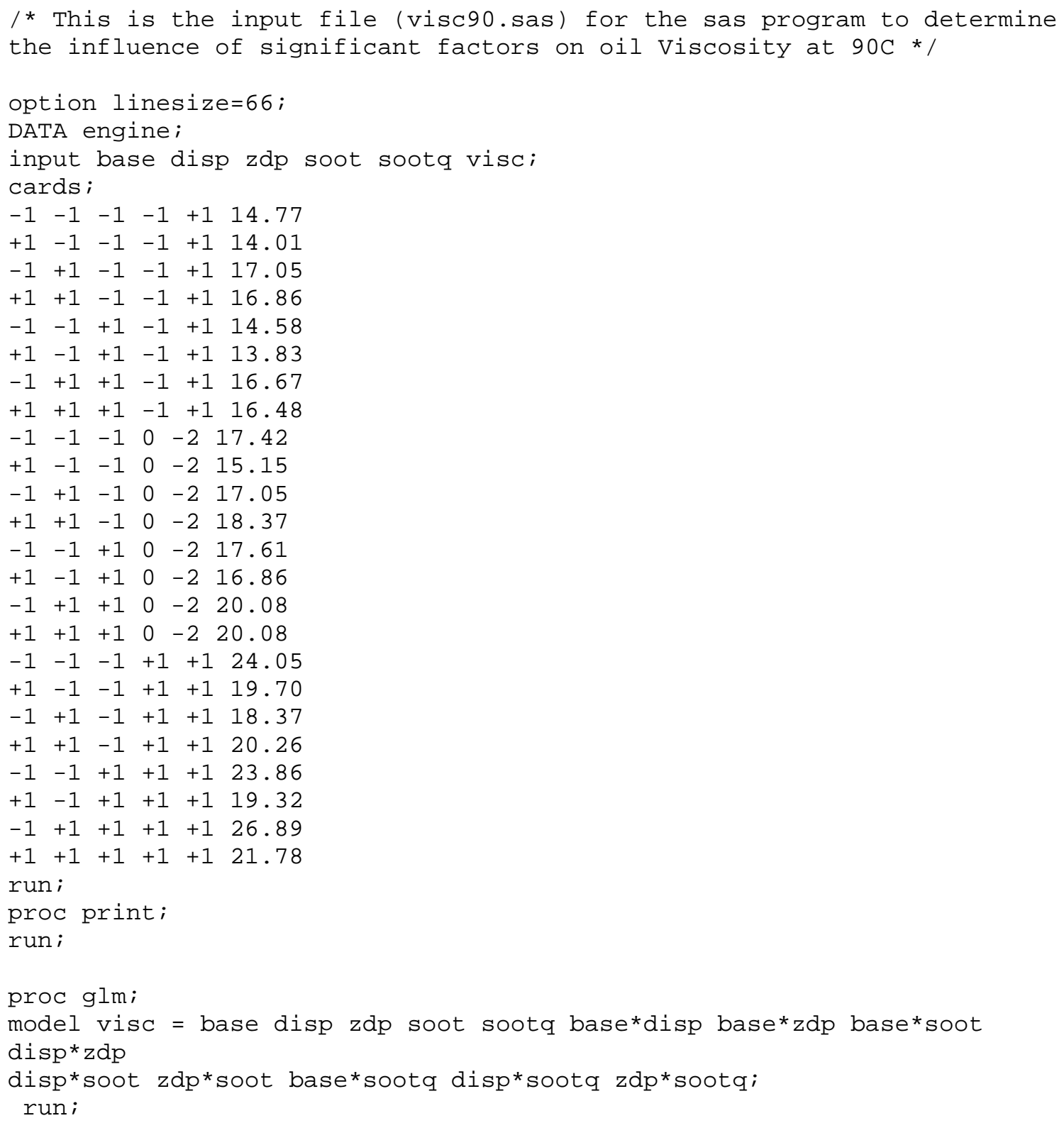


/* This is the output file (visc90.lis) for the sas program to determine the influence of significant factors on oil Viscosity at 90C */

The SAS System

$\begin{array}{rrrrrrr}\text { OBS } & \text { BASE } & \text { DISP } & \text { ZDP } & \text { SOOT } & \text { SOOTQ } & \text { VISC } \\ 1 & -1 & -1 & -1 & -1 & 1 & 14.77 \\ 2 & 1 & -1 & -1 & -1 & 1 & 14.01 \\ 3 & -1 & 1 & -1 & -1 & 1 & 17.05 \\ 4 & 1 & 1 & -1 & -1 & 1 & 16.86 \\ 5 & -1 & -1 & 1 & -1 & 1 & 14.58 \\ 6 & 1 & -1 & 1 & -1 & 1 & 13.83 \\ 7 & -1 & 1 & 1 & -1 & 1 & 16.67 \\ 8 & 1 & 1 & 1 & -1 & 1 & 16.48 \\ 9 & -1 & -1 & -1 & 0 & -2 & 17.42 \\ 10 & 1 & -1 & -1 & 0 & -2 & 15.15 \\ 11 & -1 & 1 & -1 & 0 & -2 & 17.05 \\ 12 & 1 & 1 & -1 & 0 & -2 & 18.37 \\ 13 & -1 & -1 & 1 & 0 & -2 & 17.61 \\ 14 & 1 & -1 & 1 & 0 & -2 & 16.86 \\ 15 & -1 & 1 & 1 & 0 & -2 & 20.08 \\ 16 & 1 & 1 & 1 & 0 & -2 & 20.08 \\ 17 & -1 & -1 & -1 & 1 & 1 & 24.05 \\ 18 & 1 & -1 & -1 & 1 & 1 & 19.70 \\ 19 & -1 & 1 & -1 & 1 & 1 & 18.37 \\ 20 & 1 & 1 & -1 & 1 & 1 & 20.26 \\ 21 & -1 & -1 & 1 & 1 & 1 & 23.86 \\ 22 & 1 & -1 & 1 & 1 & 1 & 19.32 \\ 23 & -1 & 1 & 1 & 1 & 1 & 26.89 \\ 24 & 1 & 1 & 1 & 1 & 1 & 21.78\end{array}$

The SAS System

General Linear Models Procedure

Number of observations in data set $=24$

The SAS System

General Linear Models Procedure

Dependent Variable: VISC

$\begin{array}{lrrrr}\text { Source } & \text { DF } & \text { Sum of Squares } & \text { F Value } & \text { Pr }>\text { F } \\ \text { Model } & 14 & 231.41558333 & 7.22 & 0.0027 \\ \text { Error } & 9 & 20.59600000 & & \\ \text { Corrected Total } & 23 & 252.01158333 & & \\ & \text { R-Square } & \text { C.V. } & \text { VISC Mean }\end{array}$




\subsection{4}

\begin{tabular}{|c|c|}
\hline Source & $\mathrm{DF}$ \\
\hline BASE & 1 \\
\hline DISP & 1 \\
\hline ZDP & 1 \\
\hline SOOT & 1 \\
\hline SOOTQ & 1 \\
\hline $\mathrm{BASE} * \mathrm{DISP}$ & 1 \\
\hline BASE*ZDP & 1 \\
\hline $\mathrm{BASE} * \mathrm{SOOT}$ & 1 \\
\hline $\mathrm{DISP} * \mathrm{ZDP}$ & 1 \\
\hline $\mathrm{DISP} * \mathrm{SOOT}$ & 1 \\
\hline $\mathrm{ZDP} * \mathrm{SOOT}$ & 1 \\
\hline BASE * SOOTQ & 1 \\
\hline DISP * SOOTQ & 1 \\
\hline $\mathrm{ZDP} * \mathrm{SOOTQ}$ & 1 \\
\hline Source & $\mathrm{DF}$ \\
\hline BASE & 1 \\
\hline DISP & 1 \\
\hline ZDP & 1 \\
\hline SOOT & 1 \\
\hline SOOTQ & 1 \\
\hline$B A S E \star D I S P$ & 1 \\
\hline BASE*ZDP & 1 \\
\hline $\mathrm{BASE} * \mathrm{SOOT}$ & 1 \\
\hline $\mathrm{DISP} \star \mathrm{ZDP}$ & 1 \\
\hline $\mathrm{DISP} * \mathrm{SOOT}$ & 1 \\
\hline $\mathrm{ZDP} * \mathrm{SOOT}$ & 1 \\
\hline BASE * SOOTQ & 1 \\
\hline DISP*SOOTQ & 1 \\
\hline $\mathrm{ZDP} * \mathrm{SOOTQ}$ & 1 \\
\hline
\end{tabular}

$$
8.230844
$$

18.3791667

$\begin{array}{rrr}\text { Type I SS } & \text { F Value } & \text { Pr }>F \\ 10.27041667 & 4.49 & 0.0632 \\ 14.69535000 & 6.42 & 0.0320 \\ 9.35001667 & 4.09 & 0.0740 \\ 156.12502500 & 68.22 & 0.0001 \\ 3.65203333 & 1.60 & 0.2382 \\ 5.17081667 & 2.26 & 0.1670 \\ 2.03001667 & 0.89 & 0.3709 \\ 6.52802500 & 2.85 & 0.1255 \\ 7.10681667 & 3.11 & 0.1119 \\ 5.64062500 & 2.46 & 0.1509 \\ 7.02250000 & 3.07 & 0.1137 \\ 2.34083333 & 1.02 & 0.3383 \\ 0.97470000 & 0.43 & 0.5303 \\ 0.50840833 & 0.22 & 0.6486\end{array}$

Type III SS

F Value

$\operatorname{Pr}>\mathrm{F}$

10.27041667

$4.49 \quad 0.0632$

14.69535000

6.420 .0320

$4.09 \quad 0.0740$

$68.22 \quad 0.0001$

156.12502500

3.65203333

5.17081667

2.03001667

6.52802500

7.10681667

5.64062500

7.02250000

2.34083333

0.97470000

0.50840833

1.60

$2.26 \quad 0.1670$

$0.89 \quad 0.3709$

$2.85 \quad 0.1255$

3.110 .1119

2.46 0.1509

$3.07 \quad 0.1137$

$1.02 \quad 0.3383$

$0.43 \quad 0.5303$

$0.22 \quad 0.6486$ \begin{tabular}{crrr|r} 
Earameter & Estimate & $\begin{array}{c}\text { T for Ho: } \\
\text { Parameter }=0\end{array}$ & Pr $>|\mathrm{T}|$ & $\begin{array}{c}\text { Std Error of } \\
\text { Estimate }\end{array}$ \\
INTERCEPT & 18.37916667 & 59.52 & 0.0001 & 0.30879095
\end{tabular}

The SAS System

General Linear Models Procedure

Dependent Variable: VISC

$\begin{array}{lrrrr}\text { Parameter } & \text { Estimate } & \begin{array}{c}\text { T for HO: } \\ \text { Parameter=0 }\end{array} & \text { Pr }>|\mathrm{T}| & \begin{array}{c}\text { Std Error of } \\ \text { Estimate }\end{array} \\ \text { BASE } & -0.65416667 & -2.12 & 0.0632 & 0.30879095 \\ \text { DISP } & 0.78250000 & 2.53 & 0.0320 & 0.30879095 \\ \text { ZDP } & 0.62416667 & 2.02 & 0.0740 & 0.30879095 \\ \text { SOOT } & 3.12375000 & 8.26 & 0.0001 & 0.37819013\end{array}$




$\begin{array}{lrrrr}\text { SOOTQ } & 0.27583333 & 1.26 & 0.2382 & 0.21834818 \\ \text { BASE*DISP } & 0.46416667 & 1.50 & 0.1670 & 0.30879095 \\ \text { BASE*ZDP } & -0.29083333 & -0.94 & 0.3709 & 0.30879095 \\ \text { BASE*SOOT } & -0.63875000 & -1.69 & 0.1255 & 0.37819013 \\ \text { DISP*ZDP } & 0.54416667 & 1.76 & 0.1119 & 0.30879095 \\ \text { DISP*SOOT } & -0.59375000 & -1.57 & 0.1509 & 0.37819013 \\ \text { ZDP*SOOT } & 0.66250000 & 1.75 & 0.1137 & 0.37819013 \\ \text { BASE*SOOTQ } & -0.22083333 & -1.01 & 0.3383 & 0.21834818 \\ \text { DISP*SOOTQ } & -0.14250000 & -0.65 & 0.5303 & 0.21834818 \\ \text { ZDP*SOOTQ } & -0.10291667 & -0.47 & 0.6486 & 0.21834818\end{array}$




\section{APPENDIX F}

\section{Polaroid pictures from the Scanning Electron Microscope}




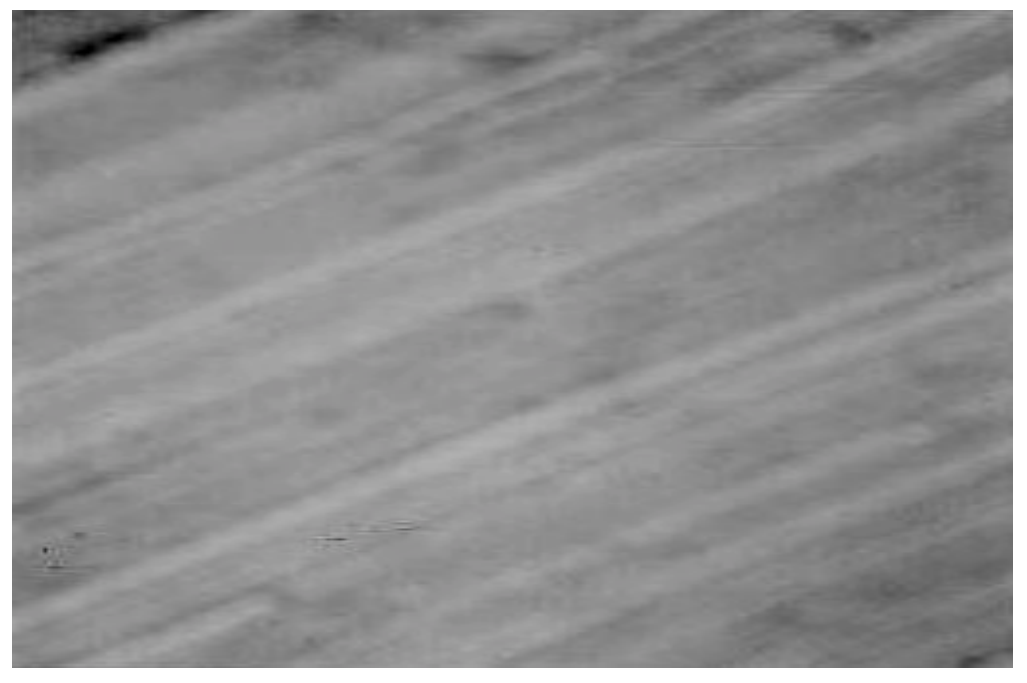

Sample \# WVU399@0\% soot

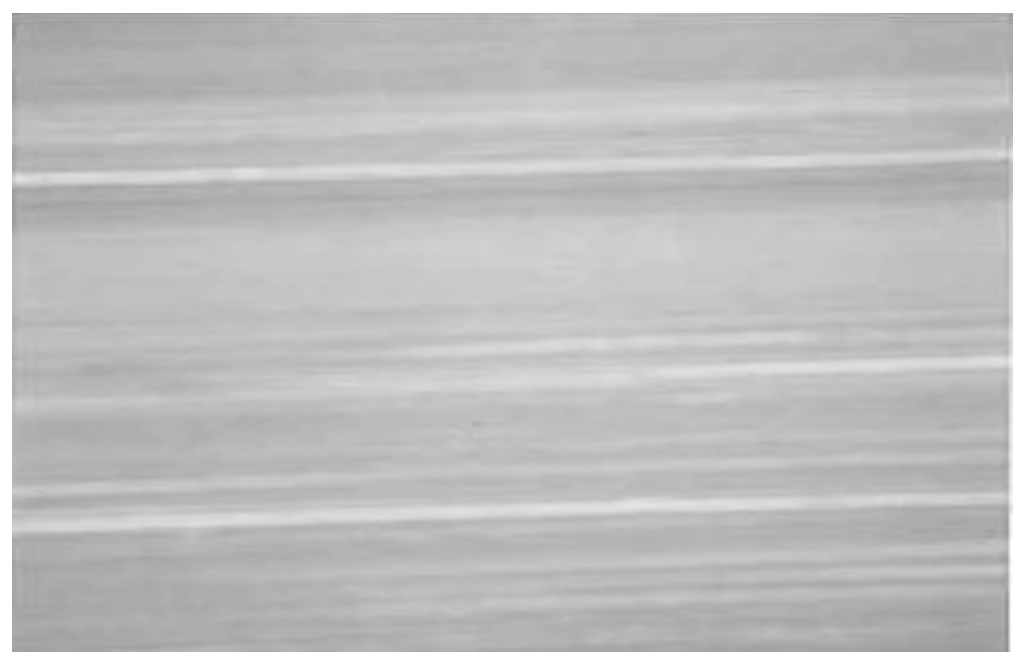

Sample \# WVU399@2\% soot 


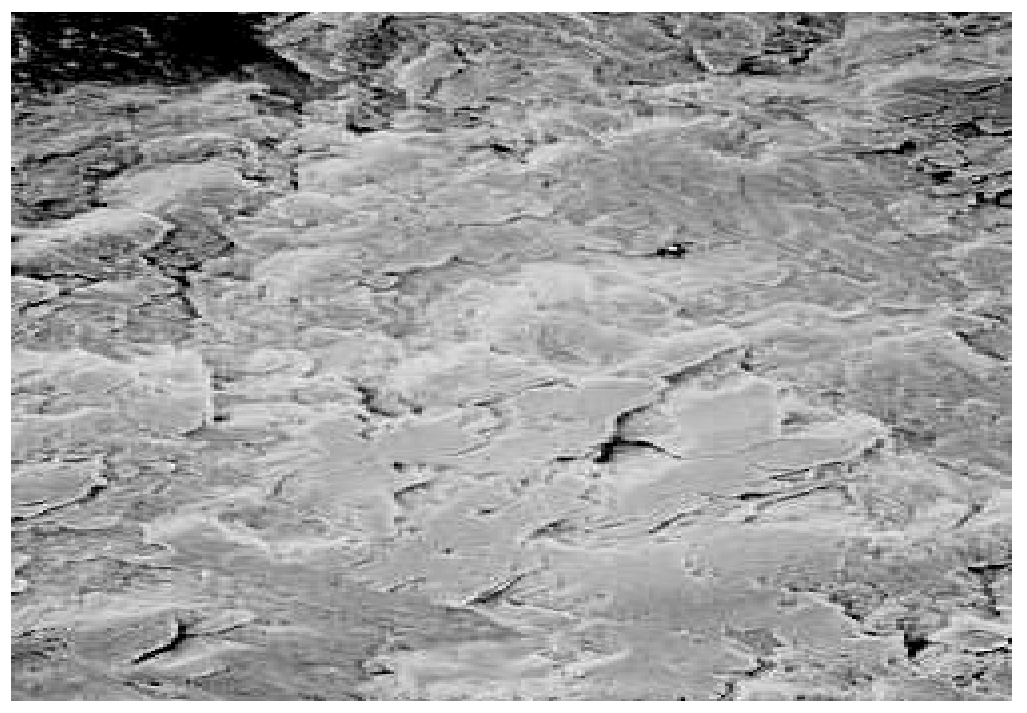

Sample \# WVU399@4\% soot

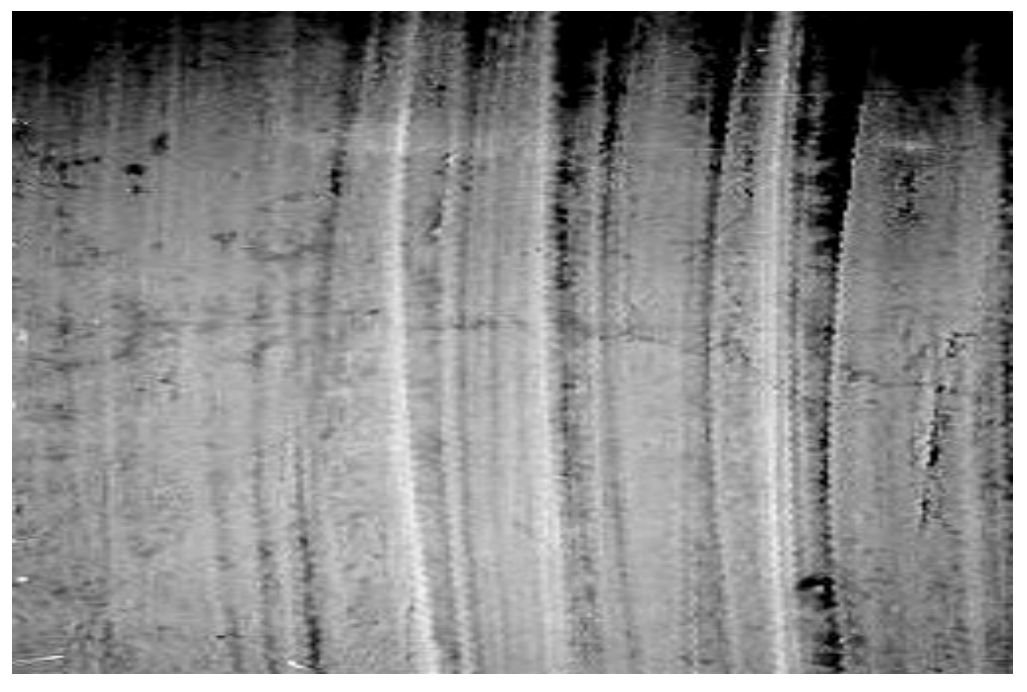

Sample \# WVU404@0\% soot 


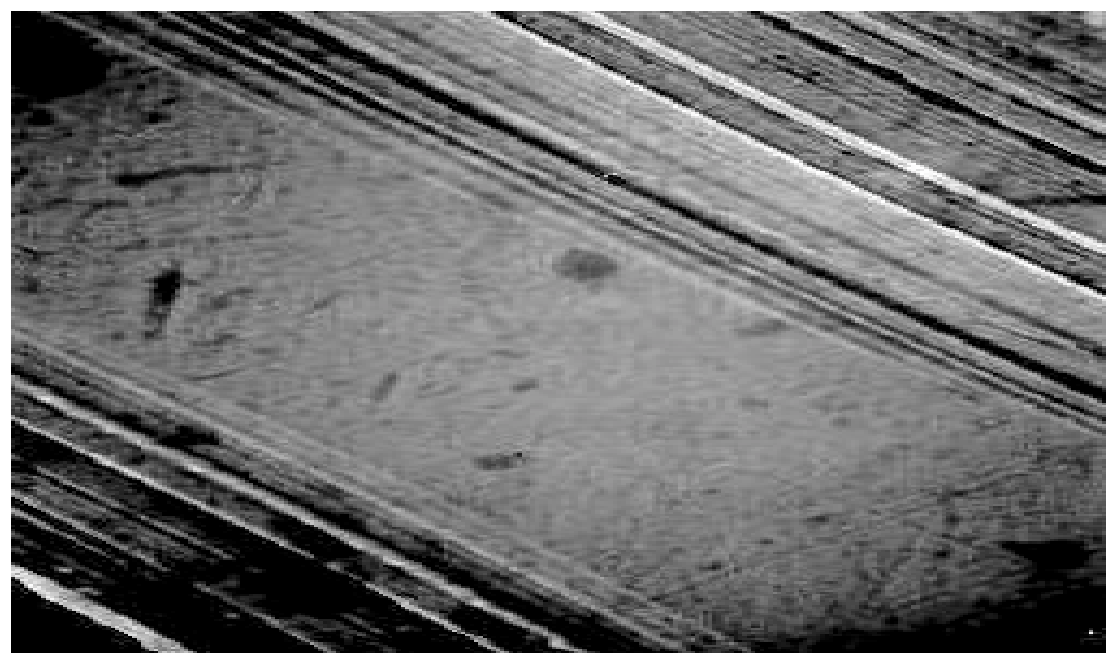

Sample \# WVU404@2\% soot

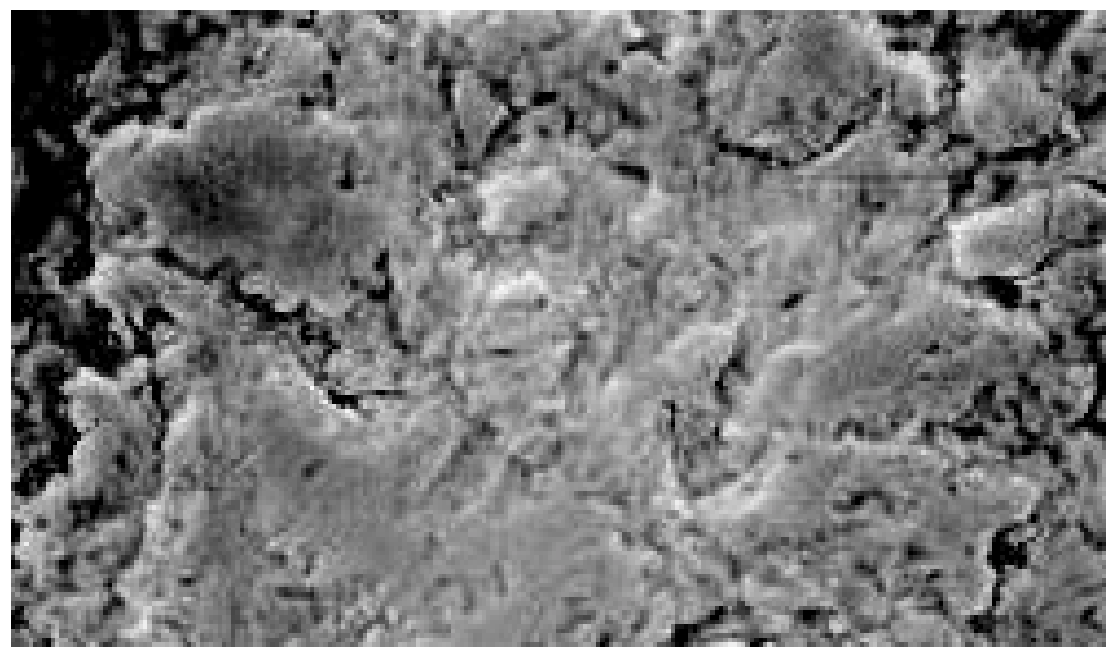

Sample \# WVU404@4\% soot 